\title{
Psychosis and the environment
}

\author{
Citation for published version (APA):
}

Frissen, A. (2016). Psychosis and the environment: multimodal assessment of environmental risk factors for psychotic disorders. [Doctoral Thesis, Maastricht University]. Datawyse / Universitaire Pers Maastricht. https://doi.org/10.26481/dis.20161221af

\section{Document status and date:}

Published: 01/01/2016

DOI:

10.26481/dis.20161221af

Document Version:

Publisher's PDF, also known as Version of record

\section{Please check the document version of this publication:}

- A submitted manuscript is the version of the article upon submission and before peer-review. There can be important differences between the submitted version and the official published version of record.

People interested in the research are advised to contact the author for the final version of the publication, or visit the DOI to the publisher's website.

- The final author version and the galley proof are versions of the publication after peer review.

- The final published version features the final layout of the paper including the volume, issue and page numbers.

Link to publication

\footnotetext{
General rights rights.

- You may freely distribute the URL identifying the publication in the public portal. please follow below link for the End User Agreement:

www.umlib.nl/taverne-license

Take down policy

If you believe that this document breaches copyright please contact us at:

repository@maastrichtuniversity.nl

providing details and we will investigate your claim.
}

Copyright and moral rights for the publications made accessible in the public portal are retained by the authors and/or other copyright owners and it is a condition of accessing publications that users recognise and abide by the legal requirements associated with these

- Users may download and print one copy of any publication from the public portal for the purpose of private study or research.

- You may not further distribute the material or use it for any profit-making activity or commercial gain

If the publication is distributed under the terms of Article $25 \mathrm{fa}$ of the Dutch Copyright Act, indicated by the "Taverne" license above, 


\title{
Psychosis and the environment
}

\author{
Multimodal assessment of environmental risk \\ factors for psychotic disorders
}


(C) copyright Aleida Frissen, Maastricht 2016

Printing: Datawyse | Universitaire Pers Maastricht

Cover Design: Christine Muris

ISBN 9789461596550 


\title{
Psychosis and the environment
}

\section{Multimodal assessment of environmental risk factors for psychotic disorders}

\author{
Proefschrift \\ ter verkrijging van de graad van doctor aan de Universiteit Maastricht, \\ op gezag van de Rector Magnificus, Prof. dr. Rianne M. Letschert, \\ volgens het besluit van het College van Decanen, \\ in het openbaar te verdedigen \\ op woensdag 21 december 2016 om 15.45 uur
}

door

Aleida Frissen

geboren 3 augustus 1984 te Maastricht 


\section{Promotor}

Prof. dr. J. van Os

\section{Copromotores}

Dr. M. Marcelis

Dr. R. Lieverse

\section{Beoordelingscommissie}

Prof. dr. T.A.M.J. van Amelsvoort (voorzitter)

Prof. dr. L. de Haan (Academisch Medisch Centrum Amsterdam)

Prof. dr. F.P.M.L. Peeters

Dr. U.A. Reininghaus

Dr. W.A. Veling (Universitair Medisch Centrum Groningen) 


\section{Contents}

$\begin{array}{lll}\text { Chapter } 1 \text { General introduction } & 7\end{array}$

Chapter 2 Schizophrenia and 1957 pandemic of influenza: meta-analysis 23

Chapter 3 Evidence that childhood urban environment is associated with blunted stress reactivity across groups of patients with psychosis, relatives of patients and controls

Chapter 4 Childhood trauma and childhood urbanicity in relation to psychotic disorder

Chapter 5 Psychotic disorder and educational achievement: a familybased analysis

Chapter 6 No evidence of association between childhood urban environment and cortical thinning in psychotic disorder

Chapter 7 Evidence that reduced gray matter volume in psychotic disorder is associated with exposure to environmental risk factors

$\begin{array}{lll}\text { Chapter } 8 & \text { General discussion } & 133\end{array}$

Summary

Samenvatting

Valorisation

List of publications 169

Curriculum Vitae

Dankwoord 

Chapter 1

General introduction 

Like every organism, humans interact with their environment. The environment can affect the individual, and likewise the individual can affect its environment. For example, the temperature of the environment affects the level of physical activity of a person and physical activity affects the temperature of the environment. Adaptation to the environment is a crucial part of evolution and continued existence. However, sometimes this adaptation may become inappropriate in a new environment: growing up in a hostile environment leads to behavioral changes, which may differ between persons: some may develop aggressive behavior, others may develop withdrawal behavior. Withdrawal from social interaction may result in less developed social skills; when the hostile environment is replaced by a friendlier climate, which invites for more interaction, the person with less developed social skills may still feel the need to withdraw, because he has not learned to interact with others, which in the new context is less adequate. The same can be argued in the case of aggressive behavior: aggressive behavior is not appropriate in a caring environment.

When evaluating a person with a psychiatric disorder, the environment, family history, and personal history always should be considered, because these could help to form a hypothesis of the mechanisms contributing to the development and persistence of the disorder. In this thesis known environmental risk factors for psychotic disorder were examined and an attempt was made to unravel how these environmental risk factors may contribute to psychotic disorder. First, epidemiological and ecological approaches were used to study environmental risk factors for psychotic disorder. Second a multimodal approach was applied, in which neuroimaging phenotypes and epidemiology were combined to study these risk factors.

\section{PSYCHOTIC DISORDER}

Psychotic disorder comprises several behavioral phenotypes in which perceptual alterations and salience dysregulation often exist in the form of hallucinations and delusions. In addition, motor symptoms are present and cognitive alterations, such as impaired memory, attention or executive functioning, and affective disturbances, both depressive and manic symptoms, are features during all phases of a psychotic disorder $(1,2)$. Beside these so-called positive symptoms, there are also negative symptoms referring to the lack of common behaviors or functions e.g. a flattening of affect or the impaired ability to begin and sustain planned activities.

Schizophrenia is the most known of all psychotic disorders and has the infamous connotation of a severe mental illness from which you can hardly recover. However, this statement does not match the data available on the course of psychosis. Remission rates of $17 \%$ to $78 \%$ in first episode schizophrenia and $16 \%$ to $62 \%$ in multiple episode schizophrenia have been reported (3). Remission is often defined by clinical (symptomatic) measures and important aspects of recovery like personal wellbeing or social 
functioning are less frequently assessed in research (4). This, while evidence shows that symptomatic and functional remission are not highly correlated(5). The lifetime prevalence of schizophrenia is estimated at $0.4 \%(6)$, while the prevalence of subclinical psychotic experiences is approximately 5\% (7). Environmental risk factors are likely to play an important role in the transition from subclinical psychotic symptoms to a clinical psychotic disorder.

\section{ETIOLOGY}

The etiology of psychotic disorder is complex and multifactorial. The concordance rate for monozygotic twins, who share $100 \%$ of their genes, is approximately $50 \%(8,9)$. With the emergence of genome-wide association studies (GWAS) and copy number variant (CNV) analysis, knowledge of the genetic basis of psychotic disorder has expanded rapidly over the last decade (10). Psychotic disorder is a highly polygenic disorder and risk genes and alleles are shared with other psychiatric disorders, e.g. bipolar disorder (10). Sensitivity for environmental risk factors is determined by the genetic background, gene $X$ environment interaction $(G \times E)$. Well-known environmental risk factors for psychotic disorder are childhood urbanicity, childhood trauma, social defeat and cannabis (11). Further, obstetric complications (12) are risk factors for psychotic disorders, although not all studies could replicate earlier findings (13).

The combination of exposure to environmental risk factors and a genetic liability for psychotic disorder is thought to result in increased mesolimbic dopamine reactivity, altered saliency and ultimately in psychotic symptoms, though dopamine is not the only neurotransmitter involved in psychotic disorders $(11,14-16)$. In this thesis, the following environmental risk factors are discussed: maternal influenza during pregnancy (an obstetric complication), childhood urbanicity (in this thesis the adjectives childhood and developmental are equally used when referring to childhood urbanicity), childhood trauma and cannabis. Whether maternal influenza is a true risk factor for psychotic disorders is uncertain, studies disagree and there is need for clarification. Childhood urbanicity, childhood trauma and cannabis are well known risk factors but the underlying pathologic processes need further clarification. The choice of these risk factors as subject for this thesis will be further discussed below.

In the last decades, abundant numbers of neuroimaging studies have been conducted in the attempt to uncover neuropathological processes of psychotic disorder. Changes in brain volumes (total, gray, white volume, cerebrospinal fluid) and cortical thickness (CT), and changes in white matter integrity or connectivity have all been related to psychotic disorder (17). In addition, functional and neurotransmitter imaging have contributed to the understanding of functional and neurochemical mechanisms underlying cognitive processes in psychotic disorder (18-20). Widespread alterations in structural and functional networks suggest that multiple brain circuits are affected (21). 
Brain alterations have long been examined in relative isolation, in that genetic and environmental influences, and their interactions were not examined in an integrated way with cerebral measures. For example, alterations of gray matter morphology are extensively described $(22,23)$ : reductions in $\mathrm{CT}(24,25)$ and reductions of gray matter volume (GMV) (26) are found in patients with a psychotic disorder, but much less in relation to $G \times E(27,28)$. Thus, it remains to be clarified whether these structural gray matter alterations are the result of a disease specific process, disease-related factors such as medication, altered neurodevelopment due to genetic liability and/or differential sensitivity to environmental risks ( $\mathrm{G} \times \mathrm{E})$.

\section{GENE X ENVIRONMENT INTERACTION}

$G \times E$ is thought to be an explanation for the differential sensitivity to the environmental risk factors childhood urbanicity (29-31), childhood trauma $(32)$, cannabis $(33,34)$ and obstetric complications (35). Research on $G \times E$ interaction is difficult: one cannot randomly assign individuals to higher levels of childhood urbanicity, childhood trauma or cannabis. Cannon and colleagues (36) were one of the first to describe a method to facilitate $G \times E$ research and overcome reporting bias and reverse causality: they used as dependent variable a biological measure associated with psychotic disorder, which is thought to be impacted by interacting genetic and environmental factors. Further, they included siblings in the study population, a group with higher familial (and possibly genetic) risk for psychotic disorder than the average population, but without the disease.

\section{THE ENVIRONMENT}

\section{Obstetric complications: maternal influenza during pregnancy}

Of all obstetric complications fetal hypoxia is the most well established risk factor for psychotic disorder (37). Like other risk factors it appears to be conditional on genetic liability for psychotic disorder (37). The evidence for prenatal maternal infection and the association with psychotic disorder is inconclusive. Maternal non-specific bacterial, respiratory or genital and reproductive infection and specific infection with herpes simplex virus type 2, Toxoplasma Gondii and rubella have been associated with psychotic disorders, however there is a large variation in effect size between studies and not all studies report significant findings (38). There has been a great interest in maternal influenza as risk factor for psychotic orders after the publication of two studies from Finland, and England and Wales conducted in 1988 and 1991, which reported an increased proportion of schizophrenia diagnoses in patients whose second trimester and fifth month of fetal life overlapped with the influenza pandemic of $1957(39,40)$. Other eco- 
logical studies trying to replicate these findings, did not find an elevated risk of any exposure during pregnancy (41) and a study in which influenza infection was serologically confirmed also did not find a significant association (42). Given the high incidence of influenza, clarification whether this is a true risk factor for psychotic disorder is needed.

\section{CHILDHOOD URBANICITY}

There is consistent evidence that urban upbringing is associated with an increased risk of developing a psychotic disorder (43). The population attributable risk is approximately $30 \%(44,45)$, meaning that if we could eliminate urban upbringing as a risk factor there would be $30 \%$ less cases of psychotic disorder. The percentage of the global population living in urban areas is set to increase, from approximately 60\% in 2010 to approximately $70 \%$ in 2030 (46), which stresses the urgency of exploring the mechanisms linking urban upbringing and psychotic disorder. The vulnerable period of impact is specific to childhood and adolescence $(47,48)$. There is meta-analytic evidence for a dose-response relationship between urban upbringing and psychotic disorder (49-51). G $\times \mathrm{E}$ interaction may be present as some studies have shown that the risk of developing a psychotic disorder after exposure to an urban environment is higher in persons with familial liability for psychotic disorder, than in persons without familial liability (29-31).

The urban environment is a complex environment, probably consisting of multiple risk factors for psychotic disorder. The elements associated with the urban environment that mediate the association with psychotic disorder, as well as the neurobiological pathways involved, remain largely unknown. Candidate factors include higher levels of perceived social isolation in urban areas (52) and greater exposure to social "defeat" occasioned for example by higher levels of competition in cities or by discrimination/social exclusion (53), as well as higher level of pregnancy and birth complications (54) or infections, for example influenza, (55) and lower level of prenatal vitamin D (56) due to reduced sunlight exposure in urban areas. No single factor, however, has been show to mediate the association between urban environment and psychotic disorder. One of the mechanisms that can be envisaged, is altered stress processing (57), due to higher levels of social defeat (53) in urban areas. Indeed, early life stress has been associated with cerebral alterations in humans (58) and in animals (59), through altered levels of neurohormones, neurotransmitters, and neurotrophic factors (60). Another explanation is the social drift theory: individuals with genetic liability for psychotic disorders are more prone to move to an urban environment. Though, this is unlikely to be the only explanation as changes in urbanicity exposure during childhood modify the risk of psychotic disorder in adulthood (50). Confounding by drug misuse is unlikely to explain the association (61), as is confounding by genetic liability to schizophrenia (44). In conclusion, the association between urban upbringing and higher risk of developing a 
psychotic disorder is well established, while the underlying mechanisms and true risk factors remain uncertain and need further exploration.

\section{CHILDHOOD TRAUMA}

Several studies have reported that childhood trauma is associated with the development of psychotic disorder in adulthood $(32,62-65)$. Examples of childhood trauma are sexual abuse, physical abuse/neglect and emotional abuse/neglect, and bullying and parental death. This evidence is further substantiated by a meta-analysis, which showed an overall odd's ratio of 2.78 for childhood adversities (65). Similar to urban upbringing, an estimated population attributable risk of around 30\% was found (65). There is evidence for a dose-response relationship between childhood trauma and psychotic disorder (66). The association between childhood trauma and psychotic disorder is not specific: childhood trauma is also associated with other psychiatric disorders, for example depressive disorders (67) and substance abuse disorders (68).

Behavioral sensitization is a proposed mechanism: it has been found that childhood trauma in patients with psychotic disorder is associated with increased stress reactivity, i.e. a stronger increase in negative emotions and psychotic intensity in reaction to daily live stressors (69). This hypothesis is supported by the neurobiological explanation: exposure to stress is thought to lead to a blunted cortical dopamine response, this is likely to reduce the inhibition of mesolimbic dopamine release and result in increased dopamine response to stress (14). Excessive dopamine has been associated with DNA damage and apoptosis (70) and stimulation of the dopamine D1 receptor may participate in dopamine-induced degeneration (71). Exposure to childhood trauma may lead to over-reactivity and dysregulation of the hypothalamic-pituitary-adrenal (HPA) axis (72), which also affects cerebral development (73).

Further, a cognitive approach may explain the association between childhood trauma and psychotic disorder: exposure to childhood trauma can lead to negative thoughts such as: nobody can be trusted; I am bad. These thoughts may grow into incorrect core beliefs about the self, the other and the world, which may lead to incorrect interpretations of everyday situations and eventually psychotic symptoms in adult life (74). Flashbacks to trauma may be accompanied by delusions to make a logic explanation for the flashbacks (75).

\section{CANNABIS}

A systematic review (76) revealed an increase in risk of psychotic disorder of about $40 \%$ in participants who had ever used cannabis. There is evidence for a dose-response relationship: when the frequency of cannabis use increased, this risk of psychotic disorder 
could be further elevated (76). Two studies confirmed that cannabis use precedes the onset of psychotic disorder $(77,78)$. Furthermore, cannabis use has been associated with an earlier age of onset of psychotic disorder (79) and has been related to the persistence of psychotic symptoms (80). G x E interaction may be present as some studies have shown that the risk of developing a psychotic disorder after cannabis use is higher in persons with genetic liability for psychotic disorder, than in persons without genetic liability $(33,34)$. The subject of a possible reverse causality has to be taken into account: individuals with a liability for psychosis may be more likely to start using cannabis as self-medication for early symptoms of psychosis (33). However even if reverse causality is one of the mechanisms linking cannabis use and psychotic disorder, cannabis could still also be involved in the causal pathway.

The endocannabinoid system plays an important role in neuronal proliferation, migration, axonal guidance, positioning of cortical interneurons, and synaptogenesis (81). The endocannabinoid hypothesis of psychotic disorder describes the disruption of normative endocannabinoid signalling, for example by the use of cannabis, during adolescence, which may result in significant disruptions in neurodevelopment and may have longstanding consequences on adult brain function. The association between cannabis and psychotic disorder can also be explained by the dopamine hypothesis: exposure to tetrahydrocannabinol (THC), the active psychotropic ingredient of cannabis, may lead to increased striatal dopamine levels (82). Although dopamine is not the only neurotransmitter involved in psychosis, dopamine is still assumed to play an important role in the emergence of psychotic symptoms (83). However, research on the association between cannabis and dopamine is not univocal: cannabis has been associated with reduced striatal dopamine synthesis capacity (84) and with blunting of striatal dopamine release (85). Cannabis use (76) has been associated with reductions of CT and GMV (86-88) in patients with a psychotic disorder, as well as with reductions of CT in healthy siblings (86), which could be the result of the disruption of normal endocannabinoid signalling or/and or dopamine induced degeneration.

\section{THE ENVIRONMENT AND THE BRAIN: GRAY MATTER ALTERATION AS THE OUTCOME OF GXE}

Although gene $\times$ environment interactions in psychotic disorder have gained great interest $(89,90)$ the number of $G \times E$ studies using structural brain phenotypes as the outcome variables is limited $(27,28,36,86)$. Interaction between genetic liability for psychotic disorders and obstetric complications has been associated with changes in GMV, CSF and hippocampal volumes $(27,36)$. Interaction between genetic liability for psychotic disorders and cannabis has been associated with cortical thinning and white matter abnormalities $(27,28)$. Further, previous analyses from our group showed that lower CT was associated with higher levels of childhood trauma in patients with psy- 
chotic disorder, but not siblings (86). To our knowledge there are no studies describing interaction between childhood urbanicity and genetic liability for psychotic disorders with structural brain phenotypes as the outcome. In this thesis interactions between the environmental risk factors childhood urbanicity, childhood trauma and cannabis and genetic liability for psychotic disorders were examined. The selected outcome measures were CT and GMV. CT and GMV were chosen because gray matter alterations are biological phenotypes associated with psychotic disorder and sensitive to the environmental exposures childhood urbanicity (91), childhood trauma $(92,93)$, and cannabis (94).

\section{STUDY DESIGN}

\section{Genetic Risk and Outcome of Psychosis (G.R.O.U.P.)}

Data was collected in multisite, longitudinal, naturalistic cohort study, the Dutch national Genetic Risk and Outcome in Psychosis (GROUP) project (95). The objectives of the GROUP study are two-fold: (1) investigating the genetic and environmental factors, and their interaction, contributing to the expression of psychosis; (2) investigating factors of vulnerability and protectiveness, and response to medication and clinical outcome. The GROUP consortium consists of the academic psychiatric centres of Amsterdam, Groningen, Maastricht and Utrecht and their affiliated mental health care institutions (including some in Belgium). The full sample consisted of 1120 patients diagnosed with a non-affective psychotic disorder, 1057 of their siblings, 919 parents of the patients and their siblings, and 590 unrelated healthy controls subjects from the general population from the Netherlands and Belgium. In Maastricht additional data were collected in an add-on longitudinal magnetic resonance imaging (MRI) study. The sample consisted of 89 patients with a diagnosis of a non-affective psychotic disorder, 95 healthy siblings of patients with a diagnosis of a non-affective psychotic disorder, and 87 control subjects.

\section{Aim and outline of this thesis}

Although there is sufficient evidence that childhood urbanicity, childhood trauma and cannabis are risk factors for psychotic disorder, the underlying etiologic processes to psychotic disorder need further exploration. Increasing knowledge on the etiology is essential for the development of new treatments and prevention. The overall aim of this thesis was to study environmental risk factors for psychotic disorder and potential mechanistic pathways of psychotic disorder, with emphasis on childhood urbanicity, but also childhood trauma, cannabis and influenza. For that purpose, not one research methodology, but different strategies were used: epidemiological, ecological and neuroimaging approaches in order to untangle the associations. In addition to patients with psychotic disorder, healthy siblings of patients with psychotic disorder were included in 
most studies. Studying the effects of environmental risk factors in healthy siblings of patients with psychotic disorder, is a favorable approach, because healthy siblings share a portion of their genes as well as the environment but there is no bias by the (pathologic) effects of the psychotic disorder or of the treatment for psychotic disorder.

In chapter 2 maternal influenza as a risk factor for schizophrenia was studied, not all previous studies agree this is a risk factor. A meta-analysis of the studies examining birth during the 9-month period after the influenza pandemic of 1957 as a risk factor for schizophrenia was performed.

In chapter 3 to 6 childhood urbanicity is the key topic. Behavioural sensitisation was tested as mechanism linking childhood urbanicity to psychotic disorder in chapter 3. Previous research revealed that individuals with psychotic disorder show increased emotional reactivity to daily life stressful events compared to individuals without psychotic disorder (96). In chapter 3 the experience sampling method (ESM) was used to study stress reactivity and its association with psychotic disorder and childhood urbanicity.

In chapter 4 childhood trauma and childhood urbanicity were examined together. It was tested whether childhood urbanicity moderates the association between childhood trauma and psychotic disorder and whether childhood urbanicity is associated with higher levels of childhood trauma in individuals with psychotic disorder.

In chapter 5 intergenerational educational achievements in psychotic disorder were studied and possible associations between intergenerational educational achievements and childhood trauma and childhood urbanicity were examined.

In the next two chapters a multimodal approach was applied to study environmental risk factors: structural neuroimaging data, objective phenotypes of psychotic disorder, were combined with epidemiologic data. In chapter 6 cortical thickness as the outcome of differential exposure to childhood urbanicity was studied. In chapter 7 gray matter volume and exposure to childhood trauma, childhood urbanicity and cannabis were studied. Both studies also explored sex differences, since findings of structural alterations seem to be more extensive in the male population with a psychotic disorder (97).

In chapter 8 the significance of the findings of the various studies in this thesis is discussed, as well as the clinical implications and recommendations for further research. 


\section{REFERENCES}

1. Keefe RS. The longitudinal course of cognitive impairment in schizophrenia: an examination of data from premorbid through posttreatment phases of illness. The Journal of clinical psychiatry. 2014;75 Suppl 2:8-13.

2. van Os J, Kapur S. Schizophrenia. Lancet. 2009;374(9690):635-45.

3. AlAqeel B, Margolese HC. Remission in schizophrenia: critical and systematic review. Harvard review of psychiatry. 2012;20(6):281-97.

4. Jose D, Ramachandra, Lalitha K, Gandhi S, Desai G, Nagarajaiah. Consumer perspectives on the concept of recovery in schizophrenia: A systematic review. Asian journal of psychiatry. 2015;14:13-8.

5. Wunderink L, Sytema S, Nienhuis FJ, Wiersma D. Clinical recovery in first-episode psychosis. Schizophr Bull. 2009;35(2):362-9.

6. McGrath J, Saha S, Chant D, Welham J. Schizophrenia: a concise overview of incidence, prevalence, and mortality. Epidemiologic reviews. 2008;30:67-76.

7. van Os J, Linscott RJ, Myin-Germeys I, Delespaul P, Krabbendam L. A systematic review and meta-analysis of the psychosis continuum: evidence for a psychosis proneness-persistence-impairment model of psychotic disorder. Psychological medicine. 2009;39(2):179-95.

8. Tsuang M. Schizophrenia: genes and environment. Biological psychiatry. 2000;47(3):210-20.

9. Genetics and mental disorders. National Institute of Mental Health's Genetics Workgroup. Biological psychiatry. 1999;45(5):559-73.

10. Kavanagh DH, Tansey KE, O'Donovan MC, Owen MJ. Schizophrenia genetics: emerging themes for a complex disorder. Mol Psychiatry. 2015;20(1):72-6.

11. van Os J, Kenis G, Rutten BP. The environment and schizophrenia. Nature. 2010;468(7321):203-12.

12. Cannon M, Jones PB, Murray RM. Obstetric complications and schizophrenia: historical and metaanalytic review. The American journal of psychiatry. 2002;159(7):1080-92.

13. Yun Y, Phillips $L$, Cotton S, Yung AR, Francey SM, Yuen HP, et al. Obstetric complications and transition to psychosis in an "ultra" high risk sample. Aust N Z J Psychiatry. 2005;39(6):460-6.

14. Howes OD, McCutcheon R, Owen MJ, Murray RM. The Role of Genes, Stress, and Dopamine in the Development of Schizophrenia. Biol Psychiatry. 2016.

15. Howes OD, Kapur S. The dopamine hypothesis of schizophrenia: version III--the final common pathway. Schizophr Bull. 2009;35(3):549-62.

16. Mizrahi R. Social Stress and Psychosis Risk: Common Neurochemical Substrates? Neuropsychopharmacology. 2016;41(3):666-74.

17. Sommer IE, Kahn RS. The contribution of neuroimaging to understanding schizophrenia; past, present, and future. Schizophrenia bulletin. 2015;41(1):1-3.

18. van den Heuvel MP, Fornito A. Brain networks in schizophrenia. Neuropsychol Rev. 2014;24(1):32-48.

19. Poels EM, Kegeles LS, Kantrowitz JT, Slifstein M, Javitt DC, Lieberman JA, et al. Imaging glutamate in schizophrenia: review of findings and implications for drug discovery. Mol Psychiatry. 2014;19(1):20-9.

20. Weinstein JJ, Chohan MO, Slifstein M, Kegeles LS, Moore H, Abi-Dargham A. Pathway-Specific Dopamine Abnormalities in Schizophrenia. Biol Psychiatry. 2016.

21. Wheeler AL, Voineskos AN. A review of structural neuroimaging in schizophrenia: from connectivity to connectomics. Frontiers in human neuroscience. 2014;8:653.

22. Honea R, Crow TJ, Passingham D, Mackay CE. Regional deficits in brain volume in schizophrenia: a metaanalysis of voxel-based morphometry studies. The American journal of psychiatry. 2005;162(12):2233-45.

23. Glahn DC, Laird AR, Ellison-Wright I, Thelen SM, Robinson JL, Lancaster JL, et al. Meta-analysis of gray matter anomalies in schizophrenia: application of anatomic likelihood estimation and network analysis. Biological psychiatry. 2008;64(9):774-81.

24. Schultz CC, Koch K, Wagner G, Roebel M, Schachtzabel C, Gaser C, et al. Reduced cortical thickness in first episode schizophrenia. Schizophrenia research. 2010;116(2-3):204-9. 


\section{Chapter 1}

25. van Lutterveld R, van den Heuvel MP, Diederen KM, de Weijer AD, Begemann MJ, Brouwer RM, et al. Cortical thickness in individuals with non-clinical and clinical psychotic symptoms. Brain : a journal of neurology. 2014;137(Pt 10):2664-9.

26. Haijma SV, Van Haren N, Cahn W, Koolschijn PC, Hulshoff Pol HE, Kahn RS. Brain volumes in schizophrenia: a meta-analysis in over 18000 subjects. Schizophrenia bulletin. 2013;39(5):1129-38.

27. Geoffroy PA, Etain B, Houenou J. Gene x environment interactions in schizophrenia and bipolar disorder: evidence from neuroimaging. Front Psychiatry. 2013;4:136.

28. French L, Gray C, Leonard G, Perron M, Pike GB, Richer L, et al. Early Cannabis Use, Polygenic Risk Score for Schizophrenia and Brain Maturation in Adolescence. JAMA Psychiatry. 2015;72(10):1002-11.

29. Weiser M, van Os J, Reichenberg A, Rabinowitz J, Nahon D, Kravitz E, et al. Social and cognitive functioning, urbanicity and risk for schizophrenia. The British journal of psychiatry : the journal of mental science. 2007;191:320-4.

30. van Os J, Pedersen CB, Mortensen PB. Confirmation of synergy between urbanicity and familial liability in the causation of psychosis. Am J Psychiatry. 2004;161(12):2312-4.

31. Van Os J, Hanssen M, Bak M, Bijl RV, Vollebergh W. Do urbanicity and familial liability coparticipate in causing psychosis? Am J Psychiatry. 2003;160(3):477-82.

32. Heins $M$, Simons $C$, Lataster $T$, Pfeifer $S$, Versmissen $D$, Lardinois $M$, et al. Childhood trauma and psychosis: a case-control and case-sibling comparison across different levels of genetic liability, psychopathology, and type of trauma. The American journal of psychiatry. 2011;168(12):1286-94.

33. Henquet C, Murray R, Linszen D, van Os J. The environment and schizophrenia: the role of cannabis use. Schizophrenia bulletin. 2005;31(3):608-12.

34. Caspi A, Moffitt TE, Cannon M, McClay J, Murray R, Harrington H, et al. Moderation of the effect of adolescent-onset cannabis use on adult psychosis by a functional polymorphism in the catechol-Omethyltransferase gene: longitudinal evidence of a gene $X$ environment interaction. Biological psychiatry. 2005;57(10):1117-27.

35. Mittal VA, Ellman LM, Cannon TD. Gene-environment interaction and covariation in schizophrenia: the role of obstetric complications. Schizophr Bull. 2008;34(6):1083-94.

36. Cannon TD, van Erp TG, Rosso IM, Huttunen M, Lonnqvist J, Pirkola T, et al. Fetal hypoxia and structural brain abnormalities in schizophrenic patients, their siblings, and controls. Arch Gen Psychiatry. 2002;59(1):35-41.

37. Cannon TD, Rosso IM, Hollister JM, Bearden CE, Sanchez LE, Hadley T. A prospective cohort study of genetic and perinatal influences in the etiology of schizophrenia. Schizophrenia bulletin. 2000;26(2):351-66.

38. Khandaker GM, Zimbron J, Lewis G, Jones PB. Prenatal maternal infection, neurodevelopment and adult schizophrenia: a systematic review of population-based studies. Psychological medicine. 2013;43(2):239-57.

39. Mednick SA, Machon RA, Huttunen MO, Bonett D. Adult schizophrenia following prenatal exposure to an influenza epidemic. Archives of general psychiatry. 1988;45(2):189-92.

40. O'Callaghan E, Sham P, Takei N, Glover G, Murray RM. Schizophrenia after prenatal exposure to 1957 A2 influenza epidemic. Lancet. 1991;337(8752):1248-50.

41. Brown AS. Prenatal infection as a risk factor for schizophrenia. Schizophrenia bulletin. 2006;32(2):200-2.

42. Brown AS, Begg MD, Gravenstein S, Schaefer CA, Wyatt RJ, Bresnahan M, et al. Serologic evidence of prenatal influenza in the etiology of schizophrenia. Archives of general psychiatry. 2004;61(8):774-80.

43. McGrath J, Scott J. Urban birth and risk of schizophrenia: a worrying example of epidemiology where the data are stronger than the hypotheses. Epidemiologia e psichiatria sociale. 2006;15(4):243-6.

44. Mortensen PB, Pedersen CB, Westergaard T, Wohlfahrt J, Ewald H, Mors O, et al. Effects of family history and place and season of birth on the risk of schizophrenia. N Engl J Med. 1999;340(8):603-8.

45. Marcelis M, Navarro-Mateu F, Murray R, Selten JP, Van Os J. Urbanization and psychosis: a study of 1942-1978 birth cohorts in The Netherlands. Psychological medicine. 1998;28(4):871-9.

46. United Nations Population Fund. State of world population 2011: People and possibilities in a wordl of 7 billion. New York: United Nations Population Fund; 2011.

47. Marcelis M, Takei N, van Os J. Urbanization and risk for schizophrenia: does the effect operate before or around the time of illness onset? Psychological medicine. 1999;29(5):1197-203. 
48. Pedersen $\mathrm{CB}$, Mortensen PB. Why factors rooted in the family may solely explain the urban-rural differences in schizophrenia risk estimates. Epidemiologia e psichiatria sociale. 2006;15(4):247-51.

49. March D, Hatch SL, Morgan C, Kirkbride JB, Bresnahan M, Fearon P, et al. Psychosis and place. Epidemiol Rev. 2008;30:84-100.

50. Krabbendam L, van Os J. Schizophrenia and urbanicity: a major environmental influence--conditional on genetic risk. Schizophrenia bulletin. 2005;31(4):795-9.

51. Vassos E, Pedersen C, Murray R, Collier D, Lewis C. A meta-analysis of the association of urbanicity with schizophrenia. Schiz Bull. 2012; in press.

52. van Os J, Driessen G, Gunther N, Delespaul P. Neighbourhood variation in incidence of schizophrenia. Evidence for person-environment interaction. The British journal of psychiatry : the journal of mental science. 2000;176:243-8.

53. Selten JP, Cantor-Graae E. Hypothesis: social defeat is a risk factor for schizophrenia? The British journal of psychiatry Supplement. 2007;51:s9-12.

54. Eaton WW, Mortensen PB, Frydenberg M. Obstetric factors, urbanization and psychosis. Schizophrenia research. 2000;43(2-3):117-23.

55. McDonald C, O'Callaghan E, Keogh F, Sham PC, Kinsella A, Morris M, et al. Number of older siblings of individuals diagnosed with schizophrenia. Schizophrenia research. 2001;47(2-3):275-80.

56. McGrath J. Hypothesis: is low prenatal vitamin D a risk-modifying factor for schizophrenia? Schizophrenia research. 1999;40(3):173-7.

57. Lederbogen F, Kirsch P, Haddad L, Streit F, Tost H, Schuch P, et al. City living and urban upbringing affect neural social stress processing in humans. Nature. 2011;474(7352):498-501.

58. Tomoda A, Suzuki H, Rabi K, Sheu YS, Polcari A, Teicher MH. Reduced prefrontal cortical gray matter volume in young adults exposed to harsh corporal punishment. Neurolmage. 2009;47 Suppl 2:T66-71.

59. Spinelli S, Chefer S, Suomi SJ, Higley JD, Barr CS, Stein E. Early-life stress induces long-term morphologic changes in primate brain. Archives of general psychiatry. 2009;66(6):658-65.

60. De Bellis MD. The psychobiology of neglect. Child maltreatment. 2005;10(2):150-72.

61. Lewis G, David A, Andreasson S, Allebeck P. Schizophrenia and city life. Lancet. 1992;340(8812):137-40.

62. Bebbington PE, Bhugra D, Brugha $T$, Singleton $N$, Farrell M, Jenkins R, et al. Psychosis, victimisation and childhood disadvantage: evidence from the second British National Survey of Psychiatric Morbidity. The British journal of psychiatry : the journal of mental science. 2004;185:220-6.

63. Janssen I, Krabbendam L, Bak M, Hanssen M, Vollebergh W, de Graaf R, et al. Childhood abuse as a risk factor for psychotic experiences. Acta psychiatrica Scandinavica. 2004;109(1):38-45.

64. Lataster T, van Os J, Drukker M, Henquet C, Feron F, Gunther N, et al. Childhood victimisation and developmental expression of non-clinical delusional ideation and hallucinatory experiences: victimisation and non-clinical psychotic experiences. Social psychiatry and psychiatric epidemiology. 2006;41(6):423-8.

65. Varese F, Smeets F, Drukker M, Lieverse R, Lataster T, Viechtbauer W, et al. Childhood adversities increase the risk of psychosis: a meta-analysis of patient-control, prospective- and cross-sectional cohort studies. Schizophrenia bulletin. 2012;38(4):661-71.

66. Read J, van Os J, Morrison AP, Ross CA. Childhood trauma, psychosis and schizophrenia: a literature review with theoretical and clinical implications. Acta psychiatrica Scandinavica. 2005;112(5):330-50.

67. Chapman DP, Whitfield CL, Felitti VJ, Dube SR, Edwards VJ, Anda RF. Adverse childhood experiences and the risk of depressive disorders in adulthood. Journal of affective disorders. 2004;82(2):217-25.

68. Afifi TO, Henriksen CA, Asmundson GJ, Sareen J. Childhood maltreatment and substance use disorders among men and women in a nationally representative sample. Canadian journal of psychiatry Revue canadienne de psychiatrie. 2012;57(11):677-86.

69. Lardinois M, Lataster T, Mengelers R, Van Os J, Myin-Germeys I. Childhood trauma and increased stress sensitivity in psychosis. Acta psychiatrica Scandinavica. 2011;123(1):28-35.

70. Luo Y, Hattori A, Munoz J, Qin ZH, Roth GS. Intrastriatal dopamine injection induces apoptosis through oxidation-involved activation of transcription factors AP-1 and NF-kappaB in rats. Molecular pharmacology. 1999;56(2):254-64. 


\section{Chapter 1}

71. Wersinger C, Chen J, Sidhu A. Bimodal induction of dopamine-mediated striatal neurotoxicity is mediated through both activation of D1 dopamine receptors and autoxidation. Molecular and cellular neurosciences. 2004;25(1):124-37.

72. Klaassens ER. Bouncing back - trauma and the HPA-axis in healthy adults. Eur J Psychotraumatol. 2010;1.

73. Heim C, Newport DJ, Heit S, Graham YP, Wilcox M, Bonsall R, et al. Pituitary-adrenal and autonomic responses to stress in women after sexual and physical abuse in childhood. JAMA : the journal of the American Medical Association. 2000;284(5):592-7.

74. Larkin W, Read J. Childhood trauma and psychosis: evidence, pathways, and implications. Journal of postgraduate medicine. 2008;54(4):287-93.

75. Read J, Agar K, Argyle N, Aderhold V. Sexual and physical abuse during childhood and adulthood as predictors of hallucinations, delusions and thought disorder. Psychology and psychotherapy. 2003;76(Pt 1):1-22.

76. Moore TH, Zammit S, Lingford-Hughes A, Barnes TR, Jones PB, Burke M, et al. Cannabis use and risk of psychotic or affective mental health outcomes: a systematic review. Lancet. 2007;370(9584):319-28.

77. Zammit S, Allebeck P, Andreasson S, Lundberg I, Lewis G. Self reported cannabis use as a risk factor for schizophrenia in Swedish conscripts of 1969: historical cohort study. Bmj. 2002;325(7374):1199.

78. Arseneault L, Cannon M, Poulton R, Murray R, Caspi A, Moffitt TE. Cannabis use in adolescence and risk for adult psychosis: Iongitudinal prospective study. Bmj. 2002;325(7374):1212-3.

79. Dekker N, Meijer J, Koeter M, van den Brink W, van Beveren N, Kahn RS, et al. Age at onset of nonaffective psychosis in relation to cannabis use, other drug use and gender. Psychological medicine. 2012;42(9):1903-11.

80. Kuepper R, van Os J, Lieb R, Wittchen HU, Hofler M, Henquet C. Continued cannabis use and risk of incidence and persistence of psychotic symptoms: 10 year follow-up cohort study. Bmj. 2011;342:d738.

81. Burns JK. Pathways from cannabis to psychosis: a review of the evidence. Front Psychiatry. 2013;4:128.

82. Kuepper R, Morrison PD, van Os J, Murray RM, Kenis G, Henquet C. Does dopamine mediate the psychosis-inducing effects of cannabis? A review and integration of findings across disciplines. Schizophrenia research. 2010;121(1-3):107-17.

83. Howes OD, Murray RM. Schizophrenia: an integrated sociodevelopmental-cognitive model. Lancet. 2014;383(9929):1677-87.

84. Bloomfield MA, Morgan CJ, Egerton A, Kapur S, Curran HV, Howes OD. Dopaminergic function in cannabis users and its relationship to cannabis-induced psychotic symptoms. Biological psychiatry. 2014;75(6):470-8.

85. Thompson JL, Urban N, Slifstein M, Xu X, Kegeles LS, Girgis RR, et al. Striatal dopamine release in schizophrenia comorbid with substance dependence. Molecular psychiatry. 2013;18(8):909-15.

86. Habets P, Marcelis M, Gronenschild E, Drukker M, van Os J. Reduced cortical thickness as an outcome of differential sensitivity to environmental risks in schizophrenia. Biological psychiatry. 2011;69(5):487-94.

87. Rais M, van Haren NE, Cahn W, Schnack HG, Lepage C, Collins L, et al. Cannabis use and progressive cortical thickness loss in areas rich in CB1 receptors during the first five years of schizophrenia. European neuropsychopharmacology : the journal of the European College of Neuropsychopharmacology. 2010;20(12):855-65.

88. Rais M, Cahn W, Van Haren N, Schnack H, Caspers E, Hulshoff Pol H, et al. Excessive brain volume loss over time in cannabis-using first-episode schizophrenia patients. The American journal of psychiatry. 2008;165(4):490-6.

89. European Network of National Networks studying Gene-Environment Interactions in S, van Os J, Rutten BP, Myin-Germeys I, Delespaul P, Viechtbauer W, et al. Identifying gene-environment interactions in schizophrenia: contemporary challenges for integrated, large-scale investigations. Schizophrenia bulletin. 2014;40(4):729-36.

90. lyegbe C, Campbell D, Butler A, Ajnakina O, Sham P. The emerging molecular architecture of schizophrenia, polygenic risk scores and the clinical implications for GxE research. Social psychiatry and psychiatric epidemiology. 2014;49(2):169-82. 


\section{General introduction}

91. Haddad L, Schafer A, Streit F, Lederbogen F, Grimm O, Wust S, et al. Brain Structure Correlates of Urban Upbringing, an Environmental Risk Factor for Schizophrenia. Schizophrenia bulletin. 2014.

92. Tomoda A, Polcari A, Anderson CM, Teicher MH. Reduced visual cortex gray matter volume and thickness in young adults who witnessed domestic violence during childhood. Plos one. 2012; 7(12):e52528.

93. Bremner JD. Effects of traumatic stress on brain structure and function: relevance to early responses to trauma. Journal of trauma \& dissociation : the official journal of the International Society for the Study of Dissociation. 2005;6(2):51-68.

94. Epstein KA, Kumra S. Altered cortical maturation in adolescent cannabis users with and without schizophrenia. Schizophr Res. 2015;162(1-3):143-52.

95. Genetic Risk and Outcome in Psychosis (GROUP) investigators. Evidence that familial liability for psychosis is expressed as differential sensitivity to cannabis: an analysis of patient-sibling and siblingcontrol pairs. Archives of general psychiatry. 2011;68(2):138-47.

96. Myin-Germeys I, van Os J, Schwartz JE, Stone AA, Delespaul PA. Emotional reactivity to daily life stress in psychosis. Archives of general psychiatry. 2001;58(12):1137-44.

97. Bora E, Fornito A, Yucel M, Pantelis C. The effects of gender on grey matter abnormalities in major psychoses: a comparative voxelwise meta-analysis of schizophrenia and bipolar disorder. Psychological medicine. 2011:1-13. 



\section{Chapter 2 \\ Schizophrenia and 1957 pandemic of influenza: meta-analysis}

Authors: Jean-Paul Selten ${ }^{1,2}$, Aleida Frissen ${ }^{1}$, Gerty Lensvelt-Mulders ${ }^{3}$, and Vera A. Morgan $^{4}$

${ }^{1}$ Department of Psychiatry, Rudolf Magnus Institute of Neuroscience, University Medical Centre Utrecht, Utrecht, The Netherlands;

${ }^{2}$ Rivierduinen Foundation, PO Box 750, 1300 AT Leiden, The Netherlands;

${ }^{3}$ Department of Methodology and Statistics, Faculty of Social Science, University of Utrecht, Utrecht, The Netherlands;

${ }^{4}$ Neuropsychiatric Epidemiology Research Unit, School of Psychiatry and Clinical Neurosciences, University of Western Australia, Perth, Australia

Schizophrenia Bulletin (2010) 36, 219-228 


\section{Chapter 2}

\section{ABSTRACT}

\section{Background}

Maternal influenza during pregnancy is a controversial risk factor for schizophrenia in the child. We conducted a meta-analysis to examine whether birth during the 9-month period after the pandemic of 1957 was a risk factor for schizophrenia.

\section{Methods}

Studies that compared the risk of schizophrenia among subjects born after the pandemic with that among those born in corresponding time periods in surrounding years were divided into those conducted in the United States, Europe, or Australia (type A studies, n 5 8) and those from Japan, where the epidemic came in 2 waves (type B studies, n 5 3 ). Other studies examined the risk among subjects born to mothers who were pregnant during the pandemic and reported having had influenza (type $\mathrm{C}$ studies, $\mathrm{n} 5 \mathrm{2}$ ). Relative risks (RRs) were extracted or calculated for each month and/or trimester of possible exposure by 2 independent authors. All analyses were performed using a fixedeffects model.

\section{Results}

The weighted results of the type A studies did not indicate a significantly increased risk of schizophrenia among children exposed during any trimester or month of prenatal life. Not a single study found a significant first- or second-trimester effect. The mean weighted RR for subjects who were in their first, second, or third trimester of prenatal life during the pandemic ( 8 effect sizes) was 0.91 (95\% confidence interval $[\mathrm{Cl}]$ : $0.85-$ 0.98), 1.00 (95\% Cl: 0.93-1.07), and 1.05 (95\% Cl: 0.98-1.12), respectively. The pooled results of the type $\mathrm{B}$ and type $\mathrm{C}$ studies were also negative.

\section{Conclusion}

Given high infection rates during the pandemic (about 50\%), these results do not support the maternal influenza hypothesis. 


\section{INTRODUCTION}

Maternal influenza during pregnancy is in many circles an established risk factor for schizophrenia. The basis to support the hypothesis, however, is controversial. The first evidence came from studies of the 1957 pandemic of A2 ("Asian") influenza. An influential study from Finland, published in 1988, reported an increased proportion of schizophrenia diagnoses in patients whose second trimester of fetal life overlapped with the influenza pandemic (1). Three years later, an investigation from England and Wales reported an $88 \%$ increased risk of schizophrenia among subjects born 5 months after the peak of the pandemic (2). Subsequent studies, however, reported inconsistent findings (3).

A limitation of these so-called ecological studies is the absence of information on exposure: Subjects are considered to be exposed if they are born in a given period after an epidemic or pandemic. A more sophisticated method of documenting exposure is the assessment of influenza antibodies in pregnant mothers. The only study to compare antibody titers in pregnancies giving rise to affected and unaffected offspring involved an American cohort born during the period 1959-1966, i.e., not exposed to the pandemic (4). Exposure to influenza virus during the first, but not the second or third, trimester of pregnancy was associated with an increased risk of schizophrenia. However, this result was inconclusive because the 95\% confidence interval $(\mathrm{Cl})$ for the measure of outcome was extremely large and included 1.0 (Mantel-Haenszel odds ratio $=7.0,95 \%$ Cl: 0.7-75.3).

Thus, a correct interpretation of the ecological investigations remains important for an evaluation of the influenza hypothesis. The absence of information on exposure does not completely invalidate these studies because infection rates during pandemics are assumed to be about $50 \%(5,6)$. When interpreting these studies, it is important to bear in mind that the likelihood of research findings being true diminishes with the number of relationships tested (7). This could be relevant here because many studies tested for an association between schizophrenia risk and exposure to influenza during any of the 9 months of prenatal life. Because this method leads to 9 statistical tests, some associations will emerge by chance.

We reasoned that if maternal influenza contributes to the etiology of schizophrenia, a pandemic should increase the risk for those in utero. We therefore performed a metaanalysis to examine whether birth during the 9-month period after the 1957 pandemic, or maternal reports of influenza during pregnancy at the time of the pandemic, were risk factors for schizophrenia in the child. 


\section{MATERIALS AND METHODS}

\section{Data Sources}

We performed a MEDLINE search (1960 to March 2008) using the key words influenza, pandemic, psychosis, schizophrenia, and paranoid, and reviewed the reference lists of relevant articles. To be included a study had to report a relative risk (RR) for children born during (part of) the 9-month period after the pandemic (or for children born to mothers who reported having had influenza). Studies that provided sufficient information to allow us to calculate the RR were also included.

\section{Study Selection}

Eighteen potentially relevant studies were retrieved (1, 2, 8-23), 5 of which were subsequently excluded(8-12). Among these was a study using data sets from England, Scotland, and Denmark that did not report patient numbers and presented the results in terms of $t$ values, which could not be translated into RRs (8). However, the data sets from England and Scotland overlapped strongly with other data sets from these countries, described in previous publications, from which we could extract RRs $(2,15)$. Unfortunately, the Danish data set was not available (it had not been saved). We excluded a second study, from Surinam and the Netherlands Antilles, because the lack of information on the number of live births in these countries made it difficult to estimate the RRs with any certainty (9). We also excluded a study from Palau because it examined schizophrenia risk by calendar year of birth (10). Finally, of the 3 overlapping studies investigating the impact of the pandemic on the Dutch population (11-13), we included the Selten and Slaets study because it provided information by gender (13).

We distinguished 3 types of studies. Those designated type A studies included 8 ecological studies from Europe, America, and Australia that compared the risk of schizophrenia among subjects born any time in the 9 months after the pandemic (ie, index period) with that among those born during corresponding periods of time in the previous and/or subsequent year (ie, control periods) (1, 2, 13-18). Although it was not known whether the mothers actually had influenza, these children were considered to have been exposed. Likewise, those born in the corresponding period in the previous and/or subsequent year were considered not to have been exposed. One type A study (15) provided information from 2 overlapping sources: the Edinburgh Psychiatric Case Register and a data set for the whole of Scotland. We used the largest data set (Scotland). Six of the type A studies only included patients who had ever been hospitalized, while 2 included outpatients as well as inpatients $(14,18)$.

Three ecological studies from Japan were designated type B studies (19-21). We distinguished between the Japanese and other ecological studies because the course of the pandemic in Japan differed markedly from that in other countries in that it came in 
2 waves, from June to July 1957 and from November to December 1957. Thus, a subject born in February 1958 could have been exposed during the first, second, or third trimester of prenatal life. Two studies examined the risk for subjects admitted to hospitals in Greater Tokyo and the southern part of Shikoku island (Kochi), respectively $(19,20)$. A third study included a survey among a randomly selected sample of hospitals and outpatient clinics throughout the whole of Japan (21). Because the degree of overlap between the national survey and the studies in Greater Tokyo and Kochi was considered to be modest, the 3 studies were retained.

Finally, 2 studies compared the risk of schizophrenia among children whose mothers reported having had influenza during the pandemic with that among those whose mothers reported not having had influenza during the pandemic $(22,23)$. These were designated type $\mathrm{C}$ studies. In most studies, the diagnosis of schizophrenia was made according to standardized criteria; however, 2 of the Japanese studies did not specify the diagnostic criteria used $(19,21)$.

\section{Data extraction}

\section{Type A studies}

Table 1 provides an overview. For the purpose of this meta-analysis, we retrieved data to enable us to extract or calculate the RR of schizophrenia for those exposed (1) at any time during pregnancy, (2) in a particular trimester of pregnancy, and (3) in a particular month of pregnancy. In all studies, births were assumed to be full-term (9-month) deliveries. Where possible, the results were considered separately for men and women. Two of the authors (J. P.S. and A.F.) independently extracted the data and calculated the RRs. Discrepancies were resolved by discussion.

We used the natural logarithm of the RR. The variance $V$ of a RR is given by the formula: $V=1 / a-1 / b+1 / c-1 / d$, where $a$ is the number of preschizophrenic births in the index period, $b$ is the number of live births in the index period, $c$ is the number of preschizophrenic births in the control period, and $d$ is the number of live births in the control period. Although 3 studies did not mention the numbers of live births $(2,14,15)$, we estimated these numbers (see below). Because an estimation is always imperfect, we also calculated the variance of each RR using another formula, $V=1 / a+1 / c$, where $a$ is the number of cases in the index period and $c$ is the number of cases in the control period. This method of variance estimation is not influenced by the size of denominators (24).

All analyses were carried out using the fixed-effects model with MetaWin 2.0 statistical software(25). A homogeneity statistic, Q, was calculated to test whether the studies could be considered to share a common population effect size. A significant $Q$ statistic indicates heterogeneity of the individual study effect sizes, which means that a certain amount of variance cannot be attributed to sampling error. If the value of $Q$ was 
statistically significant, we repeated the analysis using the random-effects model, which is more conservative and takes the extra variance into account $(24,26)$.

Table 1. Eight ecological studies from Europe, America and Australia (type A studies) of schizophrenia risk for subjects in utero in the first, second or third trimester of prenatal life during the 1957 pandemic of A2 influenza.

\begin{tabular}{|c|c|c|c|c|c|c|c|}
\hline \multirow[t]{2}{*}{$\begin{array}{l}\text { Firs author and } \\
\text { publication year }\end{array}$} & \multirow[t]{2}{*}{ Region } & \multirow[t]{2}{*}{$N^{a}$} & \multirow[t]{2}{*}{$\begin{array}{l}\text { End of follow- } \\
\text { up }\end{array}$} & \multirow[t]{2}{*}{$\begin{array}{l}\text { Timing of birth of } \\
\text { control patients }\end{array}$} & \multicolumn{3}{|c|}{$\begin{array}{l}\text { Relative risk by } \\
\text { trimester of exposure }\end{array}$} \\
\hline & & & & & $1 s t$ & 2nd & $3 r d$ \\
\hline Mednick, 1988 & $\begin{array}{l}\text { Uusimaa County, } \\
\text { Finland }\end{array}$ & 58 & 1984 & 6 previous yrs & 0.88 & 0.85 & 0.77 \\
\hline Kendell, 1989 & Scotland & 170 & 1988 & 2 previous yrs & 0.87 & 0.81 & 0.90 \\
\hline O'Callaghan, 1991 & $\begin{array}{l}\text { Regions of England } \\
\& \text { Wales }\end{array}$ & 263 & 1984 & $\begin{array}{l}2 \text { previous \& } 2 \\
\text { subsequent yrs }\end{array}$ & 0.84 & 1.24 & 1.15 \\
\hline Torrey, 1991 & 10 US States & 3368 & $1987 / 1988$ & $\begin{array}{l}1 \text { previous \& } 1 \\
\text { subsequent yr }\end{array}$ & 0.95 & 1.00 & 1.07 \\
\hline \multicolumn{2}{|c|}{ Erlenmeyer-K, 1994 Croatia } & 82 & 1990 & $\begin{array}{l}2 \text { previous \& } 2 \\
\text { subsequent yrs }\end{array}$ & 0.90 & 0.98 & 1.11 \\
\hline Selten, 1994 & The Netherlands & 654 & 1991 & $\begin{array}{l}2 \text { previous \& } 2 \\
\text { subsequent yrs }\end{array}$ & 0.86 & 0.99 & 1.01 \\
\hline McGrath, 1994 & $\begin{array}{l}\text { Queensland, } \\
\text { Australia }\end{array}$ & 156 & 1988 & $\begin{array}{l}5 \text { previous \& } 5 \\
\text { subsequent yrs }^{b}\end{array}$ & 0.57 & 1.27 & 1.21 \\
\hline Morgan, 1997 & Western Australia & 72 & 1996 & $\begin{array}{l}1 \text { previous \& } 1 \\
\text { subsequent } y r^{c}\end{array}$ & 0.86 & 1.00 & 1.86 \\
\hline
\end{tabular}

${ }^{a}$ Number of patients born in period of 9 months after pandemic

${ }^{\mathrm{b}}$ Except 1954, 1957, 1959

${ }^{\text {c}}$ See Morgan et al. (1997) for details

The arrival of A2 influenza and the peak of the epidemic differed by country. Most studies considered infants born in the first month after the peak as being exposed during the ninth month of pregnancy and classified the other months accordingly. Two studies departed from this rule and considered those born during the peak month of the epidemic as being exposed during the ninth month of pregnancy $(14,17)$. In order to apply the same method to all studies, we reclassified exposure in these 2 studies using the approach used in the other studies. Morgan et al, (18) in their study of Western Australia, increased the power of their study to find a second trimester effect by considering those born in the period from November 1957 until March 1958 as being exposed during this trimester. This was possible because the epidemic in Western Australia lasted from July to September 1957. For the purpose of the present meta-analysis, however, we reanalyzed data from this study as for the other studies. Because the peak occurred in September 1957, people born during the periods October to December 1957, January to March 1958, and April to June 1958 were considered as being exposed during the third, second, and first trimesters, respectively. 
While the extraction of RRs was straightforward in some studies, the methods used for 5 studies require further clarification. First, the study from Finland examined hospital admissions of people born in Uusimaa County, a region including Greater Helsinki (1). The authors compared the proportion of schizophrenia diagnoses among psychiatric patients born in the index period with that of schizophrenia diagnoses among patients born in the control periods. Among patients born from February 15 to May 14, 1958 (i.e., exposed to the pandemic during the second trimester of fetal life), 34.6\% were diagnosed with schizophrenia compared with $20.8 \%$ among patients born in the corresponding period in the previous 6 years. The authors controlled for differences between the index and the control groups in the risk period for psychiatric admission by excluding those subjects from the control group who had their first hospital admission at an older age than the maximum age at first admission for patients in the index group (i.e., 26 years and 56 days). The authors reported an excess of schizophrenic births among people born in Uusimaa County who were exposed during the second trimester of pregnancy. However, the proportion of schizophrenia diagnoses among hospitalized patients is not a good outcome variable for statistical analysis because it remains unclear whether an increase in the proportion is due to an increase in schizophrenia or a decrease in other diagnoses. A more direct approach involves the calculation of the risk of hospitalization for schizophrenia among subjects born in Uusimaa County. In order to calculate population-based RRs, we obtained information from the Finnish Bureau of Statistics on the number of live births in Uusimaa County for each month during 19511958. Because the 3-month periods of fetal exposure began on the 15th day of a given month (e.g., February 15, 1958, to May 14, 1958), the number of live births for the research periods was estimated by interpolation. Monthly figures by gender were not available but could be estimated using the proportion of male and female live births in Finland during the period 1950-1960 (51.2\% and 48.8\%, respectively). The calculation of population-based RRs yielded striking findings (see Table 2). To begin with, the risk of hospital admission for schizophrenia was very high (1.9\%-2.7\%) among people born in Uusimaa County and was higher than the recently estimated lifetime risk among the Finnish population (0.87\%) (27). Moreover, the RR for people exposed during the second trimester was decreased rather than increased ( $R R=0.85,95 \% \mathrm{Cl}: 0.68-1.07)$. Although the statistical analysis of the Finnish study has been criticized, 15 the decreased population-based RR is a novel finding. The recalculated schizophrenia risk among the Uusimaa population and the decreased population-based RR for exposure in the second trimester question the validity of the 1988 publication. For the purpose of the present meta-analysis, we used the population-based RRs given in table 2 .

Second, the study from 10 health regions of England and Wales compared the number of patients born in a particular index month with the mean number of patients born in the corresponding month in the 2 previous and 2 subsequent years (2). The authors assumed that there were no major fluctuations in the number of births in the general population. We estimated RRs by using the numbers of patients born in the index and 
control periods. For example, the RR for those born 5 months after the peak of the epidemic was 48 divided by 25.5 (i.e., the mean for the 4 control periods) $=1.88$. We used data from another publication to estimate the denominator needed (i.e., number of live births) to calculate the variance of the RR. According to a follow-up study of all children born in Great Britain in the week of March 3-9, 1958, the risk of developing schizophrenia was 0.0035 (22). Because the data source (hospital admissions recorded by the Mental Health Inquiry) and length of follow-up were similar for both studies, we assumed that the risk was similar among the subjects from the 10 health regions and estimated the numbers of live births and the variance of the RRs.

A third study, the study of the national registry of Scotland, compared the number of preschizophrenic births in an index month with the mean number of such births in the same month in the 2 previous years (15). The authors failed to adjust for the somewhat longer period of risk for subjects born in the control years. However, because data were collected up to 1988, most subjects had passed the period of maximum risk. The number of live births was estimated using data from another publication with the same data set in which the authors reported that the risk of hospitalization for schizophrenia and entry into the national registry was 0.00158 for people born in 1958 (28).

The fourth and largest study, conducted in the United States, used information from 10 states on the month and year of birth of all individuals diagnosed with schizophrenia who were receiving mental health services (14). The number of patients born from 1950 to 1959 was 43 778, with approximately 3368 patients being born in the 9-month period after the pandemic. Using the monthly numbers of live births in these states, the authors calculated monthly birth rates of future schizophrenic patients during the period 1950-1959, not stratified by gender. Because this study is larger than the other studies combined, and to prevent it from dominating the meta-analysis, we compared the birth rate in an index month with the average birth rate in the same calendar month of only 1 previous year and 1 subsequent year. For instance, the birth rate in November 1957 was 0.00444 . Because the mean birth rate of schizophrenic patients in November 1956 and November 1958 was 0.00390 , the RR was estimated at 44.4/39.0 $=1.138$. The authors provided sufficient information to allow an estimation of denominators.

Lastly, with regard to the Dutch study (13), we obtained information about the number of live births per month from Statistics Netherlands and calculated populationbased RRs. The epidemic in the Netherlands peaked between mid-September and midOctober 1957. Subjects born in October 1957 were regarded as being exposed during the ninth month of pregnancy, and subjects born in June 1958 were considered to have been exposed during the first month of pregnancy. The risk of subjects born in index periods was compared with that of subjects born in the corresponding periods in the 2 previous and 2 subsequent years. 
Schizophrenia and 1957 pandemic of influenza: meta-analysis

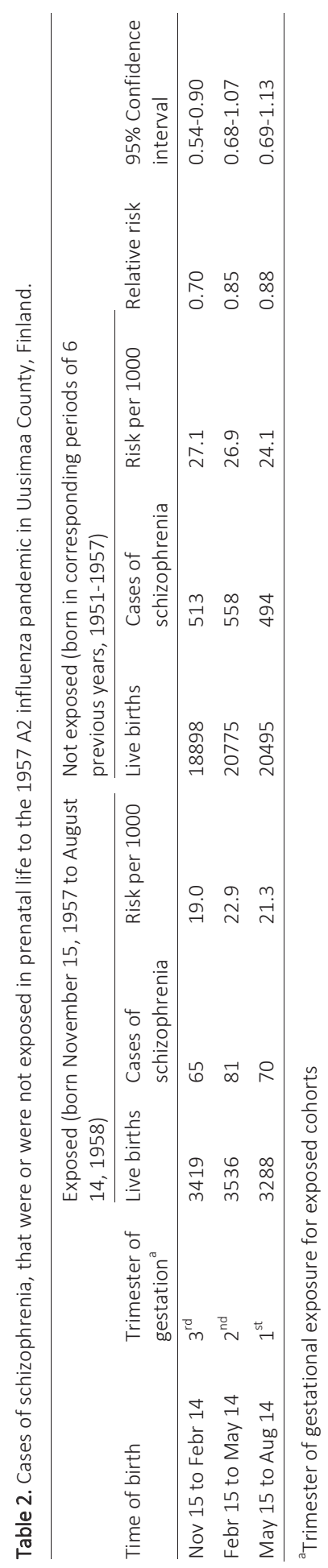




\section{Chapter 2}

\section{Type B studies}

Japanese researchers, inspired by the findings in England and Wales (2), tested the hypothesis that the risk of schizophrenia would be increased in subjects born 5 months after the epidemic, i.e., in November or December 1957 or April or May 1958. Kunugi et al (19) compared the number of patients, by gender, who had been born in the 4 above-mentioned index months with the mean number of patients born during the corresponding months of the 2 previous and 2 subsequent years (i.e., 16 calendar months). Mino et al (21) used a similar method. The only study to provide information on the number of live births was that of Izumoto et al (20). In order to apply the same method to all Japanese studies, we summed the numbers of patients born in these particular index and control months (see Table 3). We then compared the number of patients born in the 4 index months with the mean number of patients born in the 16 control months and estimated RRs. The risk of schizophrenia among Japanese men and women born in the control months of the Izumoto et al study was 0.008209 and 0.006298 , respectively. Assuming the same risk in the 2 other Japanese studies, we estimated the numbers of births in the control months for the 3 studies combined, by gender. Given the estimated RRs for males and females, the denominators for the index groups could be estimated, by gender.

Table 3. Three ecological studies from Japan (type B studies) showing cases of schizophrenia that were or were not exposed in the fifth month of prenatal life to the 1957 A2 influenza pandemic.

\begin{tabular}{|c|c|c|c|c|c|}
\hline $\begin{array}{l}\text { First author and } \\
\text { publication year }\end{array}$ & Region & $\begin{array}{l}\text { Year of follow- } \\
\text { up }\end{array}$ & $\operatorname{Exposed}^{\mathrm{a}}(N)$ & $\begin{array}{l}\text { Average for not- } \\
\text { exposed }^{\text {b }}(N)\end{array}$ & $\begin{array}{l}\text { Exposed divided } \\
\text { by average for } \\
\text { not-exposed }\end{array}$ \\
\hline \multicolumn{6}{|l|}{ Males } \\
\hline Kunugi, 1995 & Greater Tokyo & 1994 & 50 & 52.25 & \\
\hline Izumoto, 1999 & Kochi & 1996 & 19 & 19.50 & \\
\hline Mino, 200 & Japan & 1993 & 224 & 247.75 & \\
\hline Total & & & 293 & 319.50 & 0.92 \\
\hline \multicolumn{6}{|l|}{ Females } \\
\hline Kunugi, 1995 & Greater Tokyo & 1994 & 37 & 32.50 & \\
\hline Izumoto, 1999 & Kochi & 1996 & 20 & 14.25 & \\
\hline Mino, 200 & Japan & 1993 & 142 & 138.00 & \\
\hline Total & & & 199 & 184.75 & 1.08 \\
\hline \multicolumn{6}{|l|}{ Both sexes } \\
\hline Kunugi, 1995 & Greater Tokyo & 1994 & 87 & 84.75 & \\
\hline Izumoto, 1999 & Kochi & 1996 & 39 & 33.75 & \\
\hline Mino, 200 & Japan & 1993 & 366 & 385.75 & \\
\hline Total & & & 492 & 504.25 & 0.98 \\
\hline
\end{tabular}

${ }^{a}$ Exposed: born November 1957, December 1957, April 1958 or May 1958.

${ }^{\mathrm{b}}$ Not-Exposed: born in same calendar months of 2 previous and 2 subsequent years. 
Type C studies

There were 2 studies of this type. One study concerned all children born in Great Britain in the week of March 3-9, 1958 (22). Influenza during pregnancy was documented by an interview with the mother conducted by the midwife. The children were followed up by a search in the Mental Health Inquiry records.

A second study was a follow-up of individuals who had been identified originally for a prospective investigation of the association between prenatal viral infection and congenital abnormalities (23). The epidemic reached Dublin in October 1957. All women who attended antenatal clinics in the 3 principal maternity hospitals between October 1, 1957, and June 1, 1958, were asked: "Have you had influenza during pregnancy?" Using the published data, we calculated RRs for children born to mothers who reported having had influenza during the pandemic (vs the risk for children whose mothers reported not having had influenza). We also pooled the results of both studies.

\section{Data Synthesis}

The American study was larger than all other type A studies combined (14). Consequently, before conducting any meta-analyses, we used meta-analysis of variance to examine whether its effect sizes, with regard to birth in any of the 3 trimesters after the pandemic, differed significantly from those in the other studies (26). The differences were found to be statistically not significant, and we included the American study in the meta-analysis. The latter study did not provide information by gender and was not included in the separate analyses of risks for males and females.

\section{RESULTS}

\section{Type A studies}

Eight type A studies met our inclusion criteria yielding 8 effect sizes for birth in any of the 3 trimesters (or the whole 9-month period) after the pandemic and 6 effect sizes for birth in any of the 9 months. The mean weighted RR of schizophrenia among subjects exposed during the second trimester or the fifth month of prenatal life, considered risk periods in some studies, was not significantly increased. Figure 1 shows that the distribution of effect sizes across studies was random and that not a single study found a significant second-trimester effect. The mean weighted RR for subjects exposed during the first trimester of prenatal life was significantly decreased, but the other results were not significant (Table 4). The results of the separate analyses for males and females also failed to show a significantly increased risk of schizophrenia (Table 5). As shown in table 4 , the 2 methods to calculate the variance of the effect sizes yielded virtually identical 


\section{Chapter 2}

results. (The results obtained with the 2 methods to estimate variance in males and females were also similar and are available from the authors upon request.)

Of $39 \mathrm{Q}$ values calculated, 4 were statistically significant. For subjects exposed during the fifth month of prenatal life, this heterogeneity was due to a difference between the American study, 14 which reported a decreased risk $(R R=0.96)$, and the other studies, which reported an increased risk. When the analysis was conducted without the American study, the mean weighted RR was not significantly increased ( $R R=1.24,95 \%$ $\mathrm{Cl}$ : 1.00-1.55). The significant heterogeneity in the 3 other meta-analyses was not solely due to the American study.

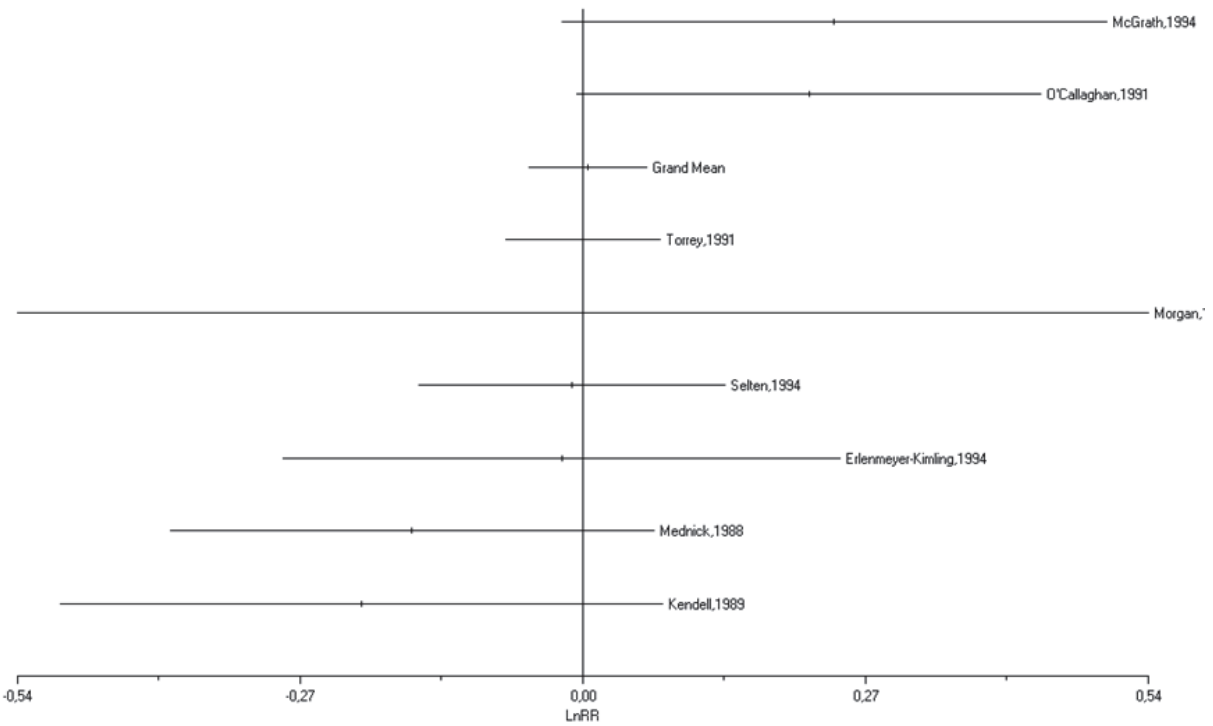

Figure 1. Natural logarithm of relative risks (and 95\% confidence intervals) for subjects included in eight ecological studies from Europe, America and Australia (type A studies) of risk for schizophrenia associated with exposure to 1957 influenza pandemic during second trimester of prenatal Life.

Studies are identified by first author and year of publication. Figure shows natural logarithm of all effect sizes and natural logarithm of grand mean 
Table 4. Mean weighted relative risks of schizophrenia for subjects born in 9-month period after 1957 pandemic of A2 influenza, by gestational age at exposure.

\begin{tabular}{|c|c|c|c|c|c|c|c|c|c|c|}
\hline \multirow[b]{3}{*}{$\begin{array}{l}\text { Gestational } \\
\text { age at } \\
\text { exposure }\end{array}$} & \multirow[b]{3}{*}{$\begin{array}{l}\text { Number } \\
\text { of effects } \\
\text { sizes }\end{array}$} & \multicolumn{6}{|c|}{ Fixed effects model } & \multirow{2}{*}{\multicolumn{3}{|c|}{$\begin{array}{l}\text { Random effects model } \\
\text { Method of variance } \\
\text { estimation } A^{a}\end{array}$}} \\
\hline & & \multicolumn{3}{|c|}{$\begin{array}{l}\text { Method of variance } \\
\text { estimation } A^{a}\end{array}$} & \multicolumn{3}{|c|}{$\begin{array}{l}\text { Method of variance } \\
\text { estimation } B^{b}\end{array}$} & & & \\
\hline & & RR & $95 \% \mathrm{Cl}$ & Q & $\mathrm{RR}$ & $95 \% \mathrm{Cl}$ & Q & $\mathrm{RR}$ & $95 \% \mathrm{Cl}$ & Q \\
\hline Month 1 & 6 & 0.89 & $0.78-1.02$ & 0.91 & 0.89 & $0.78-1.02$ & 0.91 & & & \\
\hline Month 2 & 6 & 0.87 & $0.77-1.00$ & 2.69 & 0.88 & $0.79-1.00$ & 2.68 & & & \\
\hline Month 3 & 6 & 0.98 & $0.86-1.13$ & 7.28 & 0.98 & $0.86-1.13$ & 7.27 & & & \\
\hline Month 4 & 6 & 1.02 & $0.89-1.16$ & 4.69 & 1.02 & $0.89-1.16$ & 4.68 & & & \\
\hline Month 5 & 6 & 1.06 & $0.93-1.20$ & $14.44^{*}$ & 1.06 & $0.93-1.20$ & 14.39* & 1.17 & $0.89-1.54$ & 4.62 \\
\hline Month 6 & 6 & 0.96 & $0.84-1.10$ & 2.97 & 0.96 & $0.84-1.10$ & 2.95 & & & \\
\hline Month 7 & 6 & 1.03 & $0.90-1.17$ & 3.59 & 1.03 & $0.90-1.17$ & 3.58 & & & \\
\hline Month 8 & 6 & 1.04 & $0.91-1.18$ & 2.65 & 1.04 & $0.91-1.18$ & 2.64 & & & \\
\hline Month 9 & 6 & 1.14 & $1.00-1.29$ & 2.32 & 1.14 & $1.00-1.30$ & 2.32 & & & \\
\hline Trimester 1 & 8 & 0.91 & $0.85-0.98$ & 3.93 & 0.91 & $0.85-0.98$ & 3.82 & & & \\
\hline Trimester 2 & 8 & 1.00 & $0.93-1.07$ & 10.93 & 1.00 & $0.94-1.07$ & 10.87 & & & \\
\hline Trimester 3 & 8 & 1.05 & $0.98-1.12$ & $16.85^{*}$ & 1.05 & $0.98-1.12$ & $16.65^{*}$ & 1.04 & $0.90-1.19$ & 10.33 \\
\hline $\begin{array}{l}\text { 9-Month } \\
\text { period }\end{array}$ & 8 & 0.99 & $0.96-1.03$ & $15.69 *$ & 0.99 & $0.96-1.03$ & $15.54^{*}$ & 0.98 & $0.90-1.05$ & 8.69 \\
\hline
\end{tabular}

Note: RRs, relative risks; $\mathrm{Cl}$, confidence interval

${ }^{a}$ Formula for variance estimation was $1 / a-1 / b+1 / c-1 / d$, where $a=$ number of pre-schizophrenic patients in index period, $b=$ number of live births in index period, $c=$ number of pre-schizophrenic births in control period and $d=$ number of live births in control period.

${ }^{b}$ Formula for variance estimation was $1 / a+1 / c$.

* Significant value of $Q(p<.05)$. 


\section{Chapter 2}

Table 5. Mean weighted relative risks of schizophrenia for subjects born in 9-month period after 1957 pandemic of A2 influenza, by gestational age at exposure and gender.

\begin{tabular}{|c|c|c|c|c|c|c|c|}
\hline \multirow[b]{2}{*}{$\begin{array}{l}\text { Gestational age at } \\
\text { exposure }\end{array}$} & \multirow[b]{2}{*}{$\begin{array}{l}\text { Number of } \\
\text { effects sizes }\end{array}$} & \multicolumn{3}{|c|}{ Fixed effects model ${ }^{a}$} & \multicolumn{3}{|c|}{ Random effects model ${ }^{a}$} \\
\hline & & $\mathrm{RR}$ & $95 \% \mathrm{Cl}$ & Q & $\mathrm{RR}$ & $95 \% \mathrm{Cl}$ & Q \\
\hline \multicolumn{8}{|l|}{ Males } \\
\hline Month 1 & 4 & 1.00 & $0.69-1.45$ & 0.39 & & & \\
\hline Month 2 & 4 & 0.97 & $0.67-1.41$ & 2.29 & & & \\
\hline Month 3 & 4 & 0.74 & $0.48-1.14$ & 2.08 & & & \\
\hline Month 4 & 4 & 1.06 & $0.75-1.51$ & 7.15 & & & \\
\hline Month 5 & 4 & 1.18 & $0.82-1.68$ & 4.77 & & & \\
\hline Month 6 & 4 & 0.82 & $0.56-1.21$ & 1.58 & & & \\
\hline Month 7 & 4 & 0.92 & $0.61-1.38$ & 1.68 & & & \\
\hline Month 8 & 4 & 1.18 & $0.83-1.68$ & 2.79 & & & \\
\hline Month 9 & 4 & 1.05 & $0.73-1.50$ & 2.24 & & & \\
\hline Trimester 1 & 6 & 0.88 & $0.75-1.04$ & 1.37 & & & \\
\hline Trimester 2 & 6 & 0.99 & $0.85-1.16$ & $11.60^{*}$ & 1.00 & $0.75-1.25$ & 6.01 \\
\hline Trimester 3 & 6 & 0.99 & $0.84-1.16$ & 10.61 & & & \\
\hline 9-Month Period & 6 & 0.95 & $0.87-1.04$ & $11.66^{*}$ & 0.95 & $0.81-1.11$ & 5.52 \\
\hline \multicolumn{8}{|l|}{ Females } \\
\hline Month 1 & 4 & 0.55 & $0.29-1.05$ & 1.08 & & & \\
\hline Month 2 & 4 & 0.84 & $0.49-1.41$ & 0.66 & & & \\
\hline Month 3 & 4 & 0.91 & $0.53-1.57$ & 2.08 & & & \\
\hline Month 4 & 4 & 0.84 & $0.50-1.42$ & 0.88 & & & \\
\hline Month 5 & 4 & 1.50 & $0.95-2.36$ & 7.05 & & & \\
\hline Month 6 & 4 & 1.22 & $0.75-1.98$ & 4.47 & & & \\
\hline Month 7 & 4 & 1.01 & $0.61-1.66$ & 3.40 & & & \\
\hline Month 8 & 4 & 0.93 & $0.56-1.52$ & 0.31 & & & \\
\hline Month 9 & 4 & 1.30 & $0.79-2.15$ & 3.16 & & & \\
\hline Trimester 1 & 6 & 0.80 & $0.63-1.00$ & 3.16 & & & \\
\hline Trimester 2 & 6 & 1.07 & $0.87-1.30$ & 9.51 & & & \\
\hline Trimester 3 & 6 & 1.04 & $0.85-1.28$ & 7.59 & & & \\
\hline 9-Month Period & 6 & 0.96 & $0.85-1.09$ & 3.60 & & & \\
\hline
\end{tabular}

Note: Abbreviations are explained in the first footnote to table 4.

1) formula for variance estimation was $1 / a-1 / b+1 / c-1 / d$, where $a=$ number of pre-schizophrenic patients in index period, $b=$ number of live births in index period, $c=$ number of pre-schizophrenic births in control period and $d$ = number of live births in control period.

* Significant value of $Q(p<.05)$. 


\section{Type B studies}

The pooled results of the type B studies show a $2.4 \%$ decreased risk of schizophrenia among Japanese subjects born 5 months after a wave of the A2 influenza pandemic (table 3). The estimated RR for Japanese men was $0.92(95 \% \mathrm{Cl}: 0.81-1.04)$ and that for Japanese women was 1.08 (95\% Cl: 0.92-1.26).

\section{Type C studies}

The results of both studies and the pooled results were negative (Table 6).

Table 6. Studies of schizophrenia risk for children in utero during 1957 influenza pandemic, by maternal report of influenza during pregnancy.

\begin{tabular}{|c|c|c|c|c|c|c|c|c|}
\hline & \multicolumn{3}{|c|}{ Influenza reported by mother } & \multicolumn{3}{|c|}{ Influenza denied by mother } & \multirow[b]{2}{*}{$\begin{array}{l}\text { Relative } \\
\text { risk }\end{array}$} & \multirow[b]{2}{*}{$\begin{array}{l}95 \% \\
\text { Confidence } \\
\text { interval }\end{array}$} \\
\hline & $\begin{array}{l}\text { Live } \\
\text { births }\end{array}$ & $\begin{array}{l}\text { Cases of } \\
\text { schizophrenia }\end{array}$ & $\begin{array}{l}\text { Risk per } \\
1000\end{array}$ & Live births & $\begin{array}{l}\text { Cases of } \\
\text { schizophrenia }\end{array}$ & $\begin{array}{l}\text { Risk per } \\
1000\end{array}$ & & \\
\hline $\begin{array}{l}\text { Crow, } \\
1991\end{array}$ & $1851^{a}$ & $7^{c}$ & 3.8 & 14,153 & 50 & 3.5 & 1.07 & $0.49-2.36$ \\
\hline $\begin{array}{l}\text { Cannon, } \\
1996\end{array}$ & $238^{\mathrm{b}}$ & $2^{d}$ & 8.4 & 287 & 2 & 7.0 & 1.21 & $0.17-8.50$ \\
\hline Total & 2,089 & 9 & 4.3 & 14,440 & 52 & 3.6 & 1.20 & $0.59-2.42$ \\
\hline
\end{tabular}

\footnotetext{
a Mothers exposed in first trimester $(n=231)$, second trimester $(n=945)$, third trimester $(n=675)$.

${ }^{b}$ Mothers exposed in first trimester $(n=22)$, second trimester $(n=80)$, third trimester $(n=131)$, or time of exposure not known $(n=5)$

${ }^{c}$ Cases exposed in second $(n=3)$ or third trimester $(n=4)$.

${ }^{d}$ Cases exposed in second $(n=1)$ or third trimester $(n=1)$.
}

\section{DISCUSSION}

The purpose of this meta-analysis was to examine whether birth in the 9-month period after the 1957 influenza pandemic, or maternal reports of influenza during pregnancy at the time of the pandemic, was a risk factor for schizophrenia in the child. While many of the investigations included in this meta-analysis were well designed retrospective cohort studies with sufficient power to detect an effect of the pandemic, we failed to find such an association. This is not due to the exclusion of a data set from Denmark (8), which showed an increased risk among females who were in the sixth or seventh month of prenatal life at the time of the pandemic, months that were not indicated as being high risk by other studies. Nor were the negative results accounted for by the exclusion of studies from Surinam and the Netherlands Antilles (9) or Palau (10) because these samples were extremely small and the results were considered negative. It could be 


\section{Chapter 2}

argued that the diagnoses recorded on psychiatric registries have a poor validity and thus obscured the effect of the pandemic. However, diagnoses on a number of registries have been validated $(29,30)$, and there is ample alternative confirmation of their usefulness for research. Using data from the Dutch registry, eg, Susser et al (31) were able to demonstrate that exposure to the Dutch Hunger Winter during the first trimester of prenatal life doubled the risk of schizophrenia. This effect of malnutrition was confirmed by 2 subsequent studies in China $(32,33)$. One could raise the question to what extent the results may have been influenced by publication bias, but in the absence of an association, the issue seems to be less relevant. One could suggest that positive findings have remained unpublished, but this is speculative. Because we performed multiple analyses, the reduced risk of schizophrenia among subjects exposed during the first trimester of prenatal life is probably a chance finding.

\section{Limitations}

The underreporting of influenza by mothers who were pregnant during the pandemic is a likely limitation of the type $\mathrm{C}$ studies. However, even if one assumes that all mothers who failed to report influenza had a subclinical infection, the risk of schizophrenia among exposed cohorts was well within the expected range. Because the length of the follow-up periods was limited, we cannot exclude, based on this meta-analysis, the possibility that maternal influenza may be a risk factor for late-onset schizophrenia.

\section{Origins of influenza hypothesis}

The original report on which the influenza hypothesis of schizophrenia was based had a small sample size and used an inappropriate statistical method (1). Our reanalysis of the Finnish data showed that the risk of schizophrenia was not increased among subjects exposed to influenza during the second trimester. The increased risk among subjects born in England and Wales 5 months after the peak of the pandemic may be due to chance (2). It is curious that, although the epidemic lasted several months, the plot of schizophrenic births showed a spike that was limited to 1 month (34).

\section{Studies not related to 1957 pandemic}

Studies from Scotland and Denmark found no evidence that subjects born shortly after the pandemic of 1918-1919 were at increased risk of subsequently developing schizophrenia $(8,15)$. Multiple-year studies of the relationship between monthly variations in the prevalence of influenza and the risk of schizophrenia among subjects who were in utero at the time of the influenza outbreak have yielded inconsistent findings. A study of first admissions to hospitals in England and Wales before 1980 found an association between mortality from influenza during the third to the seventh month of prenatal life 
and risk of schizophrenia in adulthood (35). However, the association was modest and explained $1 \%-2 \%$ of the variance in the risk of schizophrenia. A second study, of first admissions after 1980, failed to replicate the previous finding. The authors reported a $14 \%$ increase in the risk of schizophrenia among females born 5 months after influenza epidemics and no such increased risk among males(36). In the Netherlands, the risk of schizophrenia was found to be associated with mortality from influenza 3 months prior to birth, but this association was present in typical schizophrenics but not in less typical cases (37). A study from Western Australia found a second-trimester effect among females exposed to the 1951 influenza epidemic but no such effect among males or females exposed to epidemics occurring in 1950, 1953, 1954, or 1959 (18). Finally, 4 studies examined the relationship between the prevalence of influenza and the risk of schizophrenia in Denmark $(8,38-40)$. Each study used a different method and covered a different birth period (1911-1950, 1911- 1965, 1915-1970, and 1950-1984, respectively). Barr et al(38) reported an association between schizophrenia risk and relatively high levels of influenza exposure for the season during the sixth month of gestation but did not mention a RR. A larger study by Adams et al,(8) which included the birth cohort studied by Barr et al, found no such association. Takei et al (39) found an increased risk for subjects exposed 4 months prior to birth ( $R R=1.12,95 \% \mathrm{Cl}: 1.00-1.21)$, but Westergaard et al (40) could not replicate the findings of Takei et al even when they employed their methods and concluded that there was no association between schizophrenia risk and influenza prevalence during any month of prenatal life.

\section{Conclusions}

In order to appreciate the implications of this meta-analysis for the influenza hypothesis, it is important to be aware of the impact of the pandemic. A serological study from Sheffield, United Kingdom, found that $43 \%$ of subjects aged 20-39 years had A2 antibodies immediately after the pandemic (41). Recent publications on influenza pandemics assume that about $50 \%$ of the population is infected $(5,6)$. If maternal influenza contributes to the etiology of schizophrenia, it is difficult to understand why a pandemic infecting such a high proportion of pregnant women failed to increase the risk among their children and why there is no consistent relationship between influenza epidemics during a particular period of prenatal life and the risk of schizophrenia.

We conclude that the evidence to support the maternal influenza hypothesis is insufficient. One could argue that there is a body of literature from animal studies, indicating that prenatal exposure to influenza is associated with certain changes in brain development and behavior (42), but this does not constitute proof that this exposure is a cause of schizophrenia in humans. According to the fetal brain cytokine imbalance hypothesis, the maternal induction of proinflammatory cytokines due to a wide variety of bacterial or viral pathogens may influence the development of the fetal brain and increase the risk for schizophrenia (43). The results of the present study do not support this hypothesis. 


\section{REFERENCES}

1. Mednick SA, Machon RA, Huttunen MO, Bonett D. Adult schizophrenia following prenatal exposure to an influenza epidemic. Archives of general psychiatry. 1988;45(2):189-92.

2. O'Callaghan E, Sham P, Takei N, Glover G, Murray RM. Schizophrenia after prenatal exposure to 1957 A2 influenza epidemic. Lancet. 1991;337(8752):1248-50.

3. Brown AS. Prenatal infection as a risk factor for schizophrenia. Schizophrenia bulletin. 2006;32(2):200-2.

4. Brown AS, Begg MD, Gravenstein S, Schaefer CA, Wyatt RJ, Bresnahan M, et al. Serologic evidence of prenatal influenza in the etiology of schizophrenia. Archives of general psychiatry. 2004;61(8):774-80.

5. Ferguson NM, Cummings DA, Cauchemez S, Fraser C, Riley S, Meeyai A, et al. Strategies for containing an emerging influenza pandemic in Southeast Asia. Nature. 2005;437(7056):209-14.

6. Glass RJ, Glass LM, Beyeler WE, Min HJ. Targeted social distancing design for pandemic influenza. Emerging infectious diseases. 2006;12(11):1671-81.

7. Ioannidis JP. Why most published research findings are false. PloS Med. 2005;2:696-701.

8. Adams W, Kendell RE, Hare EH, Munk-Jorgensen P. Epidemiological evidence that maternal influenza contributes to the aetiology of schizophrenia. An analysis of Scottish, English, and Danish data. The British journal of psychiatry : the journal of mental science. 1993;163:522-34.

9. Selten JP, Slaets J, Kahn R. Prenatal exposure to influenza and schizophrenia in Surinamese and Dutch Antillean immigrants to The Netherlands. Schizophrenia research. 1998;30(1):101-3.

10. Allen JS, Nero KL. Schizophrenia and influenza in Palau. The Medical journal of Australia. 1998;168(8):421-2.

11. Susser E, Lin SP, Brown AS, Lumey LH, Erlenmeyer-Kimling L. No relation between risk of schizophrenia and prenatal exposure to influenza in Holland. The American journal of psychiatry. 1994;151(6):922-4.

12. Selten JP, Brown AS, Moons KG, Slaets JP, Susser ES, Kahn RS. Prenatal exposure to the 1957 influenza pandemic and non-affective psychosis in The Netherlands. Schizophrenia research. 1999;38(2-3):85-91.

13. Selten JP, Slaets JP. Evidence against maternal influenza as a risk factor for schizophrenia. The British journal of psychiatry : the journal of mental science. 1994;164(5):674-6.

14. Torrey EF, Bowler AE, Rawlings R, editors. An influenza epidemic and the seasonality of schizophrenic births. Second World Congress on Viruses and Mental Health; 1991; New York, NY: Plenum.

15. Kendell RE, Kemp IW. Maternal influenza in the etiology of schizophrenia. Archives of general psychiatry. 1989;46(10):878-82.

16. Erlenmeyer-Kimling L, Folnegovic Z, Hrabak-Zerjavic V, Borcic B, Folnegovic-Smalc V, Susser E. Schizophrenia and prenatal exposure to the 1957 A2 influenza epidemic in Croatia. The American journal of psychiatry. 1994;151(10):1496-8.

17. McGrath JJ, Pemberton MR, Welham JL, Murray RM. Schizophrenia and the influenza epidemics of 1954, 1957 and 1959: a southern hemisphere study. Schizophrenia research. 1994;14(1):1-8.

18. Morgan V, Castle D, Page A, Fazio S, Gurrin L, Burton P, et al. Influenza epidemics and incidence of schizophrenia, affective disorders and mental retardation in Western Australia: no evidence of a major effect. Schizophrenia research. 1997;26(1):25-39.

19. Kunugi H, Nanko S, Takei N, Saito K, Hayashi N, Kazamatsuri H. Schizophrenia following in utero exposure to the 1957 influenza epidemics in Japan. The American journal of psychiatry. 1995;152(3):450-2.

20. Izumoto Y, Inoue S, Yasuda N. Schizophrenia and the influenza epidemics of 1957 in Japan. Biological psychiatry. 1999;46(1):119-24.

21. Mino Y, Oshima I, Tsuda T, Okagami K. No relationship between schizophrenic birth and influenza epidemics in Japan. Journal of psychiatric research. 2000;34(2):133-8.

22. Crow TJ, Done DJ, Johnstone EC. Schizophrenia and influenza. Lancet. 1991(338):116-8.

23. Cannon M, Cotter D, Coffey VP, Sham PC, Takei N, Larkin C, et al. Prenatal exposure to the 1957 influenza epidemic and adult schizophrenia: a follow-up study. The British journal of psychiatry : the journal of mental science. 1996;168(3):368-71.

24. Lipsey MW, Wilson DB. Practical Meta-analysis. London, UK: Sage; 2011. 
25. Rosenberg MS, Adams DC, Gurevitch J. MetaWin: Statistical Software for Meta-analysis. 2.0 ed. Sunderland, MA: Sinauer; 2000.

26. Cooper HM, Hedges LV. The Handbook of Research Synthesis. New York, NY: Russel Sage Foundation; 1994.

27. Perala J, Suvisaari J, Saarni SI, Kuoppasalmi K, Isometsa E, Pirkola S, et al. Lifetime prevalence of psychotic and bipolar I disorders in a general population. Archives of general psychiatry. 2007;64(1):19-28.

28. Adams W, Kendell RE. Annual variation in birth rate of people who subsequently develop schizophrenia. The British journal of psychiatry : the journal of mental science. 1999;175:522-7.

29. Jablensky AV, Morgan V, Zubrick SR, Bower C, Yellachich LA. Pregnancy, delivery, and neonatal complications in a population cohort of women with schizophrenia and major affective disorders. The American journal of psychiatry. 2005;162(1):79-91.

30. Hulshoff Pol HE, Hoek HW, Susser E, Brown AS, Dingemans A, Schnack HG, et al. Prenatal exposure to famine and brain morphology in schizophrenia. The American journal of psychiatry. 2000;157(7):1170-2.

31. Susser E, Neugebauer R, Hoek HW, Brown AS, Lin S, Labovitz D, et al. Schizophrenia after prenatal famine. Further evidence. Archives of general psychiatry. 1996;53(1):25-31.

32. St Clair D, Xu M, Wang P, Yu Y, Fang Y, Zhang F, et al. Rates of adult schizophrenia following prenatal exposure to the Chinese famine of 1959-1961. JAMA : the journal of the American Medical Association. 2005;294(5):557-62.

33. Xu MQ, Sun WS, Liu BX, Feng GY, Yu L, Yang L, et al. Prenatal malnutrition and adult schizophrenia: further evidence from the 1959-1961 Chinese famine. Schizophrenia bulletin. 2009;35(3):568-76.

34. Crow TJ, Done DJ. Prenatal exposure to influenza does not cause schizophrenia. The British journal of psychiatry : the journal of mental science. 1992;161:390-3.

35. Sham PC, O'Callaghan E, Takei N, Murray GK, Hare EH, Murray RM. Schizophrenia following pre-natal exposure to influenza epidemics between 1939 and 1960. The British journal of psychiatry : the journal of mental science. 1992;160:461-6.

36. Takei N, Sham P, O'Callaghan E, Murray GK, Glover G, Murray RM. Prenatal exposure to influenza and the development of schizophrenia: is the effect confined to females? The American journal of psychiatry. 1994;151(1):117-9.

37. Takei N, Van Os J, Murray RM. Maternal exposure to influenza and risk of schizophrenia: a 22 year study from The Netherlands. Journal of psychiatric research. 1995;29(6):435-45.

38. Barr CE, Mednick SA, Munk-Jorgensen P. Exposure to influenza epidemics during gestation and adult schizophrenia. A 40-year study. Archives of general psychiatry. 1990;47(9):869-74.

39. Takei N, Mortensen PB, Klaening U, Murray RM, Sham PC, O'Callaghan E, et al. Relationship between in utero exposure to influenza epidemics and risk of schizophrenia in Denmark. Biological psychiatry. 1996;40(9):817-24.

40. Westergaard T, Mortensen PB, Pedersen CB, Wohlfahrt J, Melbye M. Exposure to prenatal and childhood infections and the risk of schizophrenia: suggestions from a study of sibship characteristics and influenza prevalence. Archives of general psychiatry. 1999;56(11):993-8.

41. Clarke SK, Heath RB, Sutton RN, Stuart-Harris CH. Serological studies with Asian strain of influenza A. Lancet. 1958;1(7025):814-8.

42. Fatemi SH, Folsom TD. The neurodevelopmental hypothesis of schizophrenia, revisited. Schizophrenia bulletin. 2009;35(3):528-48.

43. Meyer U, Feldon J, Yee BK. A review of the fetal brain cytokine imbalance hypothesis of schizophrenia. Schizophrenia bulletin. 2009;35(5):959-72. 



\section{Chapter 3}

\section{Evidence that childhood urban environment}

is associated with blunted stress reactivity across groups of patients with psychosis, relatives of patients and controls

Authors: Aleida Frissen ${ }^{1}$, Ritsaert Lieverse ${ }^{1}$, Marjan Drukker ${ }^{1}$, Philippe Delespaul $^{1}$, Tineke Lataster ${ }^{1}$, Inez Myin-Germeys ${ }^{1}$ and Jim van Os ${ }^{1,2}$ for Genetic Risk and Outcome in Psychosis (G.R.O.U.P.)

${ }^{1}$ Department of Psychiatry and Psychology, Maastricht University, The Netherlands

2 King's College London, King's Health Partners, Department of Psychosis Studies, Institute of Psychiatry, London, United Kingdom

Social Psychiatry and Psychiatric Epidemiology (2014) 49, 1579-1587 


\section{Chapter 3}

\section{ABSTRACT}

\section{Background}

Psychosis is associated with urban upbringing, and increased emotional reactivity is associated with psychosis. The aim of this study was to examine to what degree urban upbringing impacts emotional reactivity, and how this may be relevant for psychotic disorder and familial risk of psychotic disorder.

\section{Methods}

Patients with a diagnosis of non-affective psychotic disorder $(n=57), 59$ first degree relatives of patients and 75 healthy comparison subjects were studied with the Experience Sampling Method (a random time sampling technique to assess affective experience in relation to fluctuating stressors in the flow of daily life), to measure a change in negative affect in relation to subjective stress (SS). Urban exposure was defined at 5 levels, considering the population density and the number of moves between birth and the $15^{\text {th }}$ birthday, using data from the Dutch Central Bureau of Statistics and the equivalent database in Belgium.

\section{Results}

Multilevel random regression analyses showed that urban upbringing was consistently and strongly associated with a reduced increase in negative affect in relation to SS in adulthood in a dose-response fashion in all three groups. Regression coefficients in the patient group decreased from $0.148(p<0.001)$ in the lowest urbanicity level to 0.094 ( $p<0.001)$ in the highest urbanicity level.

\section{Conclusion}

The findings suggest that urban upbringing may occasion "habituation" rather than "sensitization" across groups, which may or may not be relevant for the onset of psychotic disorder. 


\section{INTRODUCTION}

Psychosis has been associated with urban birth and urban upbringing (1-5), with metaanalytic evidence of dose-response (5-7). If causal, this may be relevant, given that $50 \%$ of the global population live in urban areas, and this fraction is set to increase even further in the future (8). However, the question as to which factors associated with the urban environment may mediate this effect remains unsolved. Candidate mechanisms include higher level of perceived social isolation in urban areas (9), greater exposure to social "defeat" occasioned by higher level of competition in cities (10), as well as higher level of pregnancy and birth complications (11) or infections (12) and lower level of prenatal vitamin D (13) due to reduced sunlight exposure in urban areas. No single factor, however, has been show to mediate the association between urban environment and psychotic disorder. Confounding by drug misuse is unlikely to explain the association (14), as is confounding by genetic liability to schizophrenia (15), although part of the association may be linked to family-specific or epigenetic factors (16). The effect of urban environment may be conditional on genetic risk for psychosis (17-19), and the vulnerable period of impact is specific to childhood and adolescence $(4,20)$.

Compared to well controls, psychosis outcomes are characterized by a greater increase in negative affect in relation to daily life stressors (21). Negative affect is defined as the extent to which an individual experiences subjective stress and unpleasant engagement with the environment. Groups with high risk for psychosis show similarly increased levels of affective reactivity to stress $(21,22)$. Recently, Lederbogen and colleagues reported an association between urban upbringing and city living and altered experimental social stress processing in a sample of healthy volunteers using functional magnetic resonance imaging (23). It is therefore attractive to speculate that the higher incidence of schizophrenia in urban areas may be mediated in part by altered sensitivity to stress.

The present study aims to replicate and extend the effects of urban exposure on emotional reactivity in real life using the experience sampling method (ESM) in the Genetic Risk and Outcome in Psychosis (G.R.O.U.P.) project (24). ESM is a structured diary technique that captures thoughts, moods and their context in the flow of daily life (25). ESM is a reliable measure to demonstrate altered adult change in negative affect in relation to a stressor as a result of an early life exposure. For example, alterations in ESM measures of stress-reactivity in adults have consistently been linked to childhood trauma, in the direction of increased stress-reactivity in those so exposed (26-29). In the current study, therefore, it was predicted that childhood urbanicity would be associated with a greater increase in negative affect in relation to a stressful event, particularly in patients with psychotic disorder and in individuals with psychotic liability. 


\section{MATERIALS AND METHODS}

\section{Participants}

Data pertain to baseline measures of the ongoing multisite, longitudinal, naturalistic cohort study, the Dutch national Genetic Risk and Outcome in Psychosis (G.R.O.U.P.) project (24). The full sample consisted of 1120 patients diagnosed with a non-affective psychotic disorder, 1057 of their siblings, 919 parents of the patients and their siblings, and 590 unrelated healthy controls subjects from the general population. The selection procedure, the in- and exclusion criteria and informed consent procedure were performed as described before (24). All participants from the Maastricht region were contacted for participating in the experience sampling method. Maastricht is a city of 120,000 in the South of the Netherlands. Participation was voluntary.

\section{Experience sampling method}

The experience sampling method (ESM) was used to assess the change in negative affect in relation to stressful event in the flow of daily life (25). Subjects received a digital wristwatch and self-assessment forms collated in a booklet for each day. The watch emitted a signal (beep) at unpredictable moments between 7:30 am and 10:30 pm, ten times a day on six consecutive days. Subjects were asked to report immediately after each beep their thoughts, current context (activity, persons present, location), appraisals of the current situation and mood.

Subjects were informed about the ESM procedure during an initial briefing session. A practice form was completed to confirm that the subjects were able to understand the 7-point Likert scale format. Subjects were instructed to complete their reports immediately after the beep, thus minimizing memory distortion and to record the time at which they completed the form. Research staff called each subject several times during the actual sampling period, to assess whether they were complying with the instructions. To determine the reliability of the completed reports, the times at which the watch emitted a signal and the times at which subjects completed the reports were compared. The subjects had no access to the log of the emitted signals. All reports completed more than 15 min after the beep were excluded from the analyses. Previous research has shown that reports completed after this interval are less reliable and consequently less valid (30). Similarly, subjects with fewer than 20 valid reports (out of 60) were excluded from the analysis (30).

\section{Assessment of Mood}

Negative affect (NA), described as the extent to which an individual experiences subjective stress and unpleasant engagement with the environment (25), was assessed at each beep with six mood-related adjectives (down, guilty, insecure, lonely, anxious and 
angry/annoyed) rated on 7-point Likert scales (1, not at all; 7, very) (Cronbach's $\alpha=$ 0.81 . We calculated the mean of these six mood-related adjectives, which was used as the measure of NA.

\section{Assessment of Stress}

Stress was conceptualized as the subjectively appraised stressfulness of distinctive events (event-related stress) (21), which will be referred to as subjective stress (SS) in this paper. Both the mood measures and the stress measure in this study were derived from the experience sampling reports. To measure "event-related stress", the subject was asked to report, after each beep, the most important event that had happened between the current and the previous report. This event was subsequently rated using the question: 'how pleasant was this event', ranging on a -3 (very unpleasant) to 0 (neutral) to 3 (very pleasant) scale. The scores were reversed to allow high scores to reflect stress (-3, very pleasant; 0 , neutral; 3 , very unpleasant).

\section{Assessment of psychotic symptom dimension}

Psychosis severity was assessed with the Positive and Negative Syndrome Scale (PANSS)(31). This semi-structured interview consists of three subscales: positive symptoms (seven items), negative symptoms (seven items), and general psychopathology (16 items). All items are scored on a scale of 1 (not present) to 7 (severe). The PANSS was administered during the debriefing session of the ESM protocol.

\section{Level of Urbanicity}

We generated a historical population density record for each municipality from 1930 onwards using Statistics Netherlands and equivalent Belgium database $(32,33)$. When data was not available, missing data were calculated by linear extrapolation between two subsequent time-points. When historical names of municipalities disappeared from historical records (e.g. due to city mergers) we used the available data from the agglomerate city. We asked subjects to describe where they lived during their life. This resulted in a number of records for each subject, containing locations by age period. For each of these records, we computed the average population density (by square kilometer, excluding water) of the municipality for the matching year periods. Subsequently, it was determined where the subject lived at birth, between ages 0-4 years; between $5-9$ years; $10-14$ years; $15-19$ years; $20-39$ years; $40-59$ years; and $60+$ up to the actual age. Average population density over the period was categorized in accordance with the Dutch CBS urbanicity rating $\left(1=<500 / \mathrm{km}^{2} ; 2=500-1000 / \mathrm{km}^{2} ; 3=1000-1500 / \mathrm{km}^{2} ; 4=1500\right.$ $2500 / \mathrm{km}^{2} ; 5=2500+/ \mathrm{km}^{2}$ ). The periods $0-4$ years, $5-9$ years and $10-14$ years were merged to average urbanicity exposure between 0-14 years. The latter was used as the primary variable reflecting childhood urbanicity exposure in the analyses. This variable was collapsed a priori into 5 intervals ( 1 to $1.49=1 ; 1.5$ to $2.49=2 ; 2.5$ to $3.49=3 ; 3.5$ to $4.49=4 ; 4.5$ to $5=5$ ) to reflect the same categories as used by the Dutch CBS. 


\section{Statistical/data analyses}

All analyses were carried out using Stata 11 (34). We analyzed differences in sex, ethnicity, cannabis use, age, and IQ between ESM participants and non-participants in the Maastricht region in order to estimate possible subject selection imbalances. Differences in NA and SS in the separate urbanicity strata were analyzed. ESM data consist of multiple observations nested within persons, generating 2 levels of analysis: ESM beep level and subject level. Multilevel linear regression analysis with fixed effects and random intercepts was used to account for clustering of repeated measures within persons, using the Stata XTREG command. The regression coefficient (B) represents the effect size of the predictors and can be interpreted as the estimates in equivalent unilevel linear regression analysis. Models were fitted with NA as dependent variable and SS, age, sex and PANSS positive symptoms and negative symptoms as independent variables. In order to study differential stress-sensitivity, the three-way interaction term urbanicity $X$ group status $X$ SS was added to the regression model including all accompanying two-way interactions (group status defined as: control, relative or patient). All interaction terms were tested using the chi-square test. If the three-way interaction term was not statistically significant, the lower order model including the two two-way interaction terms of urbanicity X SS and group status X SS was analyzed. In the case of significant interaction, stratified effect sizes were calculated by combination of effects from the model containing the interactions using the Stata MARGINS routine.

In a sensitivity analysis, we also tested the model using distribution-free bootstrap analysis and using multilevel linear regression analysis with random slopes in addition to random intercepts (using the Stata XTMIXED command).

\section{RESULTS}

\section{Participants and descriptives}

Sixty patients, 71 relatives and 77 controls initiated the ESM procedure. Of the individuals in the patient group, three participants were unable to comply with the research protocol (having filled in fewer than 20 valid reports) and were, therefore, excluded from the analyses. In the relative group and in the control group, twelve and two participants were excluded, respectively. The final sample thus included 57 patients, 59 relatives and 75 controls. Sociodemographic and clinical characteristics of the final sample are summarized in Table 1.

The patient group, compared to the relative and control group, counted more men (70.2\%), more unemployed (64.9\%) and less married persons (78.9\%). The patient group had the highest level of NA (mean $=1.75$, SD $=0.75$ ). The relative group, compared to the patient and control group, was younger ( mean $=24.3, S D=11.4$ ). Table 2 
shows the means, standard deviations, medians and ranges of NA and SS for each urbanicity level. SS decreased significantly across more urban areas $(B=-0.07, p=0.04)$. $N A$, however, did not vary across the different urbanicity strata $(B=-0.01, p=0.75)$.

Table 1. Sociodemographic and clinical characteristics of the research sample

\begin{tabular}{|c|c|c|c|}
\hline & Patients & Relatives & Controls \\
\hline Sex $n(\%)$, Male & $40(70.2 \%)$ & $20(33.9 \%)$ & $22(29.3 \%)$ \\
\hline Age $(S D)^{a}$ & $28.0(8.2)$ & $24.3(11.4)$ & $32.3(11.3)$ \\
\hline Ethnicity $n(\%)$, Caucasian & $49(86.0 \%)$ & $50(84.8 \%)$ & $70(93.3 \%)$ \\
\hline Married/living together $n(\%)$ & $12(21.1 \%)$ & $30(50.9 \%)$ & $43(57.3 \%)$ \\
\hline Education $n(\%)$, Higher education & $51(92.7 \%)$ & $57(98.3 \%)$ & $72(96 \%)$ \\
\hline Work $n(\%)$, currently working & $20(35.1 \%)$ & $56(94.9 \%)$ & $72(96 \%)$ \\
\hline \multicolumn{4}{|l|}{ Diagnosis $^{b} \mathrm{n}(\%)$} \\
\hline No diagnosis or condition on axis I & $0(0.0 \%)$ & $50(86.2 \%)$ & $65(86.7 \%)$ \\
\hline Schizophrenia & $35(61.4 \%)$ & $0(0.0 \%)$ & $0(0.0 \%)$ \\
\hline Schizophreniform disorder & $1(1.8 \%)$ & $0(0.0 \%)$ & $0(0.0 \%)$ \\
\hline Schizoaffective disorder & $7(12.3 \%)$ & $0(0.0 \%)$ & $0(0.0 \%)$ \\
\hline Brief psychotic disorder & $5(8.8 \%)$ & $0(0.0 \%)$ & $0(0.0 \%)$ \\
\hline Psychotic disorder NOS & $7(12.3 \%)$ & $0(0.0 \%)$ & $0(0.0 \%)$ \\
\hline Delusional disorder & $2(3.5 \%)$ & $0(0.0 \%)$ & $0(0.0 \%)$ \\
\hline Major depressive disorder, in partial remission & $0(0.0 \%)$ & $1(1.7 \%)$ & $3(4.0 \%)$ \\
\hline Major depressive disorder, in full remission & $0(0.0 \%)$ & $7(12.1 \%)$ & $7(9.3 \%)$ \\
\hline \multicolumn{4}{|l|}{ Negative affect } \\
\hline Mean $(S D)^{a}$ & $1.75(0.75)$ & $1.31(0.53)$ & $1.29(0.32)$ \\
\hline Range $(\mathrm{Md})^{\mathrm{C}}$ & 1 - 7 (1.33) & $1-5.83(1.00)$ & $1-5.83(1.00)$ \\
\hline \multicolumn{4}{|l|}{ Subjective stress } \\
\hline Mean $(S D)^{a}$ & $-1.38(0.83)$ & $-1.43(0.64)$ & $-1.49(0.64)$ \\
\hline Range $(\mathrm{Md})^{\mathrm{C}}$ & $-3-3(-2.00)$ & $-3-3(-2.00)$ & $-3-3(-2.00)$ \\
\hline \multicolumn{4}{|l|}{ PANSS positive symptoms } \\
\hline Mean $(S D)^{a}$ & $12.49(5.18)$ & $7.25(1.24)$ & $7.21(1.57)$ \\
\hline Range $(\mathrm{Md})^{\mathrm{C}}$ & $7-26(11.00)$ & $0-10(7.00)$ & $0-14(7.00)$ \\
\hline \multicolumn{4}{|l|}{ PANSS negative symptoms } \\
\hline Mean $(S D)^{a}$ & $10.73(4.93)$ & $7.12(1.29)$ & 7.15 (1.59) \\
\hline Range $(\mathrm{Md})^{\mathrm{C}}$ & $5-30(9.00)$ & $0-12(7.00)$ & $0-14(7.00)$ \\
\hline
\end{tabular}

${ }^{\mathrm{a}}$ Values are means $\pm \mathrm{SD}=$ standard deviation

${ }^{b}$ Diagnosis was missing for 1 relative

${ }^{\mathrm{c}} \mathrm{Md}=$ median 


\section{Chapter 3}

Table 2. Means, standard deviations, ranges and medians of negative affect and subjective stress per urbanicity level $\left.\right|^{a}$

\begin{tabular}{|c|c|c|c|c|c|c|}
\hline Urbanicity level & $\begin{array}{l}1(n=42 \\
26.25 \%)\end{array}$ & $\begin{array}{l}2(n=52 \\
32.50 \%)\end{array}$ & $\begin{array}{l}3(n=24 \\
15.00 \%)\end{array}$ & $\begin{array}{l}4(n=10 \\
6.25 \%)\end{array}$ & $\begin{array}{l}5(n=32 \\
20.00 \%)\end{array}$ & $B(p)^{b}$ \\
\hline \multicolumn{7}{|l|}{ Negative affect } \\
\hline Mean (SD) & $1.43(0.57)$ & $1.56(0.63)$ & $1.29(0.32)$ & $1.20(0.16)$ & $1.46(0.71)$ & $-0.01(0.75)$ \\
\hline Range (Md) & 1 - $6(1.00)$ & 1 - 7 (1.17) & 1 - $5(1.00)$ & $1-3.33(1.00)$ & 1 - $6.5(1.00)$ & \\
\hline \multicolumn{7}{|l|}{ Subjective stress } \\
\hline Mean (SD) & $-1.36(0.73)$ & $-1.27(0.65)$ & $-1.42(0.62)$ & $-1.70(0.66)$ & $-1.61(0.75)$ & $-0.07(0.04)$ \\
\hline Range (Md) & $-3-3(-2.00)$ & $-3-3(-2.00)$ & $-3-3(-2.00)$ & $-3-3(-2.00)$ & $-3-3(-2.00)$ & \\
\hline
\end{tabular}

${ }^{a}$ Five levels op urbanicity/population density $1=<500$ inhabitants $/ \mathrm{km}^{2} ; 2=500-1000$ inhabitants $/ \mathrm{km}^{2} ; 3=$ inhabitants $1000-1500 / \mathrm{km}^{2} ; 4=$ inhabitants $1500-2500 / \mathrm{km}^{2} ; 5=2500+/ \mathrm{km}^{2}$

${ }^{\mathrm{b}}$ Linear regression analysis

$\mathrm{SD}=$ standard deviation

$\mathrm{Md}=$ median

Negative emotional reactivity to daily life stress, main effect

Multilevel regression analysis showed a weak association between SS and NA (main effect) in the total sample ( $B=0.078, p<0.001,95 \% \mathrm{Cl}=0.070$ to 0.086 ).

\section{Three-way interaction and accompanying two-way interactions}

The three way interaction term urbanicity $X$ group status $X S S\left(\chi^{2}=0.06, d f=1, p=0.80\right)$ was not statistically significant, as was the two-way interaction term urbanicity $X$ group status $\left(\chi^{2}=2.42, \mathrm{df}=1, p=0.12\right)$. The two-way interactions between group status and SS and between urbanicity and SS were statistically significant (group status X SS: $\chi^{2}=$ 35.5, $\mathrm{df}=1, p<0.001$; urbanicity X SS: $\chi^{2}=11.9, \mathrm{df}=1, p=0.001$ ). The two significant interaction terms are presented in more detail below.

\section{Group status as a modifier}

Further exploration of the significant interaction between group status and SS revealed that the association between SS and NA was largest in patients $(B=0.119, p<0.001$, $95 \% \mathrm{Cl}=0.104$ to 0.134 ; Table 4.) while the association was smaller, but still statistically significant in controls and relatives. After excluding the controls and relatives with (a history of) a mood disorder, the association remained significant (Table 3.). 
Table 3. Association between subjective stress and NA for the three groups separately ${ }^{\mathrm{a}}$

\begin{tabular}{llll}
\hline & $\mathrm{B}$ & $95 \% \mathrm{Cl}$ & $\mathrm{p}$ \\
\hline Event stress & & & \\
Controls & 0.063 & $0.052-0.075$ & $<0.001$ \\
Relatives & 0.062 & $0.047-0.077$ & $<0.001$ \\
Patients & 0.119 & $0.104-0.134$ & $<0.001$ \\
\hline
\end{tabular}

Association between subjective stress and NA for the three groups separately excluding controls $(n=10)$ and relatives ( $n=8$ ) with (a history of) mood disorders ${ }^{a}$

\begin{tabular}{llll}
\hline & $\mathrm{B}$ & $95 \% \mathrm{Cl}$ & $\mathrm{p}$ \\
\hline Event stress & & & \\
Controls & 0.062 & $0.049-0.074$ & $<0.001$ \\
Relatives & 0.049 & $0.032-0.065$ & $<0.001$ \\
Patients & 0.119 & $0.104-0.133$ & $<0.001$ \\
\hline
\end{tabular}

${ }^{a}$ Results are adjusted for age, sex and PANSS positive symptoms and negative symptoms

\section{Urbanicity as a modifier}

Follow-up investigation of the significant interaction between urbanicity and SS revealed that the association between NA and SS, became smaller in areas with a higher level of urbanicity: for a given level of SS, a smaller increase in NA was apparent in both the total sample and in patients, relatives and control strata, separately (Table 4; Figure 1). Excluding participants with (a history of) mood disorders only produced negligible differences compared to the original results (data not shown).

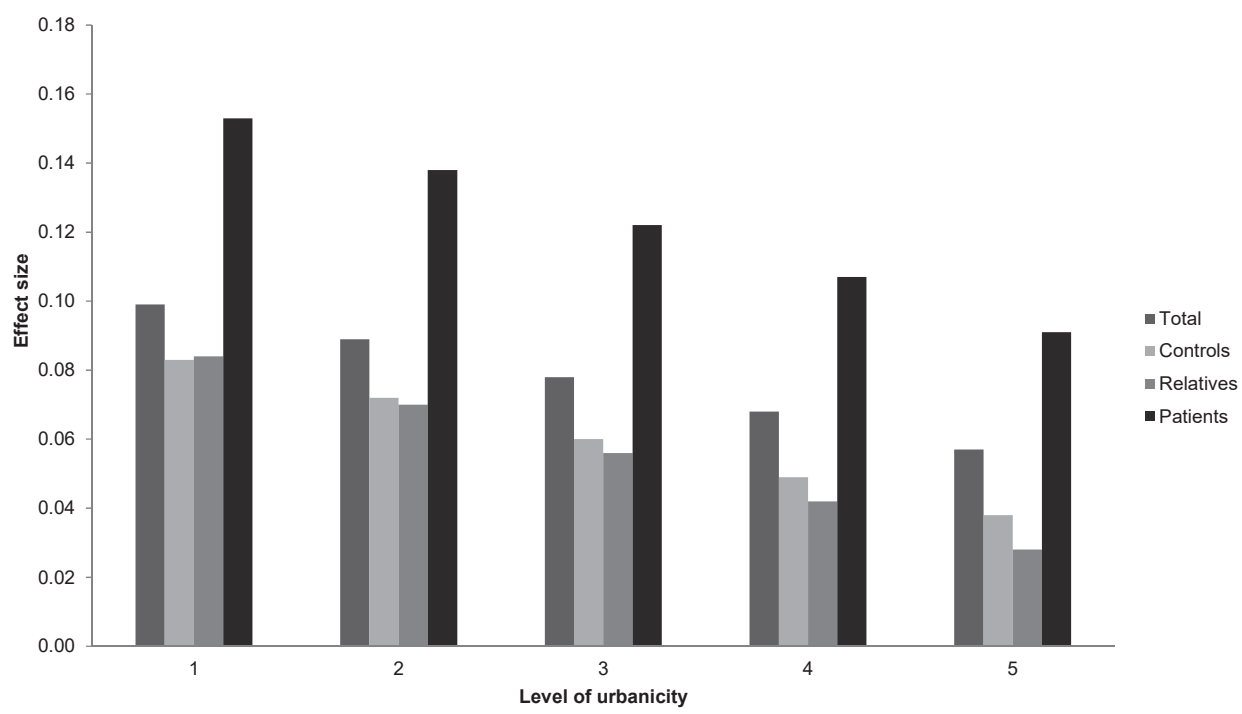

Figure 1. Effect sizes of subjective stress on negative affect across five levels of urbanicity. Effect sizes are the fixed regression coefficients (B) from the multilevel random regression model with NA as dependent variable and subjective stress as the independent variable both in the total sample and separately in controls, relatives and patients. 


\section{Chapter 3}

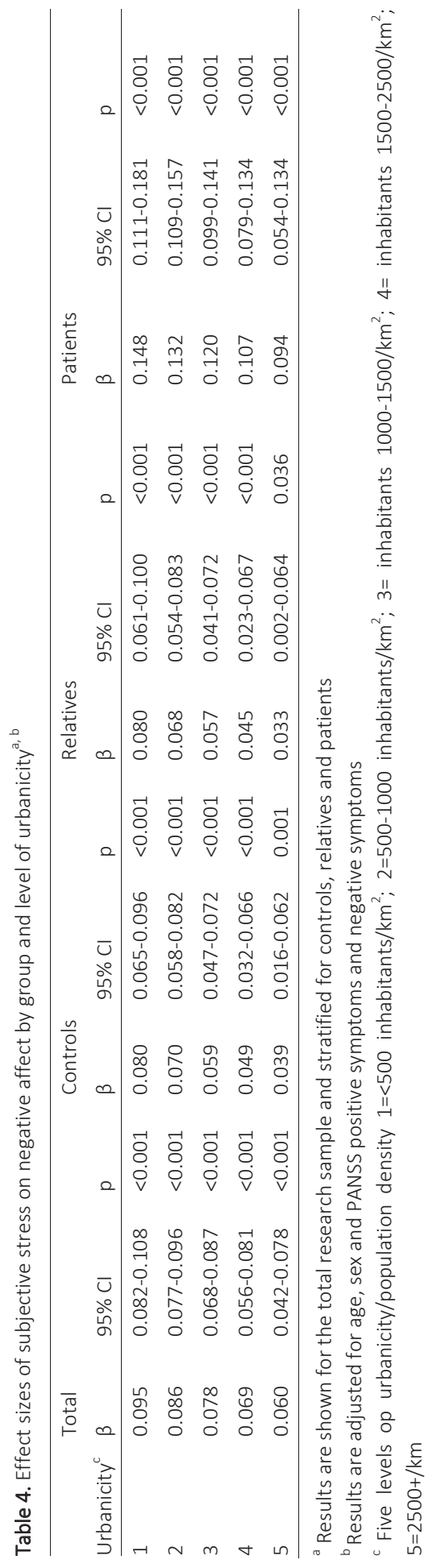


Sensitivity analysis

A qq-plot of the regression residuals was suggestive for a slightly uneven distribution. Therefore, we performed a sensitivity analysis of our final model including the two twoway interactions between group status and SS and between urbanicity and SS, using distribution-free bootstrap analysis. Both interactions were still statistically significant after bootstrap analysis (group status X SS: $\chi 2=17.09, d f=1, p<0.001 ;$ urbanicity X SS: $\chi 2$ $=5.27, \mathrm{df}=1, \mathrm{p}=0.0217$ ).

The sensitivity analyses with random slopes in addition to random intercepts, in comparison to the model with only random intercepts, showed that the two-way interaction group status $X$ SS was still significant $(\chi 2=9.88, d f=1, p=0.002)$. The urbanicity $X$ SS interaction was no longer significant by conventional alpha $(\chi 2=2.42, d f=1, p=$ 0.12 ), but was still suggestive for interaction and further stratification showed results that were comparable to the results using random intercepts only.

\section{DISCUSSION}

Although studies are consistent in showing that urbanicity is associated with elevated risk for psychosis, the underlying mechanisms remain to be elucidated. There is consistent evidence that psychotic patients display elevated levels of NA in relation to subjective stress (SS) (21). Recent findings by Lederbogen and colleagues (23) suggest that urbanicity influences stress processing in the non-patient population. The current findings confirmed that patients with psychotic disorder displayed higher levels of NA in relation to SS, regardless of level of urbanicity (Figure 1). In addition, there was evidence that urbanicity impacted the change in NA in relation to SS not only in the patient group, but also in the group of relatives and the group of well controls, with strong and consistent evidence of dose-response. However, contrary to expectation, results also indicated that urbanicity was associated with blunted rather than enhanced increase in NA, consistently across the three groups. Group status and urbanicity did not modify each other's effects on the change of NA in relation to SS.

Our observational results, therefore, contrast with the experimental findings reported by Lederbogen and colleagues, who reported that urbanicity was associated with sensitized social stress processing (23). The study of Lederbogen and the current study used contrasting methods to assess NA and stress: Lederbogen used fMRI and an experimental social stress paradigm to measure social stress processing, which can be considered laboratory-driven; in the current study, however, we used the experience sampling method to assess NA and SS, which can be considered more ecologically-driven. There are no studies directly comparing the fMRI bold signal occasioned by an experimental social stress paradigm in the scanner and ESM ecological measures of NA and SS in the flow of daily life. Differences between the two studies likely will be reducible to 
differences in methodology but are difficult to interpret in the absence of direct comparison material.

A possible explanation of these paradoxical results is that the altered change in NA in relation SS may not lie on the causal pathway between urbanicity and psychosis - rather, it may be considered an interesting epiphenomenon associated with urban life but not relevant for the association between urban environment and psychotic disorder. Another way to explain our results, is that while we focused on the impact of childhood urban environment on emotional reactivity, it may be that urban environment in adult life has an additional impact. Finally, it could be that the urban environment involves exposure to more and stronger SS, and that individuals may develop behavioral adaptation by "shutting off" from the social environment resulting in blunted increase in NA and secondary behavioral withdrawal. In the case of liability to psychotic disorder, reduced interaction with the social world may result in failure to correct early reality distortion (reality testing hypothesis) that subsequently may give rise to overt psychotic symptoms.

In line with previous work, results indicate that psychotic disorder and higher level of familial risk for psychotic disorder are associated with increased emotional reactivity to SS in a dose-response relationship $(21,35)$. There is replicated evidence that childhood trauma is also associated with increased emotional reactivity to SS as assessed by ESM (26-29), suggestive for a mechanism of behavioral sensitization. Therefore, childhood trauma and urban environment, although both associated with increased risk for psychotic disorder, do not concur in their impact on emotional response to stress and it remains unclear to what degree both findings are similarly relevant for the onset of psychotic disorder.

\section{Limitations}

The present results should be interpreted in the light of several limitations. First, the cross-sectional nature of the current data limits inference about causal directional relationships. However, the evidence supporting a gradient (dose response relationship), the strength of the association and the consistency of findings across different groups (patients, relatives and controls), support causality. Second, the use of ESM in the 'paper and pencil' form may be considered less reliable than using electronic devices (36). However, a comparative study concluded that both methods yielded similar results (37). Third, because of high between-subject heterogeneity in relation to interpretation of questions, subjective reports often are considered less reliable than subjective approaches (38). However, the validity of objective approaches should also not be taken for granted, because they ignore the person's own experience. Therefore, given that experience of stress is essentially subjective, methodology is required that can capture subjective experience, like ESM, using the individual's subjective baseline as personspecific reference against which to measure change.

Another possible limitation is the retrospective retrieval of residential history which does not allow us to rule out the possibility of recall error which, if differential, could 
have resulted in bias. Fifth, we studied the emotional reaction to SS (21), but the reverse cannot be excluded: low mood may result in subjective appraisals of the environment. Although SS and NA are closely linked, they do not a priori represent identical phenomena, as evidenced in the current report: SS differed significantly over the different urbanicity strata, with lower levels of SS in the more urban areas, while there was no large or significant variation of NA across the separate urbanicity strata.

Three individuals in the patient group, twelve in the relative group and two in the control group were excluded from the analysis, because they were unable to comply with the ESM protocol. This may have biased the results, however only in the unlikely scenario that attrition was associated differentially with the impact of the urban environment on negative affect. Seventh, it could be argued that exclusion of diary entries recorded fifteen minutes or later after the last beep, could lead to selection and possibly bias. Persons who are more emotionally reactive to SS may not be able to complete a diary form immediately when a stressful event happens because of high levels of negative emotions. However, if this were the case, the selection would be consistent across study groups. Furthermore, a study among patients with borderline personality disorder (39), who are known to have a high level of stress reactivity, showed markedly higher levels of emotional reactivity in this group, even after exclusion of all ESM data recorded 15 minutes after the beep, which makes it unlikely that the 15-minute selection threshold results in exclusion of more reactive individuals. Also, Delespaul (30) demonstrated that delayed reports (15-30 minutes and longer) display less reactivity. Eight, individuals living in urban environments may be selected by certain personality traits, for example low levels of NA in relation to SS. In this case, interpretation of causality from urban environment to behavioural outcome should be reversed in the sense that the behavioural trait predisposes for urban living. Although we cannot exclude this mechanism of person-environment correlation, the environmental exposure could not have been selected by the subjects themselves, as living environment between the ages of 0 and 15 years is determined by the parents.

Finally, the results section presents "main effects" of SS as well as regression coefficients for patients, controls and relatives, while ignoring interaction between SS and urbanicity. However, the results in table 3 taking both urbanicity and group status into account, are the final and most correct results.

\section{Conclusion}

The results suggest that early urban environment may impact adult change in NA in relation to SS, however its relevance to psychosis is unclear. More research is required with more detailed measures of risk-increasing and risk-decreasing elements over the life course in urban environments. Also, contextual level influences in the wider social environment need to be taken into account. 


\section{REFERENCES}

1. Kelly BD, O'Callaghan E, Waddington JL, Feeney L, Browne S, Scully PJ, et al. Schizophrenia and the city: A review of literature and prospective study of psychosis and urbanicity in Ireland. Schizophrenia research. 2010;116(1):75-89.

2. McGrath J, Saha S, Welham J, El Saadi O, MacCauley C, Chant D. A systematic review of the incidence of schizophrenia: the distribution of rates and the influence of sex, urbanicity, migrant status and methodology. BMC Med. 2004;2:13.

3. McGrath J, Scott J. Urban birth and risk of schizophrenia: a worrying example of epidemiology where the data are stronger than the hypotheses. Epidemiologia e psichiatria sociale. 2006;15(4):243-6.

4. Pedersen CB, Mortensen PB. Evidence of a dose-response relationship between urbanicity during upbringing and schizophrenia risk. Archives of general psychiatry. 2001;58(11):1039-46.

5. Krabbendam L, van Os J. Schizophrenia and urbanicity: a major environmental influence--conditional on genetic risk. Schizophrenia bulletin. 2005;31(4):795-9.

6. March D, Hatch SL, Morgan C, Kirkbride JB, Bresnahan M, Fearon P, et al. Psychosis and place. Epidemiologic reviews. 2008;30:84-100.

7. Vassos E, Pedersen CB, Murray RM, Collier DA, Lewis CM. Meta-analysis of the association of urbanicity with schizophrenia. Schizophrenia bulletin. 2012;38(6):1118-23.

8. United Nations Population Fund. State of world population 2011: People and possibilities in a wordl of 7 billion. New York: United Nations Population Fund; 2011.

9. van Os J, Driessen G, Gunther N, Delespaul P. Neighbourhood variation in incidence of schizophrenia. Evidence for person-environment interaction. The British journal of psychiatry : the journal of mental science. 2000;176:243-8.

10. Selten JP, Cantor-Graae E. Hypothesis: social defeat is a risk factor for schizophrenia? Br J Psychiatry Suppl. 2007;51:s9-12.

11. Eaton WW, Mortensen PB, Frydenberg M. Obstetric factors, urbanization and psychosis. Schizophrenia research. 2000;43(2-3):117-23.

12. McDonald C, O'Callaghan E, Keogh F, Sham PC, Kinsella A, Morris M, et al. Number of older siblings of individuals diagnosed with schizophrenia. Schizophrenia research. 2001;47(2-3):275-80.

13. McGrath J. Hypothesis: is low prenatal vitamin D a risk-modifying factor for schizophrenia? Schizophrenia research. 1999;40(3):173-7.

14. Lewis G, David A, Andreasson S, Allebeck P. Schizophrenia and city life. Lancet. 1992;340(8812):137-40.

15. Mortensen PB, Pedersen CB, Westergaard T, Wohlfahrt J, Ewald H, Mors O, et al. Effects of family history and place and season of birth on the risk of schizophrenia. N Engl J Med. 1999;340(8):603-8.

16. Pedersen $\mathrm{CB}$, Mortensen PB. Why factors rooted in the family may solely explain the urban-rural differences in schizophrenia risk estimates. Epidemiologia e psichiatria sociale. 2006;15(4):247-51.

17. van Os J, Hanssen M, Bak M, Bijl RV, Vollebergh W. Do urbanicity and familial liability coparticipate in causing psychosis? The American journal of psychiatry. 2003;160(3):477-82.

18. van Os J, Pedersen CB, Mortensen PB. Confirmation of synergy between urbanicity and familial liability in the causation of psychosis. The American journal of psychiatry. 2004;161(12):2312-4.

19. Weiser M, van Os J, Reichenberg A, Rabinowitz J, Nahon D, Kravitz E, et al. Social and cognitive functioning, urbanicity and risk for schizophrenia. The British journal of psychiatry : the journal of mental science. 2007;191:320-4.

20. Marcelis M, Takei N, van Os J. Urbanization and risk for schizophrenia: does the effect operate before or around the time of illness onset? Psychological medicine. 1999;29(5):1197-203.

21. Myin-Germeys I, van Os J, Schwartz JE, Stone AA, Delespaul PA. Emotional reactivity to daily life stress in psychosis. Archives of general psychiatry. 2001;58(12):1137-44.

22. Lataster $T$, Wichers M, Jacobs N, Mengelers R, Derom C, Thiery E, et al. Does reactivity to stress cosegregate with subclinical psychosis? A general population twin study. Acta psychiatrica Scandinavica. 2009;119(1):45-53. 
23. Lederbogen F, Kirsch $P$, Haddad L, Streit F, Tost $H$, Schuch $P$, et al. City living and urban upbringing affect neural social stress processing in humans. Nature. 2011;474(7352):498-501.

24. Genetic Risk and Outcome in Psychosis (GROUP) investigators. Evidence that familial liability for psychosis is expressed as differential sensitivity to cannabis: an analysis of patient-sibling and siblingcontrol pairs. Archives of general psychiatry. 2011;68(2):138-47.

25. Myin-Germeys I, Oorschot M, Collip D, Lataster J, Delespaul P, van Os J. Experience sampling research in psychopathology: opening the black box of daily life. Psychological medicine. 2009;39(9):1533-47.

26. Lardinois M, Lataster T, Mengelers R, Van Os J, Myin-Germeys I. Childhood trauma and increased stress sensitivity in psychosis. Acta psychiatrica Scandinavica. 2011;123(1):28-35.

27. Glaser JP, van Os J, Portegijs PJ, Myin-Germeys I. Childhood trauma and emotional reactivity to daily life stress in adult frequent attenders of general practitioners. Journal of psychosomatic research. 2006;61(2):229-36.

28. Kramer IM, Simons CJ, Myin-Germeys I, Jacobs N, Derom C, Thiery E, et al. Evidence that genes for depression impact on the pathway from trauma to psychotic-like symptoms by occasioning emotional dysregulation. Psychological medicine. 2011:1-12.

29. Wichers M, Schrijvers D, Geschwind N, Jacobs N, Myin-Germeys I, Thiery E, et al. Mechanisms of geneenvironment interactions in depression: evidence that genes potentiate multiple sources of adversity. Psychological medicine. 2009;39(7):1077-86.

30. Delespaul PA. Assessing Schizophrenia in Daily Life. The Experience Sampling Method. Maastricht: Maastricht University Press; 1995.

31. Kay SR, Fiszbein A, Opler LA. The positive and negative syndrome scale (PANSS) for schizophrenia. Schizophrenia bulletin. 1987;13(2):261-76.

32. Statistics Netherlands. Bevolking der Gemeenten van Nederland. The Hague: Central Bureau of Statistics publications; 1993.

33. Vanhaute E, Vrielinck S. Historische Databank van Lokale Statistieken- LOKSTAT. Gent: Universiteit Gent; 2013.

34. StataCorp. Stata Statistical Software. Release 10.0 ed: College Station, TX: Stata Corporation; 2007.

35. Lataster $T$, Wichers M, Jacobs N, Mengelers R, Derom C, Thiery E, et al. Does reactivity to stress cosegregate with subclinical psychosis? A general population twin study. Acta psychiatrica Scandinavica. 2009;119(1):45-53.

36. Stone AA, Shiffman S, Schwartz JE, Broderick JE, Hufford MR. Patient non-compliance with paper diaries. BMJ. 2002;324(7347):1193-4.

37. Green AS, Rafaeli E, Bolger N, Shrout PE, Reis HT. Paper or plastic? Data equivalence in paper and electronic diaries. Psychological methods. 2006;11(1):87-105.

38. Strauss JS. The person with schizophrenia as a person. II: Approaches to the subjective and complex. The British journal of psychiatry Supplement. 1994(23):103-7.

39. Glaser JP, Van Os J, Mengelers R, Myin-Germeys I. A momentary assessment study of the reputed emotional phenotype associated with borderline personality disorder. Psychological medicine. 2008;38(9):1231-9. 



\section{Chapter 4}

\section{Childhood trauma and childhood urbanicity in relation to psychotic disorder}

Authors: Aleida Frissen ${ }^{1}$, Ritsaert Lieverse ${ }^{1}$, Marjan Drukker ${ }^{1}$, Ruud van Winkel ${ }^{1}$, Philippe Delespaul ${ }^{1}$, GROUP Investigators ${ }^{2}$

${ }^{1}$ Department of Psychiatry and Psychology, Maastricht University, The Netherlands ${ }^{2}$ Genetic Risk and Outcome of Psychosis (GROUP) Investigators: Richard Bruggeman ${ }^{\text {, }}$ Wiepke Cahn ${ }^{b}$, Lieuwe de Haan ${ }^{c}$, René Kahn ${ }^{b}$, Carin Meijer ${ }^{c}$, Inez Myin-Germeys ${ }^{d}$ Jim $^{2}$ van Os ${ }^{\mathrm{d}, \mathrm{e}}$, Durk Wiersma ${ }^{\mathrm{a}}$

aniversity Medical Center Groningen, Department of Psychiatry, University of Groningen, The Netherlands

bUniversity Medical Center Utrecht, Department of Psychiatry, Rudolf Magnus Institute of Neuroscience, The Netherlands

${ }^{c}$ Academic Medical Centre University of Amsterdam, Department of Psychiatry, Amsterdam, The Netherlands

'Maastricht University Medical Centre, South Limburg Mental Health Research and Teaching Network, EURON, Maastricht, The Netherlands

'King's College London, King's Health Partners, Department of Psychosis Studies, Institute of Psychiatry, London, United Kingdom.

Social Psychiatry and Psychiatric Epidemiology (2015) 50, 1481-1488 


\section{Chapter 4}

\section{ABSTRACT}

\section{Background}

Urban upbringing and childhood trauma are both associated with psychotic disorders. However, the association between childhood urbanicity and childhood trauma in psychosis is poorly understood. The urban environment could occasion a background of social adversity against which any effect of childhood trauma increases. Also, any impact of the urban environment on likelihood of exposure to childhood trauma could be stronger in children who later develop psychotic disorder. The aim of this study was twofold: (i) to investigate whether childhood urbanicity moderates the effect of childhood trauma, in a model predicting psychotic disorder; (ii) to investigate whether there is an association between the urban environment and childhood trauma and whether this is moderated by genetic liability for psychotic disorder.

\section{Methods}

Patients with a diagnosis of non-affective psychotic disorder $(n=1119)$ and 589 healthy controles from the Netherlands and Belgium were studied. Childhood trauma was assessed with the Dutch version of the Childhood Trauma Questionnaire -Short Form. Urban exposure was defined at 4 levels, considering the population density, using data from Statistics Netherlands and the equivalent database in Belgium.

\section{Results}

There was a significant interaction between childhood urbanicity on the one hand and childhood trauma on the other, indicating that trauma was significantly associated with psychotic disorder, with increasing odds ratios for higher levels of childhood urbanicity. In addition, there was weak evidence that childhood urbanicity was associated with childhood trauma in the patient group: higher levels of childhood urbanicity were associated with higher trauma scores.

\section{Conclusion}

The urban environment may moderate the risk-increasing effect of childhood trauma for psychotic disorder and childhood urbanicity may be a risk factor for childhood trauma in individuals who later develop psychotic disorder. 


\section{INTRODUCTION}

Urban birth and urban upbringing (1-4), and childhood trauma (5-9) are both associated with psychotic disorder. The dynamics underlying the triangular association between childhood urbanicity, childhood trauma and psychosis remains poorly understood but is of considerable interest in the prevention and management of risk given childhood exposure to adversity.

There is evidence that the incidence of childhood trauma is linked to aspects of the urban environment: neighbourhood factors, such as impoverishment and child care burden (ratio of children to adults, and the ratio of males to females), significantly increase child abuse (10). Lower levels of social capital inherent to higher levels of urbanicity have been found to increase the odds of neglectful parenting, psychologically harsh parenting, and domestic violence (11).

It is not known whether urbanization moderates the effect of childhood trauma in psychosis. It may be hypothesized that the urban environment occasions a background of social adversity against which any effect of childhood trauma increases, which would indicate a model of moderation (Figure 1). A related hypothesis is that any impact of the urban environment on the likelihood of exposure to childhood trauma is stronger in children with higher level of genetic risk for psychotic disorder (moderation by genetic risk; Figure 2). For example, early alterations in social cognition (12-15) may increase the likelihood of exposure to childhood adversities in individuals who later develop psychotic disorder, when brought up in an urban environment. To address these issues, triangular associations between urbanicity, trauma and psychosis were examined in two directions: (i) is there evidence that childhood urban environment moderates the effect of childhood trauma on the development of psychotic disorder and (ii) is there evidence of an association between the urban environment and childhood trauma, and is this contingent on genetic liability for psychotic disorder?

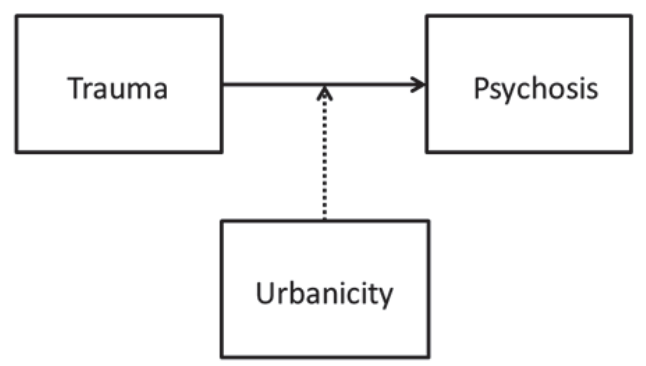

Figure 1. Childhood urbanicity moderates the association between childhood trauma and psychotic disorder. Childhood urbanicity is associated with social adversity, which is associated with stress. Any effect of childhood trauma on psychotic disorder in the urban environment may increase because of higher background levels of stress. 


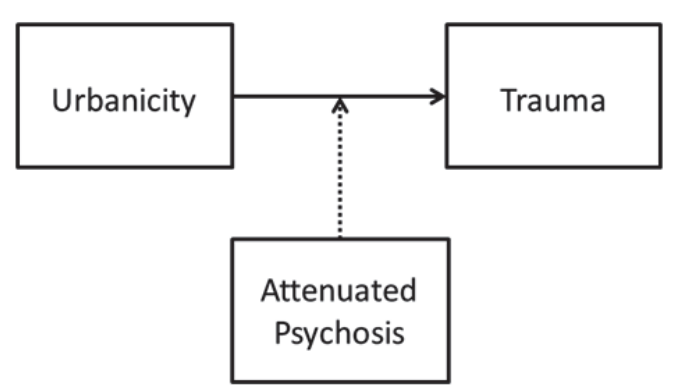

Figure 2. The association between childhood trauma and childhood urbanicity is moderated by genetic risk for psychotic disorder. When brought up in an urban environment with more social competition, genetic risk for psychotic disorder may increase the likelihood of exposure to childhood adversity, mediated by altered functioning of social cognition.

\section{MATERIALS AND METHODS}

\section{Participants}

Data pertain to baseline measures of the ongoing multisite, longitudinal, naturalistic cohort study, the Dutch national Genetic Risk and Outcome in Psychosis (GROUP) project (16). The full sample consisted of 1119 patients diagnosed with a non-affective psychotic disorder, 1057 of their siblings, 919 parents of the patients and their siblings, and 589 unrelated healthy controls subjects from the general population from the Netherlands and Belgium. Parents and siblings were not included in the current analysis.

In selected representative geographical areas of the Netherlands and (the Dutch speaking part of) Belgium, patients were identified through clinicians working in regional psychosis departments or academic centres, whose caseload was screened for inclusion criteria. Subsequently, a group of patients with a clinical diagnosis of non-affective psychotic disorder presenting consecutively at these services either as outpatients or inpatients were recruited for the study. Over 30 interviewers per site were trained for administering the assessments. The interviewers consisted of research assistants, psychologists, psychiatrists, nurses and PhD students. Before the start of the study, all interviewers met for three days of training workshops at one site (Utrecht), to practice the assessments of all measures used in the GROUP project.

Assessments took place at one of the participating regional psychosis departments or academic centres in and around Amsterdam, Utrecht, Groningen and Maastricht. If participants were unable to visit the institute, assessments at home were offered.

Inclusion criteria were the following: (1) age range 16 to 50 years; (2) diagnosis of non-affective psychotic disorder; (3) sufficient command of the Dutch language; and (4) a first contact with mental health facilities within the last 10 years. Controls had no firstdegree relative with a psychotic disorder as established by the Family Interview for 
Genetic Studies (17) with the control as informant. Diagnosis was based on the DSM-IVTR criteria (18) assessed with the Comprehensive Assessment of Symptoms and History interview (19) or Schedules for Clinical Assessment for Neuropsychiatry version2.1 (20).

The study was approved centrally by the Ethical Review Board of the University Medical Centre Utrecht. Written informed consent was obtained from all subjects after they (1) read a document with detailed information about the nature and possible consequences of the study; (2) had verbally discussed any possible concerns with the researcher; and (3) had provided clear indication that they had understood the procedure. In the Netherlands, adult patients with mental illness are considered participating citizens who have the right to make independent informed decisions including the autonomous decision to participate in research; therefore, consent of relatives was not sought.

\section{Childhood trauma}

Childhood trauma was assessed with the Dutch version of the Childhood Trauma Questionnaire Short Form (CTQ)(21). The short CTQ consists of 25 items rated on a 5-point Likert scale ( 1 = never true to 5 = very often true) enquiring about traumatic experiences in childhood. Five types of childhood maltreatment were assessed: emotional, physical and sexual abuse, and emotional and physical neglect, with five questions covering each type of trauma. The mean score for all 25 items was used as the total trauma rating (CTQ-total). CTQ data were missing for 454 persons (27\% missing data, see below). The trauma variable was dichotomized a priori into high trauma and low trauma. Conform previous analyses, the cut-off was defined as the $80^{\text {th }}$ percentile of scores for the healthy comparison subjects (8). Subjects with a score of 1.52 or higher were in the high-trauma group.

\section{Level of Urbanicity}

A historical population density record was generated for each municipality from 1930 onwards using historical data from Statistics Netherlands and the equivalent database in Belgium $(22,23)$. When data was not available, missing data were calculated by linear extrapolation between two subsequent time-points. When historical names of municipalities disappeared from historical records (e.g. due to city mergers) the available data from the agglomerate city were used. Subjects were asked to describe where they had lived at birth, between ages 0-4 years; between $5-9$ years; $10-14$ years; $15-19$ years; 20 39 years; 40-59 years; and 60+ up to the actual age. This resulted in a number of records for each subject, containing locations by age period. For each of these records, we computed the average population density (by square kilometre, excluding water) of the municipality for the matching periods. Average population density over the period was categorized in accordance with the Dutch CBS urbanicity rating $\left(1=<500 / \mathrm{km}^{2} ; 2=500\right.$ - 
$\left.1000 / \mathrm{km}^{2} ; 3=1000-1500 / \mathrm{km}^{2} ; 4=1500-2500 / \mathrm{km}^{2} ; 5=2500+/ \mathrm{km}^{2}\right)$. The periods $0-4$ years, 5-9 years and 10-14 years were collapsed to produce average urbanicity exposure between 0-14 years, rounded to the nearest whole number. Categories 3 and 4 were combined into a single category, because numbers of participants in these two categories were small compared to the other categories, this resulted in 4 categories $\left(1=<500 / \mathrm{km}^{2} ; 2=500-1000 / \mathrm{km}^{2} ; 3=1000-2500 / \mathrm{km}^{2} ; 4=2500+/ \mathrm{km}^{2}\right)$. The latter was used as the primary variable reflecting childhood urbanicity exposure in the analyses. Urbanicity data was missing for 148 persons ( $9 \%$ missing data).

\section{Intelligence Quotient}

To estimate IQ we used four subtests of the Dutch version of the Wechsler Adult Intelligence Scale-III (WAIS-III)(24) consisting of the subtests 'Information', 'Block Design', 'Digit Symbol Coding' and 'Arithmetic'. The combination of these four subtests has been shown reliable for estimating $I Q$ in schizophrenia patients and controls(25).

\section{Statistical analyses}

All analyses were performed using Stata 12 (26). To test the first hypothesis (childhood urbanicity moderates the association between childhood trauma and psychotic disorder) logistic regression models were fitted with group (group status defined as: control or patient) as the dependent variable and childhood trauma and childhood urbanicity as independent variables and age and sex as possible confounders. The two-way interaction between urbanicity (entered as a linear variable and dummy variable in separate models) and trauma (entered as a linear variable and a dichotomous variable in separate models) was added to the model to test for moderation. Interactions were evaluated by Wald test(27). In the case of significant interaction, odds ratios of trauma per category of urbanicity were calculated using the model containing the interactions, applying the Stata LINCOM routine.

To test the second hypothesis (the level of urbanization may be more strongly associated with childhood trauma in children who later develop psychotic disorder) linear regression models were fitted with the trauma rating as the dependent variable and group and childhood urbanicity as independent variables, adding age and sex as possible confounders. Because of the uneven distribution of CTQ-total a qq-plot of the regression residuals was made, to check for possible violation of model assumptions. In order to model the possible modifying effect of childhood urbanicity on measures of proxy genetic risk, the two-way interaction between urbanicity (entered as a linear variable and dummy variable) and group was added to the model. Again, interactions were evaluated by Wald test(27). In the case of significant interaction, effect sizes were calculated by combination of effects from the model containing the interactions using the Stata LINCOM routine. Childhood trauma and childhood urbanicity scores were not 
available for all participants, therefore 696 patients and 467 controls were included in the final analyses.

To account for missing values in CTQ-total, sensitivity analyses were performed using the Stata multiple imputation suite of commands (mi). Missing values were assumed to be missing at random (MAR) and sex, group and educational level were used to impute missing values for trauma. All interaction models were imputed 10 times.

\section{RESULTS}

\section{Participants, descriptives and main effects}

The total sample consisted of 1119 patients with a diagnosis of non-affective psychotic disorder and 589 control subjects. Sociodemographic and clinical characteristics of the final sample are summarized in Table 1 . Sixteen patients had a diagnosis of depression of anxiety disorder; these patients were retained in the analyses given that they had a past clinical diagnosis of psychotic disorder based on which they had been selected into the sample. The patient group had a higher proportion of men and displayed lower IQ than the control group. Multilevel linear regression analysis showed that CTQ-total was significantly higher in the patient group compared to the control group. Childhood urbanicity did not differ between the two groups (patients: $\mathrm{B}=0.02, p=0.83$ ). Childhood urbanicity was not significantly associated with childhood trauma in the total sample ( $B$ $=0.02, p=0.06$ ).

\section{Childhood urbanicity moderates the association between childhood trauma and psychosis}

The two-way interaction term childhood trauma $X$ childhood urbanicity (both variables entered as linear variables) was significant in the case-control model $\left(\chi^{2}=7.06, \mathrm{df}=1, p\right.$ $=0.01$ ). High CTQ-scores were associated with psychotic disorder with increasing odds ratios for higher levels of childhood urbanicity (Table 2). The odds ratios increased roughly linear with higher levels of childhood urbanicity.

\section{Association between urbanicity and trauma and moderation by genetic risk}

The two-way interaction term group $X$ childhood urbanicity was statistically significant in the models analysing CTQ-total $\left(\chi^{2}=5.79, \mathrm{df}=1, p=0.02\right)$. The direction of effects in the patients and in the controls appeared to be opposite, although not significantly so and may reflect a chance finding. In the patients, CTQ-total score increased with higher levels of childhood urbanicity ( $B$ linear trend $=0.02, p=0.10$ ). In the control group, 


\section{Chapter 4}

increasing levels of childhood urbanicity were associated with lower CTQ-total scores (B Linear trend $=-0.03, \mathrm{p}=0.08$ ) (Table 3).

Table 1. Subject demographics

\begin{tabular}{|c|c|c|}
\hline & $\begin{array}{l}\text { Patients } \\
(n=1119)\end{array}$ & $\begin{array}{l}\text { Controls } \\
(n=589)\end{array}$ \\
\hline Age & $27.6 \pm 8.0$ & $30.4 \pm 10.6$ \\
\hline Sex n (\%), male & $852(76.1)$ & $269(45.6)$ \\
\hline \multicolumn{3}{|l|}{ Ethnicity } \\
\hline Caucasian n (\%) & $857(76.6)$ & $530(90.0)$ \\
\hline Other n (\%) & $262(23.4)$ & $59(10.0)$ \\
\hline Childhood Urbanicity $^{a}$ & $2.7 \pm 1.6$ & $2.6 \pm 1.6$ \\
\hline $\mathrm{CTQ}^{\mathrm{b}}$ & $1.6 \pm 0.5$ & $1.3 \pm 0.4$ \\
\hline \multicolumn{3}{|l|}{ Diagnosis n (\%) } \\
\hline No diagnosis on axis I & - & $536(91.0)$ \\
\hline Schizophrenia related disorder & $792(71.4)$ & - \\
\hline Schizoaffective disorder & $120(10.8)$ & - \\
\hline Brief psychotic disorder & $33(3.0)$ & - \\
\hline Delusional disorder & $22(2.0)$ & - \\
\hline Substance induced psychotic disorder & $5(0.5)$ & - \\
\hline Psychotic disorder NOS & $118(10.6)$ & - \\
\hline Psychotic Disorder Due to Medical Condition & $1(0.1)$ & - \\
\hline Mood disorder & $16(1.4)$ & $52(8.8)$ \\
\hline Delirium & $1(0.1)$ & - \\
\hline Anxiety related disorder & - & $1(0.2)$ \\
\hline Substance related disorder & $1(0.1)$ & - \\
\hline
\end{tabular}

${ }^{a}$ Five levels op urbanicity/population density $1=<500$ inhabitants $/ \mathrm{km} 2 ; 2=500-1000$ inhabitants $/ \mathrm{km} 2 ; 3=$ inhabitants 1000-1500/km2; 4= inhabitants 1500-2500/km2; 5=2500+/km

${ }^{\mathrm{b}} \mathrm{CTQ}=$ Childhood Trauma Questionnaire, range 1-5

Table 2. Association between high trauma scores ${ }^{a}$ and patient status across levels of childhood urbanicity

\begin{tabular}{llll}
\hline & Odds ratio & $95 \% \mathrm{Cl}$ & $P$ \\
\hline Urbanicity 1 & 2.76 & $1.71-4.46$ & $<0.001$ \\
Urbanicity 2 & 4.12 & $2.27-7.45$ & $<0.001$ \\
Urbanicity 3 & 5.61 & $2.78-11.33$ & $<0.001$ \\
Urbanicity 4 & 5.66 & $2.87-11.16$ & $<0.001$ \\
\hline
\end{tabular}

$\mathrm{Cl}$ confidence interval

a The trauma variables were dichotomized a priori into high trauma and low trauma. The cutoff was defined as the $80^{\text {th }}$ percentile of scores for the healthy comparison subjects.

${ }^{\mathrm{b}}$ Four levels of urbanicity/population density $1=<500$ inhabitants $/ \mathrm{km}^{2} ; 2=500-1000$ inhabitants $/ \mathrm{km}^{2} ; 3=$ inhabitants $1000-2500 / \mathrm{km}^{2} ; 4=2500+/ \mathrm{km}$ 
Childhood trauma and childhood urbanicity in relation to psychotic disorder

Table 3. Mean CTQ-total scores by group and level of childhood urbanicity ${ }^{\mathrm{a}}$

\begin{tabular}{llllllll}
\hline \multirow{2}{*}{ Urbanicity } & \multicolumn{3}{l}{ Patients } & & \multicolumn{2}{l}{ Controls } \\
\cline { 2 - 3 } & $\mathrm{N}$ & Mean CTQ $(\mathrm{SD})$ & $\mathrm{B}(p)$ & & $\mathrm{N}$ & Mean CTQ $(\mathrm{SD})$ & $\mathrm{B}(p)$ \\
\hline 1 & 239 & $1.55(0.46)$ & & 174 & $1.40(0.39)$ & \\
2 & 157 & $1.69(0.54)$ & $0.13(<0.01)$ & 107 & $1.36(0.40)$ & $-0.03(0.60)$ \\
3 & 144 & $1.58(0.49)$ & $0.02(0.64)$ & 91 & $1.26(0.26)$ & $-0.12(0.04)$ \\
4 & 156 & $1.65(0.52)$ & $0.10(0.03)$ & 95 & $1.32(0.29)$ & $-0.07(0.21)$ \\
B linear trend & & & $0.02(0.10)$ & & & $-0.03(0.08)$ \\
\hline
\end{tabular}

CTQ childhood trauma questionnaire

SD standard deviation

$B$ represents the regression coefficients from multilevel linear regression analyses, adjusted for age and sex

${ }^{a}$ Four levels of urbanicity/population density $1=<500$ inhabitants $/ \mathrm{km}^{2} ; 2=500-1000$ inhabitants $/ \mathrm{km}^{2} ; 3=$ inhabitants $1000-2500 / \mathrm{km}^{2} ; 4=2500+/ \mathrm{km}$.

\section{Sensitivity analysis}

After imputation, the interaction between childhood trauma and childhood urbanicity in the model predicting case-control status was no longer statistically significant by conventional alpha, but was still suggestive for interaction $(\chi 2=3.58, d f=1, p=0.06)$. The interaction between childhood urbanicity and group in the model predicting CTQ-total also was reduced but still suggestive for interaction ( $\chi 2=3.47, d f=1, p=0.06)$.

\section{DISCUSSION}

The association between childhood trauma, childhood urbanicity and psychotic disorder was examined. Childhood urbanicity appeared to moderate the association between childhood trauma and psychosis: the risk-increasing effect of childhood trauma for psychotic disorder was stronger for higher levels of childhood urbanicity. Further, childhood urbanicity was at trend-level associated with childhood trauma: higher levels of childhood urbanicity were associated with higher trauma scores, but only in the patient group.

The finding that childhood urbanicity moderates the effects of childhood trauma is new, but also in line with previous findings concerning other risk factors. Kuepper and colleagues (28) suggested that urbanicity moderates the effect of cannabis use. The effect of cannabis use on psychotic symptoms was stronger in individuals who grew up in an urban environment, compared to those who grew up in a rural environment. In addition, the co-occurrence of multiple environmental risk factors for psychosis in persons with low-grade psychotic experiences, including childhood trauma and childhood urbanicity, has been associated with persistence of psychotic symptoms (29).

Childhood urbanicity may moderate the effect of childhood adversity by creating additional exposure to stress(30). Childhood trauma has been associated with altera- 
tions of the mechanisms subserving stress regulation and with altered functioning of the hypothalamic-pituitary-adrenal axis (HPA-axis) $(31,32)$. Higher levels of social isolation (33) and social defeat (34) in urban areas can lead to higher background levels of stress, which may have an additional effect on the HPA-axis. Altered functioning of the hypothalamic-pituitary-adrenal axis may impact dopaminergic signalling, and may lead to sensitization of mesolimbic dopamine neurons in early adulthood, contributing to onset of psychosis (32).

Childhood abuse and childhood neglect are two different aspects of childhood trauma. In post-hoc analyses childhood abuse and child neglect were examined separately in the model predicting psychotic disorder. Childhood urbanicity appeared to strengthen the association between childhood neglect and psychotic disorder more than the association between childhood abuse and psychotic disorder. Childhood neglect has been linked to the absence of social support, social isolation, and being in a financially disadvantaged position, all predicting suboptimal parenting (35-37). Higher levels of perceived social isolation in urban areas (33) and greater exposure to social "defeat" occasioned by higher levels of competition in cities (34) are proposed mechanisms for the association between childhood urbanicity and psychotic disorders. It is conceivable that such disadvantages occasioned by the urban environment intensify any effects of childhood neglect.

Previous studies reported an association between childhood trauma and childhood urbanicity in the non-psychotic population. Drake et al. found that especially childhood neglect, and not psychological or sexual abuse, was most powerfully associated with urban neighbourhood poverty (38). Breakdown of community social control and organization is associated with an increase of child maltreatment (39). Neighbourhood characteristics seem to have an effect on parents' level of stress and personal control, which in turn is a risk factor for physical child abuse and neglect $(40,41)$. Also the protective influence of social support on parenting behaviour diminishes in poor and dangerous neighbourhoods(42). In our total study sample, the association between childhood trauma and childhood urbanicity was in the same direction, although it was only significant at trend level. An explanation of the absence of a significant association could be that the number of participants in the higher urbanicity levels was relatively small compared to the lower urbanicity levels, resulting in low power. These results have to be interpreted carefully since more than $50 \%$ of the study subjects were patients, which may have biased these results. In a different population based sample this association may be even less or absent.

Our results suggest that individuals who later develop psychotic disorder could be more susceptible to exposure to childhood trauma when growing up in an urban environment. In controls no such trend was apparent. Because childhood trauma (9) and childhood urbanicity (43) both appear to be substantial risk factors for psychotic disorders, growing up in a city and the subsequently higher risk for childhood trauma (gene environment co-association) will even further increase the risk of psychotic disorder. 
One possible explanation for these findings is that impaired social cognition combined with living in an urban environment, with higher levels of social competition, could increase the likelihood to experience interpersonal adversity and, possibly, childhood trauma. From meta-analytic evidence, it is known that social cognition is impaired in psychotic disorder (12). In addition, social cognition is not only altered in psychotic disorder, but also in persons at genetic and clinical high risk for psychosis (13-15). Therefore, alterations in social cognition may represent a candidate explanation for the association between urbanicity and trauma in persons at higher genetic risk for psychotic disorder. This explanation needs to be tested in future research; just as replication of the current findings is necessary. It is also conceivable that the association between childhood trauma and social cognition is inverted: experience of childhood trauma may result in impaired social cognition. If this is the case than impaired social cognition could be on the causal pathway from childhood trauma to psychotic disorder. This concept is supported by a study showing deficits in theory of mind after deprivation during childhood (44).

The results may be compatible with childhood trauma partially mediating the association between childhood urbanicity and psychotic disorder. As this data set did not reveal an association between childhood urbanicity and psychotic disorder, the possibility of mediation by childhood trauma could not be tested. There was an association between childhood trauma and psychotic disorder in the study sample and therefor moderation by childhood urbanicity could be explored. The hypothesis of childhood urbanicity (partially) mediating the association between childhood trauma and psychotic disorder also could not be tested because of the absence of an association between urbanicity and psychotic disorder. Moreover, childhood trauma contributing to childhood urbanicity has less face validity than childhood urbanicity contributing to risk of childhood trauma.

\section{Limitations}

First, our findings must be interpreted with caution because the effect sizes were relatively small. Second, $27 \%$ of the trauma data was missing. However, sensitivity analyses imputing missing data showed similar results. Third, the cross-sectional and retrospective design of the present data analysis does not allow us to establish a causal link between childhood urbanicity, childhood trauma and psychosis. From these data we can only conclude that there is an association, indicating that causality has to be further investigated in future research. Further, case-control studies are sensitive to selection bias. Participation of the control subjects could have been influenced by self-selection of persons with higher levels of childhood trauma. However, if this were the case, the analyses may be considered conservative. If the opposite were true and control subjects with a history of childhood trauma were less likely to participate, there may be an overestimation of the effect. Thus, data have to be interpreted with awareness of a possible 


\section{Chapter 4}

selection bias. Fourth, the childhood trauma questionnaire is a retrospective and selfreported questionnaire. Nevertheless, the childhood trauma questionnaire is reliable in assessing trauma accurately $(45,46)$. Finally, the participants grew up in the Netherlands and Belgium which can be described as relative safe and well developed countries; in other countries urban-rural discrepancies may be more prominent. However, if this were true effect sizes in other countries would be more substantial.

\section{CONCLUSION}

The results substantially support that childhood urbanicity moderates the association between childhood trauma and psychotic disorder, and tentatively indicate that childhood urbanicity may be a risk factor for childhood trauma in individuals with a high genetic liability for psychotic disorder. Future research is needed to replicate these findings and also more research on the risk-increasing mechanisms, e.g. evaluating social cognition, in urban environments is required. 


\section{REFERENCES}

1. Kelly BD, O'Callaghan E, Waddington JL, Feeney L, Browne S, Scully PJ, et al. Schizophrenia and the city: A review of literature and prospective study of psychosis and urbanicity in Ireland. Schizophrenia research. 2010;116(1):75-89.

2. McGrath J, Scott J. Urban birth and risk of schizophrenia: a worrying example of epidemiology where the data are stronger than the hypotheses. Epidemiologia e psichiatria sociale. 2006;15(4):243-6.

3. Krabbendam L, van Os J. Schizophrenia and urbanicity: a major environmental influence--conditional on genetic risk. Schizophrenia bulletin. 2005;31(4):795-9.

4. Pedersen CB, Mortensen PB. Evidence of a dose-response relationship between urbanicity during upbringing and schizophrenia risk. Archives of general psychiatry. 2001;58(11):1039-46.

5. Bebbington PE, Bhugra D, Brugha $T$, Singleton N, Farrell M, Jenkins R, et al. Psychosis, victimisation and childhood disadvantage: evidence from the second British National Survey of Psychiatric Morbidity. The British journal of psychiatry : the journal of mental science. 2004;185:220-6.

6. Janssen I, Krabbendam L, Bak M, Hanssen M, Vollebergh W, de Graaf R, et al. Childhood abuse as a risk factor for psychotic experiences. Acta psychiatrica Scandinavica. 2004;109(1):38-45.

7. Lataster T, van Os J, Drukker M, Henquet C, Feron F, Gunther N, et al. Childhood victimisation and developmental expression of non-clinical delusional ideation and hallucinatory experiences: victimisation and non-clinical psychotic experiences. Social psychiatry and psychiatric epidemiology. 2006;41(6):423-8.

8. Heins $M$, Simons $C$, Lataster $T$, Pfeifer $S$, Versmissen $D$, Lardinois $M$, et al. Childhood trauma and psychosis: a case-control and case-sibling comparison across different levels of genetic liability, psychopathology, and type of trauma. The American journal of psychiatry. 2011;168(12):1286-94.

9. Varese F, Smeets F, Drukker M, Lieverse R, Lataster T, Viechtbauer W, et al. Childhood adversities increase the risk of psychosis: a meta-analysis of patient-control, prospective- and cross-sectional cohort studies. Schizophrenia bulletin. 2012;38(4):661-71.

10. Coulton CJ, Korbin JE, Su M. Neighborhoods and child maltreatment: a multi-level study. Child abuse \& neglect. 1999;23(11):1019-40.

11. Zolotor AJ, Runyan DK. Social capital, family violence, and neglect. Pediatrics. 2006;117(6):e1124-31.

12. Kohler CG, Walker JB, Martin EA, Healey KM, Moberg PJ. Facial emotion perception in schizophrenia: a meta-analytic review. Schizophrenia bulletin. 2010;36(5):1009-19.

13. Kohler CG, Richard JA, Brensinger CM, Borgmann-Winter KE, Conroy CG, Moberg PJ, et al. Facial emotion perception differs in young persons at genetic and clinical high-risk for psychosis. Psychiatry research. 2014.

14. Lavoie MA, Plana I, Bedard Lacroix J, Godmaire-Duhaime F, Jackson PL, Achim AM. Social cognition in first-degree relatives of people with schizophrenia: a meta-analysis. Psychiatry research. 2013;209(2):129-35.

15. Bediou B, Asri F, Brunelin J, Krolak-Salmon P, D'Amato T, Saoud M, et al. Emotion recognition and genetic vulnerability to schizophrenia. The British journal of psychiatry : the journal of mental science. 2007;191:126-30.

16. Genetic Risk and Outcome in Psychosis (GROUP) investigators. Evidence that familial liability for psychosis is expressed as differential sensitivity to cannabis: an analysis of patient-sibling and siblingcontrol pairs. Archives of general psychiatry. 2011;68(2):138-47.

17. Maxwell ME. Genetics Initiative: Family Interview for Genetic Studies (FIGS): National Institute of Mental Health; 1992.

18. APA. Diagnostic and Statistical Manual of Mental Disorders. 4 ed. Washington, DC: American Psychiatric Association; 2000.

19. Andreasen NC, Flaum M, Arndt S. The Comprehensive Assessment of Symptoms and History (CASH). An instrument for assessing diagnosis and psychopathology. Archives of general psychiatry. 1992;49(8):615-23.

20. Wing JK, Babor T, Brugha T, Burke J, Cooper JE, Giel R, et al. SCAN. Schedules for Clinical Assessment in Neuropsychiatry. Archives of general psychiatry. 1990;47(6):589-93. 


\section{Chapter 4}

21. Bernstein DP, Ahluvalia T, Pogge D, Handelsman L. Validity of the Childhood Trauma Questionnaire in an adolescent psychiatric population. Journal of the American Academy of Child and Adolescent Psychiatry. 1997;36(3):340-8.

22. Statistics Netherlands. Bevolking der Gemeenten van Nederland. The Hague: Central Bureau of Statistics publications; 1993.

23. Venkatasubramanian G, Jayakumar PN, Keshavan MS, Gangadhar BN. Schneiderian first rank symptoms and inferior parietal lobule cortical thickness in antipsychotic-naive schizophrenia. Prog Neuropsychopharmacol Biol Psychiatry. 2011;35(1):40-6.

24. Wechsler D. WAIS-III: Wechsler Adult Intelligence Scale (3rd ed.) Administration and Scoring Manual.1997.

25. Blyler CR, Gold JM, lannone VN, Buchanan RW. Short form of the WAIS-III for use with patients with schizophrenia. Schizophrenia research. 2000;46(2-3):209-15.

26. StataCorp. Stata Statistical Software. Release 10.0 ed: College Station, TX: Stata Corporation; 2007.

27. Clayton D HM. Statistical Models in Epidemiology. 1993.

28. Kuepper R, van Os J, Lieb R, Wittchen HU, Henquet C. Do cannabis and urbanicity co-participate in causing psychosis? Evidence from a 10-year follow-up cohort study. Psychological medicine. 2011;41(10):2121-9.

29. Cougnard A, Marcelis M, Myin-Germeys I, De Graaf R, Vollebergh W, Krabbendam L, et al. Does normal developmental expression of psychosis combine with environmental risk to cause persistence of psychosis? A psychosis proneness-persistence model. Psychological medicine. 2007;37(4):513-27.

30. Nemeroff CB. Neurobiological consequences of childhood trauma. The Journal of clinical psychiatry. 2004;65 Suppl 1:18-28.

31. Heim C, Newport DJ, Heit S, Graham YP, Wilcox M, Bonsall R, et al. Pituitary-adrenal and autonomic responses to stress in women after sexual and physical abuse in childhood. JAMA : the journal of the American Medical Association. 2000;284(5):592-7.

32. Walker EF, Diforio D. Schizophrenia: a neural diathesis-stress model. Psychological review. 1997;104(4):667-85.

33. van Os J, Driessen G, Gunther N, Delespaul P. Neighbourhood variation in incidence of schizophrenia. Evidence for person-environment interaction. The British journal of psychiatry : the journal of mental science. 2000;176:243-8.

34. Selten JP, Cantor-Graae E. Hypothesis: social defeat is a risk factor for schizophrenia? The British journal of psychiatry Supplement. 2007;51:s9-12.

35. Ethier L, Palacio-Quintin E, Jourdan-Ionescu C. Abuse and neglect: Two distinct forms of maltreatment? Canada's Mental Health. 1992;June(June):13 - 9.

36. Zuravin SJ. The ecology of child abuse and neglect: review of the literature and presentation of data. Violence and victims. 1989;4(2):101-20.

37. Belsky J. Etiology of child maltreatment: a developmental-ecological analysis. Psychological bulletin. 1993;114(3):413-34.

38. Drake B, Pandey S. Understanding the relationship between neighborhood poverty and specific types of child maltreatment. Child abuse \& neglect. 1996;20(11):1003-18.

39. Coulton CJ, Korbin JE, Su M, Chow J. Community level factors and child maltreatment rates. Child development. 1995;66(5):1262-76.

40. Guterman NB, Lee SJ, Taylor CA, Rathouz PJ. Parental perceptions of neighborhood processes, stress, personal control, and risk for physical child abuse and neglect. Child abuse \& neglect. 2009;33(12):897-906.

41. Molnar BE, Buka SL, Brennan RT, Holton JK, Earls F. A multilevel study of neighborhoods and parent-tochild physical aggression: results from the project on human development in Chicago neighborhoods. Child maltreatment. 2003;8(2):84-97.

42. Ceballo R, McLoyd VC. Social support and parenting in poor, dangerous neighborhoods. Child development. 2002;73(4):1310-21.

43. March D, Hatch SL, Morgan C, Kirkbride JB, Bresnahan M, Fearon P, et al. Psychosis and place. Epidemiologic reviews. 2008;30:84-100. 
44. Colvert E, Rutter M, Kreppner J, Beckett C, Castle J, Groothues C, et al. Do theory of mind and executive function deficits underlie the adverse outcomes associated with profound early deprivation?: findings from the English and Romanian adoptees study. Journal of abnormal child psychology. 2008;36(7):1057-68.

45. Goodman LA, Thompson KM, Weinfurt K, Corl S, Acker P, Mueser KT, et al. Reliability of reports of violent victimization and posttraumatic stress disorder among men and women with serious mental illness. Journal of traumatic stress. 1999;12(4):587-99.

46. Fisher HL, Craig TK, Fearon P, Morgan K, Dazzan P, Lappin J, et al. Reliability and comparability of psychosis patients' retrospective reports of childhood abuse. Schizophrenia bulletin. 2011;37(3):546-53. 



\section{Chapter 5}

\section{Psychotic disorder and educational achievement: a family-based analysis}

Authors: Aleida Frissen ${ }^{1}$, Ritsaert Lieverse ${ }^{1}$, Machteld Marcelis ${ }^{1}$, Marjan Drukker ${ }^{1}$, Philippe Delespaul ${ }^{1}$, GROUP Investigators ${ }^{2}$

${ }^{1}$ Department of Psychiatry and Psychology, Maastricht University Medical Centre, The Netherlands

${ }^{2}$ Genetic Risk and Outcome of Psychosis (GROUP) Investigators: Richard Bruggeman ${ }^{a}$, Wiepke Cahn ${ }^{b}$, Lieuwe de Haan ${ }^{c}$, René Kahn ${ }^{b}$, Carin Meijer ${ }^{c}$, Inez Myin-Germeys ${ }^{d}$ Jim van Os ${ }^{\mathrm{d}, \mathrm{e}}$, Durk Wiersma ${ }^{\mathrm{a}}$

aniversity Medical Center Groningen, Department of Psychiatry, University of Groningen, The Netherlands

bUniversity Medical Center Utrecht, Department of Psychiatry, Rudolf Magnus Institute of Neuroscience, The Netherlands

${ }^{c}$ Academic Medical Centre University of Amsterdam, Department of Psychiatry,

Amsterdam, The Netherlands

'Maastricht University Medical Centre, South Limburg Mental Health Research and Teaching Network, EURON, Maastricht, The Netherlands

'King's College London, King's Health Partners, Department of Psychosis Studies, Institute of Psychiatry, London, United Kingdom.

Social Psychiatry and Psychiatric Epidemiology (2015) 50, 1511-1518 


\section{Chapter 5}

\section{ABSTRACT}

\section{Background}

Early social and cognitive alterations in psychotic disorder, associated with familial liability and environmental exposures, may contribute to lower than expected educational achievement. The aims of the present study were to investigate (i) how differences in educational level between parents and their children vary across patients, their healthy siblings and healthy controls (effect familial liability), and across two environmental risk factors for psychotic disorder: childhood trauma and childhood urban exposure (effect environment); and (ii) to what degree the association between familial liability and educational differential was moderated by the environmental exposures.

\section{Methods}

Patients with a diagnosis of non-affective psychotic disorder ( $n=629$ ), 552 non-psychotic siblings and 326 healthy controls from the Netherlands and Belgium were studied. Participants reported their highest level of education and that of their parents. Childhood trauma was assessed with the Dutch version of the Childhood Trauma Questionnaire Short Form. Urban exposure, expressed as population density, was rated across 5 levels.

\section{Results}

Overall, participants had a higher level of education than their parents. This difference was significantly reduced in the patient group, and the healthy siblings displayed intergenerational differences that were in between those of controls and patients. Higher levels of childhood urban exposure were also associated with a smaller intergenerational educational differential. There was no evidence for differential sensitivity to childhood trauma and childhood urbanicity across the three groups.

\section{Conclusion}

Intergenerational difference in educational achievements is decreased in patients with psychotic disorder and to a lesser extent in siblings of patients with psychotic disorder, and across higher levels of childhood urban exposure. More research is required to better understand the dynamics between early social and cognitive alterations in those at risk in relation to progress through the educational system and to understand the interaction between urban environment and educational outcomes. 


\section{INTRODUCTION}

Cognitive alterations are core features during all phases of psychotic disorder, including premorbid state, onset, and longitudinal course (1-5). Cognitive alterations are associated with disabilities in every day functioning (6). The origin of cognitive alterations remains unclear, and may be confounded by motivational factors (7). Nevertheless, as cognitive alterations are present in the premorbid phases of psychosis $(4,5)$ and unaffected siblings show impaired cognitive functioning (8-10), developmental and genetic origins are likely.

Other substantiations for a developmental route come from a large Swedish birth cohort which showed lower level of school performance was associated with the development of schizophrenia (11). Early cognitive alterations may thus contribute to alterations in educational achievement. However, other studies on scholastic achievement did not find such a clear association with development of psychotic disorder. Not being in the expected class at age 14 predicted future hospital-treated disorders, but not specifically psychotic disorder (12) and poor school performance in art and handicrafts, but not academic performance was a risk factor for schizophrenia (13).

Investigating cognitive alterations in relation to educational achievement is important as it may shed light on the early origins of social disability associated with cognitive alterations in psychotic disorder. A range of non-cognitive factors are known to influence school performance and educational outcomes, socioeconomic status (14) and obstetric/perinatal complications (15-17) being well-known examples.

Few studies $(1,11)$ on cognitive or scholastic performance in psychotic disorder included data on educational performance of the parents. Parental educational level is required in order to interpret actual educational level in relation to the expected educational level as predicted by parental education (1). No studies on educational performance included the unaffected siblings of patients with psychotic disorder, which similarly will increase the accuracy of interpreting actual versus expected educational level. As far as we are aware, it remains unknown whether unaffected siblings of patients with a psychotic disorder perform below the expected level in school. Furthermore, cognitive functioning in psychotic disorder is associated with socio-demographic factors, such as childhood trauma and stress (3) and urban habitat(18). Stress and altered functioning of the hypothalamic-pituitary-adrenal (HPA) axis, with harmful effects of stress and glucocorticoids on the brain is a possible explanation for this association(19). As these factors may thus impact the association between cognitive alterations and educational achievement, inclusion of these in the analyses may be profitable.

The aim of the present study was to investigate: (i) how differences in educational level between parents and their children vary across patients, their healthy siblings and healthy controls (effect familial liability), and across two environmental risk factors for psychotic disorder: childhood trauma and childhood urban exposure (effect environment); and (ii) to what degree the association between familial liability and educational 


\section{Chapter 5}

differential was moderated by the environmental exposures (childhood trauma and childhood urbanicity).It was hypothesized that patients had lower levels of education compared to their parents, than controls in comparison with their parents, and that the healthy siblings were in between the controls and the patients in this respect. Childhood urban exposure and childhood trauma were hypothesized to negatively impact the educational differential. Thus, it was expected that in the patient group, and to a lesser degree in the sibling group, both environmental exposures would negatively influence the educational difference.

\section{MATERIALS AND METHODS}

\section{Participants}

Data pertain to baseline measures of an ongoing multisite, longitudinal, naturalistic cohort study, the Dutch national Genetic Risk and Outcome in Psychosis (GROUP) project (20). Because data on parental education were not collected for the region Groningen, this region was excluded from the analysis. Participants younger than 23 years of age were also excluded from the analysis, because it is less likely that they would have completed their educational potential (21). The sample thus consisted of 629 patients diagnosed with a non-affective psychotic disorder, 552 of their siblings, and 326 unrelated healthy control subjects from the general population from the Netherlands and Belgium. Controls were selected through a system of random mailings to addresses in the catchment areas of the cases. Exclusion criteria for controls were lifetime psychotic disorder and having a first degree relative with a lifetime psychotic disorder. The full selection procedure and in- and exclusion criteria have been described previously (20).

The study was approved centrally by the Ethical Review Board of the University Medical Centre Utrecht. Written informed consent was obtained from all subjects after they (1) read a document with detailed information about the nature and possible consequences of the study; (2) had verbally discussed any possible concerns with the researcher; and (3) had provided clear indication that they had understood the procedure. In the Netherlands, adult patients with mental illness are considered participating citizens who have the right to make independent informed decisions including the autonomous decision to participate in research; therefore, consent of relatives was not sought.

\section{Education}

In the Netherlands, most schools are state schools which are organized in primary, secondary and tertiary education tiers. From 4 until 12 years of age, all children receive 
primary education. After 12 years, children attend one of four levels of secondary education (low, intermediate, high preparatory vocational and pre-university); each level requires increasing intellectual and scholastic abilities. After passing the exams in secondary education, there are three possible levels of tertiary education (intermediate professional education, higher professional education and university).

Participants were asked to report their highest level of education and that of their parents, also if not completed. This conservative strategy was chosen as subjects with psychotic disorder are less likely to complete their education because of the emergence of psychotic symptoms (22)(mean age of onset was 25.0 in this study sample with a standard deviation of 6.5). Education was classified across 7 categories: Level 1: no education; Level 2: primary school; Level 3: lower secondary education; Level 4: intermediate professional education; Level 5: higher secondary education; Level 6: bachelor degree or equivalent (higher professional education); and Level 7: university (master degree).

\section{Childhood trauma}

Childhood trauma was assessed with the Dutch version of the Childhood Trauma Questionnaire Short Form (CTQ)(23). The short CTQ consists of 25 items rated on a 5-point Likert scale ( 1 = never true to 5 = very often true) enquiring about traumatic experiences in childhood. Five types of childhood maltreatment were assessed: emotional, physical and sexual abuse, and emotional and physical neglect, with five questions covering each type of trauma. The mean score for all 25 items was divided in tertiles (low, medium and high childhood trauma). The latter was used as the primary variable reflecting childhood trauma in the analyses. CTQ data were missing for 353 persons (23\% missing data).

\section{Level of Childhood Urbanicity}

A historical population density record was generated for each municipality from 1930 onwards using historical data from Statistics Netherlands and the equivalent database in Belgium $(24,25)$. When data was not available, missing data were calculated by linear extrapolation between two subsequent time-points. When historical names of municipalities disappeared from historical records (e.g. due to city mergers) the available data from the agglomerate city were used. Subjects were asked to describe where they had lived at birth, between ages 0-4 years; between 5-9 years; 10-14 years; $15-19$ years; 20 39 years; 40-59 years; and 60+ up to the actual age. This resulted in a number of records for each subject, containing locations by age period. For each of these records, we computed the average population density (by square kilometre, excluding water) of the municipality for the matching periods. Average population density over the period was categorized in accordance with the Dutch CBS urbanicity rating $\left(1=<500 / \mathrm{km}^{2} ; 2=500\right.$ - 


\section{Chapter 5}

$\left.1000 / \mathrm{km}^{2} ; 3=1000-1500 / \mathrm{km}^{2} ; 4=1500-2500 / \mathrm{km}^{2} ; 5=2500+/ \mathrm{km}^{2}\right)$. The periods $0-4$ years, 5-9 years and 10-14 years were collapsed to produce average urbanicity exposure between 0-14 years, rounded to the nearest whole number. Urbanicity data was missing for 132 persons ( $9 \%$ missing data).

\section{Statistical analyses}

All analyses were performed using Stata 12 (26). The main outcome variable was difference in educational level between the subject and highest level of education among the two parents (difference in education level (edu-dif) was calculated as: highest parental education - education subject).

To test whether edu-dif varied across patients with psychotic disorder, their healthy siblings and healthy controls and across categories of childhood trauma and childhood urbanicity, multilevel linear regression models were fitted with edu-dif as the dependent variable and group status (patient, sibling or control), childhood trauma (low, medium and high childhood trauma) and childhood urbanicity (5 levels of childhood urbanicity) as independent variables. Multilevel regression analysis was used to account for clustering of repeated measures within families, using the Stata XTMIXED command, with family ID modeled as the macro level. The regression coefficient (B) represents the effect size of the predictors and can be interpreted as the estimates in equivalent unilevel linear regression analysis. All independent variables were entered together as categorical variables recoded into dummy variables (model 1). In a separate analysis, independent variables were entered together as continuous variables in order to obtain linear associations (model 2). Age, sex and ethnicity were added as possible confounders. Age was added as confounder given that education, as well as access to education, may change over time. For the same reason, sex and ethnicity were added as (possible) confounders.

In order to study to what degree associations between edu-dif on the one hand and childhood trauma and childhood urbanicity on the other varied between patients, siblings and controls, two-way interactions between childhood trauma and group and between childhood urbanicity and group were added to the model of edu-dif separately (childhood trauma and childhood urbanicity are both variables with $\mathrm{n}$ categories, entered as a continuous variable and as $n-1$ dummy variables). In the case of significant interaction, stratified effect sizes were calculated by linear combination of the effects from the model containing the main effect and the interaction term using the Stata MARGINS routine. 


\section{RESULTS}

\section{Participants}

The total sample consisted of 629 patients with a diagnosis of non-affective psychotic disorder, 552 of their siblings and 326 control subjects. Sociodemographic and clinical characteristics of the final sample are summarized in Table 1 . The patients were younger and more often were male. The percentage of non-whites was higher in the patient group and the overall CTQ score and childhood urbanicity score were higher in the patient group. Patients and siblings had a significantly lower level of education than controls (controls: mean $=4.42, \mathrm{sd}=1.31$; siblings: mean $=4.24, \mathrm{sd}=1.43$; patients: mean $=3.76, \mathrm{sd}=1.48$; controls compared to patients: $p<0.001$; controls compared to siblings: $p=0.027)$. Parental education was significantly higher in the siblings compared to controls (controls: mean $=3.28, \mathrm{sd}=1.52$; siblings: mean $=3.81, \mathrm{sd}=1.71$, controls compared to siblings $p=0.004)$, and similarly directionally higher in the patients (patients: mean $=3.58, s d=1.77$, controls compared to patients $p=0.064$ ).

\section{Educational difference and main effects of group, childhood trauma and childhood urbanicity}

In all three groups, edu-dif had a negative value (Table 2, Figure 1), indicating that participants had a higher level of education than their parents. There was a significant association between group (linear trend) and edu-dif $(B=0.36, p<0.001)$. Edu-dif was significantly less negative in the patient group than in the control group $(B=0.77, p$ $<0.001$ ), while siblings were in-between the controls and the patients $(B=0.49, p=$ 0.001). The effect of maternal and paternal education was similar (maternal education: $B$ linear trend $=0.36, p<0.001$, patients: $B=0.77, p<0.001$, siblings: $B=0.43, p=0.003$; paternal education: $B$ linear trend $=0.34, p<0.001$, patients: $B=0.77, p<0.001$, siblings: $B=0.54, p<0.001)$.

Edu-dif was not associated with childhood trauma ( $B$ linear trend $=0.07, p=0.279$; Table 2). Childhood urbanicity was significantly associated with edu-dif (B linear trend = $0.11, p=0.002$ ), the main contrast being between urbanicity level 1 and the other 4 categories (Table 2, Figure 2).

\section{Interaction between group and childhood trauma or childhood urbanicity}

There was no evidence that associations between edu-dif and environmental risks differed by group (Table 3). 


\section{Chapter 5}

Table 1. Subject demographics

\begin{tabular}{|c|c|c|c|}
\hline & $\begin{array}{l}\text { Patients } \\
(n=629)\end{array}$ & $\begin{array}{l}\text { Siblings } \\
(n=552)\end{array}$ & $\begin{array}{l}\text { Controls } \\
(n=326)\end{array}$ \\
\hline Age $( \pm S D)$ & $30.8 \pm 7.0$ & $31.6 \pm 7.4$ & $35.6 \pm 9.0$ \\
\hline Sex $n(\%)$, male & $484(77.0)$ & $248(44.9)$ & $131(40.2)$ \\
\hline \multicolumn{4}{|l|}{ Ethnicity } \\
\hline Caucasian n (\%) & $484(77.0)$ & $462(83.7)$ & $299(91.7)$ \\
\hline Other $n(\%)$ & $145(23.1)$ & $90(16.3)$ & $27(8.3)$ \\
\hline Childhood Urbanicity ${ }^{a}$ & $2.9 \pm 1.6$ & $2.7 \pm 1.5$ & $2.7 \pm 1.6$ \\
\hline $\mathrm{CTQ}( \pm \mathrm{SD})$ & $1.6 \pm 0.5$ & $1.4 \pm 0.4$ & $1.4 \pm 0.4$ \\
\hline \multicolumn{4}{|l|}{ Education n (\%) } \\
\hline No education \& primary school & $7(1.2)$ & $4(0.8)$ & $2(0.6)$ \\
\hline Lower secondary education & $154(25.0)$ & $69(13.1)$ & $26(8.1)$ \\
\hline Intermediate professional education & $143(23.3)$ & $129(24.5)$ & $68(21.1)$ \\
\hline Higher secondary education & $80(13.1)$ & $38(7.2)$ & $34(10.6)$ \\
\hline Bachelor or equivalent & $132(21.5)$ & $165(31.4)$ & $122(37.9)$ \\
\hline Master or equivalent & $99(16.1)$ & $121(23.0)$ & $70(21.7)$ \\
\hline \multicolumn{4}{|l|}{ Highest parental education n (\%) } \\
\hline No education \& primary school & $57(9.8)$ & $28(5.5)$ & $17(5.3)$ \\
\hline Lower secondary education & $159(27.2)$ & $146(28.2)$ & $124(39.0)$ \\
\hline Intermediate professional education & $97(16.6)$ & $75(14.5)$ & $53(16.7)$ \\
\hline Higher secondary education & $34(5.8)$ & $25(4.8)$ & $28(8.8)$ \\
\hline Bachelor or equivalent & $121(20.7)$ & $132(25.5)$ & $67(21.1)$ \\
\hline Master or equivalent & $116(19.9)$ & $112(21.6)$ & $29(9.1)$ \\
\hline \multicolumn{4}{|l|}{ Diagnosis n (\%) } \\
\hline Schizophrenia/schizophreniform & $456(73.2)$ & & \\
\hline Schizoaffective disorder & $74(11.9)$ & & \\
\hline Brief psychotic disorder & $10(1.6)$ & & \\
\hline Delusional disorder & $8(1.3)$ & & \\
\hline Substance induced psychotic disorder & $5(0.8)$ & & \\
\hline Psychotic disorder NOS & $55(8.8)$ & & \\
\hline Psychotic Disorder Due to Medical Condition & $1(0.2)$ & & \\
\hline Mood disorder & $11(1.8)$ & & \\
\hline Delirium & $1(0.2)$ & & \\
\hline Substance related disorder & $1(0.2)$ & & \\
\hline
\end{tabular}

${ }^{\mathrm{a}}$ Five levels of urbanicity/population density $1=<500$ inhabitants $/ \mathrm{km} 2 ; 2=500-1000$ inhabitants $/ \mathrm{km} 2 ; 3=$ inhabitants 1000-1500/km2; $4=$ inhabitants 1500-2500/ $/ \mathrm{km} 2 ; 5=2500+/ \mathrm{km}$

$\mathrm{CTQ}=$ Childhood Trauma Questionnaire 
Psychotic disorder and educational achievement: a family-based analysis

Table 2. Educational difference between highest level of parental education and subject education

\begin{tabular}{|c|c|c|c|c|c|c|}
\hline & $n$ & Mean (SD) & $B(p)^{a}$ & $\mathrm{Cl}$ & \multicolumn{2}{|c|}{$\mathrm{B}$ linear trend $(p)^{\mathrm{b}} \mathrm{Cl}$} \\
\hline \multicolumn{7}{|l|}{ Group } \\
\hline Controls & 315 & $-1.14(1.57)$ & & & & \\
\hline Siblings & 510 & $-0.47(1.61)$ & $0.49(0.001)$ & $0.21-0.76$ & & \\
\hline Patients & 581 & $-0.25(1.75)$ & $0.77(<0.001)$ & $0.48-1.06$ & $0.36(<0.001)$ & $0.21-0.50$ \\
\hline \multicolumn{7}{|c|}{ Childhood Trauma } \\
\hline Low & 497 & $-0.73(1.56)$ & & & & \\
\hline Medium & 364 & $-0.61(1.61)$ & $0.07(0.56)$ & $-0.16-0.30$ & & \\
\hline High & 416 & $-0.46(1.67)$ & $0.12(0.34)$ & $-0.12-0.36$ & $0.07(0.279)$ & $-0.05-0.19$ \\
\hline \multicolumn{7}{|l|}{ Urbanicity $^{c}$} \\
\hline Level 1 & 462 & $-0.82(1.67)$ & & & & \\
\hline Level 2 & 321 & $-0.47(1.61)$ & $0.43(0.002)$ & $0.16-0.71$ & & \\
\hline Level 3 & 159 & $-0.17(1.66)$ & $0.68(<0.001)$ & $0.33-1.03$ & & \\
\hline Level 4 & 173 & $-0.47(1.61)$ & $0.49(0.007)$ & $0.13-0.84$ & & \\
\hline Level 5 & 335 & $-0.58(1.72)$ & $0.46(0.002)$ & $0.17-0.74$ & $0.11(0.002)$ & $0.04-0.18$ \\
\hline
\end{tabular}

SD standard deviation

B represents the regression coefficients from multilevel linear regression analyses, adjusted for age, sex and ethnicity

Cl 95\% confidence interval

${ }^{a}$ Model 1: All independent variables entered as categorical variables recoded into dummy variables

${ }^{b}$ Model 2: All independent variables entered as categorical variables comprised in a linear model

${ }^{\mathrm{c}}$ Five levels of urbanicity $/$ population density $1=<500$ inhabitants $/ \mathrm{km}^{2} ; 2=500-1000$ inhabitants $/ \mathrm{km}^{2} ; 3=$ inhabitants $1000-1500 / \mathrm{km}^{2} ; 4=$ inhabitants $1500-2500 / \mathrm{km}^{2} ; 5=2500+/ \mathrm{km}$

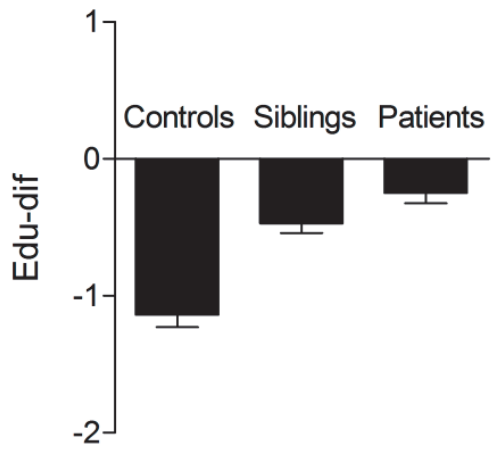

Figure 1. Educational difference (edu-dif) between highest level of parental education and subject education in controls, siblings and patients. Represented values are population means and standard error of the mean. 


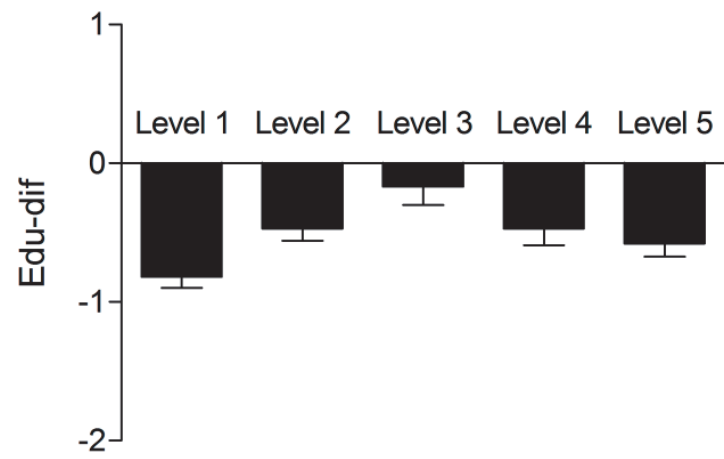

Figure 2. Educational difference (edu-dif) between highest level of parental education and subject education across five levels of urbanicity. Represented values are population means and standard error of the mean.

Table 3. Chi square tests of interaction between group status (patients, sibling or control) and childhood trauma or childhood urbanicity ${ }^{\mathrm{a}}$ in the model predicting educational difference.

\begin{tabular}{llll}
\hline & $\chi^{2 b}$ & $\mathrm{Df}^{\mathrm{c}}$ & $\mathrm{p}$ \\
\hline Childhood trauma $^{2}$ & 2.37 & 2 & 0.31 \\
Childhood trauma- dummy $^{\mathrm{d}}$ & 3.25 & 4 & 0.52 \\
Urbanicity $^{\text {Urbanicity-dummy }}$ & 1.67 & 2 & 0.43 \\
\hline
\end{tabular}

${ }^{a}$ Childhood trauma and childhood urbanicity are both categorical variables with $n$ categories, entered both as a continuous variable and as $\mathrm{n}-1$ dummy variables

${ }^{\mathrm{b}}$ Chi-square

${ }^{\mathrm{c}}$ Degrees of freedom

${ }^{\mathrm{d}}$ Childhood trauma scores divided in tertiles (low, medium, high)

${ }^{\mathrm{e}}$ Five levels of urbanicity/population density $1=<500$ inhabitants $/ \mathrm{km}^{2} ; 2=500-1000$ inhabitants $/ \mathrm{km}^{2} ; 3=$ inhabitants $1000-1500 / \mathrm{km}^{2} ; 4=$ inhabitants $1500-2500 / \mathrm{km}^{2} ; 5=2500+/ \mathrm{km}$

\section{DISCUSSION}

Educational difference (edu-dif) between subjects and their parents was studied in groups of psychotic patients, healthy siblings and healthy controls. Overall, participants had a higher level of education than their parents. This difference was significantly less in the patient group and the healthy siblings were in between the controls and the patients. Further it was tested whether edu-dif was influenced by childhood trauma and childhood urbanicity, and if this was different for patients, siblings and controls. Only childhood urban exposure had a significant influence on edu-dif: higher levels of childhood urban exposure were associated with a smaller increase in educational level. There was no evidence that this association differed for patients, siblings or controls.

In all three groups, participants had a higher level of education than their parents. A reasonable explanation for this is development of education and growing availability of 
education over time. Patients and siblings had a smaller increase in educational level than the healthy controls. This is in line with previous research indicating early cognitive alterations in psychotic disorder $(4,5)$ and also with research on alterations in cognitive functioning in first degree relatives of patients with psychotic disorder (8-10, 27). Previous research on scholastic achievements in psychotic disorder is not consistent (28). To the best of our knowledge, this is the first study to include siblings, thus shedding light on possible mediation by familial factors including genetic factors.

Our findings could be explained by several hypotheses. One plausible explanation is that early alterations in cognition, in patients and in siblings, may lead to problems in school functioning and eventually to lower levels of education. A second explanation is that altered social cognition, a specific part of cognitive functioning, that is not only impaired in psychotic disorder(29), but also in persons at genetic and clinical high risk for psychosis (30-32), elevates stress and lowers school performance. A third explanation is that the siblings of patients with a psychotic disorder receive less parental attention and guidance through their school development, as a negative consequence of the worries and attention focussed on the (pre)psychotic sib.

We did not find childhood trauma to influence intergenerational educational differential, in contrast with existing literature. Childhood trauma is associated with lower academic performance $(33,34)$, adverse effects on educational attainment (35), and academic delay (34). Boden and colleagues(14) also found that physical and sexual abuse negatively affected educational achievements, but this was largely explained by social, family and individual factors, after taking parental and maternal education into account. In this study, educational level was assessed relative to parental education, which could explain why there was no significant difference.

To our knowledge there are no other studies on childhood urban exposure and scholastic achievements. However, factors associated with the urban environment and school performance have been examined previously and are in line with our results: urban noise exposure has a negative effect on school performance (36) and lower perceived safety of schools and neighborhoods deteriorates school performance (37). Another explanation is the disappearance of small village schools and the subsequent emergence of larger schools with more pupils (38). For pupils, such a larger scaled social study environment may have negative effects on school performance.

Childhood urbanicity and childhood trauma were not differentially associated with educational differences across psychotic patients, siblings, and in controls. This makes it unlikely that childhood trauma and childhood urbanicity influence the effect of group on educational difference, in a positive or negative way.

\section{Methodological considerations}

Some limitations need to be addressed. The cross-sectional nature of the current data makes it impossible to establish a causal relationship between group status, childhood 


\section{Chapter 5}

trauma or childhood urbanicity and edu-dif; this was not the purpose of the study. Second, highest level of started education was studied, regardless of whether this was completed. This conservative approach was chosen because patients with psychotic disorder are less likely to complete education after the onset of psychotic symptoms (22). Thus, studying completed education is more likely to measure the effect of psychotic symptoms, and not of early cognitive alterations, on educational achievement. Another approach could have been to compare grades in for example primary education, however grading systems may have changed over time and not all schools may use the same grading system, making this an inaccurate measure. Further, not all factors that could possibly affect school performance were taken into account, for example family income and other non-educational factors associated with socio-economic status, or obstetric and perinatal complications. However, school attendance in the Netherlands is not dependent on income as there is universal free schooling. Fourth, the higher level of parental education for the siblings and at trend-level for the patients may have been the result of underlying selections, which could have influenced our results. However, the regression coefficients for the difference in parental education are smaller than the regression coefficients of edu-dif, which makes it unlikely that possible selection is the only explanation of the observed difference in edu-dif. Finally, the participants grew up in the Netherlands and Belgium which can be described as relatively safe and developed countries; in other counties, urban-rural discrepancies may be more prominent.

\section{Conclusion}

Patients with psychotic disorder, and to a lesser extent their healthy siblings, had a smaller increase in educational level compared with their parents than healthy controls. Although these group differences cannot be used to identify groups at high risk, it does provide a general perspective in thinking about inter-generational processes in educational achievement in the context of risk for psychosis. More work is required to better understand the dynamics between early social and cognitive alterations in those at risk in relation to progress through the educational system. Higher levels of childhood urbanicity were also associated with a smaller increase in educational level. As more people are residing in urbanised areas (39), more work is required to understand the interaction between urban environment and educational outcomes including school size, class size, level of individual educational support and class dynamics. 


\section{REFERENCES}

1. Keefe RS, Eesley CE, Poe MP. Defining a cognitive function decrement in schizophrenia. Biological psychiatry. 2005;57(6):688-91.

2. Schaefer J, Giangrande E, Weinberger DR, Dickinson D. The global cognitive impairment in schizophrenia: consistent over decades and around the world. Schizophrenia research. 2013;150(1):42-50.

3. Aas M, Dazzan P, Mondelli V, Melle I, Murray RM, Pariante CM. A systematic review of cognitive function in first-episode psychosis, including a discussion on childhood trauma, stress, and inflammation. Frontiers in psychiatry. 2014;4:182.

4. Reichenberg A, Caspi A, Harrington H, Houts R, Keefe RS, Murray RM, et al. Static and dynamic cognitive deficits in childhood preceding adult schizophrenia: a 30-year study. The American journal of psychiatry. 2010;167(2):160-9.

5. Keefe RS. The longitudinal course of cognitive impairment in schizophrenia: an examination of data from premorbid through posttreatment phases of illness. The Journal of clinical psychiatry. 2014;75 Suppl 2:8-13.

6. Green MF, Kern RS, Heaton RK. Longitudinal studies of cognition and functional outcome in schizophrenia: implications for MATRICS. Schizophrenia research. 2004;72(1):41-51.

7. Fervaha G, Zakzanis KK, Foussias G, Graff-Guerrero A, Agid O, Remington G. Motivational deficits and cognitive test performance in schizophrenia. JAMA psychiatry. 2014;71(9):1058-65.

8. Mclntosh AM, Harrison LK, Forrester K, Lawrie SM, Johnstone EC. Neuropsychological impairments in people with schizophrenia or bipolar disorder and their unaffected relatives. The British journal of psychiatry : the journal of mental science. 2005;186:378-85.

9. Cannon TD, Huttunen MO, Lonnqvist J, Tuulio-Henriksson A, Pirkola T, Glahn D, et al. The inheritance of neuropsychological dysfunction in twins discordant for schizophrenia. American journal of human genetics. 2000;67(2):369-82.

10. Hughes C, Kumari V, Das M, Zachariah E, Ettinger U, Sumich A, et al. Cognitive functioning in siblings discordant for schizophrenia. Acta psychiatrica Scandinavica. 2005;111(3):185-92.

11. MacCabe JH, Lambe MP, Cnattingius S, Torrang A, Bjork C, Sham PC, et al. Scholastic achievement at age 16 and risk of schizophrenia and other psychoses: a national cohort study. Psychological medicine. 2008;38(8):1133-40.

12. Isohanni I, Jarvelin MR, Nieminen P, Jones $P$, Rantakallio P, Jokelainen J, et al. School performance as a predictor of psychiatric hospitalization in adult life. A 28-year follow-up in the Northern Finland 1966 Birth Cohort. Psychological medicine. 1998;28(4):967-74.

13. Cannon M, Jones $\mathrm{P}$, Huttunen MO, Tanskanen A, Huttunen $\mathrm{T}$, Rabe-Hesketh $\mathrm{S}$, et al. School performance in Finnish children and later development of schizophrenia: a population-based longitudinal study. Archives of general psychiatry. 1999;56(5):457-63.

14. Boden JM, Horwood LJ, Fergusson DM. Exposure to childhood sexual and physical abuse and subsequent educational achievement outcomes. Child abuse \& neglect. 2007;31(10):1101-14.

15. Arpi E, Ferrari F. Preterm birth and behaviour problems in infants and preschool-age children: a review of the recent literature. Developmental medicine and child neurology. 2013;55(9):788-96.

16. Hadders-Algra M, Huisjes HJ, Touwen BC. Perinatal risk factors and minor neurological dysfunction: significance for behaviour and school achievement at nine years. Developmental medicine and child neurology. 1988;30(4):482-91.

17. Hadders-Algra M, Huisjes HJ, Touwen BC. Perinatal correlates of major and minor neurological dysfunction at school age: a multivariate analysis. Developmental medicine and child neurology. 1988;30(4):472-81.

18. Talreja BT, Shah S, Kataria L. Cognitive function in schizophrenia and its association with sociodemographics factors. Industrial psychiatry journal. 2013;22(1):47-53.

19. Sapolsky RM, Krey LC, McEwen BS. The neuroendocrinology of stress and aging: the glucocorticoid cascade hypothesis. Endocrine reviews. 1986;7(3):284-301. 


\section{Chapter 5}

20. Genetic Risk and Outcome in Psychosis (GROUP) investigators. Evidence that familial liability for psychosis is expressed as differential sensitivity to cannabis: an analysis of patient-sibling and siblingcontrol pairs. Archives of general psychiatry. 2011;68(2):138-47.

21. Statistics Netherlands. Jaarboek Onderwijs in Cijfers. The Hague: Central Bureau of Statistics Publications; 2011.

22. Isohanni I, Jones PB, Jarvelin MR, Nieminen P, Rantakallio P, Jokelainen J, et al. Educational consequences of mental disorders treated in hospital. A 31-year follow-up of the Northern Finland 1966 Birth Cohort. Psychological medicine. 2001;31(2):339-49.

23. Bernstein DP, Ahluvalia T, Pogge D, Handelsman L. Validity of the Childhood Trauma Questionnaire in an adolescent psychiatric population. Journal of the American Academy of Child and Adolescent Psychiatry. 1997;36(3):340-8.

24. Statistics Netherlands. Bevolking der Gemeenten van Nederland. The Hague: Central Bureau of Statistics publications; 1993.

25. Venkatasubramanian G, Jayakumar PN, Keshavan MS, Gangadhar BN. Schneiderian first rank symptoms and inferior parietal lobule cortical thickness in antipsychotic-naive schizophrenia. Prog Neuropsychopharmacol Biol Psychiatry. 2011;35(1):40-6.

26. StataCorp. Stata Statistical Software. Release 10.0 ed: College Station, TX: Stata Corporation; 2007.

27. Cannon TD, Bearden CE, Hollister JM, Rosso IM, Sanchez LE, Hadley T. Childhood cognitive functioning in schizophrenia patients and their unaffected siblings: a prospective cohort study. Schizophrenia bulletin. 2000;26(2):379-93.

28. Welham J, Isohanni M, Jones P, McGrath J. The antecedents of schizophrenia: a review of birth cohort studies. Schizophrenia bulletin. 2009;35(3):603-23.

29. Kohler CG, Walker JB, Martin EA, Healey KM, Moberg PJ. Facial emotion perception in schizophrenia: a meta-analytic review. Schizophrenia bulletin. 2010;36(5):1009-19.

30. Kohler CG, Richard JA, Brensinger CM, Borgmann-Winter KE, Conroy CG, Moberg PJ, et al. Facial emotion perception differs in young persons at genetic and clinical high-risk for psychosis. Psychiatry research. 2014.

31. Bediou B, Asri F, Brunelin J, Krolak-Salmon P, D'Amato T, Saoud M, et al. Emotion recognition and genetic vulnerability to schizophrenia. The British journal of psychiatry : the journal of mental science. 2007;191:126-30.

32. Lavoie MA, Plana I, Bedard Lacroix J, Godmaire-Duhaime F, Jackson PL, Achim AM. Social cognition in first-degree relatives of people with schizophrenia: a meta-analysis. Psychiatry research. 2013;209(2):129-35.

33. Holt MK, Finkelhor D, Kantor GK. Multiple victimization experiences of urban elementary school students: associations with psychosocial functioning and academic performance. Child abuse \& neglect. 2007;31(5):503-15.

34. Kurtz PD, Gaudin JM, Jr., Wodarski JS, Howing PT. Maltreatment and the school-aged child: school performance consequences. Child abuse \& neglect. 1993;17(5):581-9.

35. Tanaka M, Georgiades K, Boyle MH, MacMillan HL. Child Maltreatment and Educational Attainment in Young Adulthood: Results From the Ontario Child Health Study. Journal of interpersonal violence. 2014.

36. Pujol S, Levain JP, Houot H, Petit R, Berthillier M, Defrance J, et al. Association between ambient noise exposure and school performance of children living in an urban area: a cross-sectional population-based study. Journal of urban health : bulletin of the New York Academy of Medicine. 2014;91(2):256-71.

37. Milam AJ, Furr-Holden CDM, Leaf PJ. Perceived school and neighborhood safety, neighborhood violence and academic achievement in urban school children. Urban Rev. 2010;42:458-67.

38. Statistics Netherlands. Jaarboek onderwijs in cijfers 2012. The Hague: Central Bureau of Statistics publications; 2012.

39. United Nations Population Fund. State of world population 2011: People and possibilities in a wordl of 7 billion. New York: United Nations Population Fund; 2011. 


\section{Chapter 6}

\section{No evidence of association between childhood urban environment and cortical thinning in psychotic disorder}

Authors: Aleida Frissen ${ }^{1}$, Jim van Os ${ }^{1,2}$, Ritsaert Lieverse ${ }^{1}$, Petra Habets ${ }^{1}$, Ed Gronenschild ${ }^{1}$, Machteld Marcelis ${ }^{1,3^{*}}$ for Genetic Risk and Outcome in Psychosis (G.R.O.U.P.)

${ }^{1}$ Department of Psychiatry and Psychology, Maastricht University, The Netherlands,

${ }^{2}$ King's College London, King's Health Partners, Department of Psychosis Studies, Institute of Psychiatry, London, United Kingdom

${ }^{3}$ Institute for Mental Health Care Eindhoven (GGzE), Eindhoven, The Netherlands

PLOS ONE, in press 


\section{Chapter 6}

\section{ABSTRACT}

\section{Background}

The alterations in cortical morphology, such as cortical thinning, observed in psychotic disorder, may be the outcome of interacting genetic and environmental effects. It has been suggested that urban upbringing may represent a proxy environmental effect impacting cortical thickness (CT). Therefore, the current study examined whether the association between group as a proxy genetic variable (patients with psychotic disorder [high genetic risk], healthy siblings of patients [intermediate risk] and healthy control subjects [average risk]) and CT was conditional on different levels of the childhood urban environment and whether this was sex-dependent.

\section{Methods}

T1-weighted MRI scans were acquired from 89 patients with a psychotic disorder, 95 non-psychotic siblings of patients with psychotic disorder and 87 healthy control subjects. Freesurfer software was used to measure CT. Developmental urban exposure was classified as low, medium, and high, reflecting the population density and the number of moves between birth and the $15^{\text {th }}$ birthday, using data from the Dutch Central Bureau of Statistics and the equivalent database in Belgium. Multilevel regression analyses were used to examine the association between group, sex, and urban upbringing (as well as their interactions) and cortical CT as the dependent variable.

\section{Results}

CT was significantly smaller in the patient group compared to the controls $(B=-0.043, p$ $<0.001)$, but not in the siblings compared to the controls $(B=-0.013, p=0.31)$. There was no main effect of developmental urbanicity on $C T(B=0.001, p=0.91)$. Neither the three-way group $\times$ urbanicity $\times$ sex interaction $\left(\chi^{2}=3.73, p=0.16\right)$, nor the two-way group $\times$ urbanicity interaction was significant $\left(\chi^{2}=0.51, p=0.77\right)$.

\section{Conclusion}

The negative association between (familial risk for) psychotic disorder and CT was not moderated by developmental urbanicity, suggesting that reduced CT is not the outcome of familial sensitivity to the proxy environmental factor 'urban upbringing'. 


\section{INTRODUCTION}

Childhood urban environment is one of the (proxy) environmental risk factors for psychotic disorder. Both urban birth and urban upbringing have been found to contribute to the risk (1-5), with meta-analytic evidence for a dose-response relationship $(3,6,7)$. The vulnerable period of impact is specific to childhood and adolescence $(8,9)$ and the effect of the urban environment may be conditional on the genetic risk for psychotic disorder (10-12). The urban environment is a proxy risk factor, likely reflecting a complex environment. The factors associated with the urban environment that mediate this effect, as well as the neurobiological pathways involved, remain largely unknown. Candidate mechanisms include higher level of perceived social isolation in urban areas (13) and greater exposure to social "defeat" occasioned by higher level of competition in cities (14).

Reduced cortical thickness (CT) has frequently been observed in patients with psychotic disorder and to a certain extent also in their healthy relatives, suggesting that cortical thinning may represent neurodevelopmental alterations that result from a genetic liability for the disorder (15-21). Regions frequently affected are the frontal, temporal and cingulate cortex $(19,21-25)$. However, not all reports are consistent with regard to the presence of a CT intermediate phenotype. For example Boos and colleagues did not reveal cortical thinning in siblings of patients with schizophrenia (19, 26-28). Thus, these studies suggest that the cortical abnormalities in psychotic disorder reflect a disease-related process or differential sensitivity to environmental risks. Indeed, there are some studies which support the hypothesis that reduced CT may be the outcome of differential sensitivity to the environment, though studies are scarce. For example, previous analyses on the current study sample showed that lower CT was associated with higher levels of cannabis use in both patients with psychotic disorder and siblings, and with higher levels of childhood trauma in patients, but not siblings (29). Another study reported that fetal hypoxia was related to reduced gray matter volume and increased cerebrospinal fluid in patients with schizophrenia and their healthy relatives, but not in control (30). To our knowledge, there are no studies with developmental urban exposure as a risk factor and structural brain measures as the outcome in patients with psychotic disorder. However, there are two studies examining the effect of developmental urbanicity in healthy volunteers: Haddad and colleagues showed that developmental urbanity was associated with a decrease in gray matter volume in the dorsolateral prefrontal cortex and a decrease in gray matter volume of the perigenual anterior cingulate cortex (pACC) in men only (31); and Lederbogen and colleagues found that urban upbringing was related to altered activity of the perigenual anterior cingulate cortex, a key region for the regulation of negative affect and stress (32).

Developmental urbanicity has been linked to early life stress through higher levels of social isolation (13) and social defeat (14). Such a form of early life stress may be associated with cerebral alterations, as suggested by evidence from human (33-35) and ani- 


\section{Chapter 6}

mal studies (36-39). The underlying biological mechanisms may comprise hypothalamicpituitary-adrenal axis (HPA-axis) alterations, which could have direct effects (through increased cortisol levels (40)) and indirect effects (by affecting dopaminergic circuits $(41,42)$ ). Excessive dopamine (DA) is associated with DNA damage and apoptosis (43, 44 ) and stimulation of the D1 dopamine receptor might also cause neurodegeneration the striatum (45).

In conclusion, CT alterations may be the consequence of underlying operational mechanisms, such as gene-environment interactions. The hypothesis of this study was that the association between $\mathrm{CT}$, the outcome of interest in the current study, and group (patients with psychotic disorder, healthy siblings of patients and healthy control subjects), is conditional on exposure to developmental urbanicity in patients with psychotic disorder (highest genetic risk) and, to a lesser degree, in their healthy siblings (intermediate genetic risk). This phenomenon would thus be suggestive of geneenvironment interaction (GXE), or genetic control of sensitivity to the environment. Given that structural brain alterations may be more prominent in male patients(46), interactions with sex were included in the analyses.

\section{MATERIALS AND METHODS}

\section{Participants}

Data pertain to baseline measures of a longitudinal magnetic resonance imaging (MRI) study in Maastricht, the Netherlands. The sample consisted of 89 patients with a diagnosis of a non-affective psychotic disorder, 95 siblings, and 87 control subjects. Inclusion criteria for the patient group were the following: (1) age 16 to 50 years; (2) diagnosis of non-affective psychotic disorder; and (3) sufficient command of the Dutch language. Sibling non-patient status was defined as the absence of any lifetime psychotic disorder. Controls had no first-degree relative with a psychotic disorder as established by the Family Interview for Genetic Studies (47) with the control as informant. The sample included 63 families, of which 39 families contributed one patient and one discordant sibling, two families contributed one patient and two discordant siblings, and two families contributed one patient and three discordant siblings. Two families contributed two patients, seven families contributed two discordant siblings, and one family contributed three discordant siblings. In the control group, ten families contributed two siblings. In addition, 42 independent patients, 29 independent siblings, and 66 independent control subjects were included.

Diagnosis was based on DSM-IV criteria (48), assessed with the Comprehensive Assessment of Symptoms and History (CASH) interview (49). The CASH was also used to confirm the absence of a diagnosis of non-affective psychosis in the siblings and ab- 
sence of a lifetime diagnosis of any psychotic disorder or any current affective disorder in the healthy control subjects.

Before MRI acquisition, participants were screened for the following exclusion criteria: (1) brain injury (unconsciousness > 1 hour); (2) meningitis or other neurological diseases that might have affected brain structure or function; (3) cardiac arrhythmia requiring medical treatment; and (4) severe claustrophobia. In addition, subjects with metal corpora aliena were excluded from the study, as were women with intrauterine device status and (suspected) pregnancy. The selection procedure and the in- and exclusion criteria are described more elaborate in a previous paper (29).

The study was approved centrally by the Ethical Review Board of the University Medical Centre Utrecht. Written informed consent was obtained from all subjects after they (1) read a document with detailed information about the nature and possible consequences of the study; (2) had verbally discussed any possible concerns with the researcher; and (3) had provided clear indication that they had understood the procedure. In the Netherlands, adult patients with mental illness are considered participating citizens who have the right to make independent informed decisions including the autonomous decision to participate in research; therefore consent of relatives was not sought (as described previously (29)) .

\section{MEASURES}

The level of symptoms in all groups was assessed with the Positive and Negative Syndrome Scale (PANSS)(50). Educational level was defined as highest accomplished level of education. In the patient group, antipsychotic (AP) medication use was determined by the patient's report and verified with the treating consultant psychiatrist. Best estimate lifetime (cumulative) AP use was determined by multiplying the number of days of AP use with the corresponding haloperidol equivalents and summing these scores for all periods of AP use (including the exposure period between baseline assessment for the G.R.O.U.P. study and the moment of baseline MRI scanning), using the recently published converting formulas for AP dose equivalents described by Andreasen et al (51).

Substance use was measured with the Composite International Diagnostic Interview (CIDI) sections B-J-L(52). Use of cannabis and other drugs was assessed as reported frequency of use during the last 12 months, as well as lifetime use. CIDI frequency data on cannabis and other drug use was available for respectively 263 participants (3\% missing data) and 267 participants (1.5\% missing data). Alcohol use was defined as the reported number of weekly consumptions during the last 12 months. CIDI frequency data on alcohol use were available 235 participants (13.3\% missing data).

Childhood trauma was assessed with the Dutch version of the Childhood Trauma Questionnaire Short Form (CTQ)(53). The short CTQ consists of 25 items rated on a 5point Likert scale ( 1 = never true to 5 = very often true) inquiring about traumatic expe- 


\section{Chapter 6}

riences in childhood. Five types of childhood maltreatment were assessed: emotional, physical and sexual abuse, and emotional and physical neglect, with five questions covering each type of trauma. As a general measure of childhood trauma, a summary score was created by adding the mean scores of each trauma type. The CTQ data were missing for two persons (0.7\% missing data), as described in a previous study (29).

\section{Level of Urbanicity}

We generated a historical population density record for each municipality from 1930 onwards using the Dutch Central Bureau of Statistics (CBS) and equivalent Belgium database. When data was not available, linear extrapolations were computed. When historical names of municipalities disappeared from historical records (e.g. due to city mergers) we used the available data from the agglomerate city. Subjects were asked to describe where they lived during their life. This resulted in a number of records for each subject, containing locations by age period. For each of these records, we computed the average population density (by square kilometer, excluding water) of the municipality for the matching year periods. Subsequently, it was determined where the subject lived at birth, between ages 0-4 years; between 5-9 years; 10-14 years; 15-19 years; 20-39 years; $40-59$ years; and 60+ up to the actual age. Average population density over the period was categorized conform the Dutch CBS urbanicity rating $\left(1=<500 / \mathrm{km}^{2} ; 2=500\right.$ $\left.1000 / \mathrm{km}^{2} ; 3=1000-1500 / \mathrm{km}^{2} ; 4=1500-2500 / \mathrm{km}^{2} ; 5=2500+/ \mathrm{km}^{2}\right)$. The periods $0-4$ years, 5-9 years and 10-14 years were merged to average urbanicity exposure between 0-14 years. The latter divided by its tertiles was used as the primary variable reflecting developmental urbanicity exposure (low, medium, high) in the analyses. Urbanicity data were available for 263 participants (3.0 \% missing data). This urbanicity measures was also described in a previous paper (54).

\section{MRI Acquisition and Processing}

The MRI scans were acquired using a 3T Siemens scanner (Erlangen, Germany) and the following acquisition parameters: Modified Driven Equilibrium Fourier Transform $(\mathrm{MDEFT})$ sequence $=176$ slices, $1 \mathrm{~mm}$ isotropic voxel size, echo time $2.4 \mathrm{~ms}$, repetition time $7.92 \mathrm{~ms}$, inversion time $910 \mathrm{~ms}$, flip angle 15\%, total acquisition time $12 \mathrm{~min} 51 \mathrm{~s}$; Magnetization Prepared Rapid Acquisition Gradient-Echo (MPRAGE; Alzheimer's Disease Neuroimaging Initiative) sequence = 192 slices, $1 \mathrm{~mm}$ isotropic voxel size, echo time 2.6 ms, repetition time $2250 \mathrm{~ms}$, inversion time $900 \mathrm{~ms}$, flip angle $9^{\circ}$, total acquisition time $7 \mathrm{~min} 23 \mathrm{~s}$. For both anatomical scans, the matrix size was $256 \times 256$ and field of view was $256 \times 256 \mathrm{~mm}^{2}$. The number of excitations was one. Two sequences were used because of a scanner update during data collection. The total proportion of MPRAGE scans did not differ between the groups $\left(\chi^{2}=4.95, p=0.08\right)$. 


\section{Cortical Thickness Measurement}

Scans were processed and analyzed using Freesurfer stable release v5.3.0, http://surfer.nmr.mgh.harvard.edu (55-61). To measure CT, the cerebral cortex was parcellated into units based on gyral and sulcal structure $(62,63)$. Furthermore, a variety of surface-based data was created including maps of curvature and sulcal depth. This method used both intensity and continuity information from the entire three dimensional MR volume in segmentation and deformation procedures to produce representations of $\mathrm{CT}$, calculated as the closest distance from the gray/white matter boundary to the gray matter/CSF boundary at each vertex on the tessellated surface (56). The maps were created using spatial intensity gradients across tissue classes and were not restricted to the voxel resolution of the original data, thus were capable of detecting sub-millimeter differences between groups. CT measurement procedures have been validated against histological analysis (64) and manual measurements $(18,65)$. Per hemisphere there are 34 regions (68 in total) of interest (adapted from the Desikant atlas) (62); for each of these regions, CT measurements were derived by FreeSurfer and exported to Stata and R version 3.2.1. Thus, every individual had 68 CT measurements over the predefined ROls. These procedures are described in detail in a previous paper (29).

\section{Statistical/data analyses}

The CT data consist of multiple observations nested within persons and within families, generating 3 levels of analysis: 68 regional CT measures (level 1) nested in subjects (level 2) who were part of the same families (level 3) (66). Given the multilevel hierarchical structure of the data, compromising statistical independence of the observations, multilevel linear regression analyses were performed with CT as the dependent variable and subject number and family ID as random effects in all analyses. R version 3.2.1 (67) was used, employing the nlme, car and multcomp packages. Since the outcome (CT) represents means (based on varying numbers of vertices), the analyses were weighted based on the number of vertices per region. The regression coefficients (B) from the multilevel linear regression model represent the effect size of the predictors and can be interpreted identically to estimates in equivalent unilevel linear regression analyses. To check assumption of normality qq-plots of the residuals were inspected, which showed an even distribution. Also, the spread of standardized residuals against fitted values was evaluated, which was constant, i.e. there was no evidence of heteroscedasticity.

In order to study whether there is differential sensitivity to developmental urbanicity in the three groups and in both sexes, a three-way interaction between group (healthy control subject $=0$, sibling $=1$ or patient $=2$, entered as linear variable and as dummy variables with healthy control subject as the reference category), sex (male $=0$ or female $=1$ ) and developmental urbanicity (low =0, medium $=1$ or high $=2$, entered both as a linear variable and as dummy variables with 'low' urbanicity as the reference 


\section{Chapter 6}

category) was added to the model. Main effects and interaction terms were tested using the chi-square test. The statistical model was: $C T=\beta_{0}+\beta_{1}$ (group) $+\beta_{2}($ sex $)+$ $\beta_{3}$ (urbanicity) $+\beta_{4}$ (group $\times$ sex $)+\beta_{5}$ (group $\times$ urbanicity $)+\beta_{6}($ sex $\times$ urbanicity $)+\beta_{7}$ (group $\times$ sex $\times$ urbanicity). First, the three-way interaction was tested, and subsequently all the two-way interactions. Group was modelled both as linear and as dummy variables, with healthy control subjects as the reference category, in order to examine the level of dose-response. Developmental urbanicity was similarly entered both as a linear variable and as dummy variables, with 'low' urbanicity as the reference category, to examine the level of dose-response. In the case of significant interaction, individual slopes were calculated by combination of effects from the model and tested whether they differed significantly. All analyses were adjusted for the a priori selected confounders: age, sex, highest accomplished level of education and scantype (MDEFT or MPRAGE). The model was also analysed with cannabis and childhood trauma as additional confounders, because cannabis and childhood trauma have been related to changes in CT in psychotic disorder (29) and to risk for psychotic disorder.

\section{RESULTS}

\section{Participant characteristics}

Sociodemographic and clinical characteristics of the sample are summarized in Table 1. The patient group comprised more men and level of education was lowest in the patient group compared to controls and siblings. Seventy-four out of 89 patients were currently using AP medication (first generation AP: $n=3$; second generation AP: $n=71$ ), 16 patients used antidepressants, nine used benzodiazepines, six used antiepileptic medication and three used lithium. Two control subjects and three siblings used antidepressants, and one sibling used benzodiazepines. Cumulative lifetime AP exposure was not significantly associated with $C T$ in the patient group $(B<0.001, p=0.55)$.

\section{Three-way interaction with group, sex and developmental urbanicity in the model of CT}

The three-way interaction between group (linear variable and dummy variables), urbanicity (linear variable and dummy variables) and sex, in the model of CT was not significant (group linear variable $\times$ urbanicity linear variable $\times$ sex: $\chi^{2}=3.14, p=0.08$; group linear variable $\times$ urbanicity dummy variables $\times$ sex: $\chi^{2}=2.88, p=0.24$; group dummy variables $\times$ urbanicity linear variable $\times$ sex: $\chi^{2}=3.73, p=0.16$; group dummy variables $x$

urbanicity dummy variables $x$ sex: $\left.x^{2}=3.08, p=0.55\right)$, indicating that the association between CT and group was not moderated by developmental urbanicity and sex (see 
Table 2). Results did not change significantly when cannabis and childhood trauma were included in the analysis.

Table 1. Participant demographics

\begin{tabular}{llll}
\hline & $\begin{array}{l}\text { Patients } \\
(\mathrm{n}=89)\end{array}$ & $\begin{array}{l}\text { Siblings } \\
(\mathrm{n}=95)\end{array}$ & $\begin{array}{l}\text { Controls } \\
(\mathrm{n}=87)\end{array}$ \\
\hline Age at scan & $28.1 \pm 7.0$ & $29.5 \pm 8.8$ & $30.8 \pm 10.8$ \\
Sex $\mathrm{n}(\%)$, male & $60(67 \%)$ & $49(52 \%)$ & $33(38 \%)$ \\
Level of education $^{\text {Cannabis lifetime }}{ }^{\mathrm{a}}$ & $4.3 \pm 2.0$ & $5.1 \pm 2.0$ & $5.4 \pm 1.8$ \\
Other drug lifetime $^{\mathrm{a}}$ & $45.0 \pm 46.7$ & $20.0 \pm 37.7$ & $7.4 \pm 21.1$ \\
Alcohol use units/week $^{\mathrm{b}}$ & $44.6 \pm 88.7$ & $6.1 \pm 31.3$ & $2.0 \pm 11.6$ \\
Childhood urbanicity $^{c}$ & $4.9 \pm 9.0$ & $9.6 \pm 17.1$ & $5.0 \pm 7.0$ \\
Childhood trauma $^{\mathrm{d}}$ & $2.4 \pm 1.3$ & $2.3 \pm 1.4$ & $2.4 \pm 1.5$ \\
PANSS Positive $^{\text {PANSS Negative }}$ & $7.2 \pm 2.8$ & $5.8 \pm 1.5$ & $5.7 \pm 1.8$ \\
PANSS Disorganization $_{\text {PANSS Excitement }}^{10.5 \pm 5.0}$ & $12.0 \pm 5.7$ & $7.4 \pm 1.5$ & $7.3 \pm 1.1$ \\
PANSS Emotional Distress $_{\text {Age of onset }}^{12.5 \pm 4.0}$ & $9.8 \pm 2.7$ & $8.5 \pm 2.1$ & $8.2 \pm 1.0$ \\
Antipsychotics $^{\mathrm{e}}$ & $13.2 \pm 5.2$ & $10.4 \pm 0.9$ & $10.2 \pm 1.1$ \\
\hline
\end{tabular}

PANSS = Positive and negative syndrome scale .

${ }^{a}$ Mean number of times

${ }^{b}$ Weekly consumptions on the last 12 months.

'Mean level of childhood urban exposure, Five levels of urbanicity/population density $1=<500$ inhabitants $/ \mathrm{km}^{2} ; \quad 2=500-1000$ inhabitants $/ \mathrm{km}^{2} ; 3=$ inhabitants $1000-1500 / \mathrm{km}^{2} ; 4=$ inhabitants $1500-2500 / \mathrm{km}^{2}$; $5=2500+/ \mathrm{km}^{2}$.

${ }^{\mathrm{d}}$ Summary score of Childhood Trauma Questionnaire Short Form (CTQ)

'Lifetime exposure in haloperidol equivalents

Table 2. Cortical thickness as a function of group status, sex and urbanicity

\begin{tabular}{|c|c|c|c|c|c|c|}
\hline \multirow[t]{2}{*}{ Urbanicity level } & \multicolumn{2}{|l|}{ Patients } & \multicolumn{2}{|l|}{ Relatives } & \multicolumn{2}{|l|}{ Controls } \\
\hline & No. obs $(n)^{a}$ & $\mathrm{CT}^{\mathrm{b}}$ & No. obs (n) & $\mathrm{CT}$ & No. obs (n) & $\mathrm{CT}$ \\
\hline \multicolumn{7}{|l|}{ Male } \\
\hline Low & $1360(20)$ & $2.50 \pm 0.39$ & $1224(18)$ & $2.47 \pm 0.40$ & $680(10)$ & $2.51 \pm 0.42$ \\
\hline Medium & $1564(23)$ & $2.50 \pm 0.41$ & $884(13)$ & $2.51 \pm 0.38$ & $816(12)$ & $2.56 \pm 0.39$ \\
\hline High & $1088(16)$ & $2.49 \pm 0.41$ & $1156(17)$ & $2.48 \pm 0.38$ & $612(9)$ & $2.49 \pm 0.40$ \\
\hline \multicolumn{7}{|l|}{ Female } \\
\hline Low & $340(5)$ & $2.47 \pm 0.39$ & $1156(17)$ & $2.53 \pm 0.40$ & $1564(23)$ & $2.50 \pm 0.40$ \\
\hline Medium & $680(10)$ & $2.52 \pm 0.41$ & $1156(17)$ & $2.54 \pm 0.39$ & $680(10)$ & $2.52 \pm 0.39$ \\
\hline High & $884(13)$ & $2.50 \pm 0.41$ & $680(10)$ & $2.55 \pm 0.42$ & $1360(20)$ & $2.48 \pm 0.38$ \\
\hline
\end{tabular}

${ }^{\mathrm{a}}$ No. obs $=$ number of subjects $\times$ number of regions (68); numbers in parentheses indicate number of subjects.

${ }^{\mathrm{b}}$ Mean $\pm \mathrm{SD}$, Means are raw means not adjusted for covariates. 


\section{Chapter 6}

Two-way interaction between group and developmental urbanicity in the model of $C T$

There was no significant group (linear variable and dummy variables) $\times$ urbanicity (linear variable and dummy variables) interaction (group linear variable $\times$ urbanicity linear variable: $\chi^{2}=0.43, p=0.51$; group linear variable $\times$ urbanicity dummy variables: $\chi^{2}=$ 2.29, $p=0.32$; group dummy variables $\times$ urbanicity linear variable: $\chi^{2}=0.51, p=0.77$; group dummy variables $\times$ urbanicity dummy variables: $\chi^{2}=4.23, p=0.38$ ). Table 3 shows the mean values of CT per group and urbanicity level. There was no consistent pattern of reduction or increase in CT with increasing levels of developmental urbanicity in any group. Adding cannabis and childhood trauma as confounders did not change the results.

Table 3. Cortical thickness as a function of group status and urbanicity

\begin{tabular}{|c|c|c|c|c|c|c|}
\hline \multirow[b]{2}{*}{ Urbanicity level } & \multicolumn{2}{|l|}{ Patients } & \multicolumn{2}{|l|}{ Relatives } & \multicolumn{2}{|l|}{ Controls } \\
\hline & No. obs $(n)^{a}$ & $\mathrm{CT}^{\mathrm{b}}$ & No. obs (n) & $\mathrm{CT}$ & No. obs (n) & $\mathrm{CT}$ \\
\hline Low & $1700(25)$ & $2.50 \pm 0.39$ & $2380(35)$ & $2.50 \pm 0.40$ & $2244(33)$ & $2.51 \pm 0.40$ \\
\hline Medium & $2244(33)$ & $2.51 \pm 0.41$ & $2040(30)$ & $2.53 \pm 0.39$ & $1496(22)$ & $2.54 \pm 0.39$ \\
\hline High & $1972(29)$ & $2.50 \pm 0.41$ & $1836(27)$ & $2.50 \pm 0.40$ & $1972(29)$ & $2.49 \pm 0.38$ \\
\hline
\end{tabular}

${ }^{\mathrm{a}}$ No. obs $=$ number of subjects $\times$ number of regions (68); numbers in parentheses indicate number of subjects.

${ }^{\mathrm{b}}$ Mean $\pm \mathrm{SD}$, Means are raw means not adjusted for covariates.

The other two-way interactions, group $\times$ sex and urbanicity $\times$ sex, were also not significant (group $\times$ sex [both dummy variables]: $\chi^{2}=0.73, p=0.69$; urbanicity [linear variable] $\times \operatorname{sex}$ (dummy variables): $\chi^{2}=0.35, p=0.55$ ).

\section{Main effects of group and urbanicity on CT}

CT was significantly smaller in the patients compared to the controls and siblings ( $P$ vs. Con: $B=-0.043, p<0.001 ; P$ vs. Sib: $B=-0.031, p=0.006)$. The siblings were not significantly different from the controls $(B=-0.013, p=0.31)$. There was neither a significant association between sex and $C T(B=0.004, p=0.71)$, nor between developmental urbanicity (linear variable) and $C T(B<0.001, p=0.91)$. See Table 4.

\section{Post-hoc subgroup analysis}

Subgroup analysis in which only $50 \%$ of the patients with the highest PANSS positive scores were included $(n=44)$, did not affect the pattern of the findings. The three-way interaction between urbanicity (linear variable and dummy variables), group and sex, and the two-way interaction between urbanicity (linear variable and dummy variables) and group were not significant (linear variable: three-way interaction: $\chi^{2}=4.97, p=0.08$; 
two-way interaction: $\chi^{2}=1.38, p=0.50$; dummy variables: three-way interaction: $\chi^{2}=5.20$, $p=0.27$; two-way interaction: $\left.\chi^{2}=5.51, p=0.24\right)$.

Table 4. Cortical thickness by group and urbanicity level

\begin{tabular}{|c|c|c|c|c|}
\hline & No. of observations ${ }^{a}$ & $\begin{array}{l}\text { Cortical thickness } \\
\text { Mean }^{b} \pm S D\end{array}$ & $\mathrm{~B}^{\mathrm{C}}$ & $p$ \\
\hline \multicolumn{5}{|l|}{ Group } \\
\hline Controls & $5916(87)$ & $2.51 \pm 0.40$ & & \\
\hline Siblings & $6460(95)$ & $2.51 \pm 0.40$ & -0.013 & 0.31 \\
\hline Patients & 6052 (89) & $2.50 \pm 0.40$ & -0.043 & $<0.01$ \\
\hline B linear trend ${ }^{d}$ & & & -0.022 & $<0.01$ \\
\hline \multicolumn{5}{|l|}{ Urbanicity } \\
\hline Low & $6324(93)$ & $2.50 \pm 0.40$ & & \\
\hline Medium & $5780(85)$ & $2.52 \pm 0.40$ & 0.001 & 0.96 \\
\hline High & $5780(85)$ & $2.50 \pm 0.40$ & 0.001 & 0.91 \\
\hline B linear trend ${ }^{d}$ & & & 0.001 & 0.91 \\
\hline
\end{tabular}

${ }^{\mathrm{a}}$ No. of observations $=$ number of subjects $\times$ number of regions (68); numbers in parentheses indicate number of subjects.

${ }^{\mathrm{b}}$ Means are raw means not adjusted for covariates.

${ }^{\mathrm{c}} \mathrm{B}$ represent the regression coefficients from multilevel linear regression analyses, adjusted for age, sex, cannabis use and highest level of education, for group controls were the reference category and for urbanicity 'low' urbanicity level was the reference category

${ }^{d} B$ linear trend represents the summary change in CT with one unit increase in exposure level (group and urbanicity)

\section{DISCUSSION}

The current study showed that urban upbringing was not associated with reductions of $\mathrm{CT}$ in individuals with (risk for) psychotic disorder or healthy controls.

To our knowledge no previous studies on the association between developmental urban exposure levels and CT as a function of different levels of psychosis risk are available. However, an fMRI study linked early life urbanicity exposure to differential activity of the PACC in social stress processing in healthy students (32), suggesting that social stress mediates the impact of urbanicity on neural circuits, although other mechanisms can be envisaged. In the current study, there was no evidence for CT alterations in the pACC and the cingulate cortex. However, absence of structural alterations does not automatically imply absence of functional alterations: cell composition, cell activity or connectivity may be different despite normal volumes of discrete brain areas.

Epidemiological studies demonstrate that there is reason to believe that the relationship between urban upbringing and psychotic disorders is causal: (1) the findings are consistent across countries and cultures; (2) there is evidence of a dose-response relationship; and (3) urban upbringing precedes psychotic disorder (3). The current 
study revealed that $\mathrm{CT}$ reductions in patients with psychotic disorder are not moderated by developmental urbanicity. An explanation for the absence of an association between cortical thinning and developmental urbanicity in psychotic disorder is that urban upbringing may influence different neurobiological pathways that do not imply CT alteration. For example, changes in white matter could be involved or the nature of change could be functional instead of structural. In case of the latter, a potential pathologic effect of the proxy environmental risk factor associated with urbanicity on brain structure may be identified with functional MRI (32).

The absence of an association could also be explained by a small urban-rural difference. Our participants grew up in the Netherlands, which can be described as a relative safe and well developed country compared to certain other counties where the urbanrural discrepancies may be more prominent. However, studies conducted in the Netherlands did report a higher incidence of psychotic disorders related to urban upbringing $(8,68)$, indicating that although the difference is relatively small, it is still large enough to show an effect. Another explanation of the absence of a significant association could be that the number of participants in the higher urbanicity levels was relatively small compared to the lower urbanicity levels, resulting in reduced power.

Environmental factors for psychotic disorder, other than the urban exposure, have been related to gray matter reductions. For instance, a study by Cannon et al. (30) found that a history of fetal hypoxia is associated with gray matter volume reductions among patients with schizophrenia and their healthy siblings, but not among healthy controls. A plausible explanation for the relationship between this environmental exposure and gray matter reductions is that fetal hypoxia is more likely to have a direct effect on neurodevelopment than the developmental urban exposure since more than $50 \%$ of the candidate genes for susceptibility to schizophrenia are subject to regulation by hypoxia (69). In addition, fetal hypoxia has been associated with increased brain dopamine synthesis capacity and concentrations (70). In previous analyses on (partly) the same study sample as the current one, Habets and colleagues (29) found that higher levels of cannabis consumption (lifetime) and childhood trauma experiences were associated with increased cortical thinning in patients with psychotic disorder, but not in controls. In siblings, the same pattern was found for cannabis, but not for childhood trauma. Just as fetal hypoxia, cannabis exposure and developmental trauma have been more directly related to altered neurodevelopment than developmental urbanicity. Tetrahydrocannabinol (THC), the active psychotropic ingredient of cannabis, may lead to increased striatal dopamine levels (71). THC is also believed to affect synaptic plasticity and it may affect gray matter volume through a mechanism on neurotoxicity (71, 72). Childhood trauma is thought to affect dopaminergic circuits through altered functioning of the hypothalamic-pituitary-adrenal (HPA) axis (41, 42). In conclusion, the developmental urbanicity exposure may be too crude compared to the other environmental risk factors to increase cerebral cortical vulnerability in individuals with (risk for) psychotic disorder. 


\section{Methodological considerations}

This is the first study examining CT as the outcome of developmental urbanicity exposure and psychosis risk, in a relatively large study sample. Our study population is larger than most previous studies on CT in psychotic disorder $(16,18,20,22)$, although some studies had larger sample sizes e.g. the study by Goldman and colleagues (19). Further, the absence of a main effect of urbanicity does not necessarily imply insufficient power for interaction: environmental risks may only become apparent when examined in a $\mathrm{G} \times$ E model.

Population density was used as a measure of developmental urbanicity, but it is not clear whether this is a good measure of urban exposure. When the factors mediating the effect of the urbanicity exposure could be identified, the chance of finding underlying neuropathological mechanisms may increase. Future research is needed to unravel the factors related to the urban environment that mediate the higher risk for psychotic disorders.

Systematic reviews and a longitudinal study $(51,73-75)$ suggest that AP treatment contributes to the brain structural changes observed in psychotic disorders. However, there was no evidence for an association between cumulative AP dose and CT in the current sample. It is thus unlikely that this has influenced our results. 


\section{REFERENCES}

1. Kelly BD, O'Callaghan E, Waddington JL, Feeney L, Browne S, Scully PJ, et al. Schizophrenia and the city: A review of literature and prospective study of psychosis and urbanicity in Ireland. Schizophrenia research. 2010;116(1):75-89.

2. McGrath J, Saha S, Welham J, El Saadi O, MacCauley C, Chant D. A systematic review of the incidence of schizophrenia: the distribution of rates and the influence of sex, urbanicity, migrant status and methodology. BMC Med. 2004;2:13.

3. Krabbendam L, van Os J. Schizophrenia and urbanicity: a major environmental influence--conditional on genetic risk. Schizophrenia bulletin. 2005;31(4):795-9.

4. McGrath J, Scott J. Urban birth and risk of schizophrenia: a worrying example of epidemiology where the data are stronger than the hypotheses. Epidemiologia e psichiatria sociale. 2006;15(4):243-6.

5. Pedersen CB, Mortensen PB. Evidence of a dose-response relationship between urbanicity during upbringing and schizophrenia risk. Archives of general psychiatry. 2001;58(11):1039-46.

6. March D, Hatch SL, Morgan C, Kirkbride JB, Bresnahan M, Fearon P, et al. Psychosis and place. Epidemiol Rev. 2008;30:84-100.

7. Vassos E, Pedersen C, Murray R, Collier D, Lewis C. A meta-analysis of the association of urbanicity with schizophrenia. Schiz Bull. 2012; in press.

8. Marcelis M, Takei N, van Os J. Urbanization and risk for schizophrenia: does the effect operate before or around the time of illness onset? Psychological medicine. 1999;29(5):1197-203.

9. Pedersen CB, Mortensen PB. Why factors rooted in the family may solely explain the urban-rural differences in schizophrenia risk estimates. Epidemiologia e psichiatria sociale. 2006;15(4):247-51.

10. Van Os J, Hanssen M, Bak M, Bijl RV, Vollebergh W. Do urbanicity and familial liability coparticipate in causing psychosis? Am J Psychiatry. 2003;160(3):477-82.

11. van Os J, Pedersen CB, Mortensen PB. Confirmation of synergy between urbanicity and familial liability in the causation of psychosis. Am J Psychiatry. 2004;161(12):2312-4.

12. Weiser M, van Os J, Reichenberg A, Rabinowitz J, Nahon D, Kravitz E, et al. Social and cognitive functioning, urbanicity and risk for schizophrenia. The British journal of psychiatry : the journal of mental science. 2007;191:320-4.

13. van Os J, Driessen G, Gunther N, Delespaul P. Neighbourhood variation in incidence of schizophrenia. Evidence for person-environment interaction. The British journal of psychiatry : the journal of mental science. 2000;176:243-8.

14. Selten JP, Cantor-Graae E. Hypothesis: social defeat is a risk factor for schizophrenia? The British journal of psychiatry Supplement. 2007;51:s9-12.

15. Byun MS, Kim JS, Jung WH, Jang JH, Choi JS, Kim SN, et al. Regional cortical thinning in subjects with high genetic loading for schizophrenia. Schizophrenia research. 2012;141(2-3):197-203.

16. Jung WH, Kim JS, Jang JH, Choi JS, Jung MH, Park JY, et al. Cortical thickness reduction in individuals at ultra-high-risk for psychosis. Schizophrenia bulletin. 2011;37(4):839-49.

17. Goghari VM, Rehm K, Carter CS, MacDonald AW, 3rd. Regionally specific cortical thinning and gray matter abnormalities in the healthy relatives of schizophrenia patients. Cerebral cortex. 2007;17(2):41524.

18. Kuperberg GR, Broome MR, McGuire PK, David AS, Eddy M, Ozawa F, et al. Regionally localized thinning of the cerebral cortex in schizophrenia. Archives of general psychiatry. 2003;60(9):878-88.

19. Goldman AL, Pezawas L, Mattay VS, Fischl B, Verchinski BA, Chen Q, et al. Widespread reductions of cortical thickness in schizophrenia and spectrum disorders and evidence of heritability. Archives of general psychiatry. 2009;66(5):467-77.

20. Cahn W, Hulshoff Pol HE, Lems EB, van Haren NE, Schnack HG, van der Linden JA, et al. Brain volume changes in first-episode schizophrenia: a 1-year follow-up study. Archives of general psychiatry. 2002;59(11):1002-10. 
21. Fornito A, Yucel M, Patti J, Wood SJ, Pantelis C. Mapping grey matter reductions in schizophrenia: an anatomical likelihood estimation analysis of voxel-based morphometry studies. Schizophrenia research. 2009;108(1-3):104-13.

22. Gutierrez-Galve L, Wheeler-Kingshott CA, Altmann DR, Price G, Chu EM, Leeson VC, et al. Changes in the frontotemporal cortex and cognitive correlates in first-episode psychosis. Biological psychiatry. 2010;68(1):51-60.

23. Glahn DC, Laird AR, Ellison-Wright I, Thelen SM, Robinson JL, Lancaster JL, et al. Meta-analysis of gray matter anomalies in schizophrenia: application of anatomic likelihood estimation and network analysis. Biological psychiatry. 2008;64(9):774-81.

24. Oertel-Knochel V, Knochel C, Rotarska-Jagiela A, Reinke B, Prvulovic D, Haenschel C, et al. Association between psychotic symptoms and cortical thickness reduction across the schizophrenia spectrum. Cerebral cortex. 2013;23(1):61-70.

25. Honea R, Crow TJ, Passingham D, Mackay CE. Regional deficits in brain volume in schizophrenia: a metaanalysis of voxel-based morphometry studies. The American journal of psychiatry. 2005;162(12):223345.

26. Boos HB, Cahn W, van Haren NE, Derks EM, Brouwer RM, Schnack HG, et al. Focal and global brain measurements in siblings of patients with schizophrenia. Schizophrenia bulletin. 2012;38(4):814-25.

27. Honea RA, Meyer-Lindenberg A, Hobbs KB, Pezawas L, Mattay VS, Egan MF, et al. Is gray matter volume an intermediate phenotype for schizophrenia? A voxel-based morphometry study of patients with schizophrenia and their healthy siblings. Biological psychiatry. 2008;63(5):465-74.

28. Goldman AL, Pezawas L, Mattay VS, Fischl B, Verchinski BA, Zoltick B, et al. Heritability of brain morphology related to schizophrenia: a large-scale automated magnetic resonance imaging segmentation study. Biological psychiatry. 2008;63(5):475-83.

29. Habets P, Marcelis M, Gronenschild E, Drukker M, van Os J. Reduced cortical thickness as an outcome of differential sensitivity to environmental risks in schizophrenia. Biological psychiatry. 2011;69(5):487-94.

30. Cannon TD, van Erp TG, Rosso IM, Huttunen M, Lonnqvist J, Pirkola T, et al. Fetal hypoxia and structural brain abnormalities in schizophrenic patients, their siblings, and controls. Archives of general psychiatry. 2002;59(1):35-41.

31. Haddad L, Schafer A, Streit F, Lederbogen F, Grimm O, Wust S, et al. Brain Structure Correlates of Urban Upbringing, an Environmental Risk Factor for Schizophrenia. Schizophrenia bulletin. 2014.

32. Lederbogen F, Kirsch P, Haddad L, Streit F, Tost H, Schuch P, et al. City living and urban upbringing affect neural social stress processing in humans. Nature. 2011;474(7352):498-501.

33. Tomoda A, Suzuki H, Rabi K, Sheu YS, Polcari A, Teicher MH. Reduced prefrontal cortical gray matter volume in young adults exposed to harsh corporal punishment. Neurolmage. 2009;47 Suppl 2:T66-71.

34. Tomoda A, Polcari A, Anderson CM, Teicher MH. Reduced visual cortex gray matter volume and thickness in young adults who witnessed domestic violence during childhood. PloS one. 2012; 7(12):e52528.

35. Frodl T, Reinhold E, Koutsouleris N, Reiser M, Meisenzahl EM. Interaction of childhood stress with hippocampus and prefrontal cortex volume reduction in major depression. Journal of psychiatric research. 2010;44(13):799-807.

36. Schubert MI, Porkess MV, Dashdorj N, Fone KC, Auer DP. Effects of social isolation rearing on the limbic brain: a combined behavioral and magnetic resonance imaging volumetry study in rats. Neuroscience. 2009;159(1):21-30.

37. Jackowski A, Perera TD, Abdallah CG, Garrido G, Tang CY, Martinez J, et al. Early-life stress, corpus callosum development, hippocampal volumetrics, and anxious behavior in male nonhuman primates. Psychiatry research. 2011;192(1):37-44.

38. Duque A, Coman D, Carlyle BC, Bordner KA, George ED, Papademetris X, et al. Neuroanatomical changes in a mouse model of early life neglect. Brain structure \& function. 2012;217(2):459-72.

39. Spinelli S, Chefer S, Suomi SJ, Higley JD, Barr CS, Stein E. Early-life stress induces long-term morphologic changes in primate brain. Archives of general psychiatry. 2009;66(6):658-65. 


\section{Chapter 6}

40. Lu S, Gao W, Wei Z, Wu W, Liao M, Ding Y, et al. Reduced cingulate gyrus volume associated with enhanced cortisol awakening response in young healthy adults reporting childhood trauma. PloS one. 2013;8(7):e69350.

41. Heim C, Newport DJ, Heit S, Graham YP, Wilcox M, Bonsall R, et al. Pituitary-adrenal and autonomic responses to stress in women after sexual and physical abuse in childhood. JAMA : the journal of the American Medical Association. 2000;284(5):592-7.

42. Walker EF, Diforio D. Schizophrenia: a neural diathesis-stress model. Psychological review. 1997;104(4):667-85.

43. Luo Y, Umegaki H, Wang X, Abe R, Roth GS. Dopamine induces apoptosis through an oxidation-involved SAPK/JNK activation pathway. The Journal of biological chemistry. 1998;273(6):3756-64.

44. Luo Y, Hattori A, Munoz J, Qin ZH, Roth GS. Intrastriatal dopamine injection induces apoptosis through oxidation-involved activation of transcription factors AP-1 and NF-kappaB in rats. Molecular pharmacology. 1999;56(2):254-64.

45. Wersinger C, Chen J, Sidhu A. Bimodal induction of dopamine-mediated striatal neurotoxicity is mediated through both activation of D1 dopamine receptors and autoxidation. Molecular and cellular neurosciences. 2004;25(1):124-37.

46. Bora E, Fornito A, Yucel M, Pantelis C. The effects of gender on grey matter abnormalities in major psychoses: a comparative voxelwise meta-analysis of schizophrenia and bipolar disorder. Psychological medicine. 2011:1-13.

47. Maxwell ME. Genetics Initiative: Family Interview for Genetic Studies (FIGS): National Institute of Mental Health; 1992.

48. APA. Diagnostic and Statistical Manual of Mental Disorders. 4 ed. Washington, DC: American Psychiatric Association; 2000

49. Andreasen NC, Flaum M, Arndt S. The Comprehensive Assessment of Symptoms and History (CASH). An instrument for assessing diagnosis and psychopathology. Archives of general psychiatry. 1992;49(8):615-23.

50. Kay SR, Fiszbein A, Opler LA. The positive and negative syndrome scale (PANSS) for schizophrenia. Schizophrenia bulletin. 1987;13(2):261-76.

51. Navari S, Dazzan P. Do antipsychotic drugs affect brain structure? A systematic and critical review of MRI findings. Psychological medicine. 2009;39(11):1763-77.

52. WHO. Composite International Diagnostic Interview. Geneva: World Health Organization. 1990.

53. Bernstein DP, Ahluvalia T, Pogge D, Handelsman L. Validity of the Childhood Trauma Questionnaire in an adolescent psychiatric population. Journal of the American Academy of Child and Adolescent Psychiatry. 1997;36(3):340-8.

54. Frissen A, Lieverse R, Drukker M, Delespaul P, Lataster T, Myin-Germeys I, et al. Evidence that childhood urban environment is associated with blunted stress reactivity across groups of patients with psychosis, relatives of patients and controls. Soc Psychiatry Psychiatr Epidemiol. 2014;49(10):1579-87.

55. Dale AM, Fischl B, Sereno MI. Cortical surface-based analysis. I. Segmentation and surface reconstruction. Neurolmage. 1999;9(2):179-94.

56. Fischl B, Dale AM. Measuring the thickness of the human cerebral cortex from magnetic resonance images. Proceedings of the National Academy of Sciences of the United States of America. 2000;97(20):11050-5.

57. Fischl B, Salat DH, Busa E, Albert M, Dieterich M, Haselgrove C, et al. Whole brain segmentation: automated labeling of neuroanatomical structures in the human brain. Neuron. 2002;33(3):341-55.

58. Fischl B, Sereno MI, Dale AM. Cortical surface-based analysis. II: Inflation, flattening, and a surface-based coordinate system. Neurolmage. 1999;9(2):195-207.

59. Han X, Jovicich J, Salat D, van der Kouwe A, Quinn B, Czanner S, et al. Reliability of MRI-derived measurements of human cerebral cortical thickness: the effects of field strength, scanner upgrade and manufacturer. Neurolmage. 2006;32(1):180-94.

60. Jovicich J, Czanner S, Greve D, Haley E, van der Kouwe A, Gollub R, et al. Reliability in multi-site structural MRI studies: effects of gradient non-linearity correction on phantom and human data. Neurolmage. 2006;30(2):436-43. 
61. Segonne F, Dale AM, Busa E, Glessner M, Salat D, Hahn HK, et al. A hybrid approach to the skull stripping problem in MRI. Neurolmage. 2004;22(3):1060-75.

62. Desikan RS, Segonne F, Fischl B, Quinn BT, Dickerson BC, Blacker D, et al. An automated labeling system for subdividing the human cerebral cortex on MRI scans into gyral based regions of interest. Neurolmage. 2006;31(3):968-80.

63. Fischl B, van der Kouwe A, Destrieux C, Halgren E, Segonne F, Salat DH, et al. Automatically parcellating the human cerebral cortex. Cerebral cortex. 2004;14(1):11-22.

64. Rosas HD, Liu AK, Hersch S, Glessner M, Ferrante RJ, Salat DH, et al. Regional and progressive thinning of the cortical ribbon in Huntington's disease. Neurology. 2002;58(5):695-701.

65. Salat DH, Buckner RL, Snyder AZ, Greve DN, Desikan RS, Busa E, et al. Thinning of the cerebral cortex in aging. Cerebral cortex. 2004;14(7):721-30.

66. Schwartz JE, Stone AA. Strategies for analyzing ecological momentary assessment data. Health psychology : official journal of the Division of Health Psychology, American Psychological Association. 1998;17(1):6-16.

67. The R Foundation. https://www.r-project.org/ [

68. Marcelis M, Navarro-Mateu F, Murray R, Selten JP, Van Os J. Urbanization and psychosis: a study of 1942-1978 birth cohorts in The Netherlands. Psychological medicine. 1998;28(4):871-9.

69. Schmidt-Kastner R, van Os J, H WMS, Schmitz C. Gene regulation by hypoxia and the neurodevelopmental origin of schizophrenia. Schizophrenia research. 2006;84(2-3):253-71.

70. Howes OD, Murray RM. Schizophrenia: an integrated sociodevelopmental-cognitive model. Lancet. 2014;383(9929):1677-87.

71. Kuepper R, Morrison PD, van Os J, Murray RM, Kenis G, Henquet C. Does dopamine mediate the psychosis-inducing effects of cannabis? A review and integration of findings across disciplines. Schizophrenia research. 2010;121(1-3):107-17.

72. Stone JM, Day F, Tsagaraki H, Valli I, McLean MA, Lythgoe DJ, et al. Glutamate dysfunction in people with prodromal symptoms of psychosis: relationship to gray matter volume. Biological psychiatry. 2009;66(6):533-9.

73. Moncrieff J, Leo J. A systematic review of the effects of antipsychotic drugs on brain volume. Psychological medicine. 2010;40(9):1409-22.

74. Andreasen NC, Liu D, Ziebell S, Vora A, Ho BC. Relapse duration, treatment intensity, and brain tissue loss in schizophrenia: a prospective longitudinal MRI study. The American journal of psychiatry. 2013;170(6):609-15.

75. White T, Andreasen NC, Nopoulos P, Magnotta V. Gyrification abnormalities in childhood- and adolescent-onset schizophrenia. Biological psychiatry. 2003;54(4):418-26. 



\section{Chapter 7}

\section{Evidence that reduced gray matter volume in psychotic disorder is associated with exposure to environmental risk factors}

Authors: Aleida Frissen ${ }^{1}$, Jim van Os ${ }^{1,2}$, Sanne Peeters ${ }^{1}$, Ed Gronenschild ${ }^{1}$, Machteld Marcelis ${ }^{1,3^{*}}$ for Genetic Risk and Outcome in Psychosis (G.R.O.U.P.)

${ }^{1}$ Department of Psychiatry and Neuropsychology, Maastricht University, The Netherlands,

${ }^{2}$ King's College London, King's Health Partners, Department of Psychosis Studies, Institute of Psychiatry, London, United Kingdom

${ }^{3}$ Institute for Mental Health Care Eindhoven (GGzE), Eindhoven, The Netherlands

Submitted 


\section{Chapter 7}

\section{ABSTRACT}

\section{Background}

Differential genetic sensitivity to environmental factors may be expressed as structural brain alterations in psychotic disorder. The aim of this study was to examine whether cannabis use, childhood trauma and urban upbringing are associated with total gray matter volume (GMV) in individuals with (risk for) psychotic disorder and whether this is sex-specific.

\section{Methods}

T1-weighted MRI scans were acquired from 89 patients with a psychotic disorder, 95 healthy siblings of patients with psychotic disorder and 87 controls. Multilevel random regression analyses were used to examine main effects and interactions between group, sex and environmental factors in models of GMV.

\section{Results}

The three-way interaction between group, sex and cannabis (cannabis $\times$ group linear variable $\times$ sex: $\chi^{2}=12.43, p<0.01$ ), as well as developmental urbanicity (urbanicity linear variable $x$ group linear variable $x$ sex: $\chi^{2}=6.29, p=0.01$ ) were significant, indicating that cannabis use and developmental urbanicity were associated with lower GMV in the male patient group (cannabis: $B=-32.54, p<0.01$; developmental urbanicity: $B=-10.23$, $\mathrm{p}=0.03)$. For childhood trauma, the two-way interaction with group was significant (trauma linear variable $x$ group linear variable: $\chi^{2}=5.74, p=0.02$ ), indicating that childhood trauma was associated with reduced GMV in the patient group $(B=-9.79, p=0.01)$. In the model of GMV, significant main effects were apparent for group (Pat vs Con: $B=-$ 17.21, $p<0.01$; Pat vs Sibs: $B=-11.27, p<0.01)$ and cannabis $(B=-8.28, p=0.03$, corrected for group), but not for childhood trauma and developmental urbanicity.

\section{Conclusion}

The findings suggest that reduction of GMV in psychotic disorder may be the outcome of differential sensitivity to environmental risks, particularly in male patients. 


\section{INTRODUCTION}

Changes in brain volumes, changes in white matter integrity, and cortical thinning have been associated with psychotic disorder (1). Meta-analyses have confirmed reductions of gray matter volume (GMV) in patients with psychotic disorder $(2,3)$. It remains to be discovered whether these structural alterations are the result of a disease-related processes or factors, altered neurodevelopment due to genetic liability and/or differential sensitivity to environmental risks. Studies that report gray matter alterations in individuals at high familial risk for psychotic disorder and in persons at clinical high risk for psychotic disorder support the hypothesis of altered neurodevelopment associated with genetic predisposition $(4,5)$, though not all studies are consistent $(6,7)$. Reports of progressive loss of gray matter over time in patients (8-10) support the hypothesis that this is the result of a disease-specific process or disease-related factors such as medication (3).

Although gene $x$ environment interactions in psychotic disorder have been studied $(11,12)$ the number of $\mathrm{G} \times \mathrm{E}$ studies using structural brain phenotypes as the outcome variables is limited $(13,14)$. One of the first studies focused on fetal hypoxia, which was associated with reduced GMV and increased cerebrospinal fluid in individuals who had later developed schizophrenia, and in their healthy relatives (15).

Cannabis, a recognized environmental risk factor for psychotic disorder (16), has been associated with reduction of GMV (17) in patients with a psychotic disorder and with loss of cortical thickness in patient with schizophrenia and in cannabis users without schizophrenia (18). Further, cannabis has also been related to changes in white matter of the brain in patients with psychotic disorder (19) and in the general population $(19,20)$.

Childhood trauma, another risk factor for psychotic disorder (21), has been associated with reduced GMV in psychotic disorder (22). In addition, cortico-limbic GMV differences between patients with schizophrenia, patients with bipolar disorder and healthy controls have been reported in individuals with high, but not low, levels of adverse childhood experiences (23). In non-psychotic populations, associations between childhood trauma and brain development $(24)$, structure $(25,26)$ and function $(26)$ have been described.

Lastly, developmental urbanicity, as a proxy environmental risk factor for psychotic disorder (27), has not yet been examined in relation to structural gray matter alterations in this population. The risk-increasing mechanisms underlying the proxy variable developmental urbanicity remain unknown. One of the mechanisms that can be envisaged is altered stress processing (28) due to higher levels of social isolation (29) and social defeat (30) in urban areas. Indeed, early life stress has been associated with cerebral alterations in humans (31) and in animals (32), through altered levels of neurohormones, neurotransmitters, and neurotrophic factors (33). 
When examining structural brain phenotypes as a function of environmental and genetic risk, potential sex differences should be taken into account. First, with respect to the incidence, age of onset and course of disease in psychotic disorder, sex differences have been extensively described (34-37). Second, sex differences have been reported in the association between psychotic disorder and respectively childhood trauma (38) and cannabis (39). Third, there is evidence for sex differences in brain morphology in psychotic disorders (40), i.e., gray matter alterations may be more prominent in male patients with a psychotic disorder $(41,42)$.

In the present study, we hypothesized that the sensitivity to environmental risk factors (cannabis, trauma, urbanicity), as expressed by GMV alterations, is dependent on the genetic predisposition for psychotic disorder, as well as on sex. This was tested in three groups with differential proxy genetic risk for psychotic disorder: patients with a psychotic disorder (highest risk), non-psychotic siblings of patients with psychotic disorder (higher than average risk) and healthy controls (average risk).

\section{MATERIALS AND METHODS}

\section{Participants}

Data pertain to baseline measures of a longitudinal magnetic resonance imaging (MRI) study in Maastricht, the Netherlands. In selected geographic areas in the Netherlands and Belgium, patients presenting consecutively at metal health services either as outpatients or inpatients were recruited for the study. The sample consisted of 89 patients with a diagnosis of a non-affective psychotic disorder, 95 siblings, and 87 control subjects. The sample included 60 families, of which 37 families contributed one patient and one sibling, 3 families contributed one patient and two siblings, and one family contributed one patient and three siblings. One family contributed two patients, 7 families contributed two relatives, 1 family contributed three relatives, and ten families contributed two controls. In addition, 44 independent patients, 32 independent siblings, and 67 independent controls were included.

Inclusion criteria for the patient group were the following: (1) age 16 to 50 years; (2) diagnosis of non-affective psychotic disorder; and (3) sufficient command of the Dutch language. Sibling non-patient status was defined as the absence of any lifetime psychotic disorder. Controls had no first-degree relative with a psychotic disorder as established by the Family Interview for Genetic Studies (43) with the control as informant. Before $\mathrm{MRI}$ acquisition, participants were screened for the following exclusion criteria: (1) brain injury with loss of consciousness of more than 1 hour; (2) meningitis or other neurological diseases that might have affected brain structure or function; (3) cardiac arrhythmia requiring medical treatment; and (4) severe claustrophobia. In addition, subjects with 
metal corpora aliena were excluded from the study, as were women with intrauterine device status and (suspected) pregnancy.

The study was approved centrally by the Ethical Review Board of the University Medical Centre Utrecht. Written informed consent was obtained from all. The selection procedure and the in- and exclusion criteria are described in full detail in a previous paper (44).

\section{Measures}

The level of symptoms in all groups was assessed with the Positive and Negative Syndrome Scale (PANSS)(45). The Five Factor Model by van der Gaag (2006) was used, dividing the PANSS in Positive symptoms, Negative symptoms, Disorganization symptoms, Excitement, and Emotional Distress (46). Educational level was defined as highest accomplished level of education.

\section{AP medication}

Antipsychotic (AP) medication use was determined by patient report and verified with the treating consultant psychiatrist. Best estimate lifetime (cumulative) AP use was determined by multiplying the number of days of AP use with the corresponding haloperidol equivalents and summing these scores for all periods of AP use (including the exposure period between baseline assessment for the G.R.O.U.P. study and the moment of baseline MRI scanning), using the recently published conversion formulas for AP dose equivalents described in Andreasen and colleagues (47).

\section{Substance use}

Substance use was measured with the Composite International Diagnostic Interview (CIDI) sections B-J-L(48). Use of cannabis and other drugs was assessed as the reported frequency of use during the last 12 months, as well as lifetime use. CIDI frequency data on lifetime cannabis use were available for 263 participants (3.0\% missing data). In addition, cannabis was tested in urine available for 247 participants ( $8.9 \%$ missing data). The two measurers were combined into one variable, which was coded as follows: never used cannabis $=0$, ever used cannabis $=1(0.0 \%$ missing data $)$. CIDI frequency data on lifetime other (non-cannabis) drug use were available for 267 participants (1.5 $\%$ missing data). Alcohol use was defined as the reported number of weekly consumptions during the last 12 months available for 235 participants (13.3\% missing data).

\section{Childhood trauma}

Childhood trauma was assessed with the Dutch version of the Childhood Trauma Questionnaire Short Form (CTQ)(49). The short CTQ consists of 25 items rated on a 5-point Likert scale ( 1 = never true to 5 = very often true) inquiring about traumatic experiences in childhood. Five types of childhood maltreatment were assessed: emotional, physical 
and sexual abuse, and emotional and physical neglect, with five questions covering each type of trauma. As a general measure of childhood trauma a summary score was created by adding the mean scores of each trauma type. The CTQ data were missing for two persons $(0.7 \%$ missing data).

\section{Developmental urbanicity}

A historical population density record was generated for each municipality from 1930 onwards using the Dutch Central Bureau of Statistics (CBS)(50) and equivalent Belgium database(51). When data were not available, linear extrapolations were computed. When historical names of municipalities disappeared from historical records (e.g. due to city mergers) we used the available data from the agglomerate city. Subjects were asked to describe where they lived during their life. This resulted in a number of records for each subject, containing locations by age period. For each of these records, the average population density (by square kilometer, excluding water) of the municipality for the matching year periods was computed. Subsequently, it was determined where the subject lived at birth, between ages 0-4 years; between 5-9 years; $10-14$ years; $15-$ 19 years; 20-39 years; 40-59 years; and 60+ up to the actual age. Average population density over the period was categorized conform the Dutch CBS urbanicity rating $\left(1=<500 / \mathrm{km}^{2} ; \quad 2=500-1000 / \mathrm{km}^{2} ; \quad 3=1000-1500 / \mathrm{km}^{2} ; 4=1500-2500 / \mathrm{km}^{2} ; 5=2500+/ \mathrm{km}^{2}\right)$. The periods $0-4$ years, 5-9 years and 10-14 years were merged to average urbanicity exposure between 0-14 years. The latter divided by its tertiles was used as the primary variable reflecting developmental urbanicity exposure (low, medium, high) in the analyses. Urbanicity data were available for 263 participants (3.0\% missing data).

\section{MRI Acquisition and Processing}

The MRI scans were acquired using a 3T Siemens scanner (Erlangen, Germany) and the following acquisition parameters: Modified Driven Equilibrium Fourier Transform (MDEFT) sequence with 176 slices, $1 \mathrm{~mm}$ isotropic voxel size, echo time $2.4 \mathrm{~ms}$, repetition time $7.92 \mathrm{~ms}$, inversion time $910 \mathrm{~ms}$, flip angle 15, total acquisition time 12 min 51 $\mathrm{sec}$; Magnetization Prepared Rapid Acquisition Gradient-Echo (MPRAGE; Alzheimer's Disease Neuroimaging Initiative) sequence with 192 slices, $1 \mathrm{~mm}$ isotropic voxel size, echo time $2.6 \mathrm{~ms}$, repetition time $2250 \mathrm{~ms}$, inversion time $900 \mathrm{~ms}$, flip angle $9^{\circ}$, total acquisition time $7 \mathrm{~min} 23 \mathrm{sec}$. The matrix size was $256 \times 256$ and the field of view was $256 \times 256 \mathrm{~mm}^{2}$. The number of excitations was one. Two sequences were used because of a scanner update during data collection. The total proportion of MPRAGE scans did not differ between the groups (patient, sibling and control) $\left(\chi^{2}=4.95, p=0.08\right)$ or between $\operatorname{sex}\left(\chi^{2}=0.01, p=0.91\right)$.

Cortical reconstruction and volumetric segmentation was performed with the Freesurfer image analysis suite, which is documented and freely available for download online (http://surfer.nmr.mgh.harvard.edu/). The technical details of these procedures 
are described in prior publications (52-63). Briefly, this processing includes removal of non-brain tissue using a hybrid watershed/surface deformation (63), automated Talairach transformation, segmentation of the subcortical white matter and deep gray matter volumetric structures (including hippocampus, amygdala, caudate, putamen, ventricles) $(56,57)$ intensity normalization $(64)$, tessellation of the gray matter white matter boundary, automated topology correction $(54,65)$ and surface deformation following intensity gradients to optimally place the gray/white and gray/cerebrospinal fluid borders at the location where the greatest shift in intensity defines the transition to the other tissue class $(52,53,55)$. Once the cortical models are complete, a number of deformable procedures can be performed for further data processing and analysis including surface inflation (58), registration to a spherical atlas which utilized individual cortical folding patterns to match cortical geometry across subjects (59), parcellation of the cerebral cortex into units based on gyral and sulcal structure $(60,66)$, and creation of a variety of surface based data including maps of curvature and sulcal depth. This method uses both intensity and continuity information from the entire three dimensional MR volume in segmentation and deformation procedures to produce representations of cortical thickness, calculated at each vertex on the tessellated surface as the average of the distance from a point on the white surface to the closest point on the pial surface and from that point back to the closest point on the white surface (53). The maps are created using spatial intensity gradients across tissue classes and are therefore not simply reliant on absolute signal intensity. The maps produced are not restricted to the voxel resolution of the original data thus are capable of detecting submillimeter differences between groups. Procedures for the measurement of cortical thickness have been validated against histological analysis (Rosas et al., 2002) and manual measurements $(67,68)$. Freesurfer morphometric procedures have been demonstrated to show good test-retest reliability across scanner manufacturers and across field strengths $(61,69)$.

Where necessary, the skullstripping was manually edited using GIANT (General Image Analysis Tools (70). By visual inspection we observed that in many cases the white matter surface did not follow the white matter boundaries accurately. It was found that the results were much improved by taking the union of the white matter segmentation of FreeSurfer and FSL'S FAST (71). To be consistent, this technique was applied to all data sets.

\section{Statistical/data analyses}

All analyses were carried out using Stata 13 (72). The GMV data consist of individual observations nested within families, generating 2 levels of analysis. Because of the twolevel grouping structure of the data, compromising statistical independence of the observations, multilevel random linear regression analyses were performed using the Stata XTREG command, with GMV as the dependent variable and family ID modeled as 
random effect in all analyses. The regression coefficients (B) from the multilevel linear regression model represent the effect size of the predictors and can be interpreted identically to estimates in equivalent unilevel linear regression analyses.

In order to study whether there is differential sensitivity to these environmental exposures in the three groups and in both sexes, a three-way interaction between group (healthy control subject $=0$, sibling $=1$ or patient $=2$, entered as linear variable and as dummy variables with healthy control subject as the reference category), sex (male $=0$ or female $=1$ ) and cannabis (never used cannabis $=0$ or ever used cannabis $=1$ ) or childhood trauma (trauma score divided by its tertiles, low $=0$, medium $=1$ or high $=2$, entered both as a linear variable and as dummy variables with 'low' trauma as the reference category) or developmental urbanicity (low $=0$, medium $=1$ or high $=2$, entered both as a linear variable and as dummy variables with 'low' urbanicity as the reference category) was added to the model. Main effects and interaction terms were tested using the chi-square test. The statistical model was: GMV $=\beta_{0}+\beta_{1}($ group $)+\beta_{2}($ sex $)+$ $\beta_{3}$ (environment $)+\beta_{4}($ group $\times$ sex $)+\beta_{5}$ (group $\times$ environment $)+\beta_{6}$ (sex $\times$ environment $)$ $+\beta_{7}$ (group $\times$ sex $\times$ environment). First, the three-way interaction was tested, and subsequently the two-way interactions excluding sex from the interaction (group $x$ environmental factor). Group was modelled both as linear and as dummy variables, with healthy control subjects as the reference category, in order to examine the level of dose-response. Childhood trauma and developmental urbanicity were similarly entered both as a linear variable and as dummy variables, with 'low' childhood trauma and 'low' urbanicity as the reference category, to examine the level of dose-response. In the case of significant interaction, stratified effect sizes for all levels of environmental exposure, per sex and group were calculated by combination of effects from the model containing the interactions using the Stata MARGINS routine. All analyses were adjusted for the a priori selected confounders: age, educational level, total intracranial volume (ICV), group (where group was not the independent variable), sex and scantype (MDEFT or MPRAGE). To test the independent effects of the environmental factors, the interaction models were also analysed with the two environmental exposures, which were not included in the interaction, as additional confounders. Lastly, we tested if cannabis was associated with PANSS scores in the patient group, with age and sex as confounders.

\section{RESULTS}

\section{Participants and descriptives}

Sociodemographic and clinical characteristics of the sample are summarized in Table 1. The patient group comprised more men and more cannabis users than the sibling and control group. Patients used other (non-cannabis) drugs more often and had higher 
levels of childhood trauma with respect to the other groups. Weekly consumption of alcohol was highest in the sibling group.

Table 1. Subject demographics

\begin{tabular}{llll}
\hline & $\begin{array}{l}\text { Patients } \\
(\mathrm{n}=89)\end{array}$ & $\begin{array}{l}\text { Siblings } \\
(\mathrm{n}=95)\end{array}$ & $\begin{array}{l}\text { Controls } \\
(\mathrm{n}=87)\end{array}$ \\
\hline Age at scan & $28.1 \pm 7.0$ & $29.5 \pm 8.8$ & $30.8 \pm 10.8$ \\
Sex $\mathrm{n}(\%)$, male & $60(67 \%)$ & $49(52 \%)$ & $33(38 \%)$ \\
Level of education & $4.3 \pm 2.0$ & $5.1 \pm 2.0$ & $5.4 \pm 1.8$ \\
Ever used cannabis $^{\mathrm{a}}$ & $54(61 \%)$ & $33(35 \%)$ & $22(25 \%)$ \\
Other drug lifetime $^{\mathrm{b}}$ & $44.6 \pm 88.7$ & $6.1 \pm 31.3$ & $2.0 \pm 11.6$ \\
Alcohol use units/week $^{\mathrm{c}}$ & $4.9 \pm 9.0$ & $9.6 \pm 17.1$ & $5.0 \pm 7.0$ \\
Developmental urbanicity $^{\mathrm{d}}$ & $2.4 \pm 1.3$ & $2.3 \pm 1.4$ & $2.4 \pm 1.5$ \\
Childhood trauma $^{\mathrm{e}}$ & $7.2 \pm 2.8$ & $5.8 \pm 1.5$ & $5.7 \pm 1.8$ \\
PANSS Positive $^{\text {PANSS Negative }}$ & $10.5 \pm 5.0$ & $7.4 \pm 1.5$ & $7.3 \pm 1.1$ \\
PANSS Disorganization $^{\text {PANSS Excitement }}$ & $12.0 \pm 5.7$ & $8.5 \pm 2.1$ & $8.2 \pm 1.0$ \\
PANSS Emotional Distress $_{\text {Age of onset }}^{12.5 \pm 4.0}$ & $9.8 \pm 2.7$ & $10.4 \pm 0.9$ & $10.2 \pm 1.1$ \\
Antipsychotics $^{f}$ & $13.2 \pm 5.2$ & $8.6 \pm 1.4$ & $8.3 \pm 1.1$ \\
\hline
\end{tabular}

PANSS = Positive and negative syndrome scale.

${ }^{a}$ Ever used cannabis measured by Composite International Diagnostic Interview and by cannabis analysis in urine

${ }^{\mathrm{b}}$ Mean number of times

'Weekly consumptions on the last 12 months.

${ }^{d}$ Mean level of childhood urban exposure, Five levels of urbanicity/population density $1=<500$ inhabitants $/ \mathrm{km}^{2} ; \quad 2=500-1000$ inhabitants $/ \mathrm{km}^{2} ; 3=$ inhabitants $1000-1500 / \mathrm{km}^{2} ; 4=$ inhabitants $1500-2500 / \mathrm{km}$; $5=2500+/ \mathrm{km}^{2}$.

e Summary score of Childhood Trauma Questionnaire Short Form (CTQ)

fifetime exposure in haloperidol equivalent

\section{Cannabis}

The three-way interactions between cannabis, group and sex were statistically significant in the model of GMV, whereas the two-way interactions between cannabis and group were not (Table 2). The results did not change when childhood trauma or developmental urbanicity were added as a confounder. Stratified analyses showed that cannabis use was associated with lower GMV in the male patient group ( $B=-32.54$, $p<0.001)$. The regression coefficient of the male patients differed significantly from the regression coefficients of the male controls and the male siblings, with no significant difference between male siblings and controls. Stratified effect sizes for the two-way interaction were not calculated because the interaction was non-significant (Table 3 and Figure 1a). 


\section{Chapter 7}

Table 2. Interactions between group status (patient, sibling or control), environmental exposures (cannabis, childhood trauma and developmental urbanicity) and sex

\begin{tabular}{|c|c|c|c|c|}
\hline & $\begin{array}{l}\text { E linear } \times \text { Group } \\
\text { linear }^{a}\end{array}$ & $\begin{array}{l}\text { E linear } \times \text { Group } \\
\text { dummy }\end{array}$ & $\begin{array}{l}\text { E dummy } \times \text { Group } \\
\text { linear }^{c}\end{array}$ & $\begin{array}{l}\text { E dummy } \times \text { Group } \\
\text { dummy }\end{array}$ \\
\hline \multicolumn{5}{|l|}{ Cannabis $^{\mathrm{e}}$} \\
\hline $\begin{array}{l}\text { Three-way } \\
\text { interaction }\end{array}$ & - & - & $\chi^{2}=12.43, p<0.01$ & $\chi^{2}=15.18, p<0.01$ \\
\hline $\begin{array}{l}\text { Two-way } \\
\text { interaction }\end{array}$ & - & - & $x^{2}=3.20, p=0.07$ & $x^{2}=3.11, p=0.21$ \\
\hline \multicolumn{5}{|c|}{ Childhood trauma } \\
\hline $\begin{array}{l}\text { Three-way } \\
\text { interaction }\end{array}$ & $\chi^{2}=2.18, p=0.14$ & $x^{2}=4.44, p=0.11$ & $x^{2}=2.06, p=0.36$ & $x^{2}=3.31, p=0.51$ \\
\hline $\begin{array}{l}\text { Two-way } \\
\text { interaction }\end{array}$ & $\chi^{2}=5.74, p=0.02$ & $\chi^{2}=8.16, p=0.02$ & $\chi^{2}=5.28, p=0.07$ & $x^{2}=11.09, p=0.03$ \\
\hline \multicolumn{5}{|c|}{$\begin{array}{l}\text { Developmental } \\
\text { urbanicity }\end{array}$} \\
\hline $\begin{array}{l}\text { Three-way } \\
\text { interaction }\end{array}$ & $\chi^{2}=6.29, p=0.01$ & $\chi^{2}=7.91, p=0.01$ & $\chi^{2}=8.41, p=0.01$ & $\chi^{2}=10.61, p=0.03$ \\
\hline $\begin{array}{l}\text { Two-way } \\
\text { interaction }\end{array}$ & $\chi^{2}=0.66, p=0.42$ & $\chi^{2}=0.97, p=0.61$ & $\chi^{2}=3.82, p=0.15$ & $\chi^{2}=5.84, p=0.21$ \\
\hline
\end{tabular}

E=Environmental risk factor

Three-way interactions: group $\times \mathrm{E} \times$ sex, two-way interactions: group $\times \mathrm{E}$

${ }^{a}$ Trauma and urbanicity modelled as linear variable and group modelled as linear variable.

${ }^{\mathrm{b}}$ Trauma and urbanicity modelled as linear variable and group modelled as dummy variables, with controls as the reference category

c Cannabis, trauma, and urbanicity modelled as dummy variables and group modelled as linear variable. Childhood trauma: 'low' was reference category. Developmental urbanicity: 'low' was reference category.

${ }^{d}$ Cannabis, trauma, and urbanicity and group modelled as dummy variables, with controls as the reference category. Childhood trauma: 'low' was reference category. Developmental urbanicity: 'low' was reference category.

${ }^{\mathrm{e}}$ Cannabis was not modelled as linear variable, because it is a binary variable: never used cannabis or ever used cannabis.

\section{Childhood trauma}

The three-way interactions (trauma $\times$ group $\times$ sex) in the model of GMV were not significant. In the lower order model, the two-way interactions (excluding sex) were significant except for the trauma (dummy variables) $x$ group (linear variable) interaction (Table 2). This did not change when cannabis or developmental urbanicity were added as a confounder. Stratified effect sizes for the two-way interaction showed that in the patient group, there was a significant negative association between GMV and childhood trauma ( $B$ linear trend $=-9.79, p=0.01$ ). The direction of effect was the same for the medium and the high childhood trauma group, but only significant in the latter. There was no significant association between childhood trauma and GMV in the siblings or controls. The regression coefficient of the patients differed significantly from the regression coefficients of the siblings and the controls (Table 4 and Figure 2). 
Reduced gray matter volume in psychosis is associated with environmental risk factors
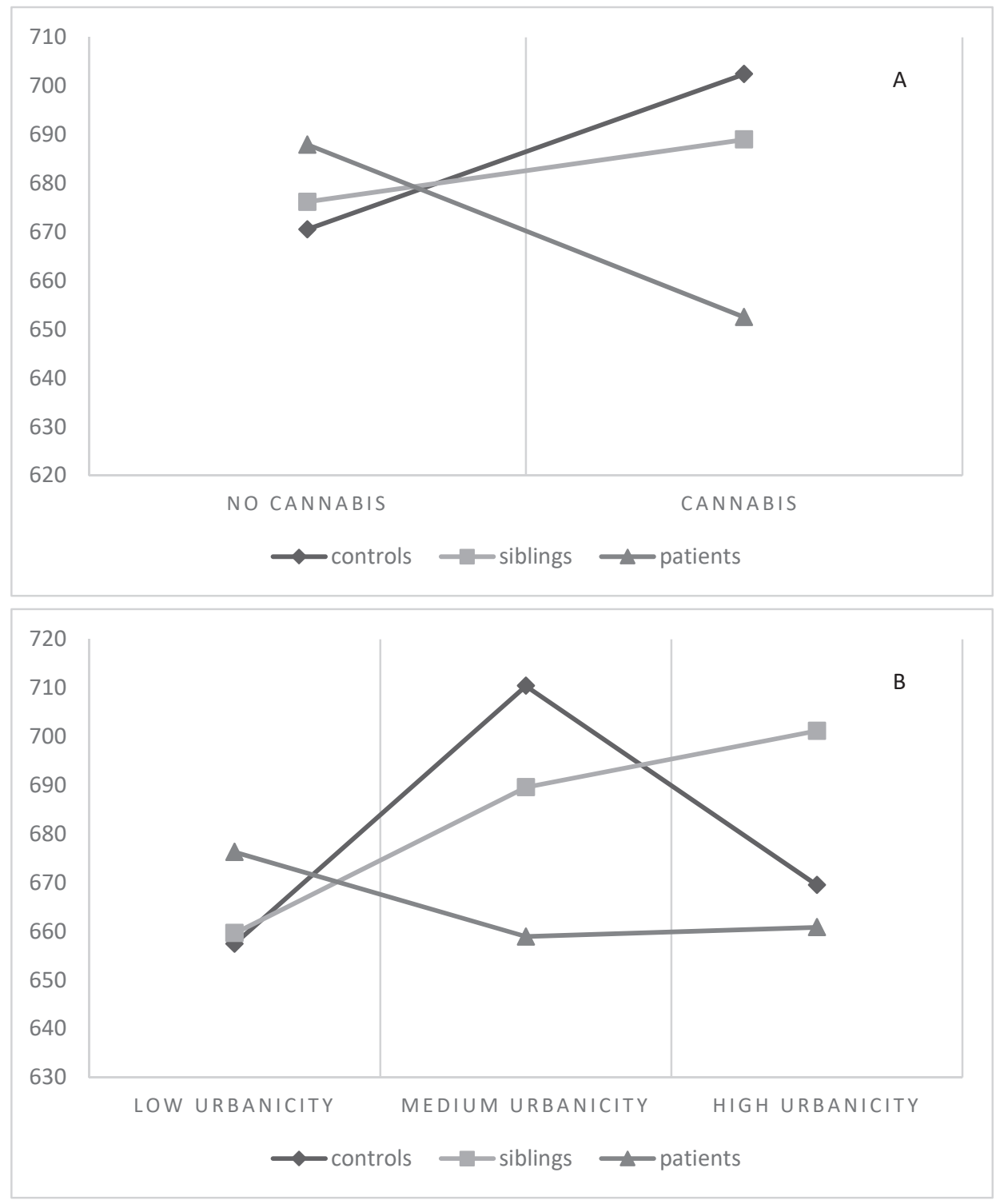

Figure 1. Interaction between environmental risk factors and group on gray matter volume in the male population. Gray matter volume in $\mathrm{mL}$, means are raw means not adjusted for covariates. A. Interaction between cannabis and group in the male population. B. Interaction between developmental urbanicity and group in the male population. 


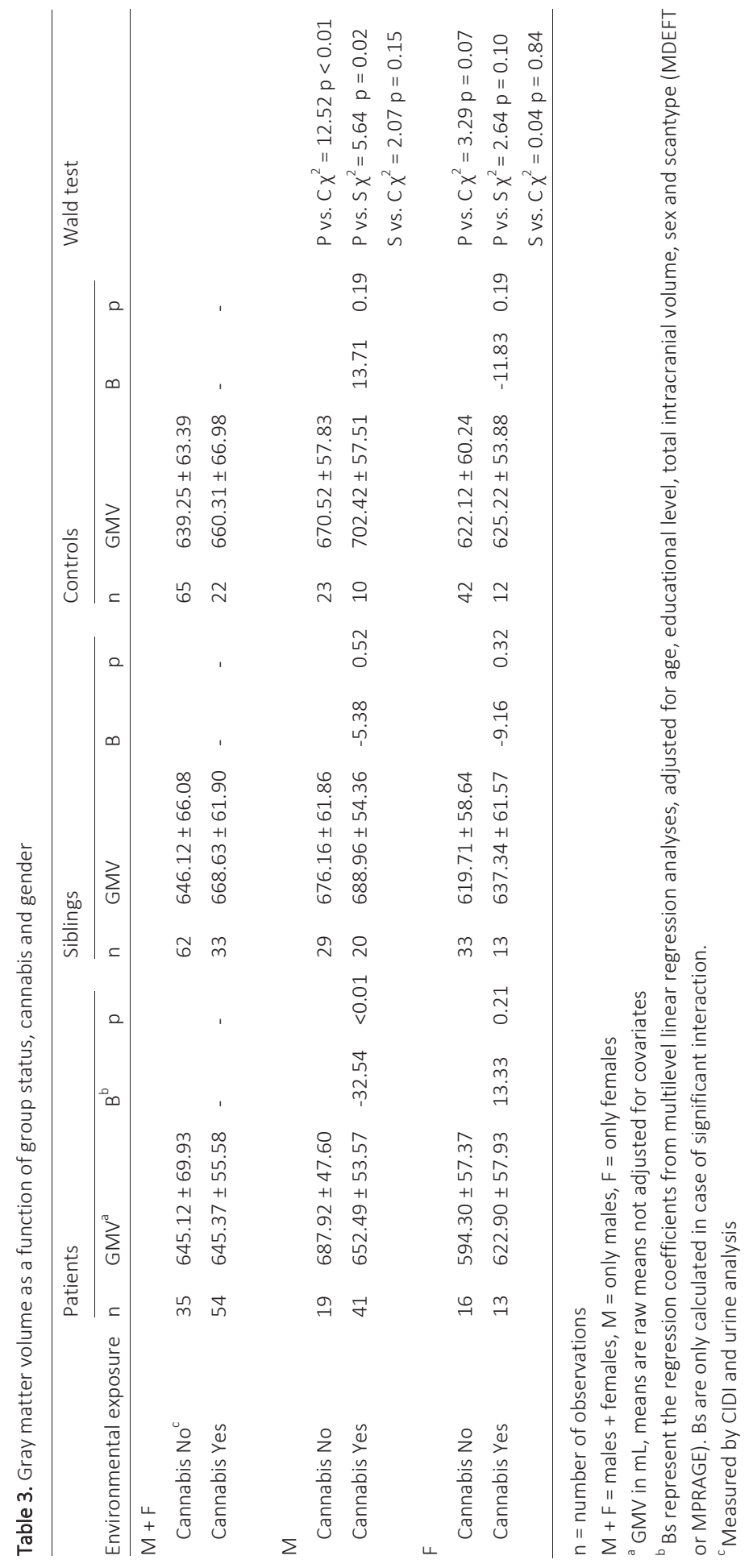




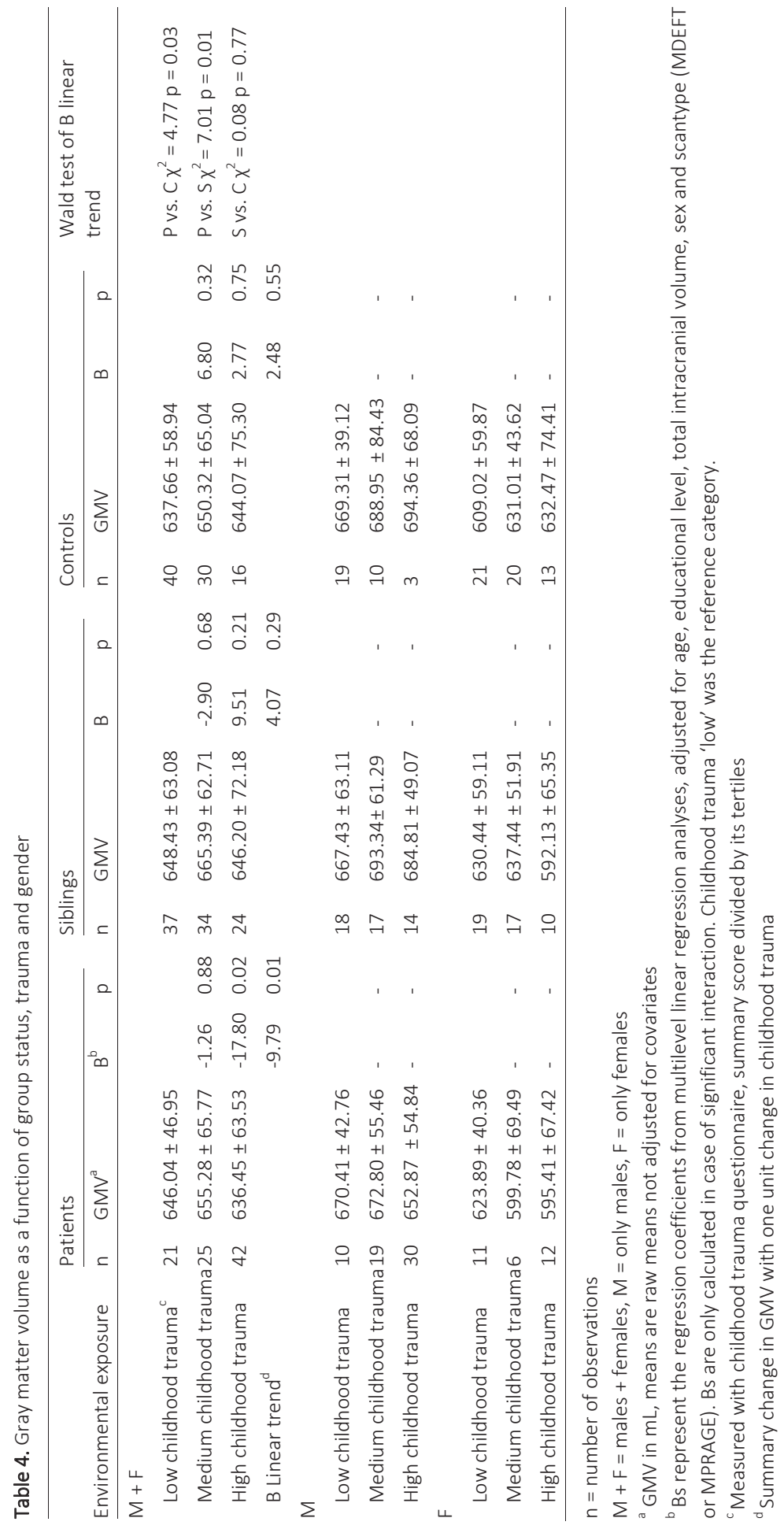




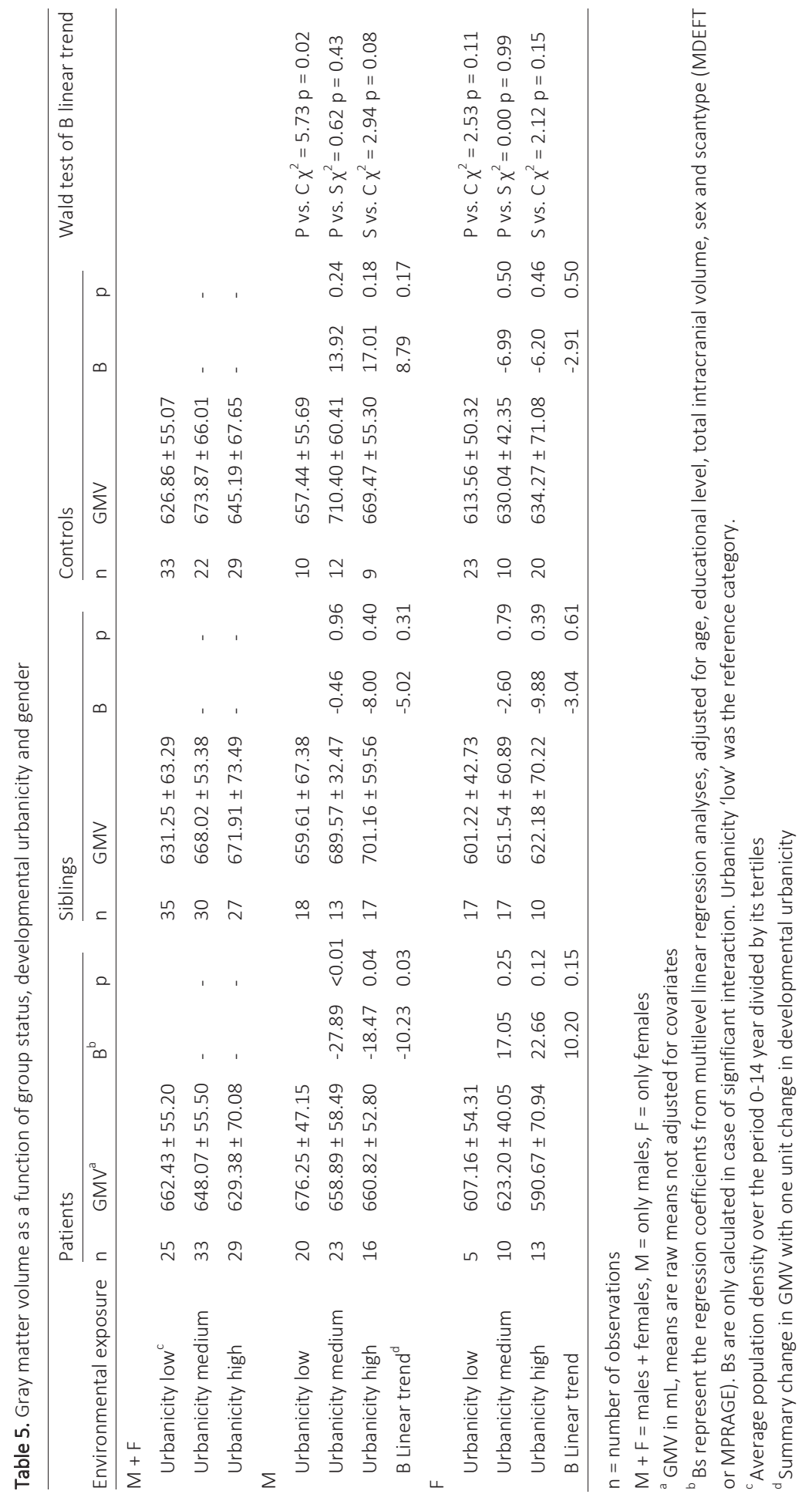




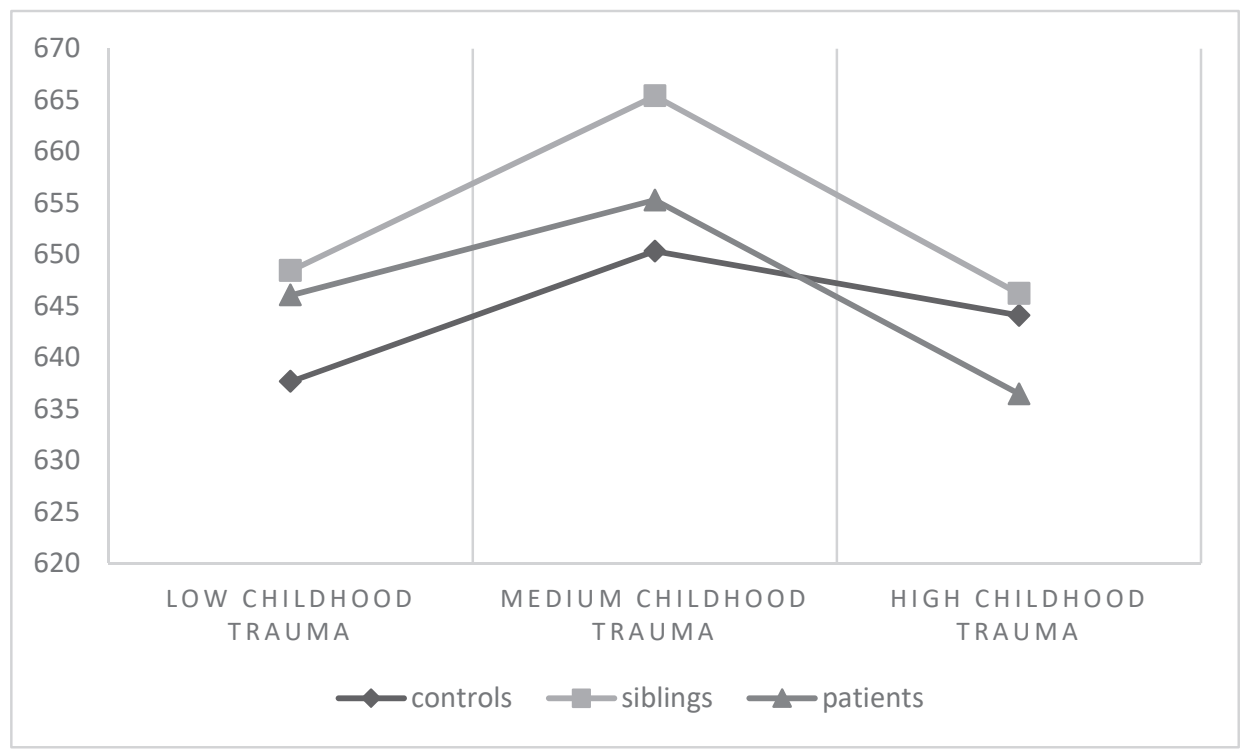

Figure 2. Interaction between childhood trauma and group on gray matter volume in the total study population (men and women). Gray matter volume in $\mathrm{mL}$, means are raw means not adjusted for covariates.

\section{Developmental urbanicity}

The three-way interactions were significant in the model of GMV. The two-way interactions were not statistically significant (Table 2). This did not change after the inclusion of cannabis and childhood trauma as additional confounders. Stratified effect sizes for the three-way interaction showed that in the male patients, there was a negative association between GMV and developmental urbanicity ( $B$ linear trend $=-10.23, p=0.03$ ). The direction of the effect was the same for the medium urbanicity group as for the high urbanicity group. The regression coefficients differed significantly between male patients and controls, whereas the difference between male patients and siblings was trend-significant. There was no significant association between developmental urbanicity and GMV in the other groups: male siblings and controls and female patients, siblings and controls (Table 5 and Figure 1b).

\section{Main effects of group, cannabis, childhood trauma, developmental urbanicity} and cumulative AP dose on GMV

GMV was significantly smaller in the patient group, compared to the controls $(B=-$ 17.21, $p<0.01)$ and compared to the sibling groups $(B=-11.27, p<0.01)$. Siblings did not differ significantly from controls $(B=-5.94, p=0.19)$. $G M V$ was smaller in individuals who ever used cannabis compared to persons who never used cannabis $(B=-8.28, p=0.03)$. 


\section{Chapter 7}

Cannabis was not associated with PANSS scores in the patient group (PANSS general symptoms: $B=0.84, p=0.57$; PANSS positive symptoms: $B=1.10, p=0.21$; PANSS negative symptoms: $B=0.41, p=0.71)$. GMV did not differ significantly across the three levels of childhood trauma ( $B$ linear trend $=-1.31, p=0.57$ ) and developmental urbanicity ( $B$ linear trend $=-2.20, p=0.33$ ) (Table 6). Cumulative AP dose was not associated with GMV (B linear trend $=0.0001, p=0.85$ ).

Table 6. Gray matter volume by group, cannabis use, childhood trauma and developmental urbanicity

\begin{tabular}{|c|c|c|c|c|}
\hline & $\mathrm{n}$ & $\begin{array}{l}\text { GMV } \\
\text { Mean } \pm S^{a}\end{array}$ & $B^{b}$ & $\mathrm{p}$ \\
\hline \multicolumn{5}{|l|}{ Group } \\
\hline Controls & 87 & $644.57 \pm 64.58$ & & \\
\hline Relatives & 95 & $653.93 \pm 65.22$ & -5.94 & 0.19 \\
\hline Patients & 89 & $645.27 \pm 61.24$ & -17.21 & $<0.01$ \\
\hline B Linear Trend ${ }^{c}$ & & & -8.72 & $<0.01$ \\
\hline \multicolumn{5}{|l|}{ Cannabis $^{d}$} \\
\hline No & 162 & $643.15 \pm 65.54$ & & \\
\hline Yes & 109 & $655.43 \pm 60.27$ & -8.28 & 0.03 \\
\hline \multicolumn{5}{|c|}{ Childhood Trauma $^{e}$} \\
\hline Low & 98 & $643.53 \pm 57.91$ & & \\
\hline Medium & 89 & $657.47 \pm 63.97$ & 2.14 & 0.62 \\
\hline High & 82 & $640.79 \pm 67.77$ & -3.06 & 0.51 \\
\hline B Linear Trend ${ }^{c}$ & & & -1.31 & 0.57 \\
\hline \multicolumn{5}{|c|}{ Developmental Urbanicity ${ }^{f}$} \\
\hline Low & 93 & $638.07 \pm 59.62$ & & \\
\hline Medium & 85 & $661.79 \pm 58.07$ & -4.33 & 0.35 \\
\hline High & 85 & $648.28 \pm 71.69$ & -4.42 & 0.32 \\
\hline B Linear Trend ${ }^{c}$ & & & -2.20 & 0.33 \\
\hline
\end{tabular}

$\mathrm{n}=$ number of observations

${ }^{a} \mathrm{GMV}$ in $\mathrm{mL}$, means are raw means not adjusted for covariates

${ }^{b}$ Bs represent the regression coefficients from multilevel linear regression analyses, adjusted for age, educational level, total intracranial volume (ICV), group (where group was not the independent variable), sex and scantype (MDEFT or MPRAGE), for group controls were the reference category, for childhood trauma 'low' childhood trauma was the reference category and for urbanicity 'low' urbanicity level was the reference category

${ }^{\mathrm{C}} \mathrm{B}$ linear trend represents the summary change in $\mathrm{CT}$ with one unit increase in exposure level

${ }^{\mathrm{d}}$ Measured by $\mathrm{CIDI}$ and urine analysis

${ }^{\mathrm{e}}$ Measured with childhood trauma questionnaire, summary score divided by its tertiles

${ }^{\mathrm{f}}$ Average population density over the period 0-14 year divided by its tertiles 


\section{DISCUSSION}

The present study examined whether alterations in whole brain GMV may be the outcome of differential sensitivity to three environmental exposures in individuals with (increased risk for) a psychotic disorder and controls. Additionally, differential effects in men and women were investigated. Cannabis use was significantly associated with reduced GMV in male patients, but not in siblings or controls. Similarly, higher levels of developmental urbanicity were significantly associated with reduced GMV in male patients, but not in siblings or controls. For childhood trauma, there was a negative association with GMV in the patient group, regardless of sex.

\section{Findings}

\section{Cannabis and GMV}

The present results on cannabis are partially in line with previous research, although studies are scarce and sex differences are not always modelled. Cannabis use in early adolescence was negatively associated with cortical thickness in male individuals with a high polygenic risk score for schizophrenia, whereas the association was absent in lowrisk male individuals or in low- or high-risk female individuals (14). Rais and colleagues showed that patients with first-episode schizophrenia who used cannabis had a more pronounced reduction of GMV [28] and cortical thinning (73) compared to non-using patients. Sex was added to the analyses as a covariate but the interaction was not examined. In a previous analysis from our group with cortical thickness (CT) as the outcome measure, it was shown that higher levels of cannabis use were associated with lower CT in patients and siblings (44). The interaction with sex was not explored. The present study showed that for GMV, like for $\mathrm{CT}$, there was a significant association with cannabis exposure, but only in male patients. In addition, there was no reduction of GMV in the siblings in relation to cannabis use, whereas for CT such an association was apparent. An explanation for this difference is that global GMV may represent a more crude brain measure than $\mathrm{CT}$, and whole brain regional $\mathrm{CT}$ (68 regions) multilevel analyses are more powerful. Malchow et al (74) reported lower volumes of the bilateral caudate nucleus in patients with a diagnosis of schizophrenia, and both a family history of schizophrenia and cannabis use, compared to patients with no or only one risk factor, not exploring sex effects. However, Kumra and colleagues (75) found that both schizophrenia and cannabis use disorder independently were associated with parietal lobe volume deficits, but there was no additive volumetric deficit in the group with comorbid schizophrenia and cannabis use. In patients with recent-onset schizophrenia and an additional diagnosis of cannabis abuse or dependence, there was no difference in global brain measures (including GMV) with respect to patients who never used cannabis (76). Again, these studies did not test sex interactions or (proxy) gene $x$ environment interactions. Koenders et al (77) found that male patients with a diagnosis of schizophrenia and 
comorbid cannabis use disorders had larger volumes of the putamen compared to those without comorbid cannabis use disorder; no other difference in brain volumes or cortical thickness were observed. In summary, previous studies are not consistent or do not provide comparative analyses. Further research or meta-analysis is required.

One of the proposed underlying mechanisms is that direct effects of tetrahydrocannabinol (THC), the active psychotropic ingredient of cannabis, may lead to increased striatal dopamine levels (78). Excessive dopamine has been associated with DNA damage and apoptosis (79) and stimulation of the dopamine D1 receptor may participate in dopamine-induced degeneration (80). However, there are also studies that report the opposite effect: cannabis use is associated with reduced dopamine synthesis capacity and blunting of dopamine release $(81,82)$. Further, THC is believed to affect synaptic plasticity and THC-related glutamergic effects may affect GMV through a mechanism of neurotoxicity $(78,83)$. Cannabis may also indirectly influence GMV: cannabis use is related to the incidence and persistence of psychotic symptoms (84) and it has been suggested that structural brain changes may be a consequence of the toxic effect of psychotic symptoms (85). In the patients of the current sample, post-hoc analyses showed absence of association between cannabis use and PANSS scores.

Sex-differences in age-related changes of GMV have been reported: in male adolescents steeper slopes of decreases in cortical gray matter are observed compared to female adolescents (86). Hypothetically, this sex-related reduction of GMV could be further deteriorated by the negative effects of THC on GMV, which could be an explanation for the observed sex differences in the current data. Further, the observed sex differences could be related to the protective role of estrogen (87). In support of this, a recent study showed that gray matter alterations in females with schizophrenia were more prominent in the postmenopausal period (88), possibly due to a decline in estrogen level. Thus, the GMV reduction associated with cannabis may be diminished by the neuroprotective and antipsychotic effects of estrogen in female patients (89), which also may be an explanation for the observed sex differences in the association between developmental urbanicity and GMV

The literature suggests that gene-environment interactions may underlie the association between cannabis and psychosis (90). The results of the present study partly support the hypothesis of gene-environment interaction, as GMV reductions were conditional on cannabis exposure in male patients with a psychotic disorder. However, in this study sample no (intermediate) effect was observed in the siblings, which would have further supported the hypothesis of gene $\mathrm{X}$ environment interaction.

\section{Childhood trauma and GMV}

The results regarding childhood trauma are partly in line with our previous analyses using CT as the outcome (26). In that study, there was evidence for an opposite association in patients and siblings: in patients, trauma was associated with a significant reduction in CT and in siblings with a (trend-significant) increase in CT. In the entire patient 
group of the current study, there was a statistically significant negative association between trauma and GMV, but no evidence for a positive association in siblings. Whole brain GMV reduction was not dependent on sex as the three-way interaction was not significant.

These results are in line with two previous studies, in which childhood sexual abuse (22) and adverse childhood experiences (23) were associated with reduced gray matter volume in patients with psychotic disorder. With regard to the effect of trauma in nonpsychotic populations, Tomoda and colleagues associated harsh corporal punishment with reduced prefrontal cortical GMV (31) and the witnessing of domestic violence during childhood with reduced visual cortex GMV and thickness in the general population (25). Physical neglect has also been associated with prefrontal cortex volume reduction in healthy controls compared to patients with a major depressive disorder (91). These results are in contrast with our findings since the control group showed no reduction of GMV in relation to childhood trauma.

Altered hypothalamic-pituitary-adrenal (HPA) axis functioning is a plausible biological mechanism, explaining the link between childhood trauma and GMV reduction (92). The HPA-axis and dopaminergic circuits in the brain affect each other, and altered HPAaxis functioning may lead to increased dopamine activity (93). Excessive dopamine release is associated with DNA damage and apoptosis (79) and stimulation of the D1 dopamine receptor may also participate in DA-induced degeneration (80), which could lead to GMV reduction. Also, the direct effects, of cortisol on the brain, atrophy and synaptic loss, through stimulating the glucocorticoid receptors, should be taken into account (94).

\section{Developmental urbanicity}

To our knowledge, this is the first study on the association between developmental urbanicity and structural brain alterations in the context of (familial risk for) psychotic disorder. Haddad and colleagues (95) studied GMV and urban upbringing in healthy subjects, reporting a negative correlation between urban upbringing and GMV of the right dorsolateral prefrontal cortex in men and women, and a negative correlation between urban upbringing and GMV in the perigenual anterior cingulate cortex in men only. Our results are in contrast, because we observed no associations between developmental urbanicity and GMV in the healthy control group. We did find a negative association between developmental urbanicity in the male patients. These divergent findings may reflect the complexity of urban upbringing as a risk factor. The urban environment consists of various elements. One of these elements or, more likely, a combination of elements may contribute to the actual risk factor for psychotic disorder, but still has to be discovered. Future research is needed to unravel which factor or which factors related to the urban environment mediate the higher risk for psychotic disorders, in order to facilitate studies that attempt to unravel underlying neurobiological pathways. 
Urban upbringing is associated with early life stress $(29,30)$, early life stress has been associated with cerebral alterations in humans (31) and in animals (32), through altered levels of neurohormones, neurotransmitters, and neurotrophic factors (33). Further, like childhood trauma, altered functioning of the HPA-axis is a plausible mechanism linking developmental urbanicity to GMV reduction. The observed sex differences could be related to the protective role of estrogen, as observed earlier (87).

\section{Methodological considerations}

Some limitations need to be addressed. Although significant group differences were found, the results need to be interpreted cautiously, since effect sizes were small and difficult to interpret in terms of biological and clinical relevance. In addition, some subgroup analyses suffered from lack of statistical power due to the small number of individuals in particular subgroups.

Patients reported more cannabis use and childhood trauma than the controls and the siblings, which makes the interpretation of the interaction more difficult since we cannot distinguish between moderation and mediation. However, it is unlikely that mediation is the only underlying mechanism because for most exposures in psychiatry, both mediation and moderation usually apply (96).

Systematic review and a longitudinal study $(97,98)$ suggest that AP treatment contributes to the brain structural changes observed in psychotic disorders, which could also be true for our study population. However, cumulative AP dose was not significantly associated with GMV in this sample, which makes it unlikely that this factor influenced the results.

Further, participants grew up in the Netherlands and Belgium which can be described as relative safe and developed countries. In other countries, urban-rural discrepancies may be more prominent. However, studies conducted in the Netherlands did report a higher incidence of psychotic disorders related to urban upbringing (99) indicating that, although the urban-rural difference may be relatively small, it is still large enough to have an effect.

The childhood trauma questionnaire is a retrospective and self-report questionnaire. This may raise questions of reliability, however studies on the use of the childhood trauma questionnaire indicate that this is a reliable measure for childhood trauma in patients $(100,101)$. In this study a biological measure, GMV, was used as dependent variable, which reduces the risk of reporting bias. However, it cannot be ruled out that brain alterations that are weakly associated with the illness still have an impact on the reporting of childhood trauma, cannabis or developmental urbanicity. Nevertheless, this applies to all observational neuroimaging studies that cannot randomly assign individuals to cannabis use, childhood trauma or developmental urbanicity. Longitudinal analyses are required to provide more robust answers on the relationship between cerebral phenotypes and genetic and environmental risk factors in psychotic disorder. 


\section{REFERENCES}

1. Sommer IE, Kahn RS. The contribution of neuroimaging to understanding schizophrenia; past, present, and future. Schizophrenia bulletin. 2015;41(1):1-3.

2. Haijma SV, Van Haren N, Cahn W, Koolschijn PC, Hulshoff Pol HE, Kahn RS. Brain volumes in schizophrenia: a meta-analysis in over 18000 subjects. Schizophrenia bulletin. 2013;39(5):1129-38.

3. Vita A, De Peri L, Deste G, Barlati S, Sacchetti E. The Effect of Antipsychotic Treatment on Cortical Gray Matter Changes in Schizophrenia: Does the Class Matter? A Meta-analysis and Meta-regression of Longitudinal Magnetic Resonance Imaging Studies. Biol Psychiatry. 2015;78(6):403-12.

4. Sprooten E, Papmeyer M, Smyth AM, Vincenz D, Honold S, Conlon GA, et al. Cortical thickness in firstepisode schizophrenia patients and individuals at high familial risk: a cross-sectional comparison. Schizophrenia research. 2013;151(1-3):259-64.

5. van Lutterveld R, van den Heuvel MP, Diederen KM, de Weijer AD, Begemann MJ, Brouwer RM, et al. Cortical thickness in individuals with non-clinical and clinical psychotic symptoms. Brain : a journal of neurology. 2014;137(Pt 10):2664-9.

6. Boos HB, Cahn W, van Haren NE, Derks EM, Brouwer RM, Schnack HG, et al. Focal and global brain measurements in siblings of patients with schizophrenia. Schizophrenia bulletin. 2012;38(4):814-25.

7. Goldman AL, Pezawas L, Mattay VS, Fischl B, Verchinski BA, Chen Q, et al. Widespread reductions of cortical thickness in schizophrenia and spectrum disorders and evidence of heritability. Archives of general psychiatry. 2009;66(5):467-77.

8. Vita A, De Peri L, Deste G, Sacchetti E. Progressive loss of cortical gray matter in schizophrenia: a metaanalysis and meta-regression of longitudinal MRI studies. Translational psychiatry. 2012;2:e190.

9. Cannon TD, Chung Y, He G, Sun D, Jacobson A, van Erp TG, et al. Progressive reduction in cortical thickness as psychosis develops: a multisite longitudinal neuroimaging study of youth at elevated clinical risk. Biological psychiatry. 2015;77(2):147-57.

10. van Haren NE, Schnack HG, Cahn W, van den Heuvel MP, Lepage C, Collins L, et al. Changes in cortical thickness during the course of illness in schizophrenia. Archives of general psychiatry. 2011;68(9):871-80.

11. European Network of National Networks studying Gene-Environment Interactions in S, van Os J, Rutten BP, Myin-Germeys I, Delespaul P, Viechtbauer W, et al. Identifying gene-environment interactions in schizophrenia: contemporary challenges for integrated, large-scale investigations. Schizophrenia bulletin. 2014;40(4):729-36.

12. Iyegbe C, Campbell D, Butler A, Ajnakina O, Sham P. The emerging molecular architecture of schizophrenia, polygenic risk scores and the clinical implications for GxE research. Social psychiatry and psychiatric epidemiology. 2014;49(2):169-82.

13. Geoffroy PA, Etain B, Houenou J. Gene x environment interactions in schizophrenia and bipolar disorder: evidence from neuroimaging. Front Psychiatry. 2013;4:136.

14. French L, Gray C, Leonard G, Perron M, Pike GB, Richer L, et al. Early Cannabis Use, Polygenic Risk Score for Schizophrenia and Brain Maturation in Adolescence. JAMA Psychiatry. 2015;72(10):1002-11.

15. Cannon TD, van Erp TG, Rosso IM, Huttunen M, Lonnqvist J, Pirkola T, et al. Fetal hypoxia and structural brain abnormalities in schizophrenic patients, their siblings, and controls. Archives of general psychiatry. 2002;59(1):35-41.

16. Moore TH, Zammit S, Lingford-Hughes A, Barnes TR, Jones PB, Burke M, et al. Cannabis use and risk of psychotic or affective mental health outcomes: a systematic review. Lancet. 2007;370(9584):319-28.

17. Rais M, Cahn W, Van Haren N, Schnack H, Caspers E, Hulshoff Pol H, et al. Excessive brain volume loss over time in cannabis-using first-episode schizophrenia patients. The American journal of psychiatry. 2008;165(4):490-6.

18. Epstein KA, Kumra S. Altered cortical maturation in adolescent cannabis users with and without schizophrenia. Schizophr Res. 2015;162(1-3):143-52.

19. Rigucci S, Marques TR, Di Forti M, Taylor H, Dell'Acqua F, Mondelli V, et al. Effect of high-potency cannabis on corpus callosum microstructure. Psychological medicine. 2016;46(4):841-54. 


\section{Chapter 7}

20. Zalesky A, Solowij N, Yucel M, Lubman DI, Takagi M, Harding IH, et al. Effect of long-term cannabis use on axonal fibre connectivity. Brain. 2012;135(Pt 7):2245-55.

21. Varese F, Smeets F, Drukker M, Lieverse R, Lataster T, Viechtbauer W, et al. Childhood adversities increase the risk of psychosis: a meta-analysis of patient-control, prospective- and cross-sectional cohort studies. Schizophrenia bulletin. 2012;38(4):661-71.

22. Sheffield JM, Williams LE, Woodward ND, Heckers S. Reduced gray matter volume in psychotic disorder patients with a history of childhood sexual abuse. Schizophrenia research. 2013;143(1):185-91.

23. Poletti S, Vai B, Smeraldi E, Cavallaro R, Colombo C, Benedetti F. Adverse childhood experiences influence the detrimental effect of bipolar disorder and schizophrenia on cortico-limbic grey matter volumes. Journal of affective disorders. 2016;189:290-7.

24. Andersen SL, Tomada A, Vincow ES, Valente E, Polcari A, Teicher MH. Preliminary evidence for sensitive periods in the effect of childhood sexual abuse on regional brain development. The Journal of neuropsychiatry and clinical neurosciences. 2008;20(3):292-301.

25. Tomoda A, Polcari A, Anderson CM, Teicher MH. Reduced visual cortex gray matter volume and thickness in young adults who witnessed domestic violence during childhood. Plos one. 2012; 7(12):e52528.

26. Bremner JD. Effects of traumatic stress on brain structure and function: relevance to early responses to trauma. Journal of trauma \& dissociation : the official journal of the International Society for the Study of Dissociation. 2005;6(2):51-68.

27. Vassos E, Pedersen CB, Murray RM, Collier DA, Lewis CM. Meta-analysis of the association of urbanicity with schizophrenia. Schizophrenia bulletin. 2012;38(6):1118-23.

28. Lederbogen F, Kirsch P, Haddad L, Streit F, Tost H, Schuch P, et al. City living and urban upbringing affect neural social stress processing in humans. Nature. 2011;474(7352):498-501.

29. van Os J, Driessen G, Gunther N, Delespaul P. Neighbourhood variation in incidence of schizophrenia. Evidence for person-environment interaction. The British journal of psychiatry : the journal of mental science. 2000;176:243-8.

30. Selten JP, Cantor-Graae E. Hypothesis: social defeat is a risk factor for schizophrenia? The British journal of psychiatry Supplement. 2007;51:s9-12.

31. Tomoda A, Suzuki H, Rabi K, Sheu YS, Polcari A, Teicher MH. Reduced prefrontal cortical gray matter volume in young adults exposed to harsh corporal punishment. Neurolmage. 2009;47 Suppl 2:T66-71.

32. Spinelli S, Chefer S, Suomi SJ, Higley JD, Barr CS, Stein E. Early-life stress induces long-term morphologic changes in primate brain. Archives of general psychiatry. 2009;66(6):658-65.

33. De Bellis MD. The psychobiology of neglect. Child maltreatment. 2005;10(2):150-72.

34. Aleman A, Kahn RS, Selten JP. Sex differences in the risk of schizophrenia: evidence from meta-analysis. Archives of general psychiatry. 2003;60(6):565-71.

35. Eranti SV, MacCabe JH, Bundy H, Murray RM. Gender difference in age at onset of schizophrenia: a meta-analysis. Psychological medicine. 2013;43(1):155-67.

36. Zhang XY, Chen da C, Xiu MH, Yang FD, Haile CN, Kosten TA, et al. Gender differences in never-medicated first-episode schizophrenia and medicated chronic schizophrenia patients. The Journal of clinical psychiatry. 2012;73(7):1025-33.

37. Cascio MT, Cella M, Preti A, Meneghelli A, Cocchi A. Gender and duration of untreated psychosis: a systematic review and meta-analysis. Early intervention in psychiatry. 2012;6(2):115-27.

38. Fisher H, Morgan C, Dazzan P, Craig TK, Morgan K, Hutchinson G, et al. Gender differences in the association between childhood abuse and psychosis. The British journal of psychiatry : the journal of mental science. 2009;194(4):319-25.

39. Decoster J, van Os J, Kenis G, Henquet C, Peuskens J, De Hert M, et al. Age at onset of psychotic disorder: cannabis, BDNF Val66Met, and sex-specific models of gene-environment interaction. American journal of medical genetics Part B, Neuropsychiatric genetics : the official publication of the International Society of Psychiatric Genetics. 2011;156B(3):363-9.

40. Abel KM, Drake R, Goldstein JM. Sex differences in schizophrenia. International review of psychiatry. 2010;22(5):417-28. 
41. Bora E, Fornito A, Yucel M, Pantelis C. The effects of gender on grey matter abnormalities in major psychoses: a comparative voxelwise meta-analysis of schizophrenia and bipolar disorder. Psychological medicine. 2011:1-13.

42. Suzuki M, Nohara S, Hagino H, Kurokawa K, Yotsutsuji T, Kawasaki Y, et al. Regional changes in brain gray and white matter in patients with schizophrenia demonstrated with voxel-based analysis of MRI. Schizophrenia research. 2002;55(1-2):41-54.

43. Maxwell ME. Genetics Initiative: Family Interview for Genetic Studies (FIGS): National Institute of Mental Health; 1992.

44. Habets P, Marcelis M, Gronenschild E, Drukker M, van Os J. Reduced cortical thickness as an outcome of differential sensitivity to environmental risks in schizophrenia. Biological psychiatry. 2011;69(5):487-94.

45. Kay SR, Fiszbein A, Opler LA. The positive and negative syndrome scale (PANSS) for schizophrenia. Schizophrenia bulletin. 1987;13(2):261-76.

46. van der Gaag M, Hoffman T, Remijsen M, Hijman R, de Haan L, van Meijel B, et al. The five-factor model of the Positive and Negative Syndrome Scale II: a ten-fold cross-validation of a revised model. Schizophrenia Research. 2006;85(1-3):280-7.

47. Andreasen NC, Pressler M, Nopoulos P, Miller D, Ho BC. Antipsychotic dose equivalents and dose-years: a standardized method for comparing exposure to different drugs. Biological psychiatry. 2010;67(3):255-62.

48. WHO. Composite International Diagnostic Interview. Geneva: World Health Organization. 1990.

49. Bernstein DP, Ahluvalia T, Pogge D, Handelsman L. Validity of the Childhood Trauma Questionnaire in an adolescent psychiatric population. Journal of the American Academy of Child and Adolescent Psychiatry. 1997;36(3):340-8.

50. Statistics Netherlands. Bevolking der Gemeenten van Nederland. The Hague: Central Bureau of Statistics publications; 1993.

51. Vanhaute E, Vrielinck S. Historische Databank van Lokale Statistieken- LOKSTAT. Gent: Universiteit Gent; 2013.

52. Dale AM, Fischl B, Sereno MI. Cortical surface-based analysis. I. Segmentation and surface reconstruction. Neurolmage. 1999;9(2):179-94.

53. Fischl B, Dale AM. Measuring the thickness of the human cerebral cortex from magnetic resonance images. Proceedings of the National Academy of Sciences of the United States of America. 2000;97(20):11050-5.

54. Fischl B, Liu A, Dale AM. Automated manifold surgery: constructing geometrically accurate and topologically correct models of the human cerebral cortex. IEEE transactions on medical imaging. 2001;20(1):70-80.

55. Dale AM, Sereno MI. Improved Localizadon of Cortical Activity by Combining EEG and MEG with MRI Cortical Surface Reconstruction: A Linear Approach. Journal of cognitive neuroscience. 1993;5(2):162-76.

56. Fischl B, Salat DH, Busa E, Albert M, Dieterich M, Haselgrove C, et al. Whole brain segmentation: automated labeling of neuroanatomical structures in the human brain. Neuron. 2002;33(3):341-55.

57. Fischl B, Salat DH, van der Kouwe AJ, Makris N, Segonne F, Quinn BT, et al. Sequence-independent segmentation of magnetic resonance images. Neurolmage. 2004;23 Suppl 1:S69-84.

58. Fischl B, Sereno MI, Dale AM. Cortical surface-based analysis. II: Inflation, flattening, and a surface-based coordinate system. Neurolmage. 1999;9(2):195-207.

59. Fischl B, Sereno MI, Tootell RB, Dale AM. High-resolution intersubject averaging and a coordinate system for the cortical surface. Human brain mapping. 1999;8(4):272-84.

60. Fischl B, van der Kouwe A, Destrieux C, Halgren E, Segonne F, Salat DH, et al. Automatically parcellating the human cerebral cortex. Cerebral cortex. 2004;14(1):11-22.

61. Han X, Jovicich J, Salat D, van der Kouwe A, Quinn B, Czanner S, et al. Reliability of MRI-derived measurements of human cerebral cortical thickness: the effects of field strength, scanner upgrade and manufacturer. Neurolmage. 2006;32(1):180-94.

62. Jovicich J, Czanner S, Greve D, Haley E, van der Kouwe A, Gollub R, et al. Reliability in multi-site structural MRI studies: effects of gradient non-linearity correction on phantom and human data. Neurolmage. 2006;30(2):436-43. 
63. Segonne F, Dale AM, Busa E, Glessner M, Salat D, Hahn HK, et al. A hybrid approach to the skull stripping problem in MRI. Neurolmage. 2004;22(3):1060-75.

64. Sled JG, Zijdenbos AP, Evans AC. A nonparametric method for automatic correction of intensity nonuniformity in MRI data. IEEE transactions on medical imaging. 1998;17(1):87-97.

65. Segonne F, Pacheco J, Fischl B. Geometrically accurate topology-correction of cortical surfaces using nonseparating loops. IEEE transactions on medical imaging. 2007;26(4):518-29.

66. Desikan RS, Segonne F, Fischl B, Quinn BT, Dickerson BC, Blacker D, et al. An automated labeling system for subdividing the human cerebral cortex on MRI scans into gyral based regions of interest. Neurolmage. 2006;31(3):968-80.

67. Kuperberg GR, Broome MR, McGuire PK, David AS, Eddy M, Ozawa F, et al. Regionally localized thinning of the cerebral cortex in schizophrenia. Archives of general psychiatry. 2003;60(9):878-88.

68. Salat DH, Buckner RL, Snyder AZ, Greve DN, Desikan RS, Busa E, et al. Thinning of the cerebral cortex in aging. Cerebral cortex. 2004;14(7):721-30.

69. Reuter M, Schmansky NJ, Rosas HD, Fischl B. Within-subject template estimation for unbiased longitudinal image analysis. Neurolmage. 2012;61(4):1402-18.

70. Gronenschild EH, Burgmans S, Smeets F, Vuurman EF, Uylings HB, Jolles J. A time-saving and facilitating approach for segmentation of anatomically defined cortical regions: MRI volumetry. Psychiatry research. 2010;181(3):211-8.

71. Zhang Y, Brady M, Smith S. Segmentation of brain MR images through a hidden Markov random field model and the expectation-maximization algorithm. IEEE transactions on medical imaging. 2001;20(1):45-57.

72. StataCorp. Stata Statistical Software. Release 10.0 ed: College Station, TX: Stata Corporation; 2007.

73. Rais M, van Haren NE, Cahn W, Schnack HG, Lepage C, Collins L, et al. Cannabis use and progressive cortical thickness loss in areas rich in CB1 receptors during the first five years of schizophrenia. European neuropsychopharmacology : the journal of the European College of Neuropsychopharmacology. 2010;20(12):855-65.

74. Malchow B, Hasan A, Schneider-Axmann T, Jatzko A, Gruber O, Schmitt A, et al. Effects of cannabis and familial loading on subcortical brain volumes in first-episode schizophrenia. European archives of psychiatry and clinical neuroscience. 2013;263 Suppl 2:S155-68.

75. Kumra S, Robinson P, Tambyraja R, Jensen D, Schimunek C, Houri A, et al. Parietal lobe volume deficits in adolescents with schizophrenia and adolescents with cannabis use disorders. Journal of the American Academy of Child and Adolescent Psychiatry. 2012;51(2):171-80.

76. Cahn W, Hulshoff Pol HE, Caspers E, van Haren NE, Schnack HG, Kahn RS. Cannabis and brain morphology in recent-onset schizophrenia. Schizophrenia research. 2004;67(2-3):305-7.

77. Koenders L, Machielsen MW, van der Meer FJ, van Gasselt AC, Meijer CJ, van den Brink W, et al. Brain volume in male patients with recent onset schizophrenia with and without cannabis use disorders. Journal of psychiatry \& neuroscience : JPN. 2014;39(6):140081.

78. Kuepper R, Morrison PD, van Os J, Murray RM, Kenis G, Henquet C. Does dopamine mediate the psychosis-inducing effects of cannabis? A review and integration of findings across disciplines. Schizophrenia research. 2010;121(1-3):107-17.

79. Luo Y, Hattori A, Munoz J, Qin ZH, Roth GS. Intrastriatal dopamine injection induces apoptosis through oxidation-involved activation of transcription factors AP-1 and NF-kappaB in rats. Molecular pharmacology. 1999;56(2):254-64.

80. Wersinger C, Chen J, Sidhu A. Bimodal induction of dopamine-mediated striatal neurotoxicity is mediated through both activation of D1 dopamine receptors and autoxidation. Molecular and cellular neurosciences. 2004;25(1):124-37.

81. Bloomfield MA, Morgan CJ, Egerton A, Kapur S, Curran HV, Howes OD. Dopaminergic function in cannabis users and its relationship to cannabis-induced psychotic symptoms. Biological psychiatry. 2014;75(6):470-8.

82. Thompson JL, Urban N, Slifstein M, Xu X, Kegeles LS, Girgis RR, et al. Striatal dopamine release in schizophrenia comorbid with substance dependence. Molecular psychiatry. 2013;18(8):909-15. 
83. Stone JM, Day F, Tsagaraki H, Valli I, McLean MA, Lythgoe DJ, et al. Glutamate dysfunction in people with prodromal symptoms of psychosis: relationship to gray matter volume. Biological psychiatry. 2009;66(6):533-9.

84. Kuepper R, van Os J, Lieb R, Wittchen HU, Hofler M, Henquet C. Continued cannabis use and risk of incidence and persistence of psychotic symptoms: 10 year follow-up cohort study. Bmj. 2011;342:d738.

85. Lieberman J, Chakos M, Wu H, Alvir J, Hoffman E, Robinson D, et al. Longitudinal study of brain morphology in first episode schizophrenia. Biological psychiatry. 2001;49(6):487-99.

86. Paus T, Nawaz-Khan I, Leonard G, Perron M, Pike GB, Pitiot A, et al. Sexual dimorphism in the adolescent brain: Role of testosterone and androgen receptor in global and local volumes of grey and white matter. Hormones and behavior. 2010;57(1):63-75.

87. Szymanski S, Lieberman JA, Alvir JM, Mayerhoff D, Loebel A, Geisler S, et al. Gender differences in onset of illness, treatment response, course, and biologic indexes in first-episode schizophrenic patients. The American journal of psychiatry. 1995;152(5):698-703.

88. Fukuta H, Ito I, Tateno A, Nogami T, Taiji Y, Arakawa R, et al. Effects of menopause on brain structural changes in schizophrenia. Psychiatry and clinical neurosciences. 2013;67(1):3-11.

89. Hayes E, Gavrilidis E, Kulkarni J. The role of oestrogen and other hormones in the pathophysiology and treatment of schizophrenia. Schizophrenia research and treatment. 2012;2012:540273.

90. Henquet C, Di Forti M, Morrison P, Kuepper R, Murray RM. Gene-environment interplay between cannabis and psychosis. Schizophrenia bulletin. 2008;34(6):1111-21.

91. Frodl T, Reinhold E, Koutsouleris N, Reiser M, Meisenzahl EM. Interaction of childhood stress with hippocampus and prefrontal cortex volume reduction in major depression. Journal of psychiatric research. 2010;44(13):799-807.

92. Heim C, Newport DJ, Heit S, Graham YP, Wilcox M, Bonsall R, et al. Pituitary-adrenal and autonomic responses to stress in women after sexual and physical abuse in childhood. JAMA : the journal of the American Medical Association. 2000;284(5):592-7.

93. Walker EF, Diforio D. Schizophrenia: a neural diathesis-stress model. Psychological review. 1997;104(4):667-85.

94. Cerqueira JJ, Catania C, Sotiropoulos I, Schubert M, Kalisch R, Almeida OF, et al. Corticosteroid status influences the volume of the rat cingulate cortex - a magnetic resonance imaging study. Journal of psychiatric research. 2005;39(5):451-60.

95. Haddad L, Schafer A, Streit F, Lederbogen F, Grimm O, Wust S, et al. Brain Structure Correlates of Urban Upbringing, an Environmental Risk Factor for Schizophrenia. Schizophrenia bulletin. 2014.

96. van Os J, Henquet C, Stefanis N. Cannabis-related psychosis and the gene-environment interaction: comments on Ferdinand et Al. 2005. Addiction. 2005;100(6):874-5.

97. Navari S, Dazzan P. Do antipsychotic drugs affect brain structure? A systematic and critical review of MRI findings. Psychological medicine. 2009;39(11):1763-77.

98. Andreasen NC, Liu D, Ziebell S, Vora A, Ho BC. Relapse duration, treatment intensity, and brain tissue loss in schizophrenia: a prospective longitudinal MRI study. The American journal of psychiatry. 2013;170(6):609-15.

99. Marcelis M, Takei N, van Os J. Urbanization and risk for schizophrenia: does the effect operate before or around the time of illness onset? Psychological medicine. 1999;29(5):1197-203.

100. Goodman LA, Thompson KM, Weinfurt K, Corl S, Acker P, Mueser KT, et al. Reliability of reports of violent victimization and posttraumatic stress disorder among men and women with serious mental illness. Journal of traumatic stress. 1999;12(4):587-99.

101. Fisher HL, Craig TK, Fearon P, Morgan K, Dazzan P, Lappin J, et al. Reliability and comparability of psychosis patients' retrospective reports of childhood abuse. Schizophrenia bulletin. 2011;37(3):546-53. 

Chapter 8

General discussion 

The overall aim of this thesis was to study environmental risk factors for psychotic disorder and potential pathways between these risk factors and psychotic disorder, with special emphasis on childhood urbanicity, but also childhood trauma, cannabis and influenza. First, epidemiological and ecological studies were performed, second a multimodal approach was applied: neuroimaging phenotypes and epidemiology were combined to study these risk factors. In addition to patients with psychotic disorder, healthy siblings of patients with psychotic disorder were included in most studies. Studying the effects of environmental risk factors in healthy siblings is a favorable approach, as the siblings share a portion of their genes but there is no bias by the (pathologic) effects of the psychotic disorder or by the treatment of psychotic disorder. In this discussion findings from the separate studies will be integrated and discussed along the lines of existing literature.

\section{CHILDHOOD URBANICITY}

Although studies are consistent in showing that childhood urbanicity is associated with elevated risk for psychotic disorder, the underlying mechanisms remain to be elucidated. In this thesis, different approaches were utilized in an attempt to unravel the association between childhood urbanicity and psychotic disorder. First, a summary of the main findings for childhood urbanicity of each study is presented, second these separate findings are integrated and discussed in a wider context.

\section{Findings}

In chapter 3 behavioral sensitization was tested as mechanism linking childhood urbanicity to psychotic disorder. The results of this study showed that patients with psychotic disorder displayed higher levels of negative affect (NA) in relation to subjective stress (SS), regardless of level of urbanicity, which is a replication of previous research $(1,2)$. Contrary to our expectations, results indicated that urbanicity was associated with blunted rather than enhanced increase in NA after exposure to SS, consistently across the three groups (patients, siblings and controls).

Next, the association between childhood urbanicity, childhood trauma and psychotic disorder was examined (chapter 4). Childhood urbanicity appeared to moderate the association between childhood trauma and psychotic disorder: the risk-increasing effect of childhood trauma for psychotic disorder was stronger for higher levels of childhood urbanicity. Childhood urbanicity appeared to strengthen the association between childhood neglect and psychotic disorder more than the association between childhood abuse and psychotic disorder. Further, our results suggested that individuals who later develop psychotic disorder could be more susceptible to exposure to childhood trauma when growing up in an urban environment. 
In chapter 5 educational achievements in psychotic disorder were studied. Overall, participants had a higher level of education than their parents. This difference was significantly less in the patient group and the healthy siblings were in between the controls and the patients. Higher levels of childhood urbanicity were associated with decreased intergenerational difference in educational achievements. However, there was no evidence that the association between intergenerational educational achievements and childhood urbanicity differed for patients, siblings or controls.

In chapter 6 and 7 structural neuroimaging was used to examine cerebral phenotypes in relation to environmental risk factors. We found that the negative association between (familial risk for) psychotic disorder and cortical thickness (CT) was not moderated by childhood urbanicity. In contrast, the negative association between psychotic disorder and gray matter volume (GMV) was moderated by childhood urbanicity in the male patients only. In the male patients, there was a negative association between GMV and childhood urbanicity.

Nonspecific findings

Childhood urbanicity appeared to be associated with characteristics that are specific for psychotic disorder, and with characteristics that are not specific for psychotic disorder. Blunted stress reactivity and decreased intergenerational educational achievements are non-specific outcomes, which were observed in the entire study population, i.e., patients with psychotic disorder, healthy siblings and controls. These non-specific results are interesting because they may provide knowledge about the impact of urbanicity on the general population, and, although the findings were not specific for psychotic disorder, it is still conceivable that they could contribute to the development of psychotic disorder.

With respect to blunted stress reactivity, it is possible that the urban environment involves exposure to more and stronger stressors and that individuals may develop behavioral adaptation. The behavioral sensitization theory argues that previous exposure to stress increases sensitivity to stress in daily life (3). Our results suggest a different process for exposure to stress in the urban environment: instead of increasing reactivity, persons seem to become less responsive to stress resulting in blunted increase in negative affect and secondary behavioral withdrawal, adaptation that could be (partly) necessary to survive in an urban environment. Thus, in the case of liability to psychotic disorder, reduced interaction with the social world may result in failure to correct early reality distortion (complying with the reality testing hypothesis (4)) and subsequently may give rise to overt psychotic symptoms.

It is conceivable that decreased intergenerational achievements in education, are associated with a subordinate position: when a person receives results or evaluations which are less compared to their peers, this could result in feelings of inferiority or in lesser judgement by others. A subordinate position is an example of social defeat. Social 
defeat has been proposed as risk factor for psychotic disorder and has been associated with sensitization of the mesolimbic dopamine system (5). Thus, decreased intergenerational achievements associated with the urban environment could contribute to development of psychotic disorder through higher levels of social defeat.

\section{Findings specific for psychotic disorder}

With regard to the more specific results for psychotic disorder, our results showed that childhood urbanicity moderates the association between childhood trauma and psychotic disorder. An explanation for this finding is that urban upbringing creates additional exposure to stress (6), for example through higher levels of social isolation (7) and social defeat (5). This background stress level may increase any effect of stress as a consequence of childhood trauma. Our results also suggested that individuals who later developed psychotic disorder could be more susceptible to exposure to childhood trauma when growing up in an urban environment. Because childhood trauma (8) and childhood urbanicity (9) both appear to be substantial risk factors for psychotic disorders, growing up in a city and the subsequently higher risk for childhood trauma (gene environment co-association: exposure to environmental conditions depends on an individual's genotype) will even further increase the risk of psychotic disorder. The association between childhood urbanicity and childhood trauma in the psychotic patients could be explained by social cognition. From meta-analytic evidence, it is known that social cognition is impaired in psychotic disorder (10). Research in young persons, age 13-24, at genetic and clinical high-risk, imply that social cognition already could be impaired before the onset of the psychotic disorder (11). The urban environment is associated with higher levels of social competition. More social competition combined with impaired social cognition, could increase the likelihood to experience interpersonal adversity and, possibly, childhood trauma. Therefore, alterations in social cognition before the onset of psychotic disorder may represent a candidate explanation for the association between childhood urbanicity and childhood trauma in persons who later developed a psychotic disorder.

\section{Childhood urbanicity and cerebral phenotypes (GMV, CT)}

Childhood urbanicity was associated with reduced GMV but not with reduced $\mathrm{CT}$ in the male patients. These results may seem contrasting. However, GMV is a measure that not only entails $\mathrm{CT}$, but also surface area and gyrification. It is possible that childhood urbanicity negatively affects surface area or gyrification, and not CT. A recent study by Smith and colleagues (12), found that in men with first-episode psychosis perinatal hypoxia was associated with surface area and gyrification, slow fetal growth was associated with surface area. Neither perinatal hypoxia nor slow fetal growth were associated with $\mathrm{CT}$. The authors explained this by the timing: CT matures late, shortly before pu- 
berty, while perinatal hypoxia and slow fetal growth are obstetric complications, which may impact early brain development. Women were not included in this study and since previous studies $(13,14)$ have shown that there are sex differences in cortical development these results may not be generalizable to women. Mutlu and colleagues (14) found that during adolescence women display higher rates of cortical thinning of the right temporal cortex, the left temporoparietal junction and the left orbitofrontal cortex. A later study by Vijayakumar (13) did not find a higher rate of cortical thinning, but they did observe sex differences across time in relation to cortical volume and surface area. A possible explanation of our findings is that childhood urbanicity has an effect on surface area and/or gyrification in the first years of life and not on CT. However, previous research on the association between childhood urbanicity and schizophrenia (15) has not shown that any specific age period during childhood particularly increases the risk for schizophrenia.

GMV reduction in association with childhood urbanicity was only observed in the male patients with psychotic disorder. In an earlier study, male adolescents showed steeper slopes of decreases in cortical gray matter compared to female adolescents (16). Hypothetically, sex-related reduction of GMV could be further deteriorated by the negative effects of childhood urbanicity on GMV. Women could be (partially) protected for this process of reduction by the protective role of estrogen (17). In support of this, a recent study showed that gray matter alterations in females with schizophrenia were more prominent postmenopausal than premenopausal (18), possibly due to a decline in estrogen level. Thus, the GMV reduction associated with higher childhood urbanicity levels may be diminished by the neuro-protective and antipsychotic effects of estrogen in female patients (19), which also very well may be an explanation for the observed sex differences in the association between cannabis and GMV (see cannabis).

It is likely that stress plays an important role in the association between reduced GMV and childhood urbanicity. Childhood urbanicity is associated with early life stress (5, 7), which has been associated with cerebral alterations, in humans (20) and in animals (21). Through elevated level of stress chemicals, such as glucocorticoids and catecholamines, stress exposure may lead to accelerated loss of neurons, delays in myelination, deviations in pruning, inhibition of neurogenesis or a stress induced decrease in brain growth factors (22). For example, exposure to (social) stress is thought to lead to a blunted cortical dopamine response and reduced inhibition of mesolimbic dopamine release, resulting in increased subcortical dopamine response $(23,24)$. Excessive dopamine, in turn, has been associated with DNA damage and apoptosis (25) and stimulation of the dopamine D1 receptor may participate in dopamine-induced degeneration (26).

To our knowledge, this is the first study on the relation between childhood urbanicity and structural brain alterations in the context of (familial risk for) psychotic disorder. Haddad and colleagues (27) studied GMV and urban upbringing in healthy subjects. They detected a negative correlation between urban upbringing and GMV of the right dorsolateral prefrontal cortex in men and women, and a negative correlation between 
urban upbringing and GMV in the perigenual anterior cingulate cortex in men only. Our results are in contrast, because we observed no associations between childhood urbanicity and CT or GMV in the healthy control group. These divergent findings may reflect the complexity of urban upbringing as a risk factor, but could also be related to methodological issues such as differences in scanning sequence and population, participants of study by Haddad and colleagues were approximately 2 years older and more than $50 \%$ was male, in our study $38 \%$ was male.

In future research, it would be interesting to not only look at CT and GMV, but also at surface area and gyrification: changes in surface area and gyrification could be an explanation for the reduced GMV in the absence of reduced CT. Sex differences need further exploration and level of urbanicity at birth and first years of life could be compared to the level of urbanicity in later childhood regarding changes in CT, surface area and gyrification.

\section{MATERNAL INFLUENZA}

A meta-analysis was conducted to examine whether birth during the 9-month period after the influenza pandemic of 1957 was a risk factor for schizophrenia. Three types of studies were distinguished. Type A studies included 8 ecological studies from Europe, America and Australia that compared the risk of schizophrenia among subjects born any time in the 9 months after the pandemic with that among those born in the corresponding periods of time in the previous and/or subsequent year. Although it was not known whether the mothers actually had influenza, these children were considered to be exposed. Recent publications on influenza pandemic assume that $50 \%$ of the population is infected. Type B studies were ecological studies from Japan. In Japan the influenza 1957 pandemic came in two waves, therefore the studies from Japan were considered to be different from the other ecological studies. Two studies compared the risk of schizophrenia among children whose mother reported having had influenza during the pandemic with that among those mothers reported not having had influenza during the pandemic, type $\mathrm{C}$ studies. The pooled results for the 3 types of studies were negative, i.e. there was no evidence for increased risk of schizophrenia after being exposed in utero to the 1957 pandemic of influenza. From this meta-analysis, the evidence to support the maternal influenza hypothesis is insufficient.

\section{Recent studies on influenza and psychotic disorder}

After our meta-analysis another meta-analysis was conducted by Cai and colleagues in 2015 (28), their conclusion was that gestational influenza did increases the risk of psychosis in adults, which is remarkable as it only includes 4 ecological studies: 3 of these ecological studies were also included in our meta-analysis (our meta-analysis contained 


\section{Chapter 8}

11 ecological studies), one was not included in our meta-analysis because it assessed the association between influenza and affective disorders (29). They further included 3 non-ecological studies in which maternal influenza was determined by medical records or serological testing. These were not included in our meta-analysis because they were not related to the influenza pandemic of 1957. One of these studies again investigated the association between influenza and bipolar disorder and was not comparable to the other studies (30). Thus, the result of this meta-analysis should be interpreted with caution. One new study was conducted after our meta-analysis in which decreased birth weight and the association with prenatal serologically determined influenza in psychotic disorder was examined (31). They found that patients with psychotic disorder had significantly lower birth weight if they had been exposed to influenza during pregnancy, this association was absent for the healthy comparison subjects. Their explanation for this finding was that factors associated with liability for psychotic disorder can make the fetus more vulnerable for obstetric complications like influenza, which can result in decreased birth weight. This study was not designed to investigate the risk of developing psychotic disorder after influenza exposure in utero.

Influenza is one of the most common infectious illnesses (32), affecting persons of all ages including women in their fertile period. The results of the current meta-analysis are reassuring with respect to the risk of psychotic disorder after exposure to influenza in utero and do not suggest that any extra precautions should be taken regarding the risk of psychotic disorder. However, influenza during pregnancy is certainly not without risks, for example pregnant hospitalized women with influenza infection have increased rates of preterm birth and fetal/neonatal death are reported (33). Therefore, antiviral treatment or vaccination for pregnant women should be considered (33). Higher occurrence of pregnancy and birth complications (34) or infections (35) are proposed mechanisms linking childhood urbanicity to psychotic disorder. The current meta-analysis makes it unlikely that higher incidence of influenza in an urban environment is one of the factors mediating the risk for psychotic disorder.

\section{CHILDHOOD TRAUMA}

\section{Findings}

In summary, the main findings for childhood trauma in this thesis are (the first two findings were discussed in the section of childhood urbanicity):

1. The association between childhood trauma and psychotic disorder was moderated by childhood urbanicity: the risk-increasing effect of childhood trauma for psychotic disorder was stronger for higher levels of childhood urbanicity; 
2. Individuals who later develop psychotic disorder could be more susceptible to exposure to childhood trauma when growing up in an urban environment: higher levels of childhood urbanicity were associated with higher trauma scores in the patient group;

3. Childhood trauma did not affect intergenerational educational achievements, and childhood trauma was not differentially associated with intergenerational educational differences across psychotic patients, siblings, and in controls;

4. Higher levels of childhood trauma were significantly associated with reduced GMV in patients, both men and women, with psychotic disorder.

\section{Childhood trauma and intergenerational educational achievements}

Previous research has associated childhood trauma with lower academic performance $(36,37)$, adverse effects on educational attainment (38), and academic delay (37). We assessed educational level relative to parental education, which is different from previous research, thus our results are not necessarily in contrast with previous studies. The study sample in this thesis was large enough, 1507 participants, to identify a potential effect of childhood trauma on educational achievements. In line with our results, Boden and colleagues (39) found that physical and sexual abuse negatively affected educational achievements, but this effect was no longer significant after inclusion of social, family and individual factors, such as parental education, as confounders. Thus, our results and the results from the study from Boden and colleagues suggest that the context, such as level of parental education, should be considered when studying educational achievements in association with childhood trauma.

\section{Childhood trauma and GMV}

With regard to the association between childhood trauma and GMV reduction in patients with psychotic disorder, stress-induced altered functioning of the hypothalamicpituitary-adrenal (HPA) axis may be considered as underlying mechanism (40,41). The HPA-axis and dopaminergic circuits in the brain affect each other, and altered HPA-axis functioning may lead to increased dopamine activity (42). Also, the direct effects, atrophy and synaptic loss, of cortisol on the brain, through stimulation of the glucocorticoid receptors, should be taken into account (43). Lastly, increased levels of dopamine in response to stress, through blunted cortical dopamine response and reduced inhibition of mesolimbic dopamine release (23), may result in dopamine induced degeneration $(25,26)$.

Previous research on the association between gray matter alterations and childhood trauma in psychotic disorder revealed similar results, although studies are scarce. Earlier analyses from our group using CT as the outcome (26), found that childhood trauma 
was associated with a reduction in CT in patients with psychotic disorder. Sheffield and colleagues showed an association between childhood trauma and reduced GMV in psychotic disorder (44). Reduced cortico-limbic GMV in patients with schizophrenia has been reported in individuals with high, but not low, levels of adverse childhood experiences, patients with bipolar disorder showed similar results but to a lesser extent (45). The finding of reduced GMV after exposure to childhood trauma may very well be nonspecific for psychotic disorder, as similar results have been found for depressive disorder $(46,47)$, bipolar disorder (48) and posttraumatic stress disorder (49).

Our results in the healthy controls may seem at contrast with previous research on the effect of childhood trauma in the non-psychotic population, since we did not found an association between GMV and childhood trauma in this group. Childhood maltreatment in non-psychotic populations has been associated with alterations in the anterior cingulate cortex, dorsal lateral prefrontal cortex and orbitofrontal cortex (50). We could not retrieve any negative studies on childhood trauma and gray matter alterations, which could imply a publication bias. Another explanation for the difference in findings in traumatized non-psychotic populations and the healthy controls described in this thesis, is that the latter had less trauma exposure compared with the individuals studied in the childhood maltreatment studies.

\section{CANNABIS}

\section{Cannabis and GMV}

Cannabis use was significantly associated with reduced GMV in male patients, but not in siblings or controls. In the female study population, patients, siblings and controls, there was no association between cannabis use and GMV. In a previous analysis from our group with CT as the outcome measure, it was shown that higher levels of cannabis use were associated with lower CT in patients and siblings (51), but the interaction with sex was not explored. An explanation for the differential group findings is that global GMV may represent a more crude brain measure than $\mathrm{CT}$, and whole brain regional CT (68 regions) multilevel analyses are more powerful. Another explanation is related to timing: CT matures shortly before puberty (12), gyrification and surface area are two other measures which entail to GMV, but mature earlier. Cannabis use often commences around puberty (52) and thus may impact CT more than GMV, because surface area and gyrification are already matured before puberty.

Previous studies of other groups on cannabis and gray matter alterations in psychotic disorder show inconsistent results and sex differences are not always modelled. Cannabis use in early adolescence was negatively associated with CT in male individuals with a high polygenic risk score for schizophrenia, whereas the association was absent in low-risk male individuals or in low- or high-risk female individuals (53). Rais and colleagues showed that patients with first-episode schizophrenia who used cannabis had a 
more pronounced reduction of GMV (28) and cortical thinning (54) compared to nonusing patients. Sex was added to the analyses as a covariate but the interaction was not examined. Malchow et al (55) reported lower volumes of the bilateral caudate nucleus in patients with a diagnosis of schizophrenia and a history of cannabis abuse but only if they had a family history of schizophrenia, implying $G \times E$ interaction. Effects of sex were not explored.

Kumra and colleagues (56) found that both schizophrenia and cannabis use disorder independently were associated with parietal lobe volume deficits, but there was no additive volumetric deficit in the group with comorbid schizophrenia and cannabis use. In patients with recent-onset schizophrenia and an additional diagnosis of cannabis abuse or dependence, there was no difference in global brain measures (including GMV) with respect to patients who never used cannabis (57). Again, these studies did not test interactions with sex or (proxy) gene $x$ environment interactions. Koenders et al (58) found that male patients with a diagnosis of schizophrenia and comorbid cannabis use disorders had larger volumes of the putamen compared to those without comorbid cannabis use disorder; no other difference in brain volumes or CT were observed. In summary, previous studies are not consistent or do not provide comparative analyses, and interactions with sex and $\mathrm{G} \times \mathrm{E}$ interaction have not been given sufficient attention. Further research or meta-analysis is required.

Disruption of endocannabinoid signalling by the use of cannabis could be an explanation for the reduction of GMV, as the endocannabinoid system plays an important role in neuronal proliferation, migration, axonal guidance, positioning of cortical interneurons, and synaptogenesis (59). Furthermore, tetrahydrocannabinol (THC), the active psychotropic ingredient of cannabis, may lead to increased striatal dopamine levels (60, 61). Excessive dopamine and stimulation of the dopamine D1 receptor may participate in dopamine-induced degeneration $(26,62,63)$. However, there are also studies that report the opposite effect: cannabis use is associated with reduced dopamine synthesis capacity and blunting of dopamine release $(64,65)$. Further, THC is believed to affect synaptic plasticity and THC related glutamatergic effects may affect GMV through a mechanism of neurotoxicity $(60,66,67)$. Cannabis may also indirectly influence GMV: cannabis use is related to the incidence and persistence of psychotic symptoms (68) and it has been suggested that the 'toxic effect' of psychotic symptoms through the degenerative effects of dopamine, may impact brain structure (69). As discussed previously the sex differences may be related to the protective role of estrogen (17).

\section{CONCLUSION}

In this thesis, multiple approaches were used to study several environmental risk factors for psychotic disorder. There was no evidence for increased risk of schizophrenia after being exposed in utero to the 1957 pandemic of influenza. Childhood urbanicity was 


\section{Chapter 8}

associated with reduced stress-reactivity and reduced intergenerational educational performance in the entire study population (patient with psychotic disorder, siblings and healthy controls), although these findings were not specific for psychotic disorder, it is still conceivable that they could contribute to the development of psychotic disorder Further, childhood urbanicity and childhood trauma were found to impact each other: the risk-increasing effect of childhood trauma for psychotic disorder was stronger for higher levels of childhood urbanicity and persons with a liability for psychotic disorder may be more likely to experience trauma in childhood in the presence of childhood urbanicity. The neuroimaging findings in this thesis imply that reduction of GMV in psychotic disorder may be the outcome of differential sensitivity to the environmental risk factors childhood urbanicity, childhood trauma and cannabis, particularly in male patients.

\section{CLINICAL IMPLICATIONS}

Although the studies included in this thesis do not directly lead to altered strategies in the treatment of psychotic disorder, indirectly there are some implications with respect to prevention and treatment. In areas of higher urbanicity there should be more awareness for childhood trauma, especially in families that could be considered vulnerable, for example due to genetic liability for psychotic disorder. Further, educational achievements should be monitored with respect to the level of urbanicity. This could be realized at the end of primary and secondary education: in the Netherlands at the end of primary and secondary school nationwide general tests are executed, these results could be used to further examine the effect of the urban environment on scholastic achievements. If the negative association between urbanicity and educational achievements would be confirmed in future research, this could have implications for reorganization of educational system in cities.

In the diagnostic process of psychotic disorder attention should be paid to the environmental risk factors in the history of the patient. The findings from the structural neuroimaging studies support that childhood urbanicity, childhood trauma and cannabis are environmental factors that play a significant role in psychotic disorder. Patients are often looking for an explanation of why they became ill. Better understanding of the underlying mechanisms by the clinician and translating these mechanisms to the patient, may help to strengthen the therapeutic alliance, as he or she may feel better understood. Good therapeutic alliance is an important predictor of therapy outcome (70). Further, the clinician should be aware that stress reactivity could be altered in patients with psychotic disorder. Mindfulness and cognitive-behavioral interventions could be used to reduce stress reactivity and improve daily life functioning. 


\section{FUTURE RESEARCH}

Future research is needed to unravel which factor or which factors related to the urban environment mediate the higher risk for psychotic disorders, in order to facilitate studies that attempt to unravel pathologic pathways. The urban environment consists of various elements. One of these elements or, more likely, a combination of elements may contribute to the actual risk factor for psychotic disorder, but still has to be discovered. Our research suggests that childhood trauma could be one of those elements. As childhood urbanicity seems to have an effect on stress processing (blunted stress reactivity) and childhood urbanicity strengthens the effects of stress experience as a consequence of childhood trauma, it would be most logical to investigate factors that are related to social stress more closely, not only environmental social stress factors, but also within-person factors associated with social stress, for example social cognition. Further, not only risk increasing elements of urban life should be studied, risk decreasing elements are equally interesting. More work is required to understand the interaction between urban environment and educational outcomes. Possible mediating factors could be school size, class size, level of individual educational support and class dynamics, and would be interesting to study. Finally, in this thesis cross-sectional study designs were used, from which we cannot establish causal relations. Longitudinal analyses and meta-analyses are needed to provide more definite answers on the relationship between cerebral phenotypes and genetic and environmental risk factors, in psychotic disorder. 


\section{REFERENCES}

1. Myin-Germeys I, van Os J, Schwartz JE, Stone AA, Delespaul PA. Emotional reactivity to daily life stress in psychosis. Archives of general psychiatry. 2001;58(12):1137-44.

2. Lataster $T$, Wichers M, Jacobs N, Mengelers R, Derom C, Thiery E, et al. Does reactivity to stress cosegregate with subclinical psychosis? A general population twin study. Acta psychiatrica Scandinavica. 2009;119(1):45-53.

3. Collip D, Myin-Germeys I, Van Os J. Does the concept of "sensitization" provide a plausible mechanism for the putative link between the environment and schizophrenia? Schizophrenia bulletin. 2008;34(2):220-5.

4. Bentall RP. The illusion of reality: a review and integration of psychological research on hallucinations. Psychological bulletin. 1990;107(1):82-95.

5. Selten JP, Cantor-Graae E. Hypothesis: social defeat is a risk factor for schizophrenia? The British journal of psychiatry Supplement. 2007;51:s9-12.

6. Nemeroff CB. Neurobiological consequences of childhood trauma. The Journal of clinical psychiatry. 2004;65 Suppl 1:18-28.

7. van Os J, Driessen G, Gunther N, Delespaul P. Neighbourhood variation in incidence of schizophrenia. Evidence for person-environment interaction. The British journal of psychiatry : the journal of mental science. 2000;176:243-8.

8. Varese F, Smeets F, Drukker M, Lieverse R, Lataster T, Viechtbauer W, et al. Childhood adversities increase the risk of psychosis: a meta-analysis of patient-control, prospective- and cross-sectional cohort studies. Schizophrenia bulletin. 2012;38(4):661-71.

9. March D, Hatch SL, Morgan C, Kirkbride JB, Bresnahan M, Fearon P, et al. Psychosis and place. Epidemiologic reviews. 2008;30:84-100.

10. Kohler CG, Walker JB, Martin EA, Healey KM, Moberg PJ. Facial emotion perception in schizophrenia: a meta-analytic review. Schizophrenia bulletin. 2010;36(5):1009-19.

11. Kohler CG, Richard JA, Brensinger CM, Borgmann-Winter KE, Conroy CG, Moberg PJ, et al. Facial emotion perception differs in young persons at genetic and clinical high-risk for psychosis. Psychiatry research. 2014.

12. Smith GN, Thornton AE, Lang DJ, MacEwan GW, Kopala LC, Su W, et al. Cortical morphology and early adverse birth events in men with first-episode psychosis. Psychological medicine. 2015;45(9):1825-37.

13. Vijayakumar N, Allen NB, Youssef G, Dennison M, Yucel M, Simmons JG, et al. Brain development during adolescence: A mixed-longitudinal investigation of cortical thickness, surface area, and volume. Human brain mapping. 2016;37(6):2027-38.

14. Mutlu AK, Schneider M, Debbane M, Badoud D, Eliez S, Schaer M. Sex differences in thickness, and folding developments throughout the cortex. Neurolmage. 2013;82:200-7.

15. Pedersen CB, Mortensen PB. Evidence of a dose-response relationship between urbanicity during upbringing and schizophrenia risk. Archives of general psychiatry. 2001;58(11):1039-46.

16. Paus T, Nawaz-Khan I, Leonard G, Perron M, Pike GB, Pitiot A, et al. Sexual dimorphism in the adolescent brain: Role of testosterone and androgen receptor in global and local volumes of grey and white matter. Hormones and behavior. 2010;57(1):63-75.

17. Szymanski S, Lieberman JA, Alvir JM, Mayerhoff D, Loebel A, Geisler S, et al. Gender differences in onset of illness, treatment response, course, and biologic indexes in first-episode schizophrenic patients. The American journal of psychiatry. 1995;152(5):698-703.

18. Fukuta H, Ito I, Tateno A, Nogami T, Taiji Y, Arakawa R, et al. Effects of menopause on brain structural changes in schizophrenia. Psychiatry and clinical neurosciences. 2013;67(1):3-11.

19. Hayes E, Gavrilidis E, Kulkarni J. The role of oestrogen and other hormones in the pathophysiology and treatment of schizophrenia. Schizophrenia research and treatment. 2012;2012:540273.

20. Tomoda A, Suzuki H, Rabi K, Sheu YS, Polcari A, Teicher MH. Reduced prefrontal cortical gray matter volume in young adults exposed to harsh corporal punishment. Neurolmage. 2009;47 Suppl 2:T66-71. 
21. Spinelli S, Chefer S, Suomi SJ, Higley JD, Barr CS, Stein E. Early-life stress induces long-term morphologic changes in primate brain. Archives of general psychiatry. 2009;66(6):658-65.

22. De Bellis MD. The psychobiology of neglect. Child maltreatment. 2005;10(2):150-72.

23. Howes OD, McCutcheon R, Owen MJ, Murray RM. The Role of Genes, Stress, and Dopamine in the Development of Schizophrenia. Biol Psychiatry. 2016.

24. Mizrahi R. Social Stress and Psychosis Risk: Common Neurochemical Substrates? Neuropsychopharmacology. 2016;41(3):666-74.

25. Luo Y, Hattori A, Munoz J, Qin ZH, Roth GS. Intrastriatal dopamine injection induces apoptosis through oxidation-involved activation of transcription factors AP-1 and NF-kappaB in rats. Mol Pharmacol. 1999;56(2):254-64.

26. Wersinger C, Chen J, Sidhu A. Bimodal induction of dopamine-mediated striatal neurotoxicity is mediated through both activation of D1 dopamine receptors and autoxidation. Molecular and cellular neurosciences. 2004;25(1):124-37.

27. Haddad L, Schafer A, Streit F, Lederbogen F, Grimm O, Wust S, et al. Brain Structure Correlates of Urban Upbringing, an Environmental Risk Factor for Schizophrenia. Schizophrenia bulletin. 2014.

28. Xiao YY, Cai J, Wang XY, Li FD, Shang XP, Wang XX, et al. Prognosis and survival of 128 patients with severe avian influenza $A(H 7 N 9)$ infection in Zhejiang province, China. Epidemiology and infection. 2015;143(9):1833-8.

29. Selten JP, Morgan VA. Prenatal exposure to influenza and major affective disorder. Bipolar Disord. 2010;12(7):753-4.

30. Parboosing R, Bao Y, Shen L, Schaefer CA, Brown AS. Gestational influenza and bipolar disorder in adult offspring. JAMA Psychiatry. 2013;70(7):677-85.

31. Fineberg AM, Ellman LM, Buka S, Yolken R, Cannon TD. Decreased birth weight in psychosis: influence of prenatal exposure to serologically determined influenza and hypoxia. Schizophrenia bulletin. 2013;39(5):1037-44.

32. Clark NM, Lynch JP, 3rd. Influenza: epidemiology, clinical features, therapy, and prevention. Seminars in respiratory and critical care medicine. 2011;32(4):373-92

33. Meijer WJ, van Noortwijk AG, Bruinse HW, Wensing AM. Influenza virus infection in pregnancy: a review. Acta obstetricia et gynecologica Scandinavica. 2015;94(8):797-819.

34. Eaton WW, Mortensen PB, Frydenberg M. Obstetric factors, urbanization and psychosis. Schizophrenia research. 2000;43(2-3):117-23.

35. McDonald C, O'Callaghan E, Keogh F, Sham PC, Kinsella A, Morris M, et al. Number of older siblings of individuals diagnosed with schizophrenia. Schizophrenia research. 2001;47(2-3):275-80.

36. Holt MK, Finkelhor D, Kantor GK. Multiple victimization experiences of urban elementary school students: associations with psychosocial functioning and academic performance. Child abuse \& neglect. 2007;31(5):503-15.

37. Kurtz PD, Gaudin JM, Jr., Wodarski JS, Howing PT. Maltreatment and the school-aged child: school performance consequences. Child abuse \& neglect. 1993;17(5):581-9.

38. Tanaka M, Georgiades K, Boyle MH, MacMillan HL. Child Maltreatment and Educational Attainment in Young Adulthood: Results From the Ontario Child Health Study. Journal of interpersonal violence. 2014.

39. Boden JM, Horwood LJ, Fergusson DM. Exposure to childhood sexual and physical abuse and subsequent educational achievement outcomes. Child abuse \& neglect. 2007;31(10):1101-14.

40. Heim C, Newport DJ, Heit S, Graham YP, Wilcox M, Bonsall R, et al. Pituitary-adrenal and autonomic responses to stress in women after sexual and physical abuse in childhood. JAMA : the journal of the American Medical Association. 2000;284(5):592-7.

41. Klaassens ER. Bouncing back - trauma and the HPA-axis in healthy adults. Eur J Psychotraumatol. $2010 ; 1$.

42. Walker EF, Diforio D. Schizophrenia: a neural diathesis-stress model. Psychological review. 1997;104(4):667-85.

43. Cerqueira JJ, Catania C, Sotiropoulos I, Schubert M, Kalisch R, Almeida OF, et al. Corticosteroid status influences the volume of the rat cingulate cortex - a magnetic resonance imaging study. Journal of psychiatric research. 2005;39(5):451-60. 


\section{Chapter 8}

44. Sheffield JM, Williams LE, Woodward ND, Heckers S. Reduced gray matter volume in psychotic disorder patients with a history of childhood sexual abuse. Schizophrenia research. 2013;143(1):185-91.

45. Poletti S, Vai B, Smeraldi E, Cavallaro R, Colombo C, Benedetti F. Adverse childhood experiences influence the detrimental effect of bipolar disorder and schizophrenia on cortico-limbic grey matter volumes. Journal of affective disorders. 2016;189:290-7.

46. Frodl T, Reinhold E, Koutsouleris N, Reiser M, Meisenzahl EM. Interaction of childhood stress with hippocampus and prefrontal cortex volume reduction in major depression. Journal of psychiatric research. 2010;44(13):799-807.

47. Chaney A, Carballedo A, Amico F, Fagan A, Skokauskas N, Meaney J, et al. Effect of childhood maltreatment on brain structure in adult patients with major depressive disorder and healthy participants. J Psychiatry Neurosci. 2014;39(1):50-9.

48. Duarte DG, Neves Mde C, Albuquerque MR, de Souza-Duran FL, Busatto G, Correa H. Gray matter brain volumes in childhood-maltreated patients with bipolar disorder type I: A voxel-based morphometric study. Journal of affective disorders. 2016;197:74-80.

49. Chalavi S, Vissia EM, Giesen ME, Nijenhuis ER, Draijer N, Cole JH, et al. Abnormal hippocampal morphology in dissociative identity disorder and post-traumatic stress disorder correlates with childhood trauma and dissociative symptoms. Human brain mapping. 2015;36(5):1692-704.

50. Teicher MH, Samson JA. Annual Research Review: Enduring neurobiological effects of childhood abuse and neglect. J Child Psychol Psychiatry. 2016;57(3):241-66.

51. Habets P, Marcelis M, Gronenschild E, Drukker M, van Os J. Reduced cortical thickness as an outcome of differential sensitivity to environmental risks in schizophrenia. Biological psychiatry. 2011;69(5):487-94.

52. van Laar M, Guus C, van Gageldonk A, van Ooyen-Houben M, Croes C, Meijer R, et al. The Netherlands drug situation 2011. Utrecht: Trimbos Instituut; 2011.

53. French L, Gray C, Leonard G, Perron M, Pike GB, Richer L, et al. Early Cannabis Use, Polygenic Risk Score for Schizophrenia and Brain Maturation in Adolescence. JAMA Psychiatry. 2015;72(10):1002-11.

54. Rais M, van Haren NE, Cahn W, Schnack HG, Lepage C, Collins L, et al. Cannabis use and progressive cortical thickness loss in areas rich in CB1 receptors during the first five years of schizophrenia. European neuropsychopharmacology : the journal of the European College of Neuropsychopharmacology. 2010;20(12):855-65.

55. Malchow B, Hasan A, Schneider-Axmann T, Jatzko A, Gruber O, Schmitt A, et al. Effects of cannabis and familial loading on subcortical brain volumes in first-episode schizophrenia. European archives of psychiatry and clinical neuroscience. 2013;263 Suppl 2:S155-68.

56. Kumra S, Robinson P, Tambyraja R, Jensen D, Schimunek C, Houri A, et al. Parietal lobe volume deficits in adolescents with schizophrenia and adolescents with cannabis use disorders. Journal of the American Academy of Child and Adolescent Psychiatry. 2012;51(2):171-80.

57. Cahn W, Hulshoff Pol HE, Caspers E, van Haren NE, Schnack HG, Kahn RS. Cannabis and brain morphology in recent-onset schizophrenia. Schizophrenia research. 2004;67(2-3):305-7.

58. Koenders L, Machielsen MW, van der Meer FJ, van Gasselt AC, Meijer CJ, van den Brink W, et al. Brain volume in male patients with recent onset schizophrenia with and without cannabis use disorders. Journal of psychiatry \& neuroscience : JPN. 2014;39(6):140081.

59. Burns JK. Pathways from cannabis to psychosis: a review of the evidence. Front Psychiatry. 2013;4:128.

60. Kuepper R, Morrison PD, van Os J, Murray RM, Kenis G, Henquet C. Does dopamine mediate the psychosis-inducing effects of cannabis? A review and integration of findings across disciplines. Schizophrenia research. 2010;121(1-3):107-17.

61. Kuepper R, Ceccarini J, Lataster J, van Os J, van Kroonenburgh M, van Gerven JM, et al. Delta-9tetrahydrocannabinol-induced dopamine release as a function of psychosis risk: 18F-fallypride positron emission tomography study. PLoS One. 2013;8(7):e70378.

62. Chen J, Rusnak M, Luedtke RR, Sidhu A. D1 dopamine receptor mediates dopamine-induced cytotoxicity via the ERK signal cascade. J Biol Chem. 2004;279(38):39317-30.

63. Chen J, Rusnak M, Lombroso PJ, Sidhu A. Dopamine promotes striatal neuronal apoptotic death via ERK signaling cascades. Eur J Neurosci. 2009;29(2):287-306. 
64. Bloomfield MA, Morgan CJ, Egerton A, Kapur S, Curran HV, Howes OD. Dopaminergic function in cannabis users and its relationship to cannabis-induced psychotic symptoms. Biological psychiatry. 2014;75(6):470-8.

65. Thompson JL, Urban N, Slifstein M, Xu X, Kegeles LS, Girgis RR, et al. Striatal dopamine release in schizophrenia comorbid with substance dependence. Molecular psychiatry. 2013;18(8):909-15.

66. Stone JM, Day F, Tsagaraki H, Valli I, McLean MA, Lythgoe DJ, et al. Glutamate dysfunction in people with prodromal symptoms of psychosis: relationship to gray matter volume. Biological psychiatry. 2009;66(6):533-9.

67. Egerton A, Fusar-Poli P, Stone JM. Glutamate and psychosis risk. Curr Pharm Des. 2012;18(4):466-78.

68. Kuepper R, van Os J, Lieb R, Wittchen HU, Hofler M, Henquet C. Continued cannabis use and risk of incidence and persistence of psychotic symptoms: 10 year follow-up cohort study. Bmj. 2011;342:d738.

69. Lieberman J, Chakos M, Wu H, Alvir J, Hoffman E, Robinson D, et al. Longitudinal study of brain morphology in first episode schizophrenia. Biological psychiatry. 2001;49(6):487-99.

70. Martin DJ, Garske JP, Davis MK. Relation of the therapeutic alliance with outcome and other variables: a meta-analytic review. Journal of consulting and clinical psychology. 2000;68(3):438-50. 

Summary
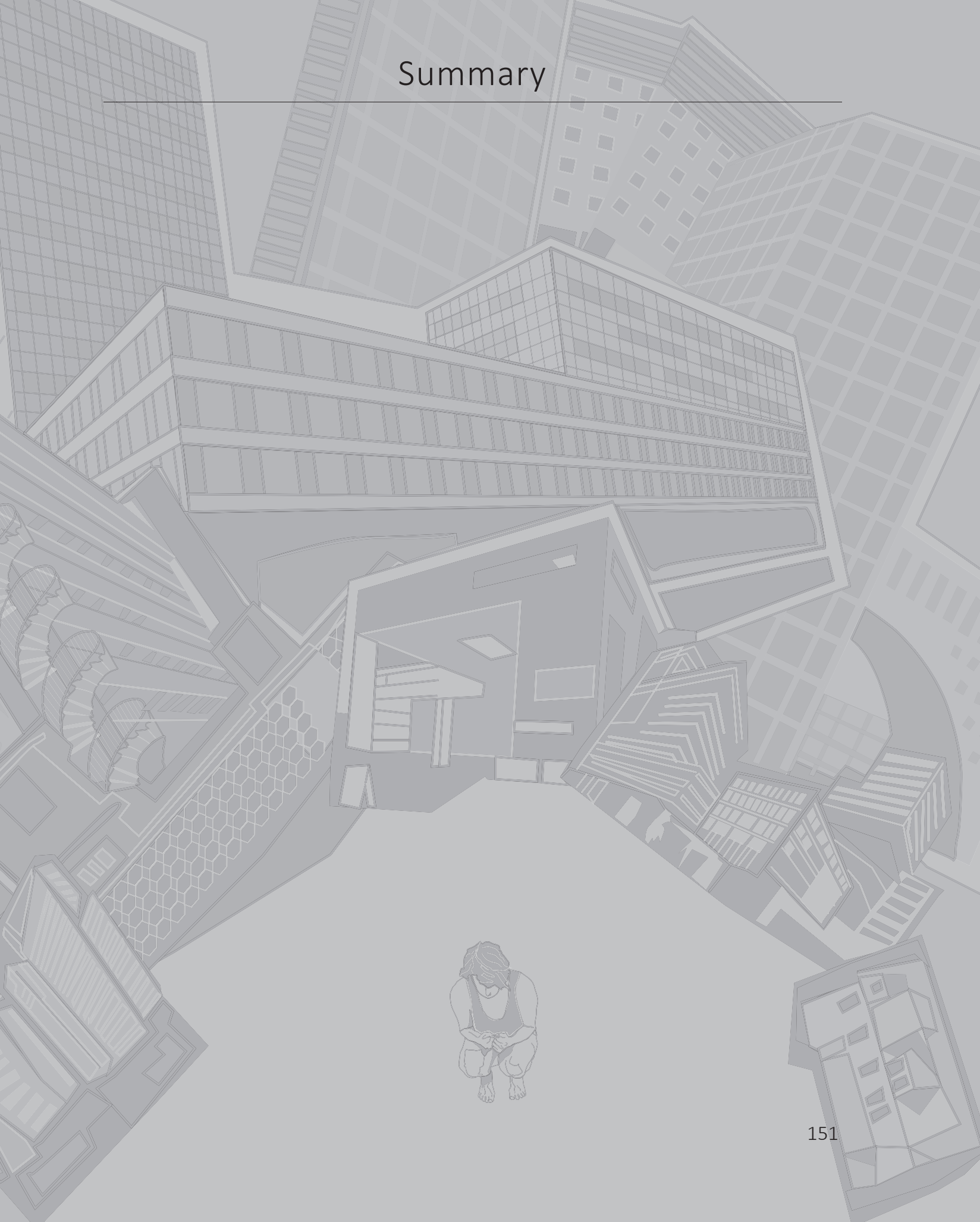

In this thesis known environmental risk factors for psychotic disorders were studied and an attempt was made to unravel how these environmental risk factors may contribute to psychotic disorders. Although there is sufficient evidence that childhood urbanicity, childhood trauma and cannabis are risk factors for psychotic disorder, the underlying etiologic processes to psychosis need further exploration. Whether maternal influenza is a true risk factor for psychotic disorders is uncertain, studies disagree and there is need for clarification. Instead of focussing on one research methodology, different strategies were used: epidemiological, ecological and neuro-imaging approaches were used in an attempt to untangle the associations. In addition to patients with a psychotic disorder and healthy controls, healthy siblings of patients with a psychotic disorder were included in most studies.

In Chapter 1 the environmental risk factors, which are studied in this thesis, are discussed: maternal influenza during pregnancy, childhood urbanicity, childhood trauma and cannabis. Previous research describing the association between these risk factors and psychotic disorder is summarized and possible underlying (neuro-biological) pathways are debated. In addition, previous research of structural neuroimaging findings in association with these environmental risk factors are discussed.

In Chapter 2 maternal influenza as a risk factor for schizophrenia was studied. Not all studies agree that maternal influenza is a risk factor. A meta-analysis was conducted to examine whether births during the nine-month period following the influenza pandemic of 1957 was a risk factor for schizophrenia. Three types of-studies were distinguished: Type A studies included eight ecological study groups from Europe, America and Australia that compared the risk of schizophrenia among subjects born any time within the nine-month period following the influenza pandemic with that amongst those born in the corresponding periods of time in the previous and/or subsequent year. Although it was not known whether the mothers actually had influenza, it was assumed that these children had been exposed. Recent publications on influenza pandemics assume that $50 \%$ of the population is infected. Type B studies were ecological studies from Japan. The Japanese (1957) influenza pandemic arrived in two waves. For this reason, the Japanese studies were considered to be different from the other ecological studies. Two studies compared the risk of schizophrenia among children whose mothers reported having had influenza during the pandemic with those mothers who reported not having had influenza during the pandemic, type $\mathrm{C}$ studies. The pooled results for the three types of studies were negative: there was no evidence for increased risk of schizophrenia after being exposed in utero to the 1957 pandemic of influenza. From this metaanalysis the evidence to support the maternal influenza hypothesis is insufficient.

Behavioural sensitisation was tested as a mechanism that links childhood urbanicity to psychotic disorders in Chapter 3. Previous research revealed that individuals with psy- 
chotic disorders showed increased emotional reactivity to stressful daily life events compared to individuals without a psychotic disorder. In Chapter 3 the experience sampling method (ESM) was used to study stress reactivity and its association with psychotic disorders and childhood urbanicity. The study population consisted of patients with a psychotic disorder, healthy siblings of patients with a psychotic disorder, and healthy controls. The findings demonstrated that patients with a psychotic disorder displayed higher levels of negative affect (NA), in relation to subjective stress (SS), regardless of urbanicity levels. This is a replication of previous research. Contrary to our expectations, results indicated that urbanicity was associated with blunted rather than enhanced increase in NA after exposure to SS, consistently across the three groups (patients, siblings and controls). The findings suggest that urban upbringing may occasion "habituation" rather than "sensitization" across groups, which may or may not be relevant for the onset of a psychotic disorder.

In Chapter 4 childhood trauma and childhood urbanicity were examined together. The study population was comprised of patients with a psychotic disorder and healthy controls. Tests were carried out to see whether childhood urbanicity moderates the association between childhood trauma and psychotic disorder and whether childhood urbanicity is associated with higher levels of childhood trauma in individuals with a psychotic disorder. Childhood urbanicity appeared to moderate the association between childhood trauma and psychosis: the risk-increasing effect of childhood trauma for psychotic disorder was stronger for higher levels of childhood urbanicity. Further, our results suggested that individuals who later develop a psychotic disorder could be more susceptible to childhood trauma when growing up in an urban environment.

In Chapter 5 intergenerational educational achievements in psychotic disorder were examined and whether childhood trauma and childhood urbanicity influence intergenerational educational performance. Overall, the participants had a higher level of education than their parents. This difference was significantly less in the patient group and the healthy siblings were in between the controls and the patients. Higher levels of childhood urbanicity were associated with decreased intergenerational difference in educational achievements. However, there was no evidence that associations between intergenerational educational achievements and childhood urbanicity differed for patients, siblings or controls. Childhood trauma did not seem to affect intergenerational educational achievements, and childhood trauma was not differentially associated with intergenerational educational differences across psychotic patients, siblings, and in controls.

In Chapters 6 and 7 a multimodal approach was applied to study environmental risk factors: structural neuro-imaging data, objective phenotypes of psychotic disorder, are combined with epidemiologic data. Both chapters also explored gender differences, 
since findings of structural alterations in psychotic disorders seem to be more extensive in the male population. Patients with a psychotic disorder, healthy siblings and healthy controls were included in the study population. In Chapter 6 cortical thickness (CT) as the outcome of differential exposure to urban upbringing was studied. CT was significantly lower in the patient group compared to the controls, but not in the siblings compared to the controls. There was no evidence that the negative association between (familial risk for) psychotic disorder and CT was moderated by childhood urbanicity.

In Chapter 7 gray matter volume (GMV) and exposure to childhood trauma, childhood urbanicity and cannabis was studied. GMV was significantly smaller in the patient group compared to the controls; siblings did not differ significantly from controls. In contrast with the results of Chapter 6 , the negative association between psychotic disorder and GMV was moderated by childhood urbanicity in the male patients only. In the male patients there was a negative association between GMV and childhood urbanicity. Higher levels of childhood trauma were significantly associated with reduced GMV in patients, both male and female. Cannabis use was significantly associated with reduced GMV in male patients. The findings suggest that reduction of GMV in psychotic disorder may be the outcome of differential sensitivity to environmental risks, particularly in male patients.

In Chapter 8 the main findings of the separate studies are discussed and integrated with one another. The clinical implications of this thesis and possible directions of future research are described. 



\section{Samenvatting}

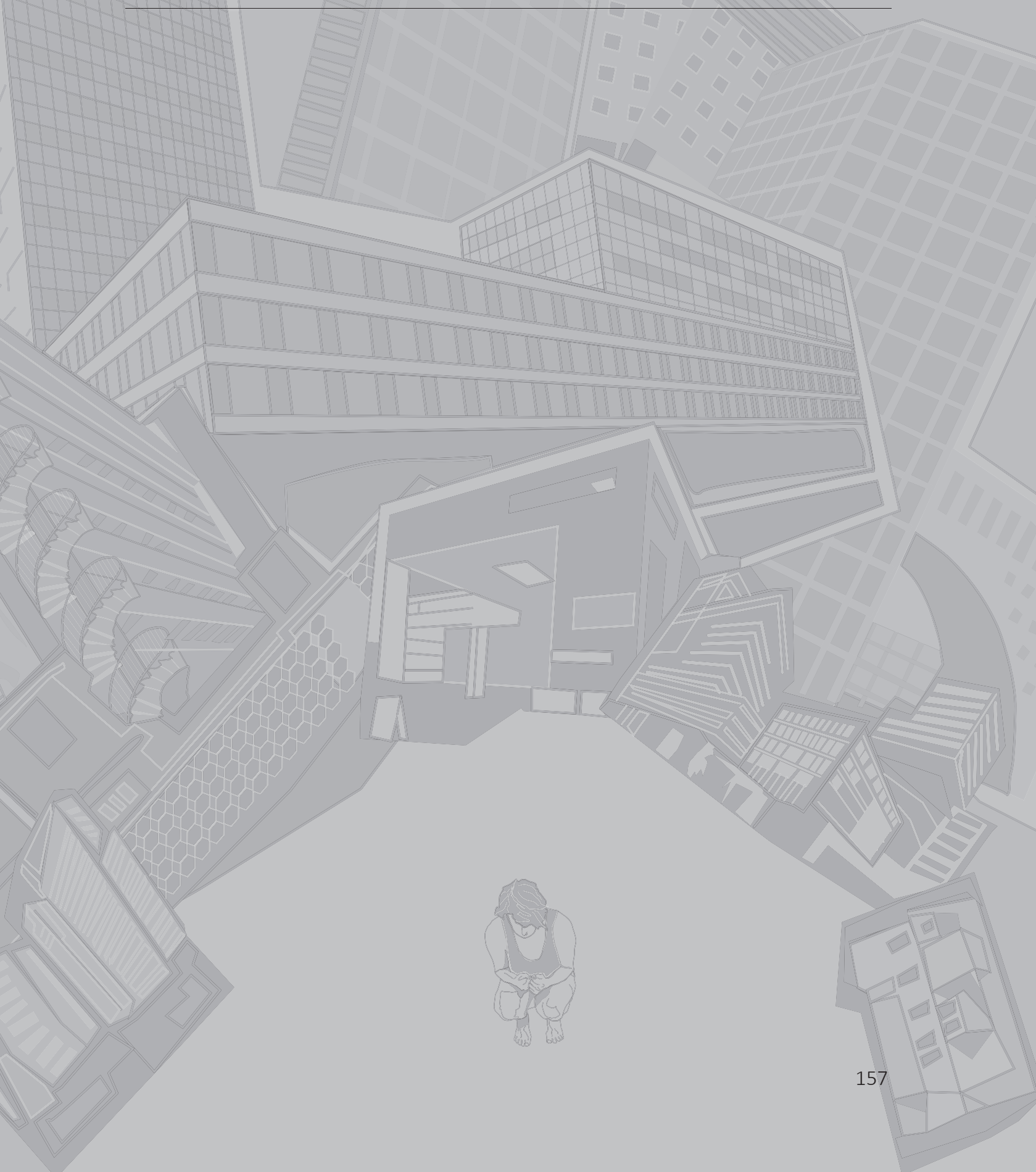



In dit proefschrift werden omgevingsrisicofactoren voor psychotische stoornissen onderzocht. Hoewel er voldoende bewijs is dat opgroeien in een stedelijke omgeving, jeugdtrauma en cannabis risicofactoren zijn voor het ontwikkelen van een psychotische stoornis, zijn de onderliggende etiologische processen nog onvoldoende bekend. Of influenza infectie van de moeder tijdens de zwangerschap daadwerkelijk een risicofactor is voor psychotische stoornissen is nog niet duidelijk. In dit proefschrift werden verschillende onderzoekstechnieken gebruikt in een poging de relatie tussen de risicofactoren en psychotische stoornissen te verhelderen, namelijk epidemiologische en ecologische methoden, en structurele beeldvorming van het brein. In de meeste studies werden niet alleen patiënten met een psychotische stoornis en gezonde controles geïncludeerd, maar ook gezonde broers en zussen van patiënten met een psychotische stoornis.

In hoofdstuk 1 wordt een overzicht gegeven van de omgevingsrisicofactoren die in dit proefschrift werden bestudeerd, namelijk: influenza infectie van de moeder tijdens de zwangerschap, opgroeien in een stedelijke omgeving, jeugdtrauma en cannabis. Er wordt een samenvatting gegeven van voorgaand onderzoek dat de relatie tussen psychotische stoornissen en deze risicofactoren beschrijft en van mogelijke onderliggende processen. Ook wordt er aandacht besteed aan structureel beeldvormend onderzoek van het brein in relatie tot psychotische stoornissen en bovengenoemde risicofactoren.

Influenza infectie van de moeder tijdens zwangerschap als risicofactor voor psychotische stoornissen is het onderwerp van hoofdstuk 2. Eerdere studies naar deze risicofactor zijn het niet eens, wat maakt dat het tot nu toe onvoldoende duidelijk is of dit daadwerkelijk een risicofactor is voor het ontwikkelen van een psychotische stoornis. Er werd een meta-analyse uitgevoerd om te onderzoeken of geboorte gedurende 9 maanden na de influenza pandemie van 1957 een risicofactor is voor schizofrenie. Drie typen studies werden onderscheiden. Type A studies zijn 8 ecologische studies die werden uitgevoerd in Europa, Amerika en Australië. In deze studies werd het risico op het ontwikkelen van schizofrenie in personen die werden geboren 9 maanden na de pandemie vergeleken met het risico in de jaren voorafgaand en volgend op de pandemie. Hoewel het in deze studies niet bekend is of de moeders daadwerkelijk een influenza infectie hebben doorgemaakt, werden deze kinderen beschouwd als blootgesteld aan de risicofactor. Recent onderzoek laat zien dat gedurende een influenza pandemie $50 \%$ van de populatie geïnfecteerd raakt. Type B studies zijn 3 ecologische studies uit Japan. In Japan waren er twee golven van de influenza pandemie, daarom werden deze studies anders beschouwd dan type A studies. Tenslotte, waren er ook 2 studies die het risico op schizofrenie bij moeders die rapporteerden influenza te hebben gehad vergeleken met moeders die rapporteerden geen influenza te hebben gehad, type $C$ studies. De samengevoegde resultaten van de type $A$, B en $C$ studies waren negatief: er was geen bewijs van een verhoogd risico op schizofrenie na blootstelling aan de influenza pandemie van 1957 in utero. Deze meta-analyse levert onvoldoende bewijs voor de maternale influenza hypothese. 
In hoofdstuk 3 werd onderzocht of gedragssensitisatie een mogelijk proces is dat de relatie tussen opgroeien in stedelijke omgeving en psychotische stoornissen kan verklaren. Eerder onderzoek liet zien dat personen met een psychotische stoornis een toegenomen emotionele reactiviteit laten zien als reactie op dagelijkse stressoren vergeleken met personen zonder een psychotische stoornis. In hoofdstuk 3 werd gebruik gemaakt van de experience sampling method om stress-reactiviteit en de relatie met psychotische stoornis en opgroeien in de stad te onderzoeken. De studie populatie bestond uit patiënten met een psychotische stoornis, gezonde broers/zussen en gezonde controles. De resultaten bevestigden eerder onderzoek en lieten zien dat patiënten met een psychotische stoornis meer negatieve emoties ervaarden na blootstelling aan subjectieve stress, onafhankelijk van stedelijkheid gedurende de jeugd. Tegengesteld aan onze verwachtingen was dat hogere stedelijkheid gedurende de jeugd was geassocieerd met een verminderde toename van negatieve emoties na blootstelling aan subjectieve stress in alle drie de groepen (patiënten, broers en zussen en controles). Deze resultaten suggereren dat opgroeien in de stad leidt tot gewenning in plaats van sensitisatie, het is nog niet duidelijk of dit relevant is voor het ontwikkelen van een psychotische stoornis.

In hoofdstuk 4 werden de risicofactoren opgroeien in stedelijke omgeving en jeugdtrauma beiden onderzocht. De onderzoekspopulatie bestond uit patiënten met een psychotische stoornis en gezonde controles. Er werd getoetst of opgroeien in de stad de associatie tussen jeugdtrauma en psychotische stoornissen beïnvloedt en of opgroeien in de stad geassocieerd is met meer jeugdtrauma bij personen met een psychotische stoornis. Opgroeien in de stad leek de relatie tussen jeugdtrauma en psychotische stoornissen te beïnvloeden: het risico verhogende effect van jeugdtrauma was groter bij hogere stedelijkheid gedurende de jeugd. Ook lieten de resultaten zien dat personen die op latere leeftijd een psychotische stoornis ontwikkelen mogelijk meer worden blootgesteld aan jeugdtrauma wanneer ze opgroeien in een stedelijke omgeving.

In hoofdstuk 5 werd gekeken naar prestaties in onderwijs in relatie tot psychotische stoornissen en of jeugdtrauma en opgroeien in de stad invloed hadden op deze relatie. In de gehele studiepopulatie hadden de deelnemers een hoger opleidingsniveau dan hun ouders. Dit verschil was significant kleiner bij de patiënten met een psychotische stoornis, de gezonde broers en zussen zaten qua uitkomst tussen de patiënten en de controles in. Hogere stedelijkheid gedurende de jeugd was geassocieerd met een verminderd intergenerationeel verschil in opleidingsprestaties. Er was geen bewijs dat de associatie tussen intergenerationele opleidingsprestaties en stedelijkheid gedurende de jeugd verschilde voor patiënten, broers/zussen en controles. Jeugdtrauma leek intergenerationele opleidingsverschillen niet te beïnvloeden, ook niet in de drie groepen afzonderlijk. 
In hoofdstuk 6 en 7 werd een multimodale benadering gebruikt: structurele beeldvorming van het brein werd gecombineerd met epidemiologische data. In beide hoofdstukken werden ook geslachtsverschillen onderzocht, omdat structurele afwijkingen van het brein bij psychotische stoornissen groter lijken in de mannelijke populatie. Patiënten met een psychotische stoornis, gezonde broers/zussen en gezonde controles werden geïncludeerd in deze studies. In hoofdstuk 6 werd onderzocht of verschillende maten van blootstelling aan stedelijkheid gedurende de jeugd invloed had op de dikte van de cortex. Corticale dikte was significant minder in patiënten in vergelijking met controles, maar niet in broers/zussen in vergelijking met controles. Er waren geen aanwijzingen dat de negatieve associatie tussen psychotische stoornis en corticale dikte werd beïnvloed door stedelijkheid tijdens de jeugd.

In hoofdstuk 7 werd gekeken naar het totaal volume van de grijze stof in relatie tot jeugdtrauma, stedelijkheid tijdens de jeugd en cannabis. Het volume van de grijze stof volume was significant lager in de patiënten in vergelijking met de controles, broers/zussen verschilden niet significant van de controles. In tegenstelling tot de resultaten van hoofdstuk 6, leek de associatie tussen psychotische stoornissen en grijze stof volume wel beïnvloed te worden door stedelijkheid tijdens de jeugd, maar alleen in de mannelijke patiënten. In de mannelijke patiënten was er sprake van een negatieve associatie tussen grijze stof volume en stedelijkheid tijdens de jeugd. Jeugdtrauma was geassocieerd met een sterkere reductie van grijze stof volume in de patiënten, zowel mannen als vrouwen. Cannabis was significant geassocieerd met afname van grijze stof volume in de mannelijke patiënten. Deze resultaten suggereren dat afname van het volume van de grijze stof in het kader van een psychotische stoornis het resultaat kan zijn van blootstelling aan omgevingsfactoren, vooral in mannelijke patiënten.

In hoofdstuk 8 worden de hoofdbevindingen van de afzonderlijke studies besproken en geïntegreerd met elkaar. Klinische implicaties en mogelijke richtingen voor verder onderzoek worden benoemd. 

Valorisation

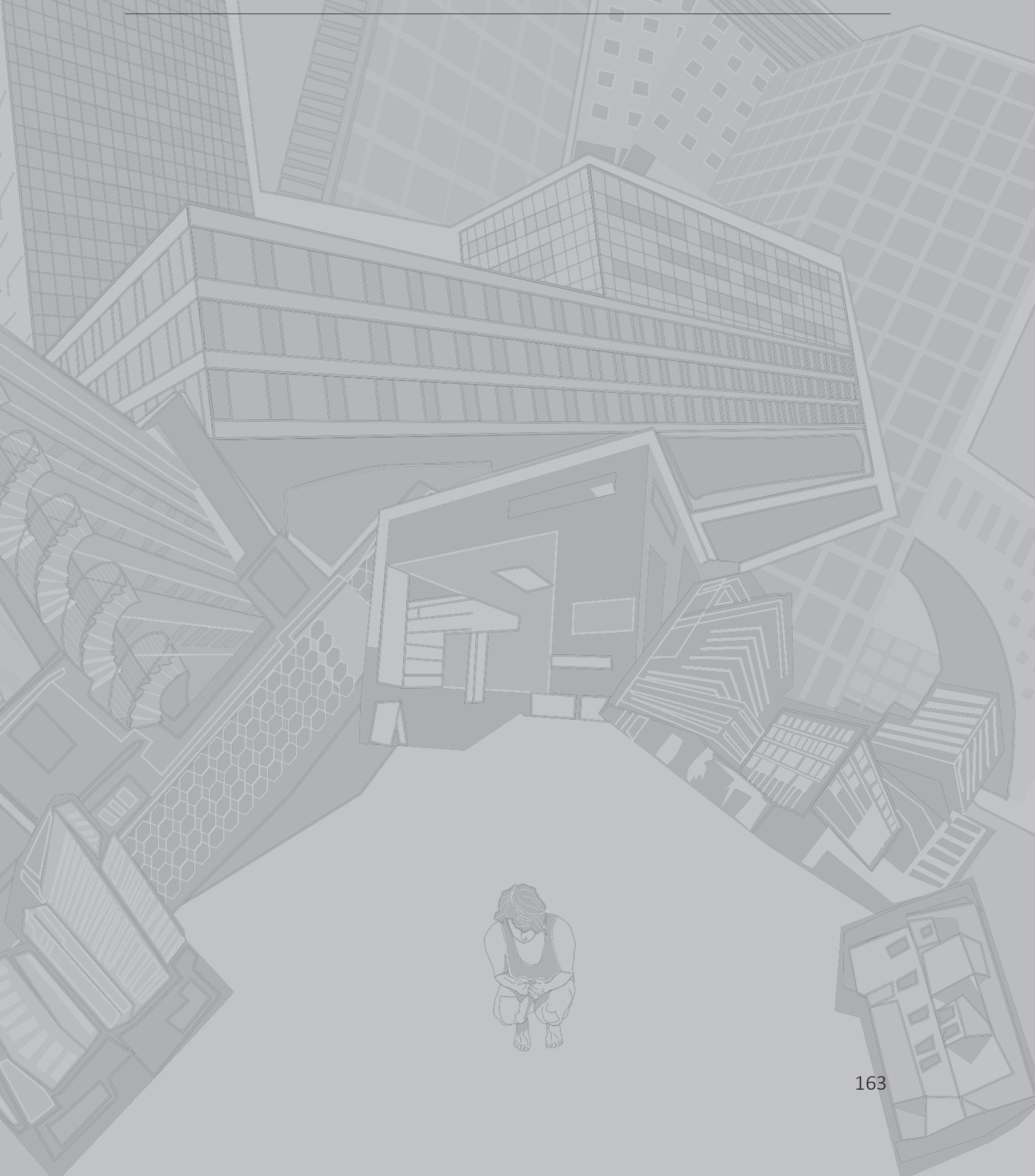



In this thesis known environmental risk factors for psychotic disorder are discussed and an attempt is made to unravel how these environmental risk factors may lead to psychotic disorder. Although these studies do not directly lead to different treatments or prevention plans for psychotic disorder they do have societal importance. The costs for mental health care have doubled over ten years' time: from 2.91 billion in 2000 to 6.14 billion in 2010 (1). Psychotic disorders are responsible for a reasonable part of this increase in costs (1). In 2012 the government of the Netherlands started with severe retrenchments in mental health care, this lead to, among others, reduction of inpatient beds and reduction of caregivers working in mental health care. These measures force us to reorganize mental health care. We need to improve prevention, earlier intervention and treatment plans enabling patient with a severe mental disorder to live, with good quality of life, in society. Treatment plans should be better tailored to the needs of the individual patient. These goals cannot be reached without better understanding of etiologic and pathologic processes.

Better understanding of etiologic processes can give direction to development of new treatments. Current treatments are mainly focused on the reduction of positive psychotic symptoms, with varying rates of success. New treatment should not only focus on the reduction of hallucinations or delusions, but should also target skills that can be affected in psychotic disorder such as social or communication skills. In this thesis altered stress processing in psychotic disorder was observed, and this was also related to urban environment during childhood. Stress processing could be a focus of treatment which may not alter positive psychotic symptoms but could increase social functioning and independency, enabling patients to find a meaningful daytime activity and participate in society, which will hopefully result in improvement of quality of life and less use of mental health care.

Increasing knowledge of pathologic processes and environmental risk factors may help us to better identify persons with increased risk of developing psychotic disorder and to intervene in earlier stages. In this thesis we found that patients with psychotic disorder, and to a lesser extent their healthy siblings, had a smaller increase in educational level compared with their parents than healthy controls. Although these group differences cannot directly be used to identify groups at high risk, it does provide a general perspective in thinking about intergenerational processes in educational achievement in the context of risk for psychosis. More work is required to better understand the dynamics between early social and cognitive alterations in those at risk in relation to progress through the educational system. Higher levels of childhood urbanicity were also associated with decreased intergenerational difference in educational achievements. As more people are residing in urbanised areas (2), more work is required to understand the interaction between urban environment and educational outcomes including school size, class size, level of individual educational support and class dynamics. If the negative association between urbanicity and educational achievements would be confirmed in future research, this could have implications for 
reorganization of educational system in cities. Further, as our results suggest that individuals who later develop psychotic disorder could be more susceptible to exposure to childhood trauma when growing up in an urban environment, there should be more awareness for childhood trauma in areas of higher urbanicity, especially in families that could be considered vulnerable, for example because of genetic liability for psychotic disorder.

Influenza is one of the most common infectious illnesses (3), affecting persons of all ages including women in their fertile period. The results of the meta-analysis included in this thesis are reassuring with respect to the risk of psychotic disorder after exposure to influenza in utero and do not suggest that any extra precautions should be taken because of risk of psychotic disorder. However, influenza during pregnancy is certainly not without risks, for example pregnant hospitalized women with influenza infection have increased rates of preterm birth and fetal/neonatal death are reported (4). Therefore, antiviral treatment or vaccination for pregnant women should be considered.

In chapter 6 and 7 an advanced approach to assessing environmental risks factors was applied: structural neuroimaging data, objective phenotypes of psychotic disorder, were combined with a proxy variable for genetic risk for psychotic disorder (patients: highest genetic risk; siblings: intermediate genetic risk; controls: lowest genetic risk) and epidemiologic data. The findings suggest that structural alterations in psychotic disorder may be the outcome of differential sensitivity to environmental risks, particularly in male patients. This is important for future neuroimaging research in psychotic disorder, because it argues that environmental risk factors and gender cannot be left out of the analyses. 


\section{REFERENCES}

1. Bijenhof A, Folkertsma M, Kommer G, Slobbe L, Polder J. Kostenontwikkeling GGZ. Bilthoven: RIVM; 2012.

2. United Nations Population Fund. State of world population 2011: People and possibilities in a wordl of 7 billion. New York: United Nations Population Fund; 2011.

3. Clark NM, Lynch JP, 3rd. Influenza: epidemiology, clinical features, therapy, and prevention. Seminars in respiratory and critical care medicine. 2011;32(4):373-92.

4. Meijer WJ, van Noortwijk AG, Bruinse HW, Wensing AM. Influenza virus infection in pregnancy: a review. Acta obstetricia et gynecologica Scandinavica. 2015;94(8):797-819. 



\section{List of publications}

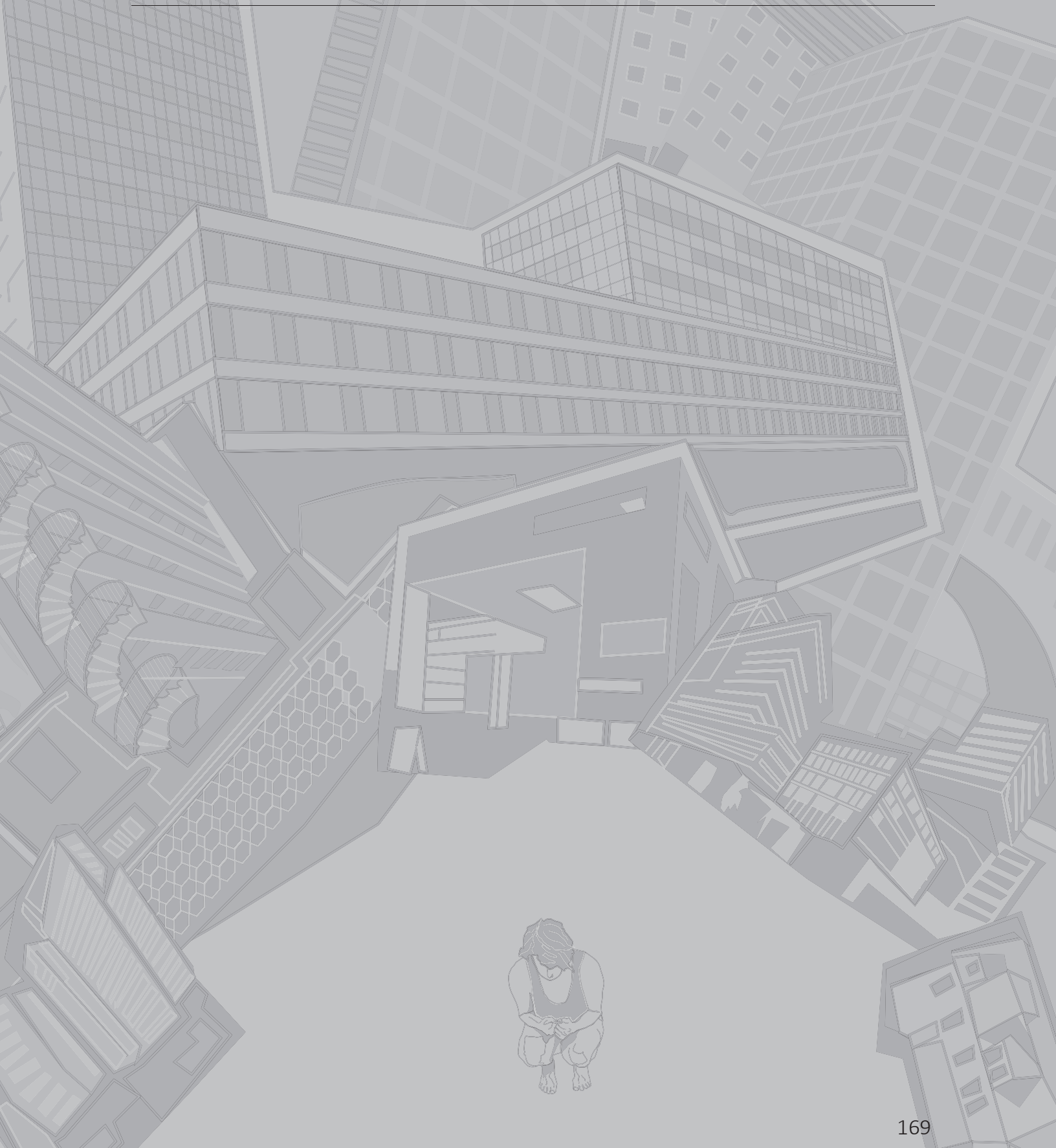



Selten JP, Frissen A, Lensvelt-Mulders G, Morgan VA. Schizophrenia and 1957 pandemic of influenza: meta-analysis. Schizophr Bull. 2010;36(2):219-28.

Frissen A, Lieverse R, Drukker M, Delespaul P, Lataster T, Myin-Germeys I, van Os J; for G.R.O.U.P. Evidence that childhood urban environment is associated with blunted stress reactivity across groups of patients with psychosis, relatives of patients and controls. Soc Psychiatry Psychiatr Epidemiol. 2014;49(10):1579-87.

Frissen A, Lieverse R, Drukker M, van Winkel R, Delespaul P, G.R.O.U.P Investigators. Childhood trauma and childhood urbanicity in relation to psychotic disorder. Soc Psychiatry Psychiatr Epidemiol. 2015;50(10):1481-8.

Frissen A, Lieverse R, Marcelis M, Drukker M, Delespaul P, G.R.O.U.P. Investigators. Psychotic disorder and educational achievement: a family-based analysis. Soc Psychiatry Psychiatr Epidemiol. 2015;50(10):1511-8.

Frissen A, van Os J, Lieverse R, Habets P, Gronenschild E, Marcelis M; for G.R.O.U.P. No evidence of association between childhood urban environment and cortical thinning in psychotic disorder. PLoS ONE, in press.

Frissen A, van Os J, Peeters S, Gronenschild E, Marcelis M; for G.R.O.U.P. Evidence that reduced gray matter volume in psychotic disorder is associated with exposure to environmental risk factors. Submitted. 

Curriculum Vitae

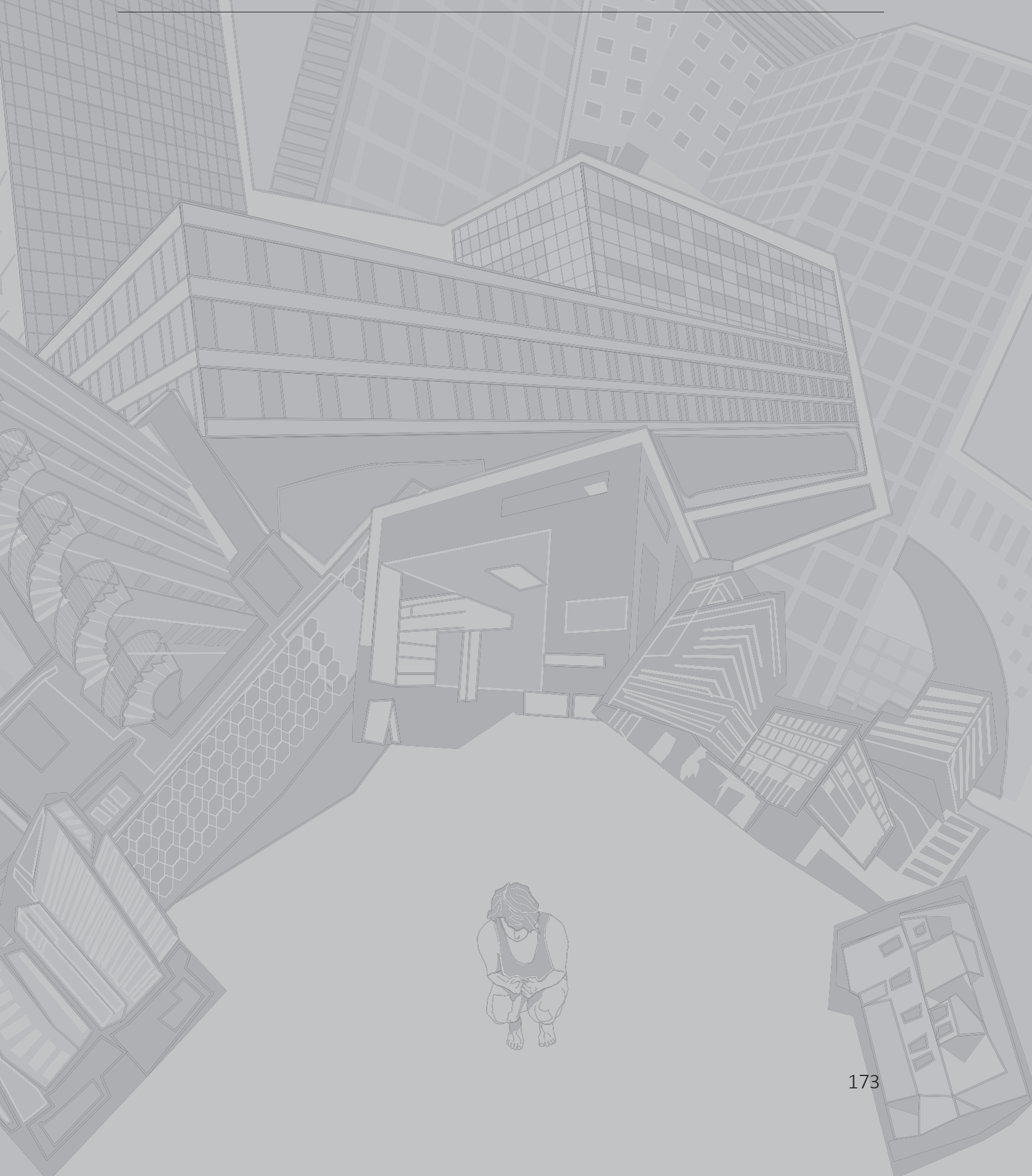



Aleida Frissen was born 3 August, 1984, in Maastricht, the Netherlands. She attended secondary school at St. Maartens College in Maastricht from 1996 to 2002. After secondary school Aleida attended Utrecht University as a medical student and graduated in 2009. Her medical training was followed by a residency in psychiatry at the Mondriaan Zorggroep. As part of her psychiatric training Aleida worked at Mondriaan Zorggroep, Orbis Medical Center, Maastricht University Medical Center and RIAGG Maastricht. In 2012 Aleida began her PhD Trajectory. She completed her psychiatric training in 2014 and took up employment as a psychiatrist at Virenze RIAGG Maastricht in the divisions of Mood and Anxiety Disorders. Aleida resides in Maastricht with her husband Kostan Reisinger and two children, Nina and Max. 

Dankwoord 

Beste Jim, eerlijk gezegd was het nooit in me opgekomen om te promoveren, totdat jij naar me toe kwam met "an offer I couldn't refuse". In alle avond- en weekenduurtjes heb ik me wel eens afgevraagd of ik je hiervoor nou dankbaar moest zijn of niet, maar nu ik met trots terug kan kijken op dit proefschrift, ben ik dat zeker. Hartelijk dank voor de fijne samenwerking!

Beste Ritsaert, nadat ik was ingegaan op Jim zijn voorstel, kwam ik erachter dat ik bijzonder weinig kaas had gegeten van papers schrijven. Jouw hulp bij mijn eerste wetenschappelijke woorden vormen de basis van dit proefschrift. Ik kon ook altijd bij je terecht voor een nuchter advies als de finish even uit het oog was.

Beste Machteld, toen ik geaccepteerd had dat Jim me erin had geluisd, kwam jij met het idee om MRI data in mijn proefschrift te verwerken. Dit was al helemaal nooit in me opgekomen. Jouw enthousiasme en gedrevenheid hebben dit proefschrift meer diepgang gegeven en ervoor gezorgd dat we het onderste uit de kan hebben gehaald.

Beste Marjan en Wolfgang, zonder jullie onuitputtelijke kennis in de wereld van Stata en $\mathrm{R}$ en enzovoorts was ik "blind and deaf on the middle of a freeway". Dank voor jullie geduld met een statibeet als ik.

Beste $\mathrm{Ed}$, het is ongelofelijk hoeveel data een enkele machine kan produceren. Je stond altijd voor me klaar om mijn vragen over MRI data te beantwoorden.

Beste Truda, Ine, Jolanda, Trees en Ron. Jullie zijn de ruggengraat van de afdeling, bedankt voor alle ondersteuning!

Alle andere lieve collega's van de universiteit, vooral Christine, Sanne, Martine, Mayke en kamergenootje Catherine, bedankt voor de fijne lunches, praatjes, adviezen en uitstapjes!

De leden van de beoordelingscommissie wil ik graag bedanken voor het lezen en beoordelen van dit proefschrift.

Lieve Christine, je kaftontwerpen worden langzaamaan legendarisch. Dank je wel voor je behulpzaamheid, creativiteit en vooral het prachtige resultaat.

Dear Lori, many thanks for guarding the appropriate use of the English language throughout this thesis, I solemnly apologize if there's any "stone coal English" left.

Jacomine, lieve vriendin en paranimf, veertien jaar geleden begon onze vriendschap in een studentenhuis op Kanaleneiland en zagen we samen op tegen de tentamens. Nu 
zien we samen op tegen de verdediging, voor mij is het een enorme geruststelling dat jij aan mijn zijde staat!

Lieve oma, dat je op deze leeftijd nog altijd even benieuwd bent naar hoe het met al mijn vrienden en vriendinnen gaat, vind ik heel bijzonder en laat zien hoe lief jij bent. Opa, jij was waarschijnlijk de enige van de familie geweest die dit proefschrift echt had bestudeerd en vervolgens allerlei kritische vragen had gesteld. Ik had het zo bijzonder gevonden als je er op de dag van de verdediging bij had kunnen zijn, ik mis je.

Lieve Aleid, Menno en Kim, zo fijn om jullie dichtbij te hebben!

Arkon, ik vraag me af waarom ik vroeger als klein meisje voortdurend bij mijn ouders om een broertje of een zusje zeurde, terwijl ik er al lang één had.

Lieve schoonfamilie, Anna, Remco, Justus, Emma en Lieke, altijd even geïnteresseerd in mijn voortgang.

Lieve pappa en mamma, zonder jullie was me dit nooit gelukt. Altijd hebben jullie mij geholpen en gesteund waar jullie konden, al stonden studie en prestaties nooit bovenaan jullie lijstje van wat belangrijk is. Ik weet dat ik wat jullie betreft nog altijd kapper kan worden. Jullie zijn de liefste ouders!

Lieve Kostan, jij kan mij grijze haren bezorgen door je woede die gericht is op niet werkende apparaten of op Ajax, het gat dat je in je hand hebt als het eten betreft (30 euro voor 100g koffie?! En dan wat zeggen over mijn gezichtsreiniger) of je energie die onuitputtelijk lijkt te zijn. Soms lijkt het alsof ik drie kinderen heb in plaats van twee... Maar het zijn juist deze dingen die maken dat ik zo veel van je hou en altijd weer kan lachen. Jij hebt me zo vaak geholpen tijdens mijn promotietraject, soms met de inhoud, maar vaak juist door me af te leiden. Met je humor en vastberadenheid help je me overal doorheen en ga ik uitdagingen aan die ik anders voorbij had laten gaan.

Nina en Max, als het soms niet mee zit en ik zie jullie lieve gezichtjes ben ik alles al weer vergeten, jullie zijn het belangrijkste wat er is. 